\title{
AHTR Mechanical, Structural, and Neutronic Preconceptual Design
}

\section{September 2012}

\author{
Prepared by \\ V. K. Varma \\ D. E. Holcomb \\ F. J. Peretz \\ E. C. Bradley \\ D. Ilas \\ A. L. Qualls \\ N. M Zaharia
}

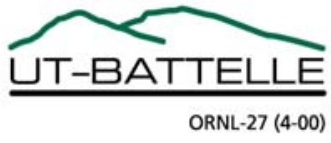




\title{
DOCUMENT AVAILABILITY
}

Reports produced after January 1, 1996, are generally available free via the U.S. Department of Energy (DOE) Information Bridge.

Web site http://www.osti.gov/bridge

Reports produced before January 1, 1996, may be purchased by members of the public from the following source.

\author{
National Technical Information Service \\ 5285 Port Royal Road \\ Springfield, VA 22161 \\ Telephone 703-605-6000 (1-800-553-6847) \\ TDD 703-487-4639 \\ Fax 703-605-6900 \\ E-mail info@ntis.gov \\ Web site http://www.ntis.gov/support/ordernowabout.htm
}

Reports are available to DOE employees, DOE contractors, Energy Technology Data Exchange (ETDE) representatives, and International Nuclear Information System (INIS) representatives from the following source.

Office of Scientific and Technical Information

P.O. Box 62

Oak Ridge, TN 37831

Telephone 865-576-8401

Fax 865-576-5728

E-mail reports@osti.gov

Web site http://www.osti.gov/contact.html

\begin{abstract}
This report was prepared as an account of work sponsored by an agency of the United States Government. Neither the United States Government nor any agency thereof, nor any of their employees, makes any warranty, express or implied, or assumes any legal liability or responsibility for the accuracy, completeness, or usefulness of any information, apparatus, product, or process disclosed, or represents that its use would not infringe privately owned rights. Reference herein to any specific commercial product, process, or service by trade name, trademark, manufacturer, or otherwise, does not necessarily constitute or imply its endorsement, recommendation, or favoring by the United States Government or any agency thereof. The views and opinions of authors expressed herein do not necessarily state or reflect those of the United States Government or any agency thereof.
\end{abstract}


Fuel Cycle and Isotopes Division Reactor and Nuclear Systems Division

\title{
AHTR MECHANICAL, STRUCTURAL, AND NEUTRONIC PRECONCEPTUAL DESIGN
}

\author{
Venugopal K. Varma \\ David E. Holcomb \\ Fred J. Peretz \\ Eric C. Bradley \\ Dan Ilas \\ A. L. Qualls \\ Nathaniel M. Zaharia
}

Date Published: September 2012

Prepared by

OAK RIDGE NATIONAL LABORATORY

Oak Ridge, Tennessee 37831-6283

managed by

UT-BATTELLE, LLC

for the

U.S. DEPARTMENT OF ENERGY

under contract DE-AC05-00OR22725 



\section{CONTENTS}

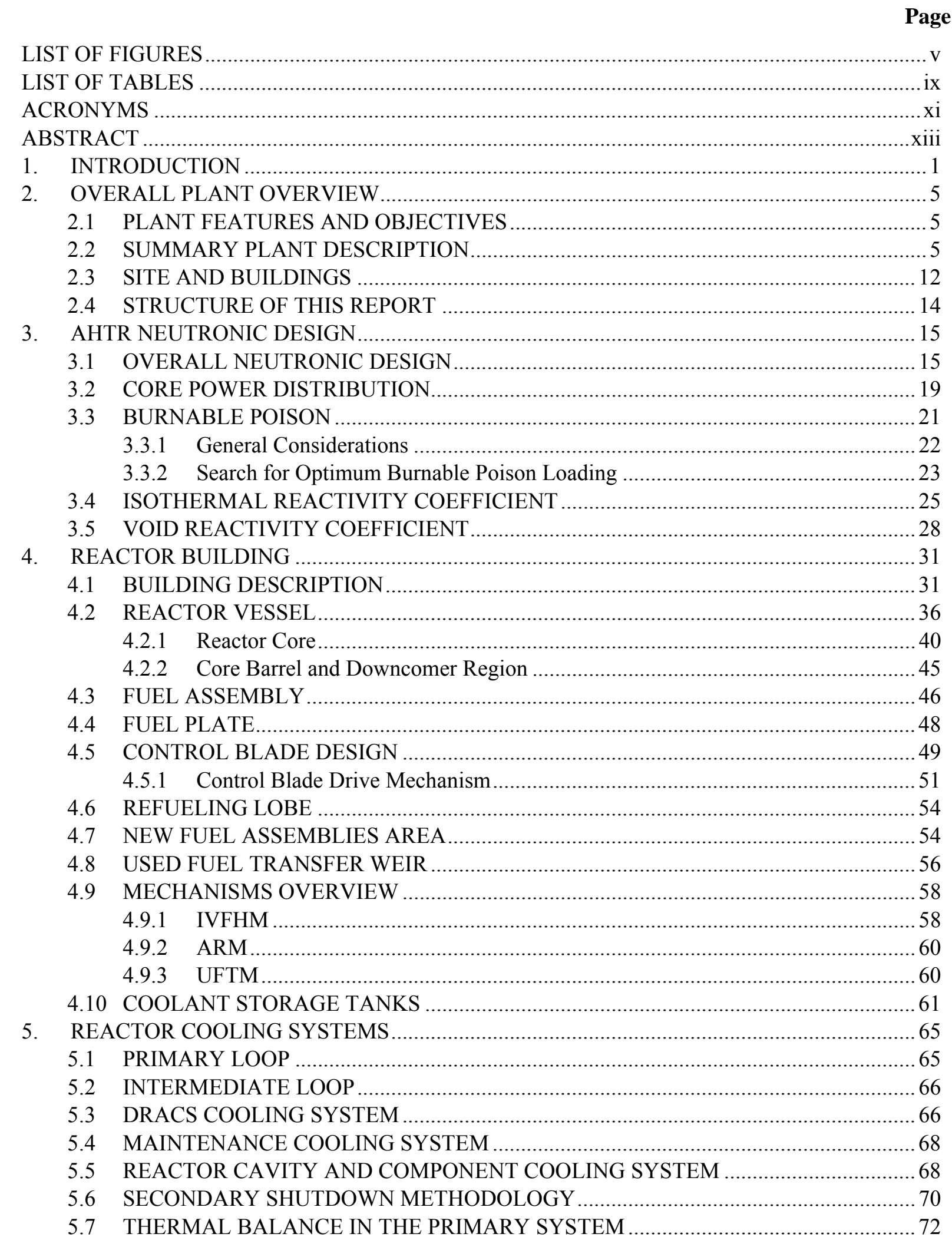




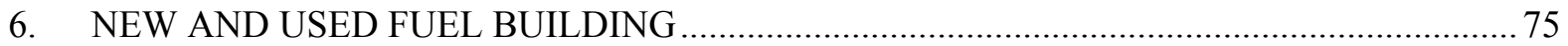

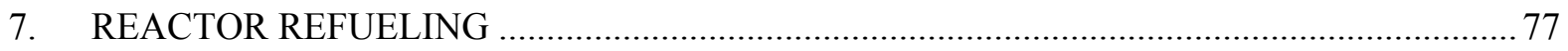

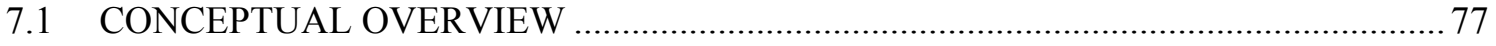

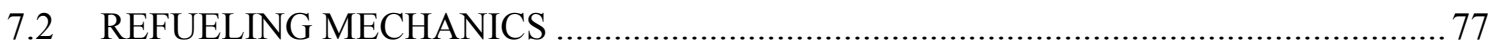

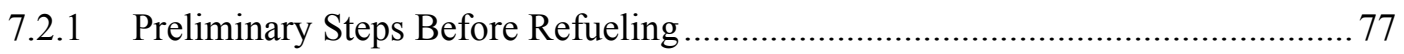

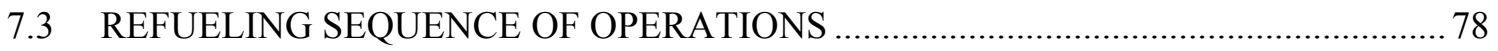

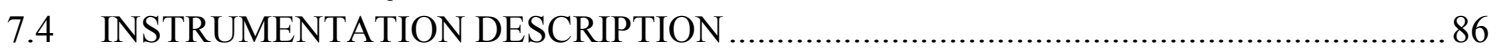

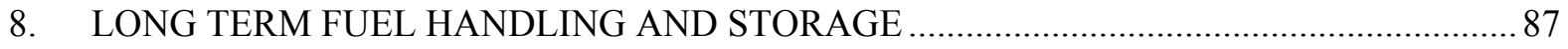

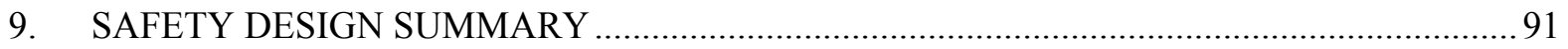

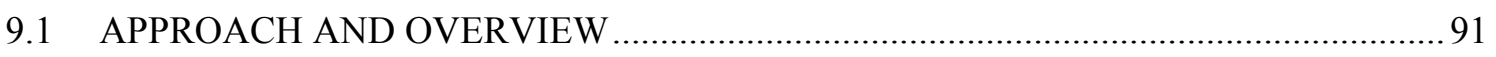

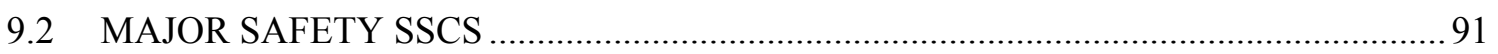

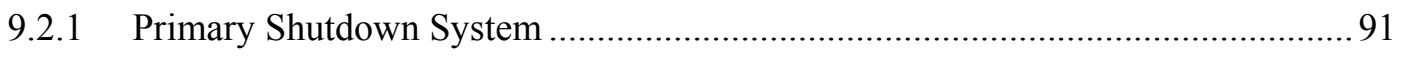

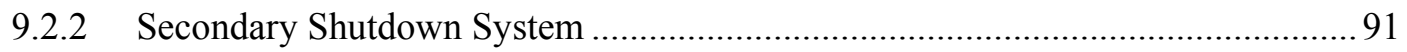

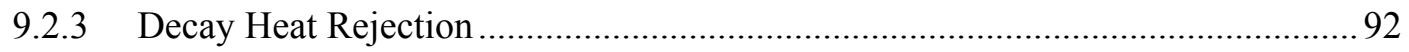

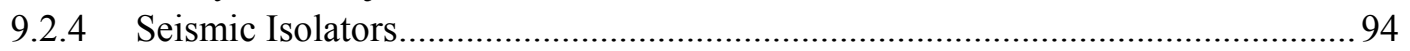

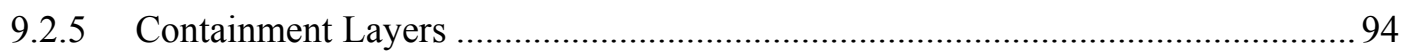

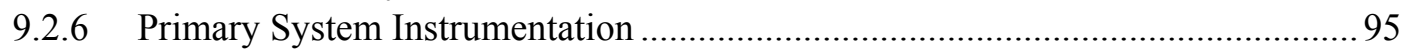

9.3 DESIGN FOR ACCIDENT AVOIDANCE AND/OR MITIGATION ............................ 96

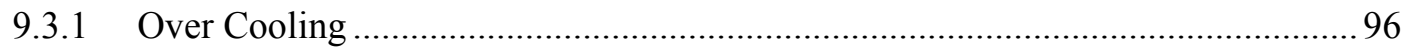

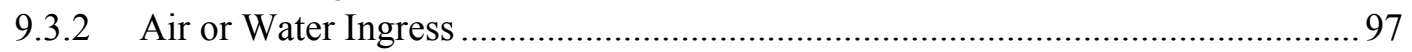

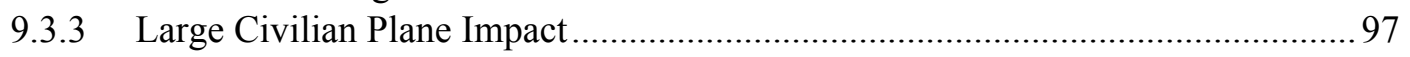

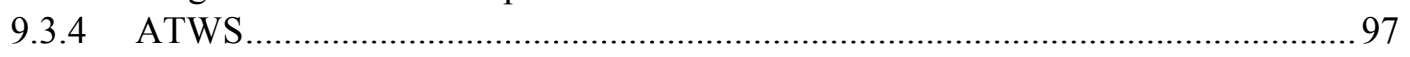

9.3.5 Inadvertent Control Element Movement ............................................................ 97

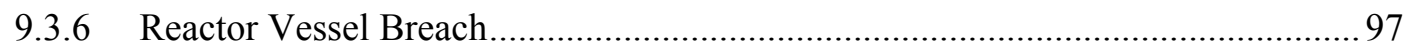

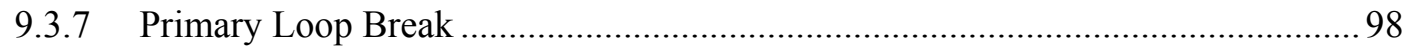

9.3.8 Loss of Forced Flow ................................................................................... 98

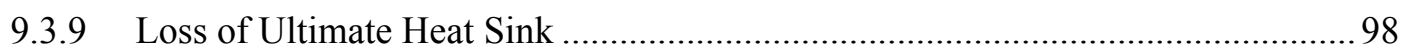

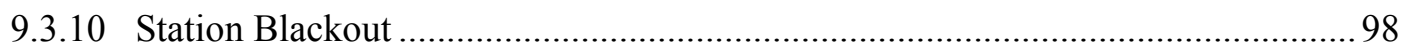

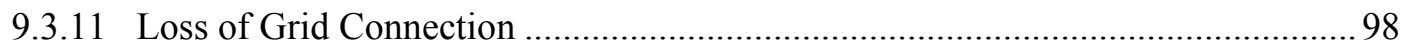

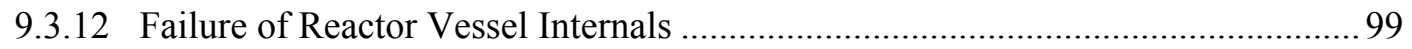

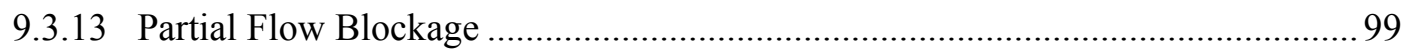

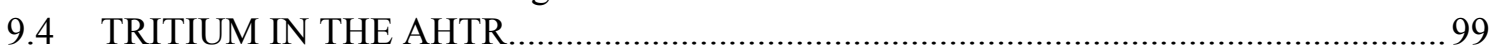

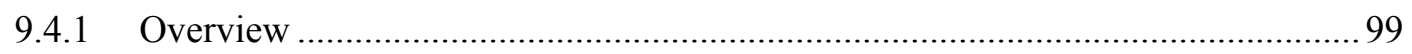

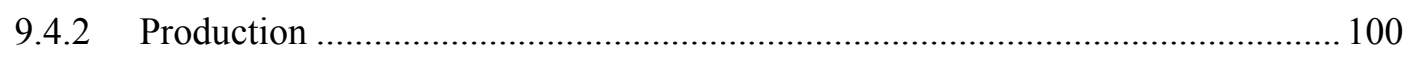

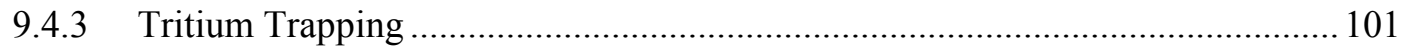

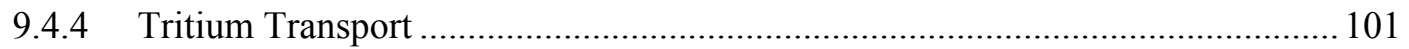

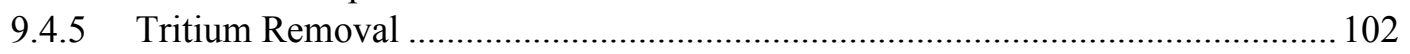

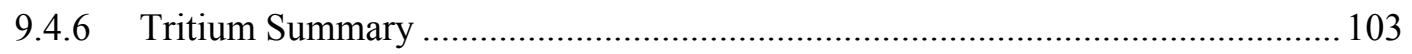

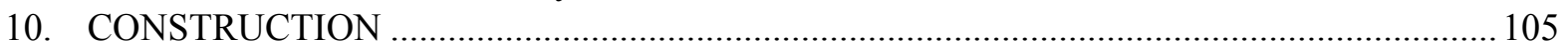

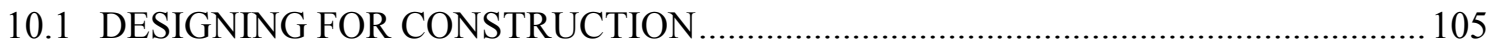

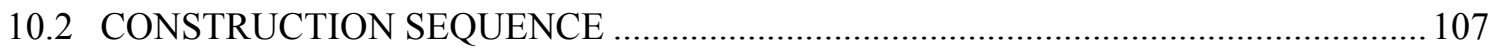

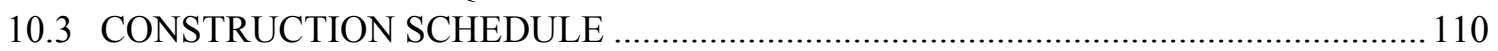

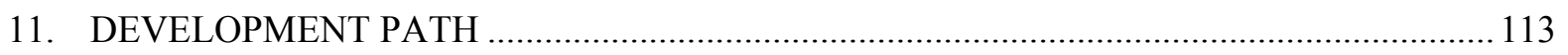

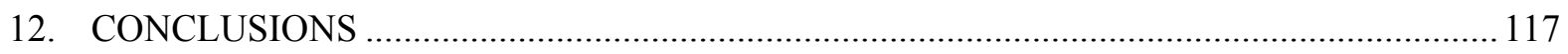

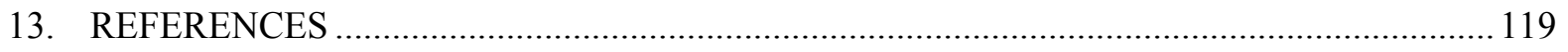




\section{LIST OF FIGURES}

Figure

Page

Fuel and control blade assembly

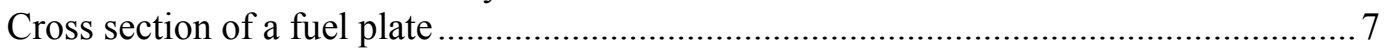

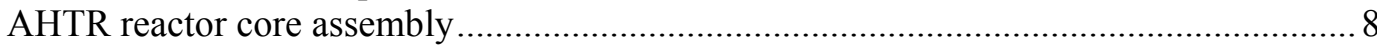

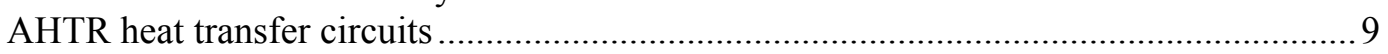

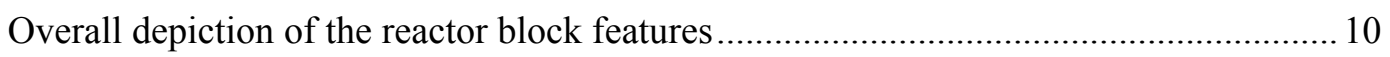

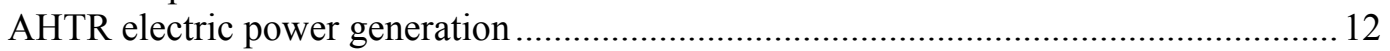

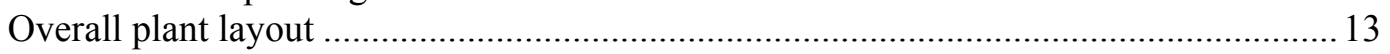

The FY 2012 baseline AHTR core model showing the two-batch checkerboard

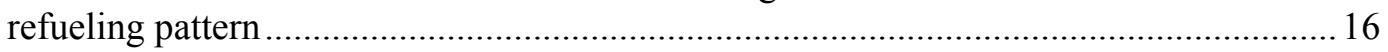

Comparison of the AHTR core multiplication constant for different core options ........... 18

LRM and direct calculation comparison of the two-batch cycle

AHTR core model for power distribution calculations .................................................. 19

Radial power distributions for different AHTR core options (fresh fuel) .......................20

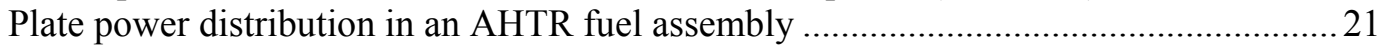

Placement of the $\mathrm{Eu}_{2} \mathrm{O}_{3}$ grains (red dots) at the center of the fuel plate ...........................22

Typical reactivity evolution for a reactor core using burnable poison............................2 23

AHTR reactivity evolution for similar amounts of BP which are distributed

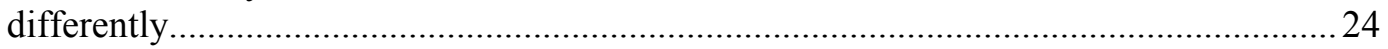

Linear dependence of the AHTR reactivity on the absorbing area ................................. 24

AHTR reactivity evolution for different amounts of BP ...

Comparison of the isothermal temperature reactivity coefficient for FY 2011

and FY 2012 fresh reference cores

Isothermal temperature reactivity coefficient for FY 2012 AHTR reference core at

different moments during the fuel cycle

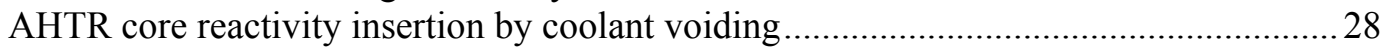

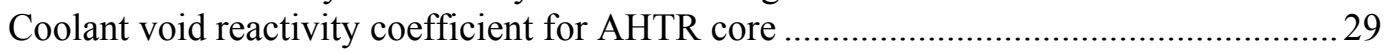

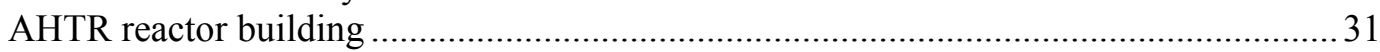

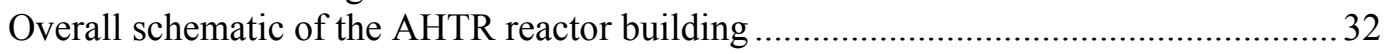

Reactor building excavation, foundation, and seismic isolation.................................... 33

Seal between the reactor building and the soil outside the retaining wall ......................... 33

Seismic isolation close

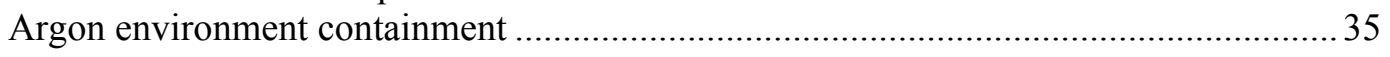

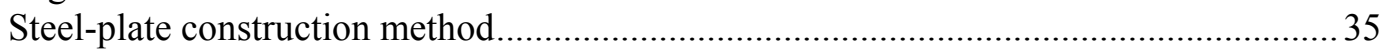

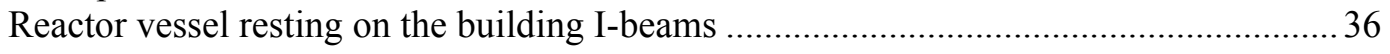

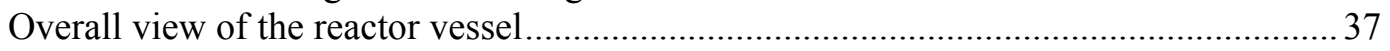

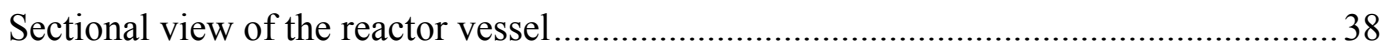

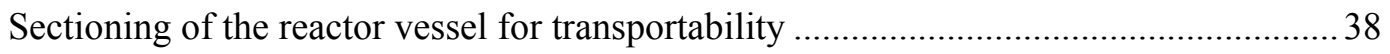

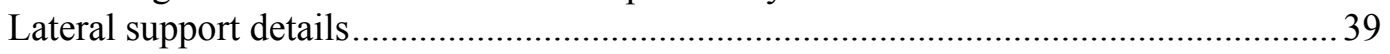

Top support plate fabricated from two thin plates with a truss structure in between ....... 40

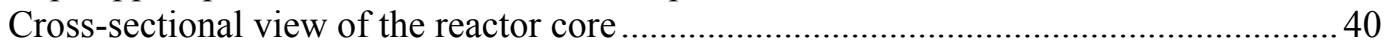

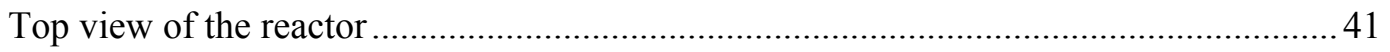

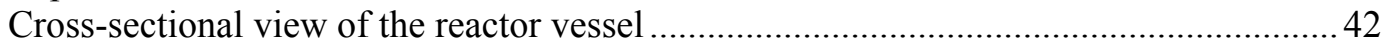

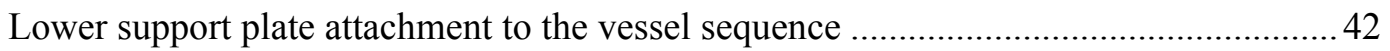

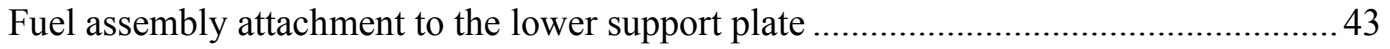

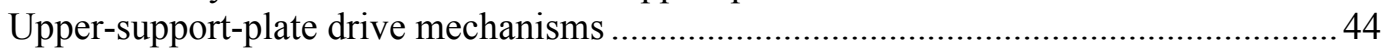

Upper-core support plate in contact with fuel assembly .............................................. 44

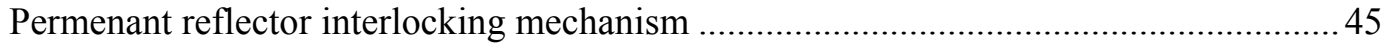


Transverse cross section of a group of fuel assemblies showing the interassembly spacing ......

Transverse cross section of the fuel assembly with dimensions in centimeters ................48

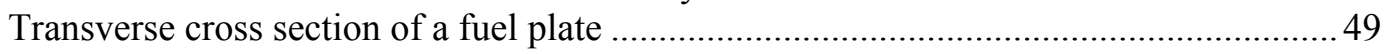

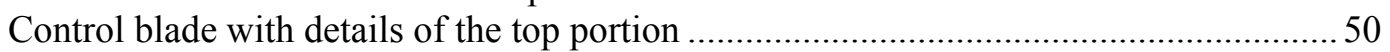

Upper end of the fuel assembly with control blade inserted............................................5 50

AHTR upper vessel components in exploded view with retracted control blade ..............51

Control blade motor assembly ................................................................................5

Control blade attachment to the leader rods ................................................................ 52

Control blade guide tube resting on the fuel assembly while leader rod is connected

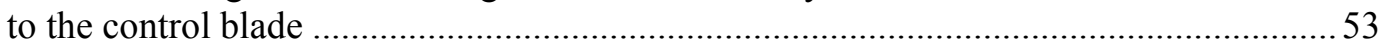

Control blade assembly in stowed position ................................................................5

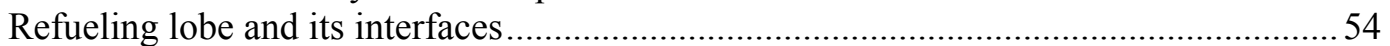

New fuel assembly area with loading platform ………………………………………....5

Seal on the loading platform at the new fuel assembly area ............................................ 55

Lateral guides on the fuel-handling carriage.............................................................56

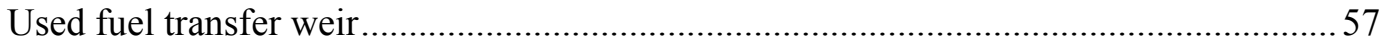

Grapple attached to the fuel assembly ………………………………………….....5

Reactor top view showing all three manipulators.......................................................5

IVFHM with the rail and carriage system.................................................................59

IVFHM holding the fueling assembly and showing details of the gripper ........................59

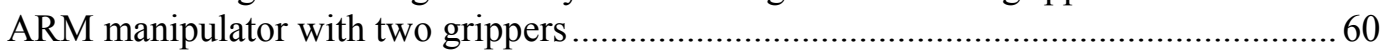

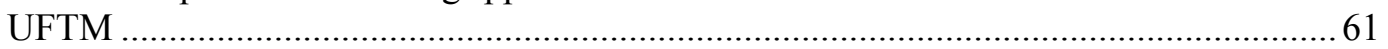

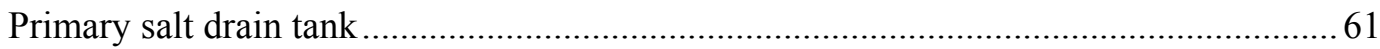

Intermediate salt piping, catch pan, and drain tank........................................................6. 62

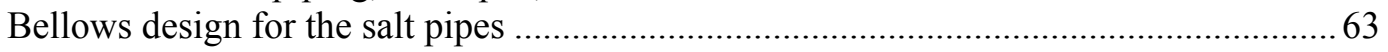

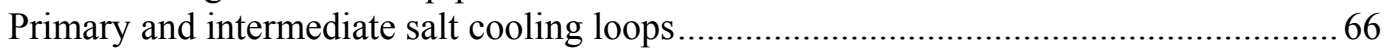

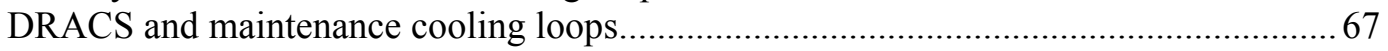

Typical response of the AHTR vessel and shields to a loss-of-primary-coolant-flow accident: (a) high emissivity and (b) low emissivity ………………………………............ 69

Secondary shutdown poison salt cartridge configuration ............................................... 71

New and used fuel building ...................................................................................... 75

Guide tube pressing down on the fuel assembly ........................................................78

Control blade detached from leader rod...................................................................... 79

Leader rods and guide tubes fully retracted ............................................................ 79

Control blade assembly stowed to the side ………………………………………….... 80

The upper core support plate drive rods are raised bringing it next to the upper

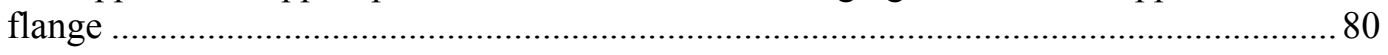

Upper core support plate is raised allowing access to the fuel assemblies for

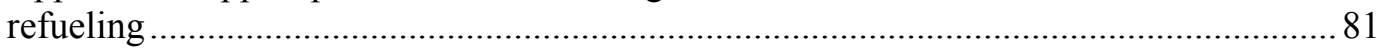

The mechanism for shortening the upper core support plate drive motor .......................... 81

New fuel sssembly transfer from UFTM to ARM ...................................................... 82

IVFHM grasping the fuel assembly ………………………………………………...... 82

Exchange of used and new fuel assemblies between IVFHM and ARM .........................8 83

ARM manipulator transfers the fuel assembly to UFTM. UFTM loads the fuel in the carousel. UFTM then obtains a new fuel assembly …………………………………..... 84

Control blade flange with a single control blade drive mechanism retracted ....................8 85

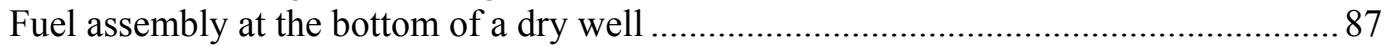

Fuel assembly power as a functional time after shutdown ...............................................8 88

Secondary shutdown canisters in AHTR downcomer region ...........................................92 


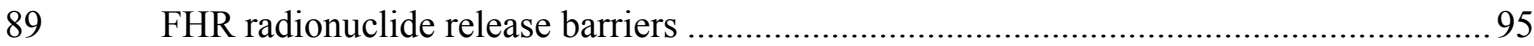

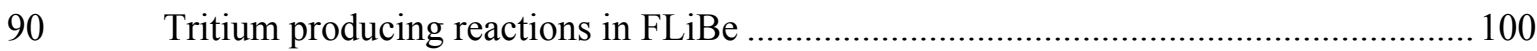

91 Dissolved hydrogen to gas phase ratio vs temperature in FLiBe................................ 102

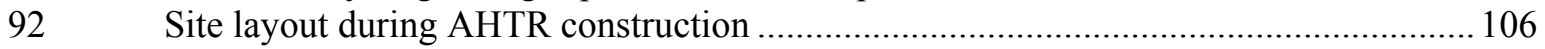

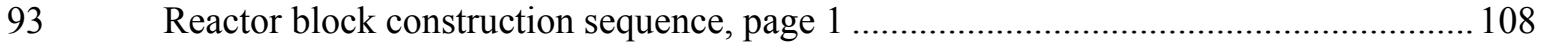

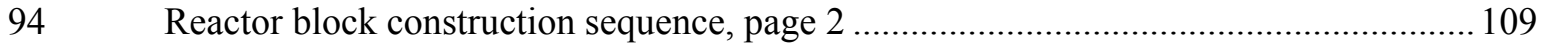

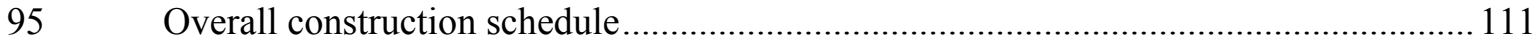

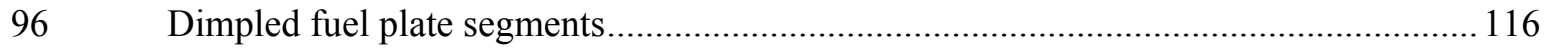





\section{LIST OF TABLES}

Table $\quad$ Page

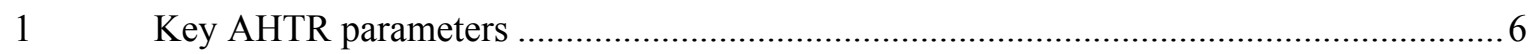

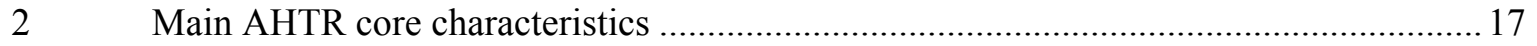

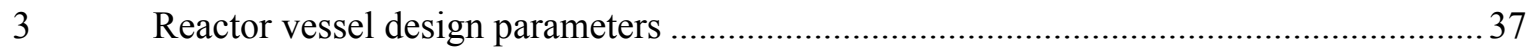

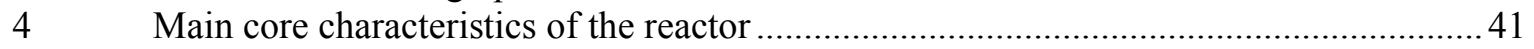

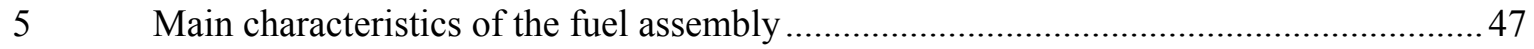

$6 \quad$ Material characteristics of the fuel assembly ......................................................... 48 



\section{ACRONYMS}

$\begin{array}{ll}\text { AGR } & \text { advanced gas reactor } \\ \text { AHTR } & \text { advanced high-temperature reactor } \\ \text { ARM } & \text { annular ring manipulator } \\ \text { BOC } & \text { beginning of cycle } \\ \text { BP } & \text { burnable poison } \\ \text { C-C composite } & \text { carbon-carbon composite } \\ \text { CHM } & \text { carbon-to-heavy metal atomic ratio } \\ \text { DOE-NE } & \text { Department of Energy-Office of Nuclear Energy } \\ \text { DRACS } & \text { direct reactor auxiliary cooling system } \\ \text { EOC } & \text { end of cycle } \\ \text { FHR } & \text { Fluoride salt-cooled High-temperature Reactor } \\ \text { FLiBe } & \text { Lithium Fluoride Beryllium Fluoride } \\ \text { IVFHM } & \text { in-vessel fuel-handling manipulator } \\ \text { LRM } & \text { linear relativity model } \\ \text { LWR } & \text { light-water reactor } \\ \text { M/A } & \text { maximum to average } \\ \text { MT } & \text { metric ton } \\ \text { NFAA } & \text { New Fuel Assembly Area } \\ \text { NPP } & \text { nuclear power plant } \\ \text { pcm } & \text { percent millirho } \\ \text { SiC-SiC composite } & \text { silicon carbide-silicon carbide composite } \\ \text { SMR } & \text { small modular reactor } \\ \text { SSC } & \text { systems, structures, and components } \\ \text { TRISO } & \text { Tristructural Isotropic } \\ \text { UFTM } & \text { used fuel transfer manipulator } \\ & \end{array}$





\begin{abstract}
This report provides an overview of the mechanical, structural, and neutronic aspects of the Advanced High Temperature Reactor (AHTR) design concept. The AHTR is a design concept for a large output Fluoride salt cooled High-temperature Reactor (FHR) that is being developed to enable evaluation of the technology hurdles remaining to be overcome prior to FHRs becoming an option for commercial reactor deployment. This report documents the incremental AHTR design maturation performed over the past year and is focused on advancing the design concept to a level of a functional, self-consistent system. The reactor concept development remains at a preconceptual level of maturity. While the overall appearance of an AHTR design is anticipated to be similar to the current concept, optimized dimensions will differ from those presented here.

The AHTR employs plate type coated particle fuel assemblies with rapid, off-line refueling. Neutronic analysis of the core has confirmed the viability of a 6-month two-batch cycle with $9 \mathrm{wt}$ \% enriched uranium fuel. Refueling is intended to be performed automatically under visual guidance using dedicated robotic manipulators. The report includes a preconceptual design of the manipulators, the fuel transfer system, and the used fuel storage system. The present design intent is for used fuel to be stored inside of containment for at least six months and then transferred to local dry wells for intermediate term, on-site storage.

The mechanical and structural concept development effort has included an emphasis on transportation and constructability to minimize construction costs and schedule. The design intent is that all components be factory fabricated into rail transportable modules that are assembled into subsystems at an on-site workshop prior to being lifted into position using a heavy-lift crane in an open-top style construction.

While detailed accident identification and response sequence analysis has yet to be performed, the design concept incorporates fully passive responses to all identified design basis or non-very-low frequency beyond design basis accidents as well as multiple levels of radioactive material containment. Key building design elements include (1) below grade siting to minimize vulnerability to aircraft impact, (2) multiple natural circulation decay heat rejection chimneys, (3) seismic base isolation, and (4) decay heat powered back-up electricity generation.
\end{abstract}





\section{INTRODUCTION}

The Advanced High Temperature Reactor (AHTR) is a design concept for a large-output [3400 MW(t)] fluoride-salt-cooled high-temperature reactor (FHR). FHRs, by definition, feature low-pressure liquid fluoride salt cooling, coated-particle fuel, a high-temperature power cycle, and fully passive decay heat rejection. As high-temperature plants, FHRs can support either high-efficiency electricity generation or process heat production. The AHTR reactor concept development remains at a preconceptual level of maturity. The dimensions presented in this report are intended to be useful for concept evaluation but do not reflect the optimization necessary to form a realistic design. The present design space exploration, however, indicates that reasonable design options exist for all of the AHTR's systems, structures, and components (SSCs).

This report represents continued maturation of the AHTR conceptual design beyond the core design, systems evaluation, and economic modeling performed in 2011., ${ }^{1,2}$ Over the past decade of FHR evaluation, no overall concept viability issues have been identified. The AHTR mechanical and structural evaluation, described in this report, represents an attempt to develop a reasonable plant configuration and is intended to assist in identifying the remaining FHR technology hurdles. A reasonably mature conceptual design is required to confidently predict the cost of the AHTR's energy. Performing the concept development enables identification of technology development issues thereby providing direction to the development tasks.

FHRs offer the potential to generate large amounts of electricity with virtually no impact on the environment. Further, their high degree of passive safety precludes large accidents that would significantly harm the public. No known resource limits exist that preclude widespread, large-scale FHR deployment. FHRs, however, remain a longer-term, power production option. A principal development focus is thus on shortening, to the extent possible, the overall development time (i.e., the time to market) by focusing on initial efforts on the longest lead-time issues. Shortening the FHR time to market includes safety evaluation and licensing approach development as well as both concept and technology development and demonstration. Apart from achieving technical feasibility, minimizing overall FHR lifecycle costs is the dominant development objective. Thus, the on-going FHR development program uses overall lifecycle cost minimization as a guiding principle.

Light-water reactors (LWRs) are the current standard in nuclear power plant (NPP) technology. The potential performance and characteristics of FHRs are, thus, most appropriately compared against LWRs. The value of the comparison is admittedly somewhat limited in that FHRs will compete not just against LWRs but also other electricity generators and gasoline producers in that a principal product for hightemperature reactors is anticipated to be liquid hydrocarbon fuels.

FHRs have two central development challenges: (1) maturing the technology sufficiently to enable deployment and (2) achieving a sufficiently low cost of generation to become a preferred energy provider. The basic challenge for FHRs as compared to LWR designs is achieving low-costs while maintaining an acceptable level of safety. The high-degree of passive safety afforded by FHRs provides the opportunity for a dramatic break from the cost vs safety dilemma inherent in LWR NPP designs.

Much of the cost escalation seen in deploying LWRs over the past several decades stems from increased system complexity and the scale of specialized structures required. More thorough understanding of the plant materials, technologies, and operations are required to avoid equivalent FHR cost escalations and thus reduce the risk for investment. Some modern LWR designs mitigate cost escalation by either increasing their passive safety [(Gen III + designs with enhanced passive safety) or decreasing their scale (Small Modular Reactors (SMRs)]. FHRs represent a much larger opportunity for lowering costs than incrementally improved LWRs. Not employing high pressures in the reactor building avoids major, 
expensive, specialized structures such as a high-pressure vessel, high-pressure piping, and a high-pressure containment. Moreover, the full passive safety of FHRs allows them to realize the cost advantages provided by economies of scale without the complexity and negative economies of scale for multiple, redundant safety systems associated with large LWRs. For example, passive decay heat rejection of FHRs is provided by several smaller natural circulation based systems operating in parallel. The decay heat rejection capability of the reactor can therefore be increased incrementally as the design output power is increased. Further, the radioactive release source term remains small for any size FHR since fuel failure only results in noble gas release with the remainder of the fission products chemically bound into the lowpressure coolant. Additionally, the large amount of time afforded by FHR passive safety characteristics to respond to transients avoids the requirement for expensive, rapidly responding instruments and components. The dramatic lowering of the radionuclide release potential inherently provided by FHRs also offers the potential for more affordably meeting the regulatory requirements for power reactors lowering the costs for design certification. The full passive safety of FHRs also means that they will not require emergency diesel generators, redundant grid connection, or require being shut down during grid upsets. Since FHRs have multiple passive heat removal paths, they can be run back in the event of a grid outage, instead of shutting down, and later used to support re-powering the grid.

The AHTR concept development activity is focusing on maximizing the cost advantages afforded by FHRs. The AHTR's large power output takes advantage of economies of scale, yet the design avoids high-pressure components in the reactor building. The AHTR design employs a multiheat transport loop configuration to minimize its requirements for large, specialized components with a design goal of enabling rail transport of all components. The AHTR reactor vessel is a particularly strong example of transportation cost differences from large LWRs. As the AHTR operates at atmospheric pressure its vessel will only require thin walls allowing for final fabrication at an on-site workshop from pieces producible with known technologies by multiple potential vendors. The AHTR design concept also minimizes cost through minimizing the number of custom, unproven technologies employed. Notably, the AHTR is designed for rapid, off-line refueling using visually guided overhead cranes without any motors or instruments immersed in the salt. Also, the AHTR as a passively safe design can take maximum advantage of the revolution in instrumentation and controls for component and system health monitoring that has occurred over the past few decades without incurring the provability encumbrance (in depth validation and verification of digital components) that has prevented widespread deployment of modern instrumentation and communication technology at LWRs.

The AHTR is a large, modular reactor intended to be constructed from a set of factory-fabricated components and on-site workshop assembled modules. Given that nuclear power currently only accounts for roughly $8 \%$ of the U.S. energy production, the aging of the existing fleet of LWRs, the capability of high temperature reactors to produce hydrocarbon fuels, ${ }^{3}$ the strategic importance of avoiding dependence on energy imports from unstable (and unfriendly) parts of the world, and the anticipated growth in demand for non-polluting power over the coming decades, significant potential exists for production of large numbers of AHTRs providing opportunity for learning in the production of repeated modules. Thus, large modular reactors are anticipated to be able to take advantage of repeated, modular, factory fabrication nearly as much as their smaller counterparts.

The AHTR is a thermal neutron spectrum uranium fueled reactor and therefore, its sustainability relies on the availability of uranium resources. The emerging realization that uranium is a plentiful resource with crustal availability similar to zinc or tin that is widely deposited around the world ${ }^{4}$ provides confidence in uranium fuel availability for the foreseeable future at reasonable cost even with large-scale, worldwide deployment.

FHRs have only existed as a distinct reactor class for a decade. No FHR reactor has ever been built or even reached the level of maturity necessary for confident economic analysis. The lower level of technical maturity and the likelihood of more than a decade of focused technology development efforts before commercial deployment means that FHRs are less able to attract private development capital than nearer 
term alternatives. A test reactor, however, would provide a much higher degree of confidence in the viability of FHRs and could be constructed using existing materials at sufficiently small scale so as to limit the licensing time requirements. Designing such an FHR test reactor is a principal focus of a current Department of Energy Office of Nuclear Energy (DOE-NE) sponsored integrated research project being performed jointly by the Massachusetts Institute of Technology, the University of California at Berkeley, and the University of Wisconsin. ${ }^{5}$

The majority of cost for any NPP is incurred before beginning to generate any return on investment. As such, a primary research driver is to lower the cost and time of construction by simplifying systems and structures. The concept development activities described in this report supports minimizing construction costs and time by providing an early phase draft sequence of operations necessary for constructing a plant allowing later development efforts to focus on particularly costly elements. The report also provides a description of the fuel manipulation aspects of scheduled AHTR outages to assist in developing understanding of plant availability limits and operating costs.

Construction costs are minimized by a combination of approaches.

- The AHTR is a large, modular reactor formed by assembling a number of factory-fabricated modules.

- The containment building has much thinner (lower cost and easier to fabricate walls) due to the lack of potential for internal pressurization and being located below grade.

- All components are sized for rail or potentially air transport.

- Site assembly is primarily in a dedicated workshop with module interconnections performed insitu.

- Open top construction in conjunction with a heavy lift crane is employed to maximize access for module installation.

- Reactor vessel has thinner walls (than an LWR) enabling assembly in local workshop from prefabricated sections.

A more detailed FHR development roadmap will be necessary (and remains to be created) to provide reasonable assurance that the longest lead-time items are being appropriately addressed. However, it is already apparent that structural composite materials, fuels, component testing, and licensing have a decade or more of development time remaining. The FHR development program has already begun to address some of the long lead-time items in a limited fashion.

- FHR safety assessment and licensing approach development have begun at a low-effort level. ${ }^{6}$

- Initial advanced materials options assessments have been performed..$^{7-9}$

- Component demonstration planning has been initiated. ${ }^{10}$ 



\section{OVERALL PLANT OVERVIEW}

\subsection{PLANT FEATURES AND OBJECTIVES}

The AHTR plant described in this report is intended to safely, efficiently, and economically produce large amounts of electricity with minimal impact on the environment. The AHTR has a design mixed mean core outlet temperature of $700^{\circ} \mathrm{C}$, which enables a peak steam temperature of $650^{\circ} \mathrm{C}$. The AHTR's steam temperature matches that of the most advanced fossil power plants, allowing leveraging recent steam cycle technologies developed for the much larger fossil power industry. The increased temperature enables a substantial increase in plant thermal efficiency ( $45 \%$ vs 33\%) over existing light-water-cooled reactor plants. The AHTR provides a large amount of base load electricity without emitting gaseous pollutants or carbon dioxide. The high plant efficiency reduces thermal effluents and demands on cooling water, and the resulting increase in electrical output reduces the levelized cost of electricity in comparison to a light-water-cooled reactor plant of similar thermal power output.

The primary fluoride salt coolant, a mixture of lithium fluoride and beryllium fluoride salts, is an effective heat transfer medium and remains liquid at atmospheric pressures up to about $1400^{\circ} \mathrm{C}$ Pressurization of the primary coolant circuit is not required, and thick-walled pressure vessels, piping, and containment vessels are avoided. The power density in the reactor core is less than that in existing light-water-cooled reactors. The coated particle fuel, originally developed for high-temperature gas-cooled reactors, allows high-temperature operation with substantial thermal margins to fuel failure. Passively activated salt circuits driven only by natural circulation discharge reactor decay heat directly to the atmosphere. Large emergency power systems are not required for reactor safety. Barriers to the release of radioactivity include the cladding layers of the fuel particles, the salt, the physical boundary of the high-quality argon cover gas, and the reactor building structure.

The overall objectives for the AHTR design concept are as follows:

- plant operational life of at least 60 years,

- net thermal efficiency of $45 \%$,

- plant availability of $92 \%$,

- all essential safety features passive, with no operator action required at any time to prevent fuel damage or large off-site release,

- construction time less than 36 months, first concrete to fuel load,

- all components transportable by rail or air, and

- levelized unit cost of electricity lower than competing technologies.

\subsection{SUMMARY PLANT DESCRIPTION}

With 3,400 MW of nuclear power in the core and a net electrical power rating of 1,530 MW, an overall efficiency of $45 \%$ is achieved. The primary heat transfer fluid is $2 \mathrm{LiF}_{-} \mathrm{BeF}_{2}$, a salt mixture commonly referred to as $\mathrm{FLiBe}$. Heat is transferred first to an intermediate salt, a mixture of $\mathrm{KF}$ and $\mathrm{ZrF}_{4}$, and then transferred to a supercritical water power cycle. A similar salt is used the direct reactor auxiliary coolant system (DRACS) circuits, which transfer decay heat directly to the atmosphere. No other ultimate heat sink is required to achieve safety objectives. Other salt loops are used for normal heat transfer during maintenance, and for cooling used fuel. Thermally powered Stirling engine pumps are used to enhance the performance of the maintenance and used fuel cooling systems, ensuring safe plant conditions even with a complete loss of all ac power systems. The key parameters of the AHTR are summarized in Table 1. 
Table 1. Key AHTR parameters

\begin{tabular}{|c|c|c|}
\hline Parameter & Value & Units \\
\hline \multicolumn{3}{|l|}{ Overall parameters } \\
\hline Core thermal power & 3,400 & MW \\
\hline Net electrical power & 1,530 & MW \\
\hline Overall thermal efficiency & $45 \%$ & - \\
\hline \multicolumn{3}{|l|}{ Reactor core parameters } \\
\hline Fuel type & \multicolumn{2}{|c|}{ TRISO particles in graphite plates } \\
\hline Uranium composition & $\mathrm{UCO}$ & - \\
\hline Fuel enrichment & 9.00 & wt. $\%{ }^{235} \mathrm{U} / \mathrm{U}$ \\
\hline Number of fuel assemblies & 252 & - \\
\hline Assembly lattice type & Hexagonal & - \\
\hline Fuel plates per assembly & 18 & - \\
\hline Moderator and reflector & Graphite & - \\
\hline Core height (fueled region) & 5.5 & $\mathrm{~m}$ \\
\hline Equivalent core diameter (fueled region) & 7.81 & $\mathrm{~m}$ \\
\hline \multicolumn{3}{|l|}{ Primary salt circuit parameters } \\
\hline Primary coolant salt & $2 \mathrm{LiF}-\mathrm{BeF}_{2}$ & - \\
\hline Average reactor outlet temperature & 700 & ${ }^{\circ} \mathrm{C}$ \\
\hline Primary coolant return temperature & 650 & ${ }^{\circ} \mathrm{C}$ \\
\hline Primary coolant flow rate & 28,500 & $\mathrm{~kg} / \mathrm{s}$ \\
\hline Primary coolant pressure & Atmospheric & - \\
\hline Number of loops & 3 & - \\
\hline \multicolumn{3}{|l|}{ Intermediate salt circuit parameters } \\
\hline Intermediate coolant salt & $\mathrm{KF}-\mathrm{ZrF} \mathrm{F}_{4}$ & - \\
\hline Intermediate salt supply temperature & 675 & ${ }^{\circ} \mathrm{C}$ \\
\hline Intermediate salt return temperature & 600 & ${ }^{\circ} \mathrm{C}$ \\
\hline Intermediate salt flow rate & 43,200 & $\mathrm{~kg} / \mathrm{s}$ \\
\hline Intermediate salt pressure & Atmospheric & - \\
\hline Number of loops & 3 & - \\
\hline \multicolumn{3}{|l|}{ Power cycle parameters } \\
\hline Fluid to high pressure turbine & Supercritical steam & - \\
\hline Turbine supply temperature & 650 & ${ }^{\circ} \mathrm{C}$ \\
\hline Turbine supply pressure & 24 & $\mathrm{MPa}$ \\
\hline Turbine generator type & Tandem-compound & - \\
\hline \multicolumn{3}{|l|}{ Decay heat removal } \\
\hline DRACS heat transfer salt & $53 \% \mathrm{KF}-47 \% \mathrm{ZrF}_{4}$ & $\mathrm{~mol} \%$ \\
\hline DRACS heat sink & atmosphere & - \\
\hline Number of DRACS loops & 3 & - \\
\hline DRACS maximum power & 8.75 & MW \\
\hline
\end{tabular}

The AHTR reactor core is based on a hexagonal array of 252 fuel assemblies, as shown in Fig. 1. Each fuel assembly consists of 18 fuel plates, with three clusters of six plates each. The entire fuel assembly is fabricated of high-temperature materials. The assemblies are about $6 \mathrm{~m}$ long, supported by a central "Y" formed by a carbon-carbon composite structure and enclosed in a hexagonal carbon-carbon fuel channel box. Every assembly is provided with a Y-shaped control blade, inserted into the central structural 
member. The control blade is a molybdenum hafnium carbide structure. A leader rod attaches to the top of the control blade.

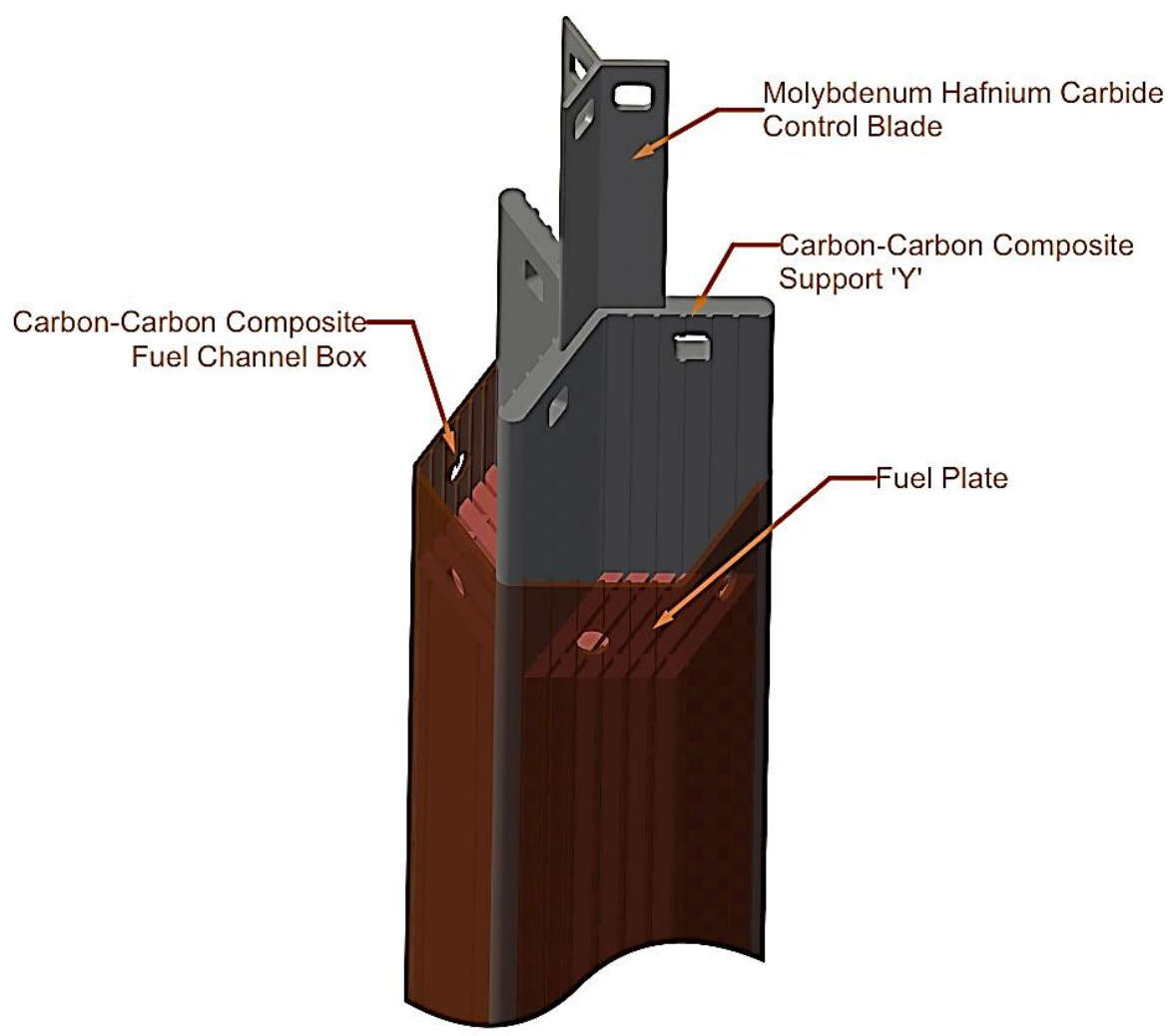

Fig. 1. Fuel and control blade assembly.

A cross section of a fuel plate is shown in Fig. 2. The fuel itself is in the form of tristructural isotropic (TRISO) particles, with a UCO kernel enclosed in a layer of pyrolytic graphite, a silicon carbide cladding layer, and another layer of pyrolytic graphite. Individual TRISO particles, less than $1 \mathrm{~mm}$ in diameter, are pressed into a high-density graphite matrix as two fuel stripes near the edges of the fuel plate. Discrete particles of burnable poison are also included near the center of the plate. An exterior graphite sleeve covers the fuel stripes, and spacers are formed into the outer surface to maintain the coolant gap between adjacent plates, central support sections, and the channel box.

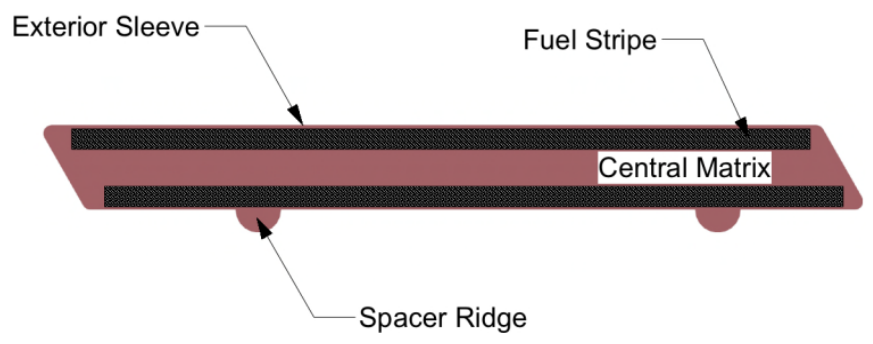

Fig. 2. Cross section of a fuel plate. 
The assembled reactor core assembly is shown in Fig. 3. The 252 fuel assemblies are set on the lower core support plate. The assemblies themselves are slightly buoyant in the primary salt; the control blade structure increases the average density to just above that of the salt. Hexagonal replaceable graphite elements are placed immediately adjacent to the fuel assemblies, and a permanent graphite reflector is located around the outer perimeter of the core. The beryllium in the primary salt provides some additional moderation, and the lithium is isotopically pure ${ }^{7} \mathrm{Li}$ to minimize tritium production. The upper core support plate holds the core components in place and restrains the core components against the upward salt flow.

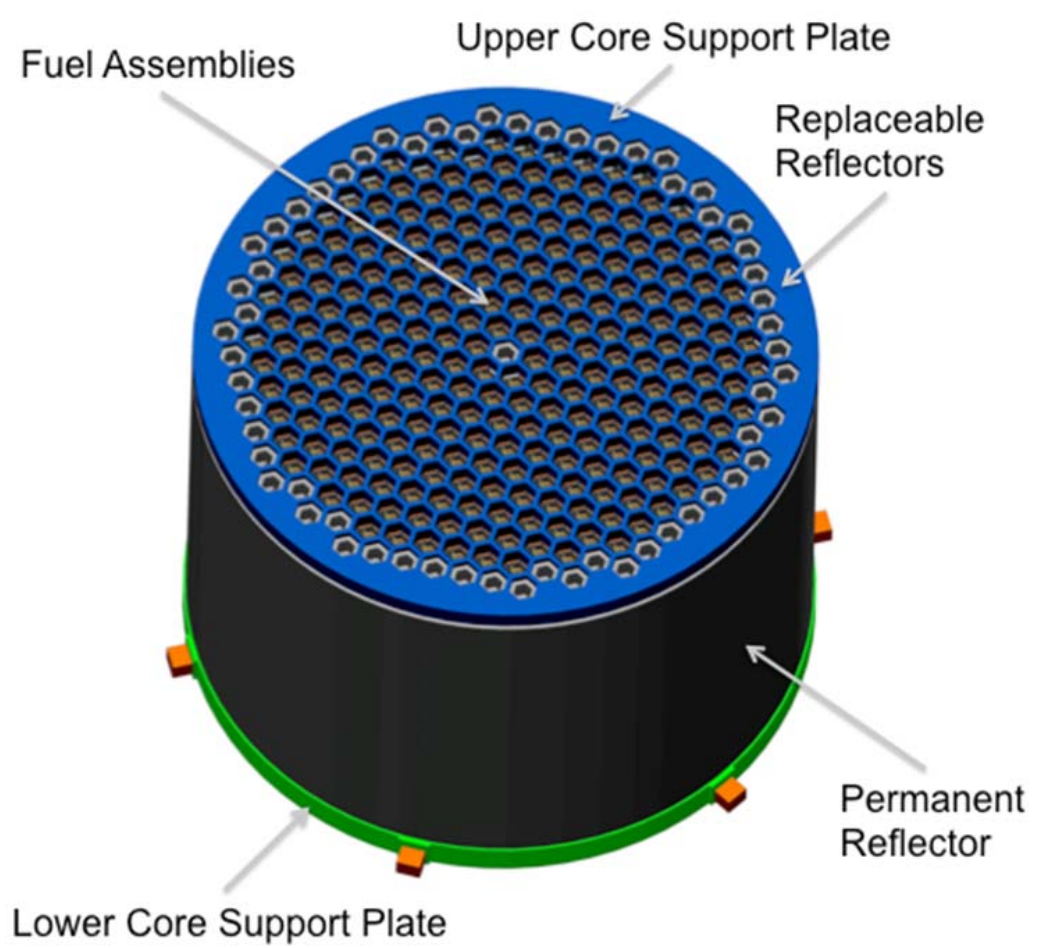

Fig. 3. AHTR reactor core assembly.

One-half of the fuel assemblies are replaced every six months. The refueling operation is supposed to be performed in about 2-3 days. The reactor core assembly is designed for access from above. Control leader rods are located above and can be withdrawn into a moveable structure to obtain access for refueling. Each fuel assembly has a grappling collar designed to mate with remote-handling equipment. Because the AHTR is not a pressurized reactor and is maintained near operating temperature so that the salt does not freeze, refueling operations can begin shortly after reactor shutdown. A visually guided, remotely operating system has been developed for fuel handling. New and used fuel-handling systems are described in Chapters 4 and 7 of this report. The neutronic design of the reactor core is described in Chapter 3.

The main heat transfer paths for the AHTR are depicted in Fig. 4. The reactor core is set in a vessel with all penetrations near the top. A core barrel structure separates incoming salt flow down the outer annulus from the hot salt exiting the top of the core. Salt normally flows up through the core, allowing for a natural circulation within the vessel. A DRACS heat exchanger is also located in flow channels in the outer annulus. In the event that forced flow through the core stops, this heat exchanger transfers decay heat from the primary salt to an intermediate DRACS circuit that in turn transfers heat to atmospheric air in a natural draft chimney. The primary salt flow path through the annulus is provided with a flow diode. 
When primary salt forced flow is present, there is little flow through this section and the heat loss through the DRACS is minimized. If flow stops, natural circulation allows the flow path in these sections of the annulus to reverse, unconstrained by the flow diode. Operation of the three DRACS loops is discussed further in Section 5.3.

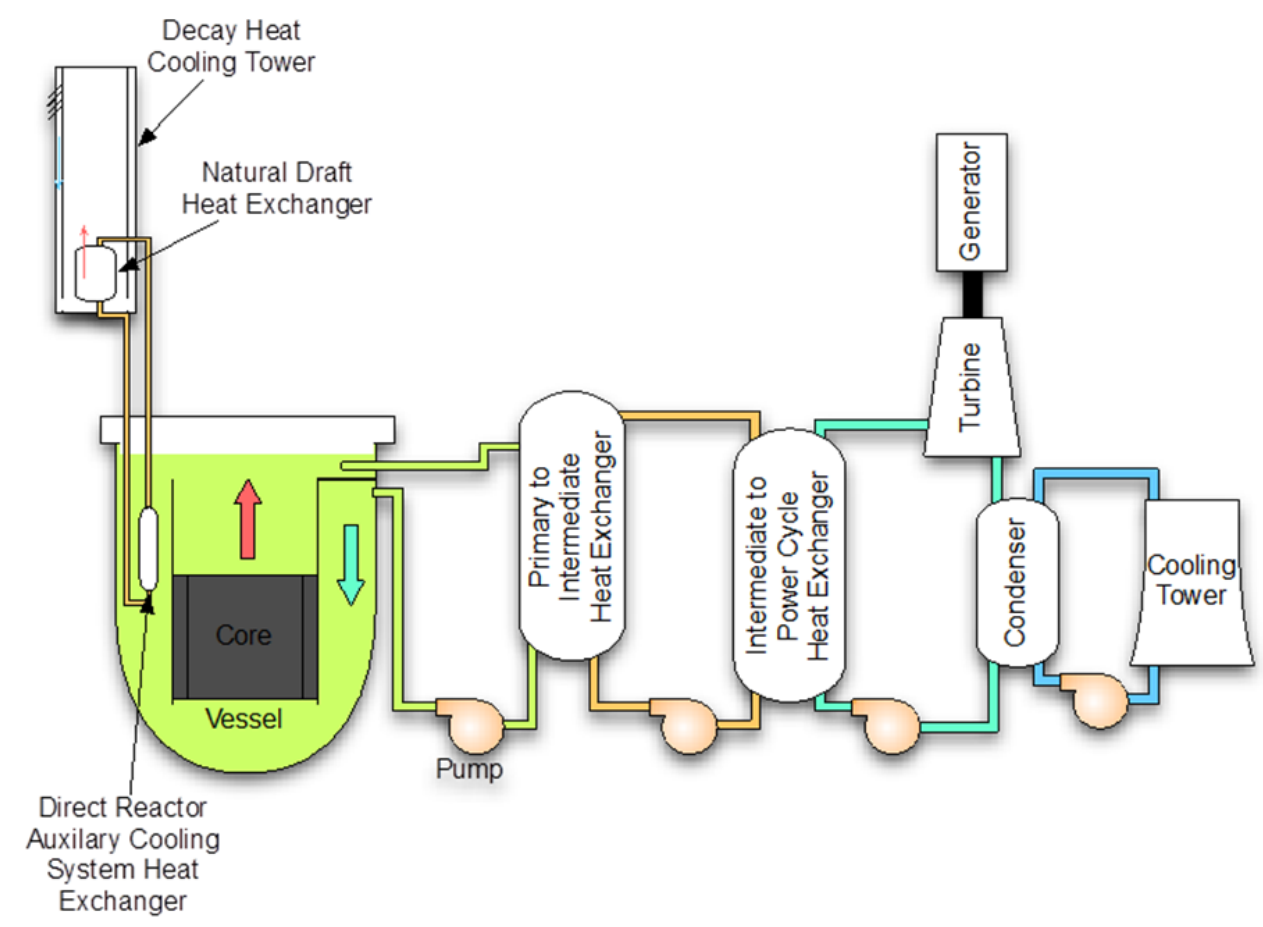

Fig. 4. AHTR heat transfer circuits.

Under normal operating conditions, the primary FLiBe salt transfers heat to a $\mathrm{KF}-\mathrm{ZrF}_{4}$ intermediate salt, which in turn carries heat to the power cycle. The use of an intermediate salt keeps water out of the reactor building and allows for isolation between the reactor block and the power system. The intermediate salt is relatively inexpensive, does not contain beryllium, and does not contain lithium that could degrade primary salt should leakage allow the two to mix. There are three loops each of primary and intermediate salt, with three primary-to-intermediate salt heat exchangers. A cover gas control system is used to remove tritium that is released by both the primary and intermediate salts. Control of tritium is discussed further in Sect. 9.4.

Heat from the intermediate cycle is used to produce supercritical and reheat steam in the power cycle. For high-efficiency operation, a natural draft evaporative cooling tower is used to reject heat from the power cycle. With the high steam temperature, reasonable power generation efficiency can be achieved with alternative heat rejection systems that reduce water consumption, such as hybrid wet-dry cooling towers. The normal maintenance decay heat removal system and the used fuel cooling systems discharge heat to the atmosphere in a manner similar to the DRACS system, augmented by forced flow (including the use of Stirling engine pumps for reliability under loss-of-power conditions).

The AHTR reactor structure is set below grade and rests on seismic isolation pillars, as shown in Fig. 5. A cylindrical outer shell is constructed first, with a supporting basemat. A cylindrical reactor support structure, with another base slab, is set on seismic isolation pillars. All systems needed for safe operation of the reactor, including decay heat removal, are supported by the seismically isolated structure. 


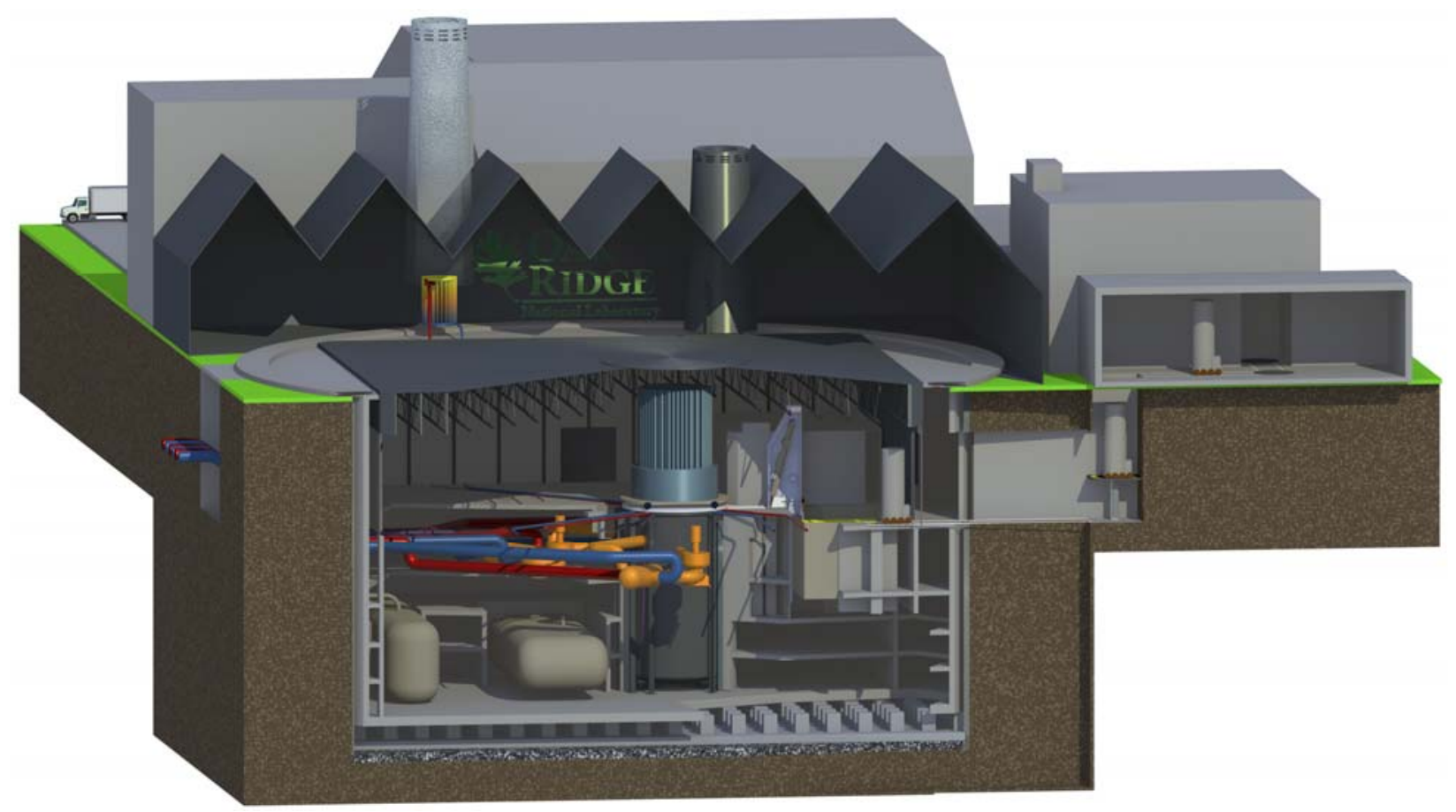

Fig. 5. Overall depiction of the reactor block features.

The reactor assembly is set in a concrete silo at the center of a rectangular enclosure in the reactor building. This silo fits closely around the reactor vessel such that, even if the vessel itself were to fail, the resulting salt level would still cover the core. A high-grade dry argon cover gas is provided for the reactor vessel and the primary salt circuit. A drain tank for the primary salt is located at the lowest level of the building; the salt level can be lowered to the top of the maintenance heat exchanger for various maintenance activities. The top of the reactor vessel is open but is covered with a vessel and set of tubes that enclose the control leader rods in their uppermost position. The entire primary salt system is also kept in the reactor building, as is the DRACS piping up to the heat exchangers in the base of the natural draft air stacks. The rectangular area at the operating floor, and much of the lower level, is enclosed in an argon cover gas. The reactor vessel and most of the structure is set below grade, providing protection against wind-driven missiles and aircraft hazards.

There are multiple barriers that preclude release of fission products into the environment. The first is the TRISO particle itself, clad with silicon carbide and layers of pyrolytic graphite. The second barrier is the primary salt system, with the high-purity argon cover gas. Most radionuclides that could be released from the fuel matrix would be retained in the salt, with tritium and noble gases collected in the argon cleanup system. The third barrier is the rectangular argon-filled structure, with the associated lower areas in the reactor building. The salt does not boil, even at accident conditions, and no significant quantities of water are introduced into this area. A thick-walled pressure vessel, typical of containments at existing LWRs, is not required. The argon enclosure is tightly closed, with airlocks at any point of entry. The fourth barrier is the outer structure in which the reactor building is set, providing additional isolation of the reactor building from groundwater and similar release paths. The reactor building, its interfaces with the reactor itself, and the salt drain tanks are described in more detail in Chapter 4.

New fuel is unloaded in the fuel-handling building adjacent to the reactor building, set on carts, and moved into a drying area on the operating floor of the reactor building. This removes moisture and oxygen from the fuel before introducing it into the reactor, helping to maintain salt chemistry. Fuel assemblies are then introduced into a salt-filled fuel handling lobe on the side of the vessel. Remotely operated tools are used to exchange used fuel assemblies for new assemblies. The used assemblies are 
pulled up over a weir and transferred to a pool filled with low-cost salt, located in the fuel-handling building. From there, they are eventually removed to a handling cask where they are transported to storage wells under a pad adjacent to the fuel-handling building. The entire refueling process and equipment are described in Chapters 4 and 7.

The control and electrical power supply building is located adjacent to the reactor building. The safety of the reactor does not depend on a continuous supply of ac power, and only industrial-type backup power systems are used.

Maintaining the purity and chemical balance of the salt is important both to limit corrosion in the salthandling systems and to maintain clarity for visual maintenance and refueling operations. A portion of the primary salt purification system, including hydrofluorination and fluid-phase contacting processes, is located in the lower portions of the reactor building. Other salt processing and waste management systems are located outside the reactor building.

Maintaining low-pressure conditions in the reactor building for all accident scenarios is partly based on limiting the quantity of water used for cooling or other applications, and thus limiting the potential for steam generation. Argon, air, and other nonboiling cooling fluids will be used in place of traditional water-cooling systems for component cooling and other reactor applications. Because of the large quantities of argon used to inert the reactor and surrounding areas, and to be used for cooling, a cryogenic argon storage system will be located near the reactor building.

Long-term passive safety requires cooling the reactor silo structure, limiting the temperature of the concrete. In normal operation, reflective insulation and a partially evacuated, argon-filled barrier are maintained between the reactor assembly and the concrete silo walls. With natural circulation decay heat removal, the temperature of the reactor assembly does rise. Cold argon, supplied from the liquid argon evaporator system, will be used to help keep the silo concrete temperature down. A Stirling engine coupled to a blower will be used to assist with the flow. These systems are described more fully in Sections 5.5, 9.2, and 9.3.

The power cycle is similar to that of advanced supercritical coal plants, as shown in Fig. 6 . The three primary coolant salt loops carry heat from the core to a heat exchanger, which transfers heat to an intermediate salt circuit. Each primary loop includes a primary-to-intermediate heat exchanger and a primary coolant pump. Three corresponding intermediate salt circuits carry heat out of the reactor structure to the supercritical water/steam reheat heat exchangers at the turbine building. Here, water pressurized to about $24 \mathrm{MPa}(3,500 \mathrm{psia})$ is heated to about $600^{\circ} \mathrm{C}\left(1200^{\circ} \mathrm{F}\right)$ - conditions well above the critical point. Steam flows through the high-pressure turbine, back to a salt-to-steam reheater, and then to the intermediate-pressure turbine. The exhaust from the intermediate-pressure turbine is passed to the low-pressure turbines, where it is condensed at very low pressure. The generator system is typical of similar power plants. Because the temperature of the reheat steam is much higher than that in light-water power plants, there is no need for large moisture separator/reheater vessels ahead of the low-pressure turbines. 


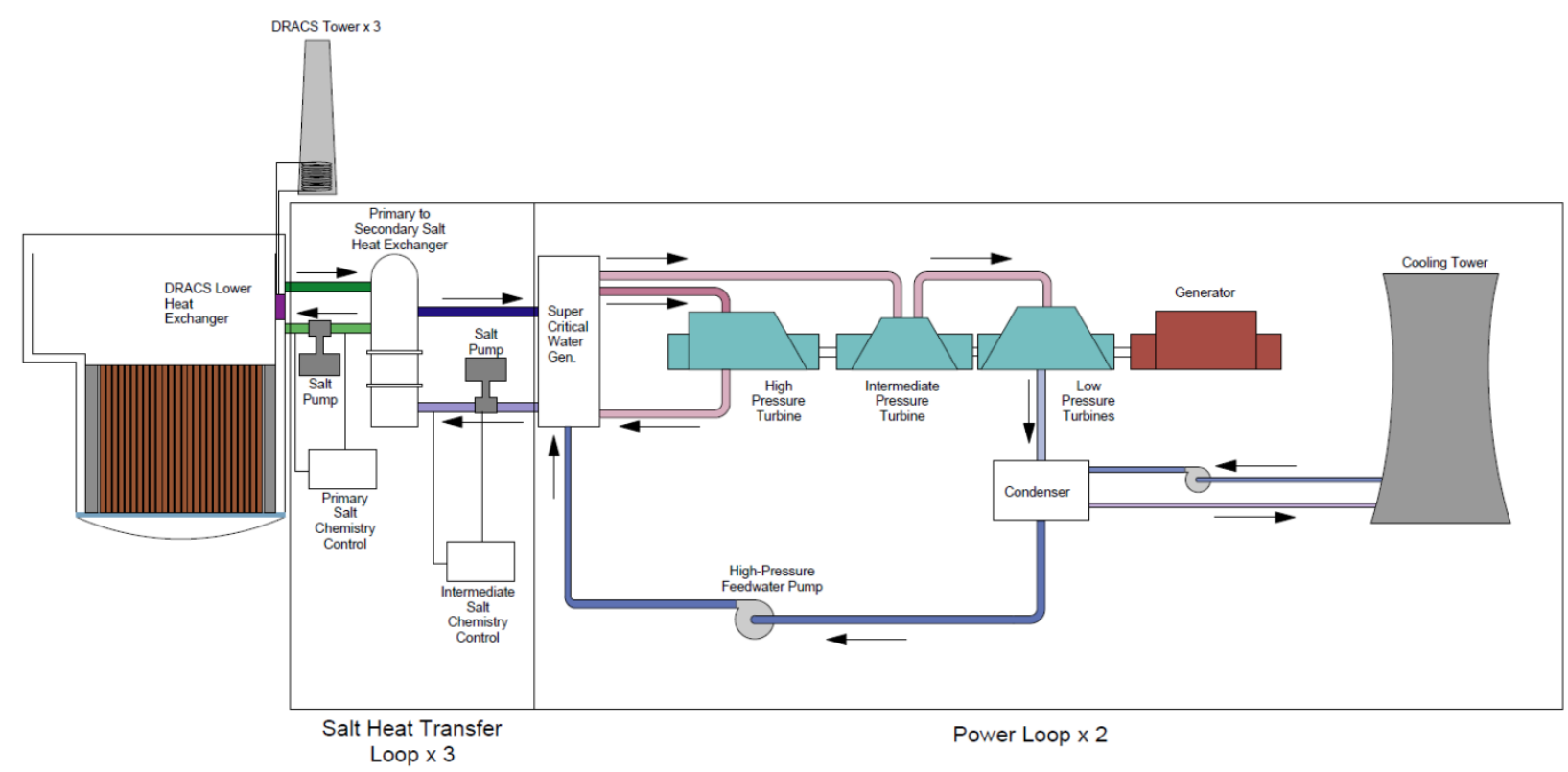

Fig. 6. AHTR electric power generation.

The turbine-generator operates at $3600 \mathrm{rpm}$. If a single shaft is used, it will be coupled to a 1,600 MW(e) generator. This is larger than typical superheated steam fossil plant installations but is within the range of newer LWR plants such as the Mitsubishi US-APWR. If two parallel shafts are used, each would be rated at $800 \mathrm{MW}(\mathrm{e})$, a typical rating for fossil plants. The current building layout accommodates two shafts.

The baseline condenser system is typical of modern steam plants, with two natural draft evaporative cooling towers rejecting heat from a condenser operating at an absolute pressure of about $2 \mathrm{~mm} \mathrm{Hg}$. Makeup water would be drawn from a nearby surface water source. Alternatives for situations where surface water is limited or unavailable would be a hybrid wet-dry cooling tower, or water-to-air heat exchangers. If water is available but large cooling towers are not desired, smaller forced-draft evaporative towers could also be used. The overall plant efficiency would be reduced with the alternative systems but would remain higher than existing LWR plants.

The condensate and feedwater system would also be typical of existing steam plants. Condensate booster pumps would move condensate through a condensate polishing system and three or four low-pressure feedwater heaters. A deareator would precede feedwater booster pumps, which supply water to steamdriven, high-pressure feedwater pumps. Feedwater then passes through three high-pressure feedwater heaters before reentering the intermediate salt heat exchangers. Further optimization and final selection of the number of turbine generator shafts will influence the number of parallel components throughout the system.

\subsection{SITE AND BUILDINGS}

The arrangement of the AHTR complex, on a generic site located near a river or other water body, is shown in Fig. 7. Numbers throughout this section refer to the numbers shown in the figure. The site is divided into a secure reactor operations zone and a lower-security power plant zone, with the intermediate salt pipe tunnel connecting the two. 
The central feature is the reactor building (1), described previously. The low-profile, rectangular structure covers the cylindrical shell and the rectangular, argon-filled reactor zone. Three air stacks for the DRACS are shown, along with a smaller air stack for the maintenance heat exchanger.

During construction, the first features to appear are a heavy-lift crane pad (2) and a construction shop facility (3). This allows for shop fabrication of large modules, which are then lifted from the shop to the reactor using the mobile crane. Shop fabrication is more efficient, more reliable, and lower cost than field fabrication. All components brought to the site for assembly will fit on rail cars or can be airlifted using a heavy-lift helicopter.

The fuel-handling building (4) is seen adjacent to the reactor building, and the used fuel storage wells (5) are just to the left of the fuel-handling building. This provides a contiguous path for new and used fuel to pass between the reactor and fuel-handling buildings, and from the fuel-handling building to the storage wells. The storage wells are drilled to a depth of $800 \mathrm{~m}$ (the stacked height of half of a reactor core's worth of fuel), are fully cased, cemented and monitored for water inleakage, and provide sufficient interim storage for the used fuel accumulated during the 60-year operating life of the facility. If necessary, future expansion of the storage well facility is possible.

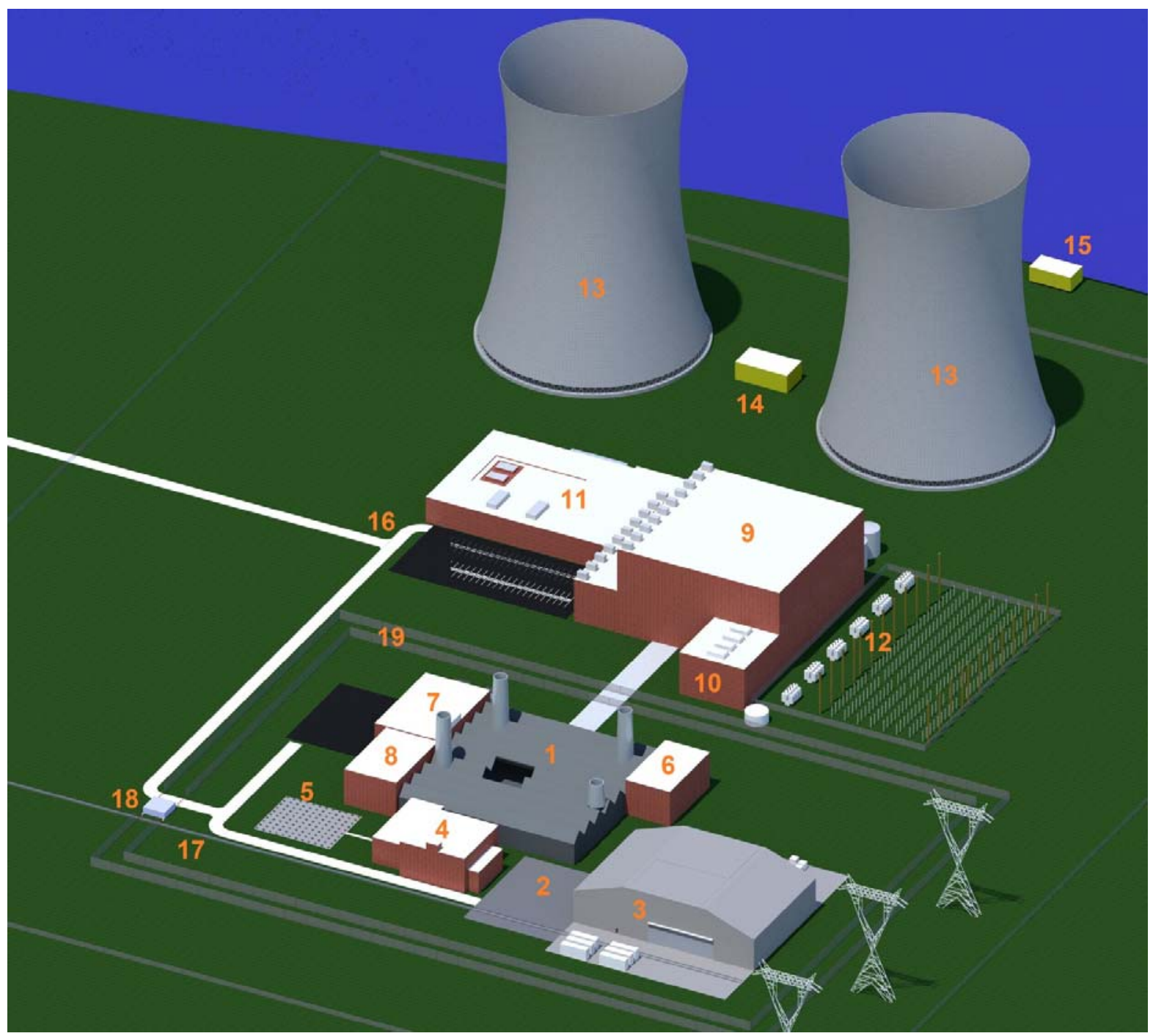

Fig. 7. Overall plant layout. 
Salt and radioactive waste processing equipment is located in a building adjacent to the reactor building (6). The control and electrical building (7) is also adjacent to the reactor building. This structure houses the control and operator support areas, as well as providing electrical power distribution for facilities in the reactor zone. At this time, the control and electrical functions are only described at a high level, and the building will be further refined as the design develops. Similarly, the reactor auxiliary equipment building (8) will be further defined as the design progresses.

The central feature of the power plant zone is the turbine building (9). This structure is typical of existing power plants and is currently sized to allow two parallel turbine-generator sets. An attached structure (10) houses the intermediate salt-to-steam cycle heat exchangers and some turbine facility support equipment. A low wing on the turbine building houses the condensate/feedwater equipment. The support and administration building (11) provides space for power plant support equipment, including ventilation systems, shop facilities, and support laboratories, and also includes personnel support areas. A simulator and training facility is not yet shown. The main transformers and switchyard (12) area adjacent to the turbine-generators, with high-voltage power transmission lines connecting the site to the grid.

The main features of the circulating water system are the two natural draft, evaporative cooling towers (13). A circulating water pumphouse and treatment building (14) is located near the towers, and a makeup water pumphouse (15) is seen at the surface water source.

Road (16) and rail access (17) to the site is seen to the left. The main parking lot, adjacent to the administration building, is within the property protection area. A common security portal (18) is used for both road and rail access into the secure reactor area. The security barriers (19) are seen encircling the reactor area.

\subsection{STRUCTURE OF THIS REPORT}

The remainder of this report describes the areas of focus through fiscal year 2012. Chapter 3 describes neutronic performance of the core, with a focus on reactivity coefficients, optimization of burnable poison, core lifetime, and refueling scenarios. Chapter 4 addresses the development of concepts for reactor building construction, arrangement, and seismic performance for the reactor and primary salt circuits and their arrangement into the reactor building, and for the location of salt storage tanks and for handling new and used fuel assemblies.

Chapter 5 describes work on the reactor cooling systems, including the primary and intermediate salt systems, the DRACS performance, the maintenance and fuel pool cooling systems, component and reactor cavity cooling systems, emergency cooling of the reactor silo, and the remote mechanisms required for maintenance.

The arrangement of the new and used fuel-handling building is covered in Chapter 1, and the refueling system itself is discussed in Chapter 7. Chapter 8 describes concepts for long-term fuel handling and storage.

Chapter 9 describes the overall approach to AHTR safety. Sections of this chapter address the primary and secondary shutdown systems, decay heat rejection under normal and degraded conditions for fuel in the reactor and the used fuel pool, seismic isolation and design features, and barriers to the release of radionuclides. Anticipated performance in response to a variety of scenarios is discussed. The chapter ends with an evaluation of tritium production, transport, trapping, and removal.

Advanced construction techniques, the construction sequence for the nuclear island, and an initial outline of a construction schedule are discussed in Chapter 10. The future development path for the AHTR is discussed in Chapter 11, followed by conclusions and references. 


\section{AHTR NEUTRONIC DESIGN}

\subsection{OVERALL NEUTRONIC DESIGN}

The AHTR neutronic preconceptual design developed in 2011 (Refs. 1 and 11) and has continued to be refined to better reflect the economic, performance, and operational constraints imposed as the design concept has matured. In particular, the AHTR baseline design fuel enrichment has been lowered to $9 \mathrm{wt}$. $\%$ and the carbon-to-heavy metal (CHM) atomic ratio has been raised by a factor of two (to 400) to minimize the fuel and enrichment costs. Further, a higher density carbonaceous matrix material $\left(1.75 \mathrm{~g} / \mathrm{cm}^{3}\right)$ was employed in the current design to achieve a higher discharge burnup and to better reflect the state of the art in fuel fabrication. The main goals of the 2012 neutronic evaluations for AHTR were to assess the impact of the increased carbon density in the fuel plates, to develop a more detailed AHTR core model for assessing the axial and radial power peaks, and to provide a more detailed assessment of burnable poison (BP) use in the AHTR core.

The AHTR core cross-sectional view in Fig. 8 shows the two-batch checkerboard refueling pattern adopted. The "checkerboard" refueling pattern is realized by replacing every other fuel assembly on a given ring of assemblies with fresh fuel assemblies. As noticed, the central fuel assembly is replaced with a replaceable graphite reflector. Channels within the central column may be used for instrumentation and the startup neutron source. With this exception, all the dimensions and geometric layout are preserved from the 2011 baseline model.

Table 2 shows the main core characteristics of the 2012 AHTR baseline model. Noticeable in this table are the increases in power densities (almost double), both per grain and in the fueled region of the fuel plate due to the reduced total mass of the fuel compared to the 2011 reference. The once-through fuel cycle length reduces the refueling outage interval to roughly 6 months due to the combined effect of the reduced heavy metal load and lower fuel enrichment. Adoption of a two-batch fuel cycle however increases the in-core fuel residence time to 1 year. The thermal hydraulic parameters, calculated with the same model as in 2011, remain largely unchanged. However, the maximum fuel temperature is decreased by about $20^{\circ} \mathrm{C}$ because of the thinner fuel stripes.

The AHTR core continues to make use of the Advanced Gas Reactor (AGR) fuel currently being developed under DOE-NE sponsorship. ${ }^{12}$ The numbering in the fuel reference (e.g., AGR-1) refers to the irradiation experiment number. Different fuel parameters are being tested in each of the irradiations. 


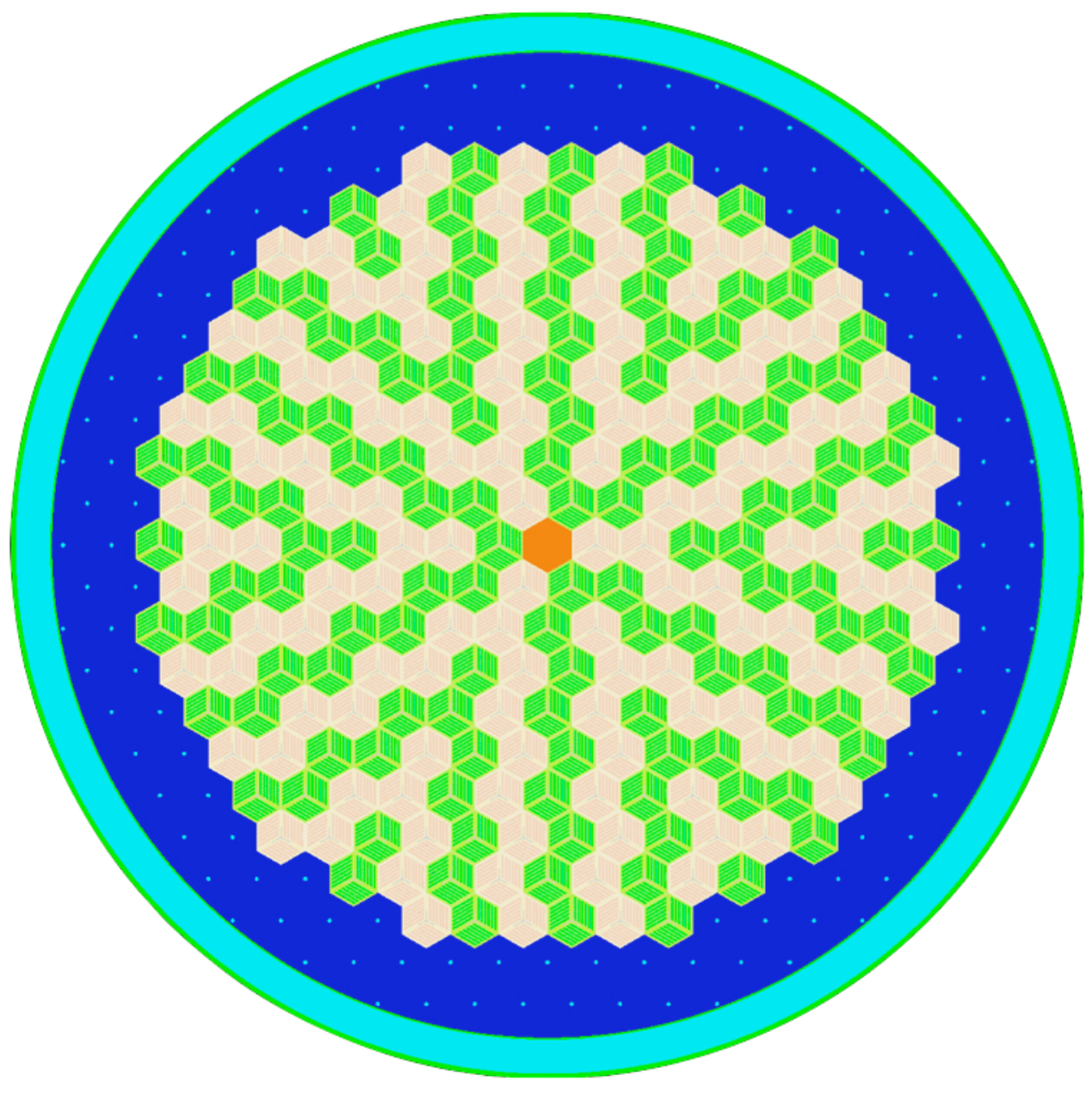

Fig. 8. The FY 2012 baseline AHTR core model showing the two-batch checkerboard refueling pattern.

The curves in Fig. 9 show the impact on the criticality of the AHTR core of different core design and fuel management options. The 2011 reference core provided a calculated lifetime of $\sim 2.15$ years using the AGR-2-like fuel at $19.75 \%$ enrichment. Maintaining the same geometric design but switching to the AGR-5/6 type of fuel increases slightly the lifetime of the once-through core to $\sim 2.25$ years, due to the slightly higher CHM ratio caused in turn by the higher density of the carbon in the fuel matrix.

Increasing the CHM atomic percentage ratio from 205 to 400 for the 9 wt. $\%{ }^{235} \mathrm{U} / \mathrm{U}$, AGR-5/6-based design, leads to the current AHTR core design. This core roughly maintains the same once-through lifetime as the $\mathrm{CHM}=205,9$ wt. $\%{ }^{235} \mathrm{U} / \mathrm{U}$, AGR-5/6-based design, while significantly decreasing the initial excess reactivity. 
Table 2. Main AHTR core characteristics

\begin{tabular}{l|c|c}
\hline \multicolumn{1}{c|}{ Parameter } & Value & Units \\
\hline Power (thermal) & 3,400 & $\mathrm{MW}$ \\
Assembly lattice type & Hexagonal & - \\
Fuel type & Coated particle & - \\
Moderator & Graphite & - \\
Reflector & Graphite & - \\
Coolant pressure drop across core & 1 & $\mathrm{~atm}$ \\
Core height (including axial reflector) & 6.0 & $\mathrm{~m}$ \\
Core diameter (including radial reflector) & 9.56 & $\mathrm{~m}$ \\
Average power per grain & 77 & $\mathrm{~mW} / \mathrm{particle}^{3}$ \\
Average power density in fuelled region & 97 & $\mathrm{~W} / \mathrm{cm}^{3}$ \\
Volumetric core power density & 12.9 & $\mathrm{MW} / \mathrm{m}^{3}$ \\
Mass of heavy metal (fresh core) & 17.48 & $\mathrm{MT}$ \\
Fuel enrichment & 9.00 & $\mathrm{wt} . \%{ }^{235} \mathrm{U} / \mathrm{U}$ \\
Mass of fissile & 1.6 & $\mathrm{MT}$ \\
Fuel cycle length (once-through, no BP) & 0.80 & $\mathrm{years}$ \\
Fuel cycle length (once-through, with BP) & 0.72 & $\mathrm{years}$ \\
Fuel residence time in core (two batch) & 1.0 & $\mathrm{year}$ \\
Average fuel discharge burnup & 71 & $\mathrm{GWd} / \mathrm{MT}$-heavy \\
Maximum fuel temperature (average assembly) & 837 & $\mathrm{metal}$ \\
Average coolant flow velocity (intra-assembly flow) & 1.94 & ${ }^{\circ} \mathrm{C}$ \\
Coolant volumetric flow rate & 14.56 & $\mathrm{~m} / \mathrm{s}$ \\
Average Reynolds number (intra-assembly flow) & 7,241 & $\mathrm{~m} / \mathrm{s}$ \\
\hline
\end{tabular}

Based on the once-through fuel cycle behavior, the behavior of a two-batch fuel management scheme can be predicted based on the Linear Reactivity Model (LRM). ${ }^{13}$ The dashed curve in Fig. 9 shows the LRManticipated behavior of the equilibrium two-batch 2012 AHTR reference core for the two-batch fuel management core. This curve confirms the feasibility of the 6-month, two-batch cycle length.

The applicability of the LRM-anticipated two-batch evolution of the AHTR core multiplication constant is demonstrated in Fig. 10 through direct calculation based on the checkerboard refueling pattern shown in Fig. 8. The direct calculation predicts a slightly higher reserve of reactivity at the end of the 6-month, two-batch fuel cycle, which is a desirable result. 


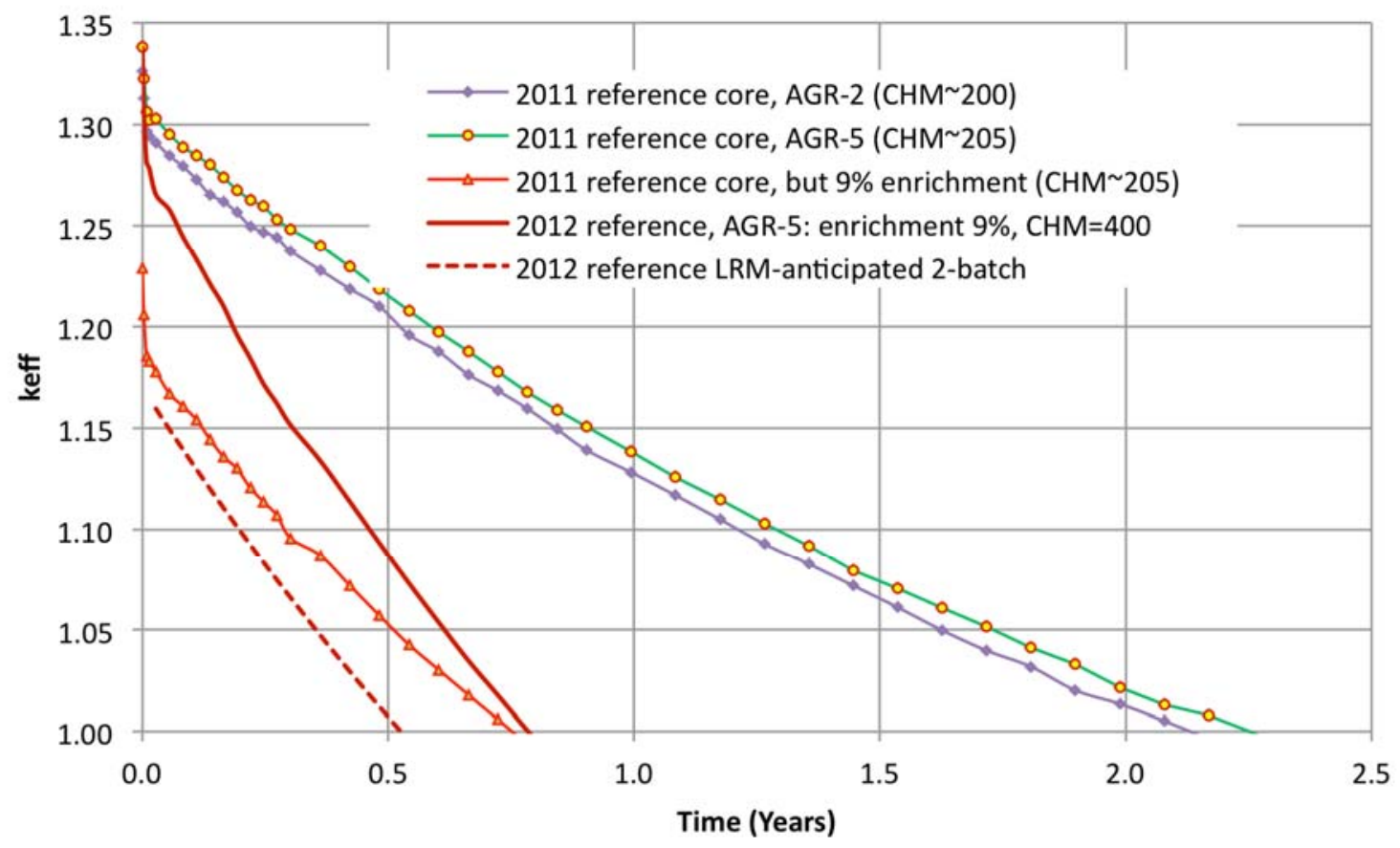

Fig. 9. Comparison of the AHTR core multiplication constant for different core options.

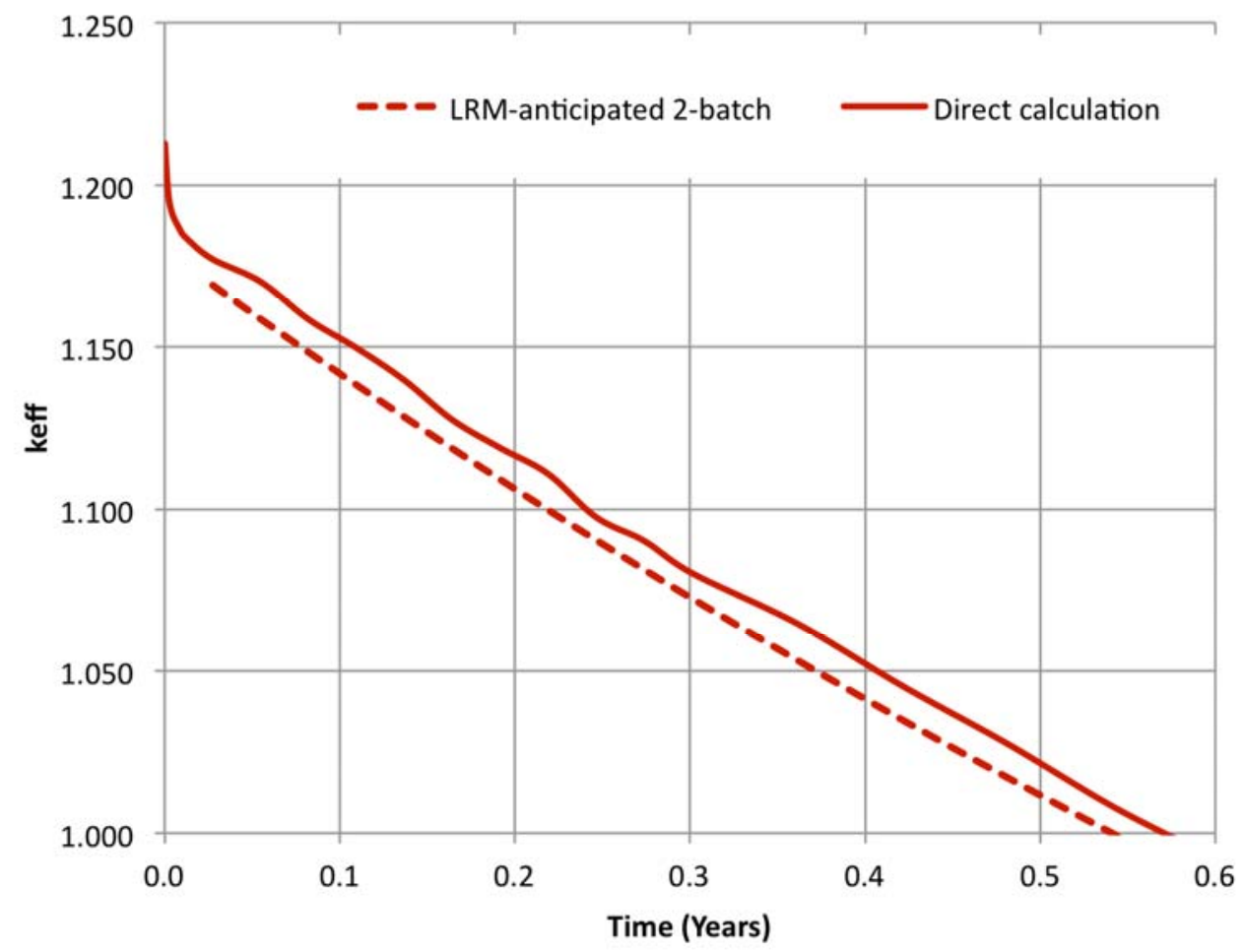

Fig. 10. LRM and direct calculation comparison of the two-batch cycle. 


\subsection{CORE POWER DISTRIBUTION}

Mapping the power distribution in a reactor core enables evaluation of the limiting thermal and irradiation conditions. The power distribution calculations during the 2011 AHTR effort were performed on a simple, coarse core model that divided the core into six regions, two radial and three axial. For 2012, a more detailed model with nine radial regions and five 110-cm-long axial regions was developed. The new model is shown in Fig. 11 and consists of nine hexagonally concentric rings of fuel assemblies. Each fuel assembly is further divided axially into five equal sections, $110 \mathrm{~cm}$ long each, which, for future reference, will be called "fuel blocks," or, simply, "blocks." There are $252 \times 5=1260$ fuel blocks in the AHTR core. The average power per each fuel block is then $(3,400 \mathrm{MW}) /(1260$ blocks $)=2.7 \mathrm{MW} / \mathrm{block}$. Based on the calculated power distribution, it can then be calculated a maximum-to-average (M/A) ratio for the power generated in the blocks of the AHTR core. The power per assembly can be found by integrating axially the block-wise power distribution. The average power per fuel assembly will then be $(2.7 \mathrm{MW} / \mathrm{block}) \times$ (5 blocks/assembly) $=13.5 \mathrm{MW} /$ assembly.

Because of the AHTR core geometry model used, the fuel assemblies in a radial ring are considered identical. In reality, slight variations can occur between fuel assemblies in different regions of the ring. These possible variations are not taken into account by the current model. In particular, these variations can be larger for the outermost rings that border the radial reflector.

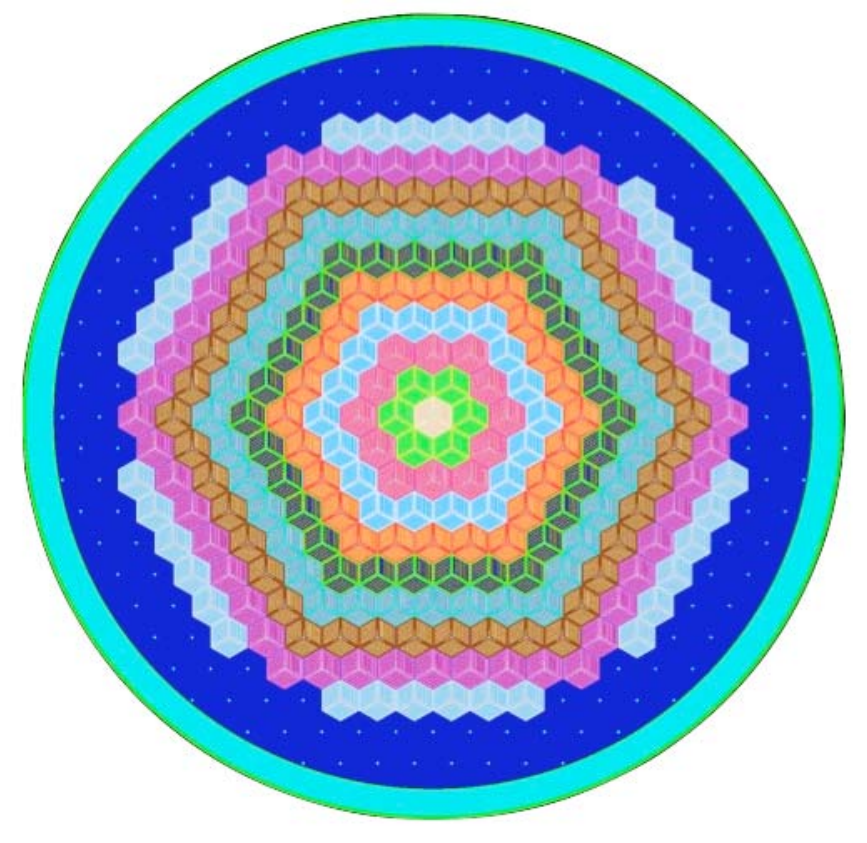

Fig. 11. AHTR core model for power distribution calculations.

The results of power distribution calculations using the AHTR core model of Fig. 11 are shown in Fig. 12 for four fresh AHTR bare core options. This figure shows the ring-dependent radial power distributions (radial peaking factors) and also the block-wise M/A ratios (block-wise peaking factors).

Fig. shows that the 2011 AHTR core design provided a lower peaking factor with an M/A ratio of 1.52 and a radial peaking factor of $\sim 1.2$. With the lower enrichment, the block-wise peaking factor increases to $\mathrm{M} / \mathrm{A}=1.75$ and the radial peaking factor increases to just over 1.3. Further, increasing the CHM ratio leads to additional increase in the peaking factors: $\mathrm{M} / \mathrm{A}=2.09$ and a radial peaking factor of over 1.5 . Finally, 
using BP particles in the AHTR design leads to a decrease in the peaking factors. For one of the BP options, the $\mathrm{M} / \mathrm{A}$ ratio decreased to 1.98 with a radial peaking factor below 1.5.

The radial peaking factor is correlated with the maximum fuel temperature of Table 2 . The $837^{\circ} \mathrm{C}$ value shown in Table 2 . was calculated with a radial peaking factor of 1.5 , considered typical. This maximum fuel temperature would decrease to $818^{\circ} \mathrm{C}$ for a radial peaking factor of 1.2 and would increase to almost $890^{\circ} \mathrm{C}$ for a radial peaking factor corresponding to a bare cylindrical reactor (with a Bessel function-like radial power distribution which predicts a radial peaking factor of $\sim 2.3$ ).

Rings 7, 8, and 9 generate less-than-average power per assembly, and the inner six rings generate morethan-average power per assembly for the fresh AHTR core. This is a general trend, independent of the specific configuration used. The power distributions will flatten over the course of the fuel cycle. Therefore the peaking values calculated are expected to represent upper bounds for the assembly/block peaking factors. Fuel peaking factors are not anticipated to be design limiting due to the large margin between operating conditions and fuel damage. However, in general the reactivity control scheme will be to flatten the power distribution by removing exterior control rods first and progressing toward the center as fuel is consumed during the cycle.

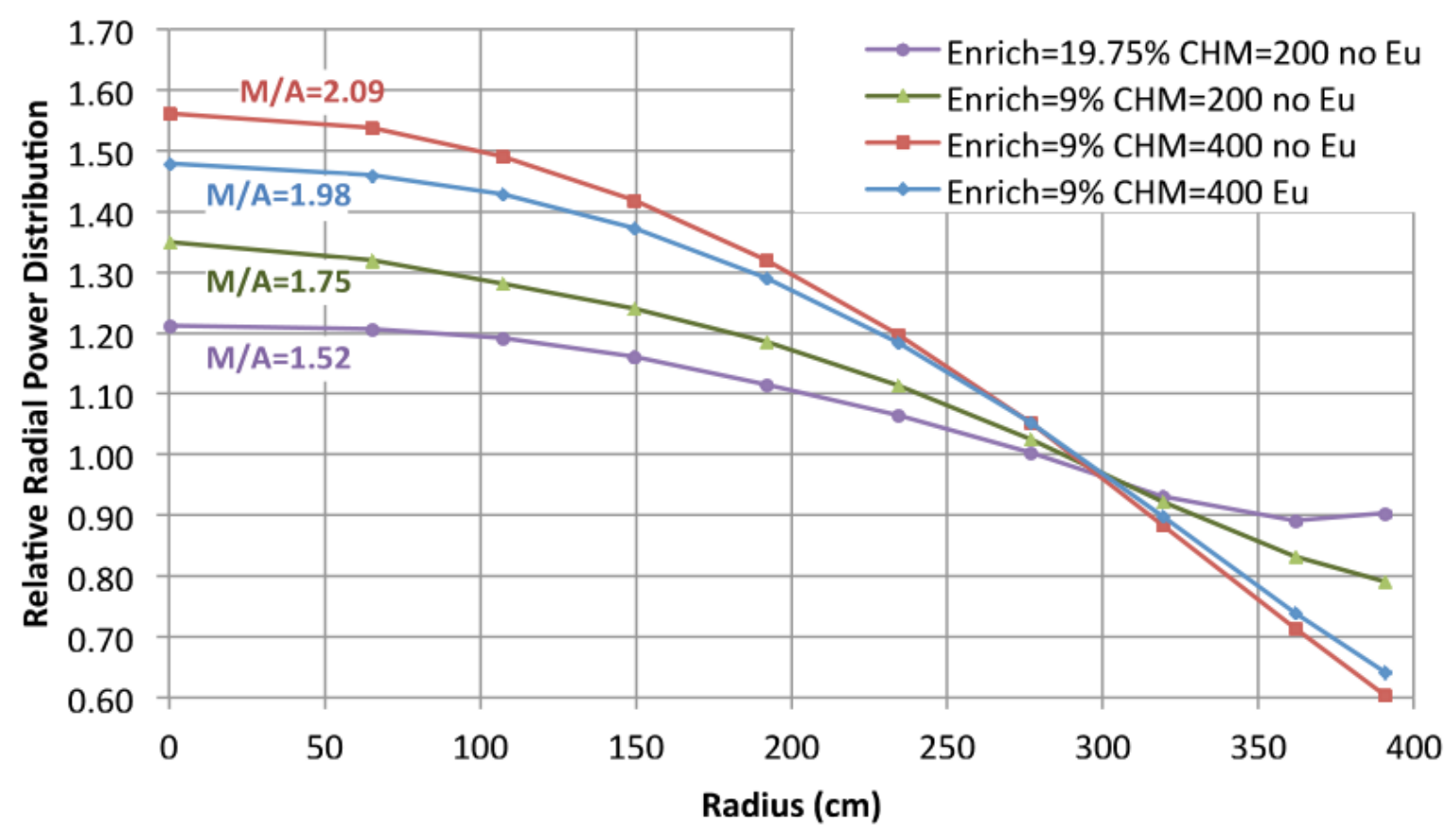

Fig. 12. Radial power distributions for different AHTR core options (fresh fuel).

In addition to the power distributions at the assembly/block level, the intra-assembly power distribution was also evaluated at the plate level. For this purpose, a single-assembly model reflected laterally was built to simulate an infinite reactor of identical fuel assemblies. In this model each plate was modeled separately. Using this model it was determined that the three plates that share the same position relative to the central C-C Y-shape and the channel box also share, with good approximation, the same power. Therefore, it is enough to analyze the plate-to-plate power distribution within $1 / 3$ of the fuel assembly. The average over the whole reactor of the power generated in one plate is $(13.5 \mathrm{MW} / \mathrm{assembly}) /$ $(18$ plates/assembly $)=0.75 \mathrm{MW} /$ plate. The results for the relative plate power distribution of the six plates in each $1 / 3$ of the fuel assembly are shown in Fig. 13. This power distribution can be well approximated with a parabolic function. The distribution, which shows power peaks in plates 1 and 6 near the carbon- 
rich regions of channel box and Y-shape, is asymmetric with the power in the plate closest to the Y-shape being the highest. The asymmetry is due to the different thicknesses of the carbonaceous material in the two regions bounding plates 1 and 6 . The plate-to-plate peaking factor in this case is about $\sim 1.1$. The calculations were performed for an assembly model typical of the 2011 reference AHTR model; however, the trend is expected to hold for the current design.

The peaking factor result for the plate can be combined with the radial peaking factors determined above to find the hottest plate in the reactor. As it turns out, the hottest plates are the plates next to the Y-shape in the innermost fuel assembly ring of the AHTR core. The power generated in each of these plates can be estimated to be $(0.75 \mathrm{MW} /$ plate $) \times(1.5$ radial factor $) \times(1.1$ plate-to-plate factor $)=1.24 \mathrm{MW}$, which is $65 \%$ higher than the average power per plate.

The longitudinal power distribution within each plate (along the $\sim 22.5-\mathrm{cm}$ length of the plate) was not evaluated but is expected to be similar to the plate-to-plate distribution shown in Fig. 13 with the power peaking occurring at the end of the plate adjacent to the Y-shape. This longitudinal plate power distribution will further increase the local peaking factors in an AHTR reactor. At this level of detail, the thermal-hydraulic model employed to estimate the maximum fuel temperature breaks down since it assumes a longitudinally infinite long plate, and hence a longitudinally flat power distribution within each plate.

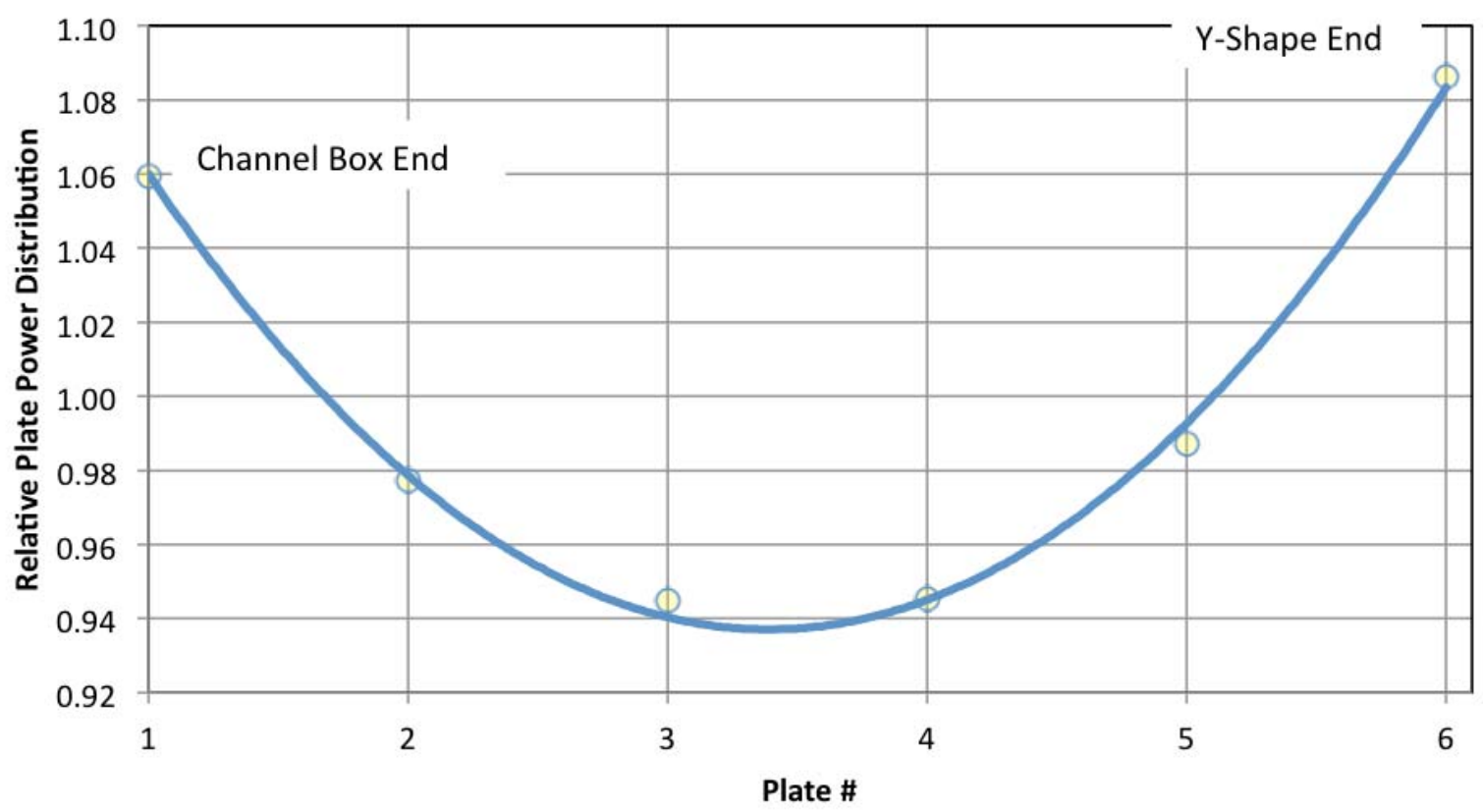

Fig. 13. Plate power distribution in an AHTR fuel assembly.

\subsection{BURNABLE POISON}

The use of BP in the AHTR core is important for at least three reasons. First, the initial core excess reactivity is too large to be handled by the control blades alone. For example, for the fresh 2012 reference core, the excess reactivity is $\sim 18 \% \Delta \mathrm{k} / \mathrm{k}$ after the xenon buildup and stays at a significantly large value for an extended period of time. The use of control blades alone in this case will result in large axial power distribution distortions, which would result in axially unequal burnup of the fuel assembly, with the lower half of the assembly being depleted much faster than the upper half. Second, BP use in the AHTR core 
flattens the power distribution. Third, the use of the BP, has a positive effect on the void coefficient of reactivity, as will be shown in the next sections.

All neutronic calculations, including the depletion calculations with BP, were performed using the SCALE6.1 version ${ }^{14}$ of the SCALE package. After the completion and the analysis of the depletion calculations, which are very resource intensive, it was detected that, as a result of an issue not documented in the SCALE6.1 manual, the code did not perform the depletion of the BP regions correctly. Namely, the newly created isotopes resulting from the transmutation of the initial, naturally occurring europium isotopes $\left({ }^{151} \mathrm{Eu}\right.$ and $\left.{ }^{153} \mathrm{Eu}\right)$ are not carried along during the depletion time steps. This led to neglecting the negative reactivity induced by the isotopes that are building up in the burnable particle regions, an effect that cannot be neglected without affecting the overall behavior of the system at later times during operation. As a result, the studies presented in this section and its sub-sections (as well as the other results of the neutronic chapter that involve BP) have more of a qualitative value. What can be retained, however, are the general procedures developed for the treatment of the BP.

\subsubsection{General Considerations}

For the AHTR core, the option chosen was to use the BP as pyrocarbon-overcoated sintered grains of $\mathrm{Eu}_{2} \mathrm{O}_{3}$ powder placed at the center of the fuel plate, as shown in Fig. 14. The europium oxide has a high thermal stability with a melting point temperature at $2350^{\circ} \mathrm{C}$. The free parameters that were chosen for the AHTR design with BP were the size of the $\mathrm{Eu}_{2} \mathrm{O}_{3}$ grains and their number. These two parameters together with the density of the $\mathrm{Eu}_{2} \mathrm{O}_{3}$ grains determine the $\mathrm{BP}$ loading per fuel plate. The density of the $\mathrm{Eu}_{2} \mathrm{O}_{3}$ particles used in this study was chosen to be $5.0 \mathrm{~g} / \mathrm{cm}^{3}$ ( $68 \%$ of theoretical density).

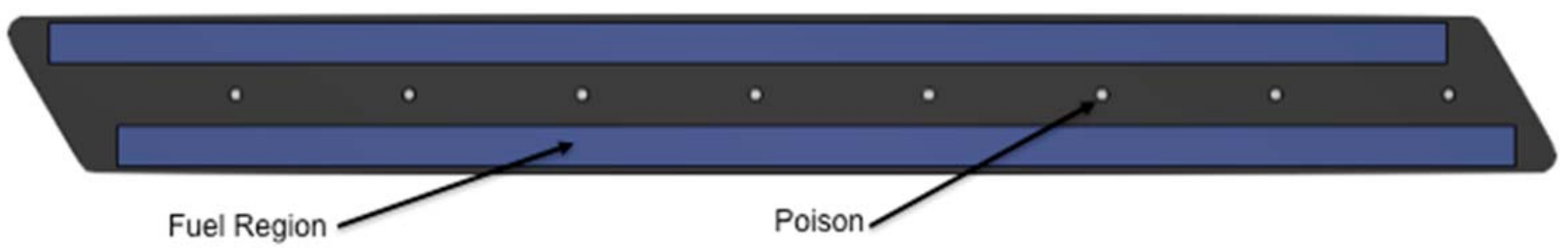

Fig. 14. Placement of the $\mathrm{Eu}_{2} \mathrm{O}_{3}$ grains (white dots) at the center of the fuel plate.

Figure 15 shows the typical behavior of the reactivity of a reactor core with BP loading as compared to the behavior for the bare core that uses no BP. The use of BP can significantly lower the large initial excess reactivity typical of the bare core. A further fast ( $\sim 3$ days) decrease in reactivity is due to the xenon buildup to its equilibrium concentration in the core. When the xenon reaches its equilibrium concentration, the reactivity of the core reaches a local minimum. This local minimum moment is followed by a temporary increase in reactivity due to the BP depleting at a higher rate than the fuel. The core reactivity then increases until it reaches a local maximum, which under certain conditions can also be a global maximum (possibly higher than the initial reactivity). The difference between the local maximum reactivity and the local minimum determines the reactivity swing of the core. After the reactivity maximum is reached, the core reactivity curve asymptotically approaches the reactivity curve of the core without BP. At fuel discharge time, the core with BP still has a lower reactivity than the core without BP. This difference between the two curves at the fuel discharge time determines the reactivity penalty due to the use of the BP. This reactivity penalty also translates in a fuel cycle penalty, as shown in Fig. 15. 


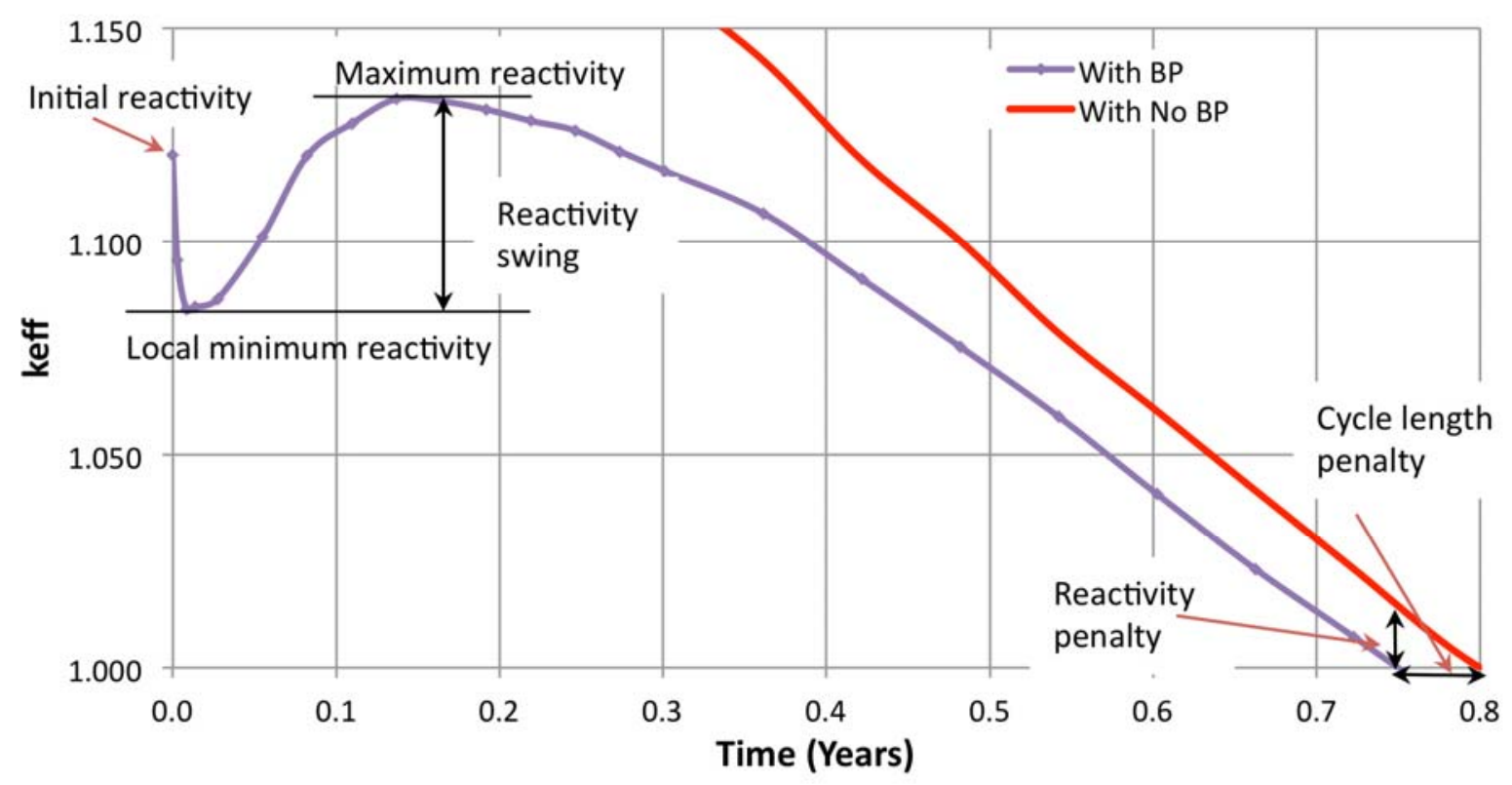

Fig. 15. Typical reactivity evolution for a reactor core using burnable poison.

\subsubsection{Search for Optimum Burnable Poison Loading}

As mentioned above, the search parameters for the design of the AHTR BP loading were the size of the $\mathrm{BP}$ particles and their number. The density of the $\mathrm{Eu}_{2} \mathrm{O}_{3}$ particles was fixed at $5.0 \mathrm{~g} / \mathrm{cm}^{3}$. The distribution pattern of the BP particles within the plate was also fixed as a one-particle-thick layer of BP at the center of the plate (Fig. 14). Figures 16 and 18. show the behavior of the AHTR multiplication constant for an initial core for three configurations with similar initial amounts of BP but distributed differently as $47 \times 150 \mu \mathrm{m}(47$ spherical BP particles per horizontal layer in each plate, each particle with a radius of $150 \mu \mathrm{m})$, as $12 \times 250 \mu \mathrm{m}$, or as $4 \times 350 \mu \mathrm{m}$. As shown, the evolution of the AHTR reactivity can be quite different during the initial stage of the reactor operation for different BP distributions, even though the initial total amount of BP is fairly similar for the three configurations. The initial multiplication constant of the AHTR system depends primarily on the total BP area "seen" by the neutrons, if the BP is a fairly black absorber. Therefore, a finer granulation has a more absorbing effect at the beginning of the irradiation cycle than a coarser granulation, for the same total mass of BP. The dependence of the AHTR initial reactivity on the absorbing area shows a linear dependence if the size of the particles is maintained constant (Fig. 17). This linearity turns out to be preserved for short irradiation time, at the beginning of the core life. In particular, it holds for the local minimum reactivity. From the above observations and from an analysis of Fig. 16, one can conclude that a coarser BP particle distribution is advantageous for minimizing the reactivity swing at the beginning of the irradiation cycle. 


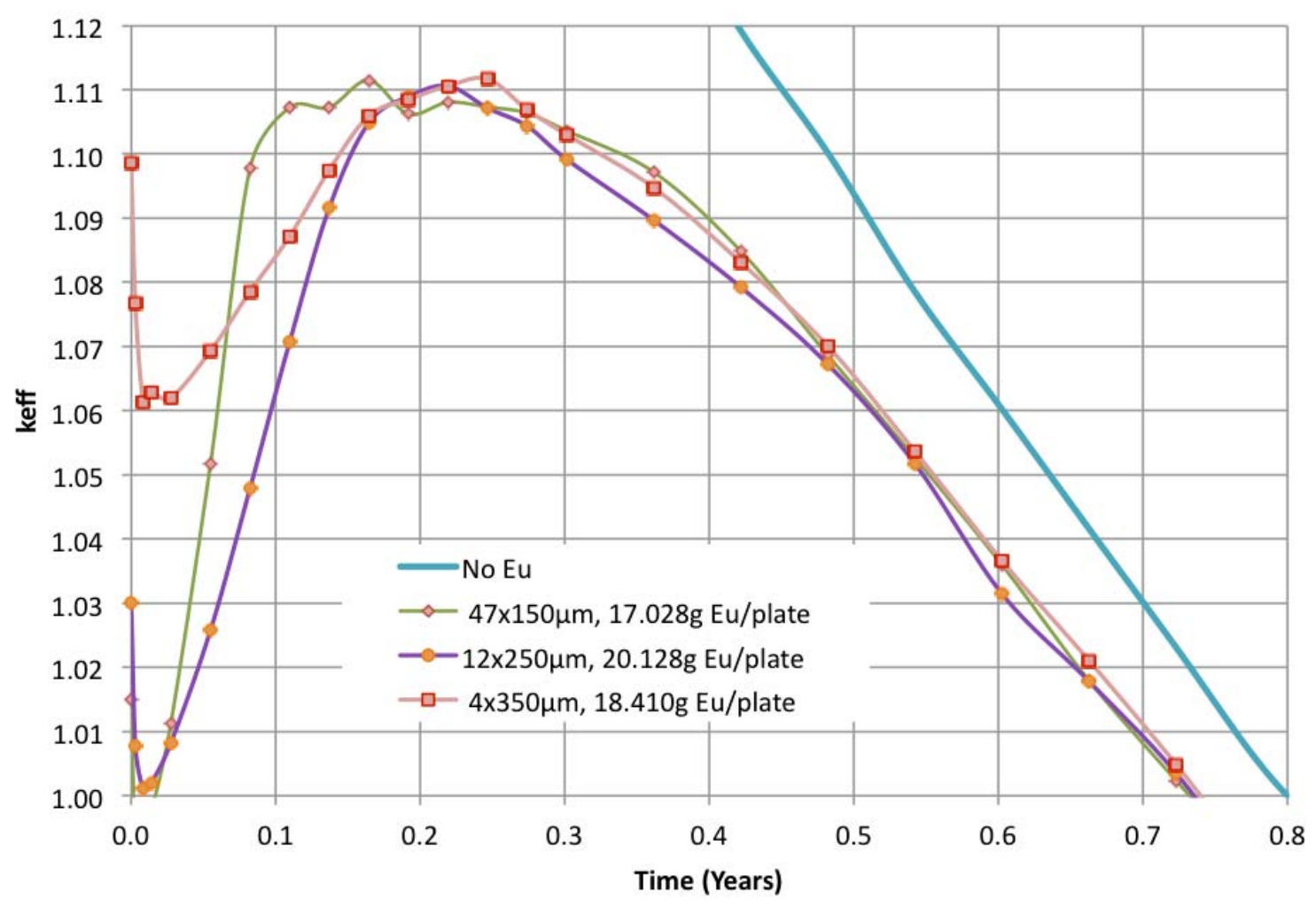

Fig. 16. AHTR reactivity evolution for similar amounts of BP which are distributed differently.

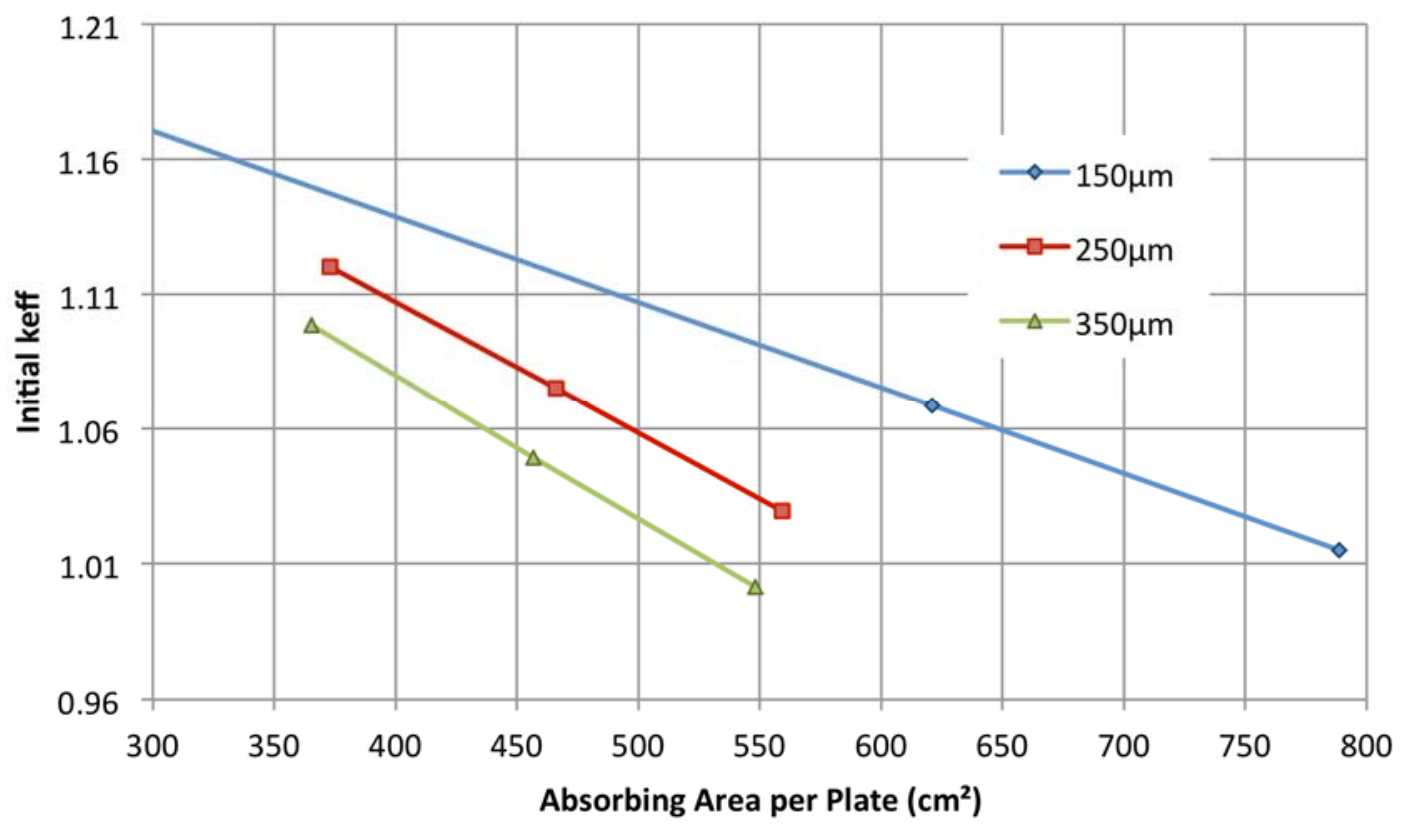

Fig. 17. Linear dependence of the AHTR reactivity on the absorbing area. 


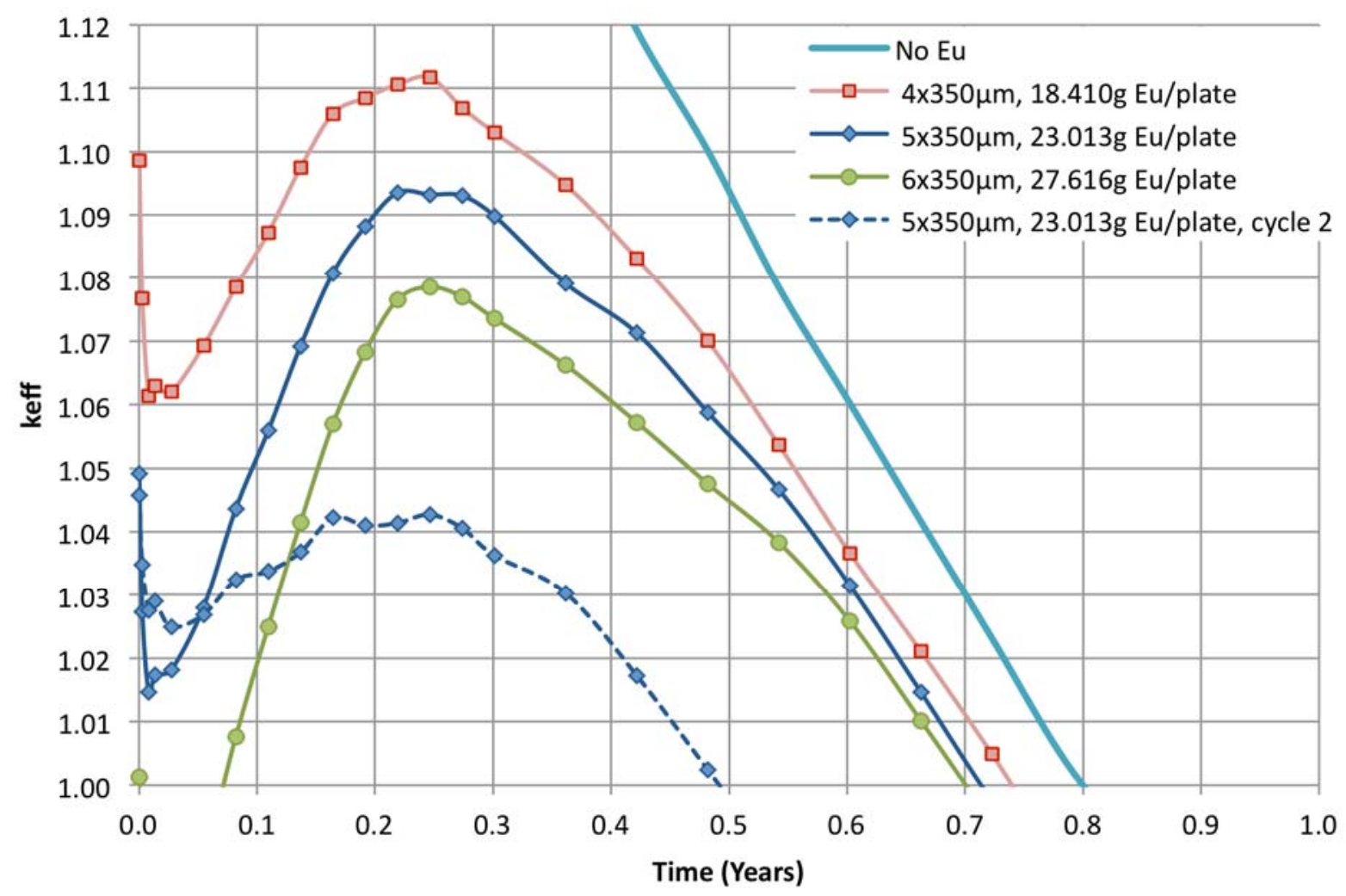

Fig. 18. AHTR reactivity evolution for different amounts of BP.

For the 350- $\mu \mathrm{m}$-radius BP particles, an additional search was performed to optimize the amount of BP, so that the equilibrium lifetime of the AHTR core is maintained at 6 months and at the same time the excess reactivity of the core is below $10 \% \Delta \mathrm{k} / \mathrm{k}$ at any time during the reactor operation (Fig. 18). To obtain an equilibrium cycle length of 6 months, the initial core cycle length should be 0.75 years, according to the LRM theory for a two-batch core.

As shown in Fig. 18. AHTR reactivity evolution for different amounts of BP. choosing a $5 \times 350 \mu \mathrm{m}$ configuration (for a mass of $23.013 \mathrm{~g}$ of europium per fuel plate), a cycle length of 6 months is obtained, with a good approximation, for the equilibrium cycle. The equilibrium cycle reactivity calculation (dashed line on Fig. 18) was obtained through direct calculation for a checkerboard two-batch core.

The $5 \times 350 \mu \mathrm{m}$ AHTR core configuration was chosen as a reference model. The AHTR core reactivity is maintained below $5 \% \Delta \mathrm{k} / \mathrm{k}$ at any time during the equilibrium cycle for this distribution of BP particles.

\subsection{ISOTHERMAL REACTIVITY COEFFICIENT}

The isothermal temperature reactivity coefficient was evaluated for several configurations at the beginning of initial cycle (fresh fuel) over the temperature interval [800K, 1850K] (approximately $\left.\left[500^{\circ} \mathrm{C}, 1600^{\circ} \mathrm{C}\right]\right)$ in order to isolate the effect of each change in the AHTR core reference model. The isothermal temperature coefficient of reactivity, $(\partial \rho / \partial \mathrm{T})_{i s o}$, is calculated as the derivative of the reactivity induced by an isothermal change in the temperature of the core considering the core in an isothermal condition (i.e., uniform temperature everywhere) with all the other parameters maintained constant. 
Starting with the 2011 reference core (Fig. 19), decreasing the fuel enrichment and switching to the AGR-5/6 type of fuel (this has a minimal effect, changing the CHM ratio from 200 to 205 ) is beneficial on the isothermal temperature reactivity coefficient. A decrease of about $2 \mathrm{pcm} / \mathrm{K}$ can be observed in this case, making the isothermal coefficient more negative. An increase of the CHM ratio to a value of 400, that brings the configuration to the 2012 parameters, has the effect of bringing the isothermal coefficient behavior to one similar to the 2011 reference. Finally, adding the BP particles $(5 \times 350 \mu \mathrm{m}$ configuration $)$ has a strong effect upon the isothermal temperature reactivity coefficient, in the desired direction. For this fresh reference core with $\mathrm{BP}(5 \times 350 \mu \mathrm{m}$ configuration $)$, the isothermal temperature coefficient over the specified temperature interval can be approximated with a linear function:

$$
\left(\frac{\partial \rho}{\partial T}\right)_{i s o}(p c m / K)=-16.4+3.59 \times 10^{-3} T(K) .
$$

As seen in Fig. 19, the isothermal reactivity coefficient increases with a few $\mathrm{pcm} / \mathrm{K}$ over the temperature interval but stays in the negative domain with a good margin.

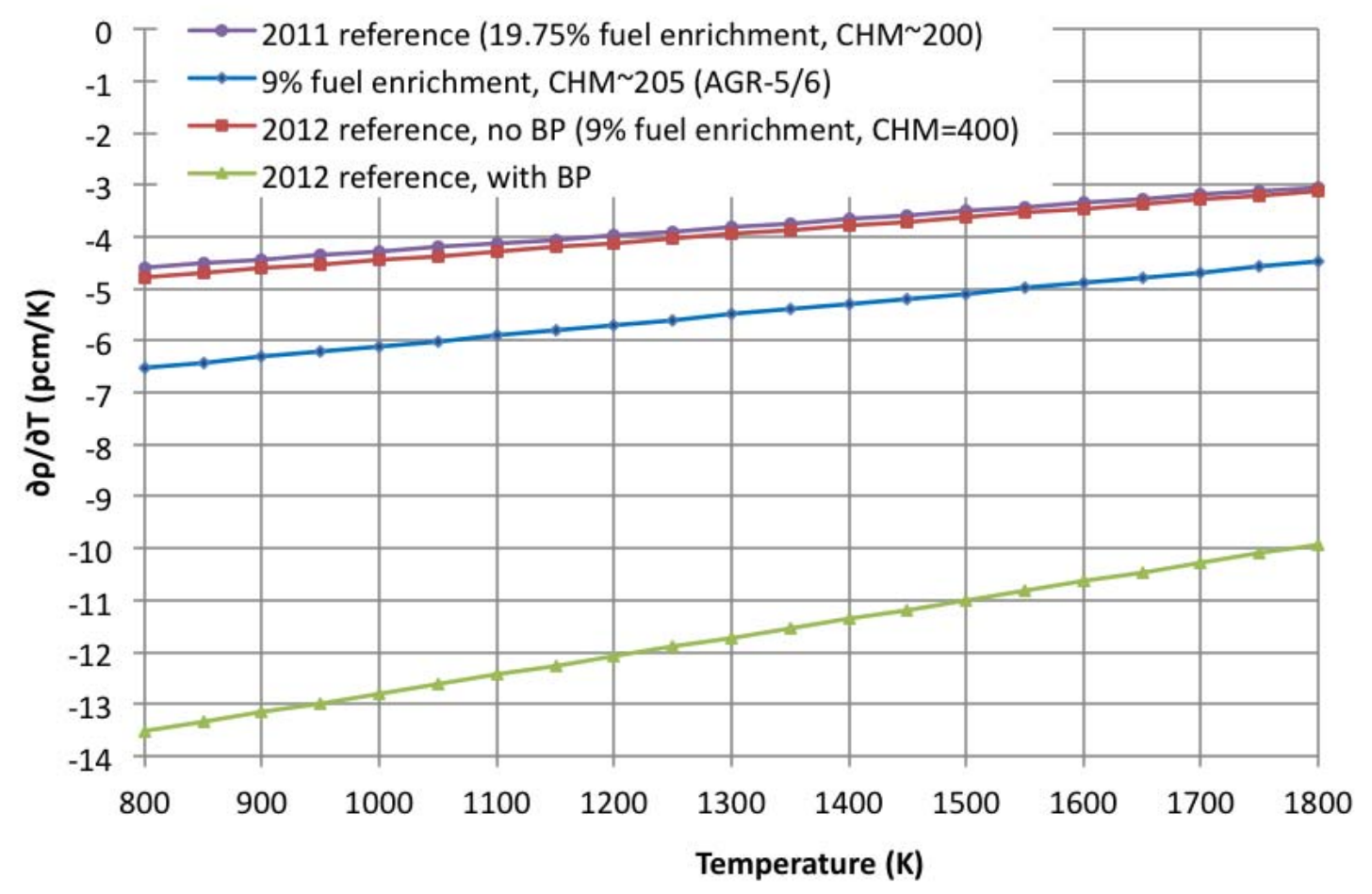

Fig. 19. Comparison of the isothermal temperature reactivity coefficient for FY 2011 and FY 2012 fresh reference cores.

The behavior of the isothermal temperature coefficient of reactivity was further analyzed for two additional times during the AHTR fuel cycle: at the end of the initial core cycle (EOC1) and at the beginning of the second (equilibrium) cycle (BOC2). As seen in Fig. 20, the isothermal coefficient stays negative at all times over the temperature interval of interest. At the end of the initial fuel cycle, the isothermal coefficient can become more positive (but still negative) at low temperatures but becomes more negative as the temperature increases. The resulting negative slope of this dependence on temperature is a desirable feature, meaning that the negative reactivity insertion increases as the temperature of the core goes up. The same trend is preserved at the beginning of the second (equilibrium) 
cycle, when half of the fuel assemblies were replaced with fresh fuel (still with the same BP content as the initial fresh core). In addition, the reactivity coefficient becomes more negative even at low temperatures, again a desirable feature. These behaviors are the result of the interplay among the low energy resonances in the fuel, fission products, and BP nuclei.

For the EOC1 case, the isothermal coefficient can be approximated analytically with the equation

$$
\left(\frac{\partial \rho}{\partial T}\right)_{\text {iso }}(p c m / K)=7.72-1.09 \times 10^{-2} T(K),
$$

while at the beginning of the second cycle, the linear approximation gives

$$
\left(\frac{\partial \rho}{\partial T}\right)_{i s o}(p c m / K)=-4.03-3.94 \times 10^{-3} T(K) \text {. }
$$

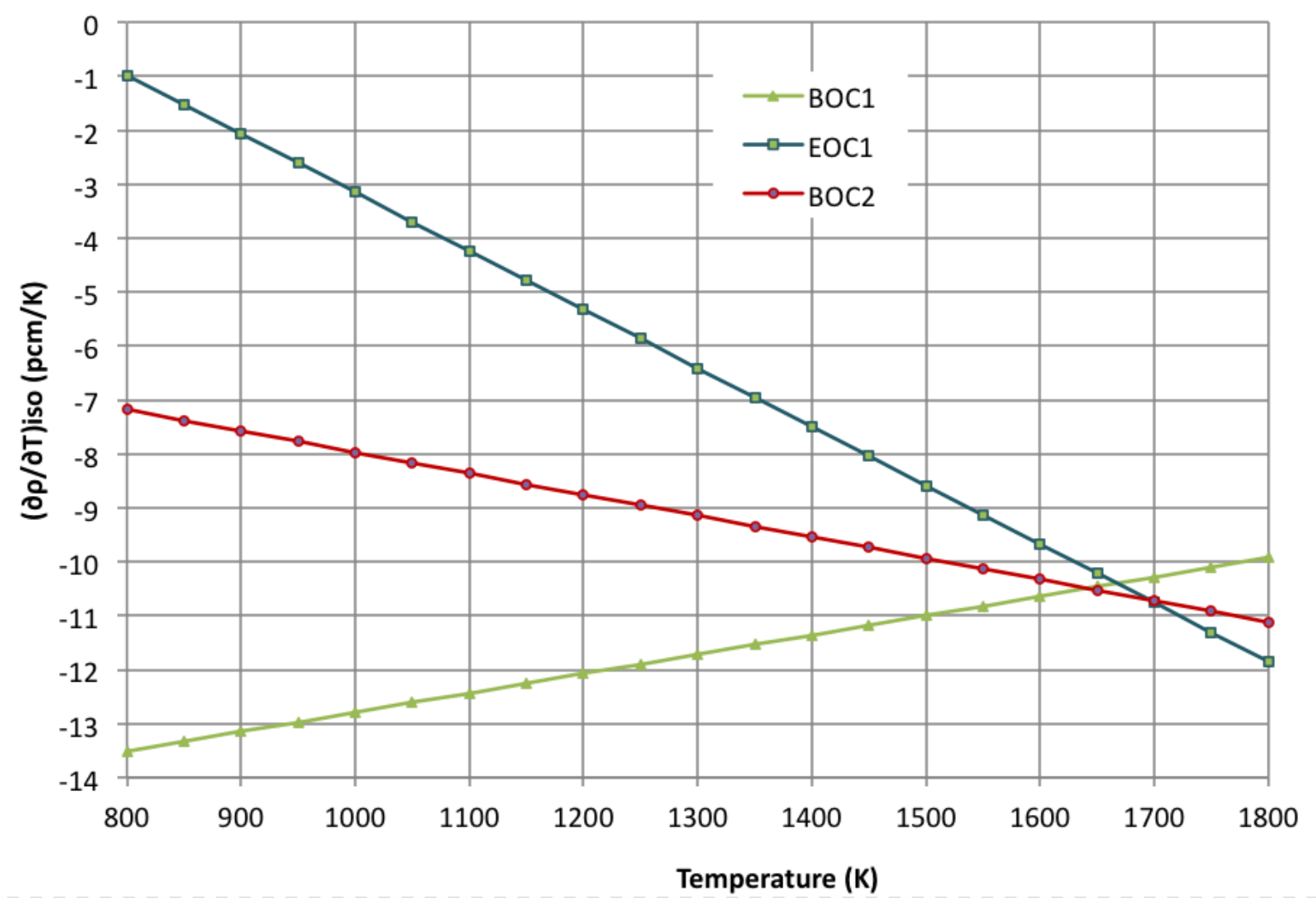

Fig. 20. Isothermal temperature reactivity coefficient for FY 2012 AHTR reference core at different moments during the fuel cycle.

The temperature coefficient is dominated by the fuel (Doppler) reactivity coefficient. For a fresh AHTR core (2012 reference with no BP), the coolant reactivity coefficient is practically zero if the change in density is not accounted for, ${ }^{*}$ while the moderator temperature coefficient has a small negative value (less than $1 \mathrm{pcm} / \mathrm{K}$ in magnitude, again not accounting for any change in density), but the Doppler coefficient is around $-3 \mathrm{pcm} / \mathrm{K}$, similar to the isothermal coefficient inferred from Fig. 19.

${ }^{*}$ The change in coolant density is accounted for in the void reactivity section. 


\subsection{VOID REACTIVITY COEFFICIENT}

For the 2011 design, the void reactivity coefficient was estimated for fresh (BOC) reference core and for the EOC of the initial core by simply evaluating the core reactivity with and without coolant. It was also determined that a fresh initial core with no BP and with 19.75\% enriched fuel can have a positive void reactivity coefficient if the CHM ratio increases (beyond 450 ).

This year's estimations extended the 2011 results to the 2012 reference AHTR core (with and without $\mathrm{BP}$ ), accounted for the two-batch fuel cycle by performing estimations at the $\mathrm{BOC}$ of the equilibrium cycle, and improved the detail by considering more points in the interval $[0 \%, 100 \%]$ for the void fraction (a 10\% increment). The decrease in fuel enrichment to $9 \%$ from $19.75 \%$ in the 2011 reference core, coupled with the higher value for the CHM ratio leads to a positive value for the void reactivity coefficient. As actually removing coolant from the core would lead to gross fuel overheating (and thus large negative reactivity insertion), a positive void coefficient is not judged to be unacceptable provided that voiding the core cannot lead to prompt criticality, no fuel damage is predicted to occur from any transient power increase, and that the overall core temperature reactivity coefficient remains negative. The dependence of the void reactivity coefficient on the void fraction can be approximated with a linear function for the fresh (BOC) AHTR 2012 reference core with no BP. It has a larger value for small void fractions, $(\partial \rho / \partial \alpha)=26 \mathrm{pcm} / \%$ void, and a smaller value when the core is fully voided, $(\partial \rho / \partial \alpha)=13$ $\mathrm{pcm} / \%$ void.

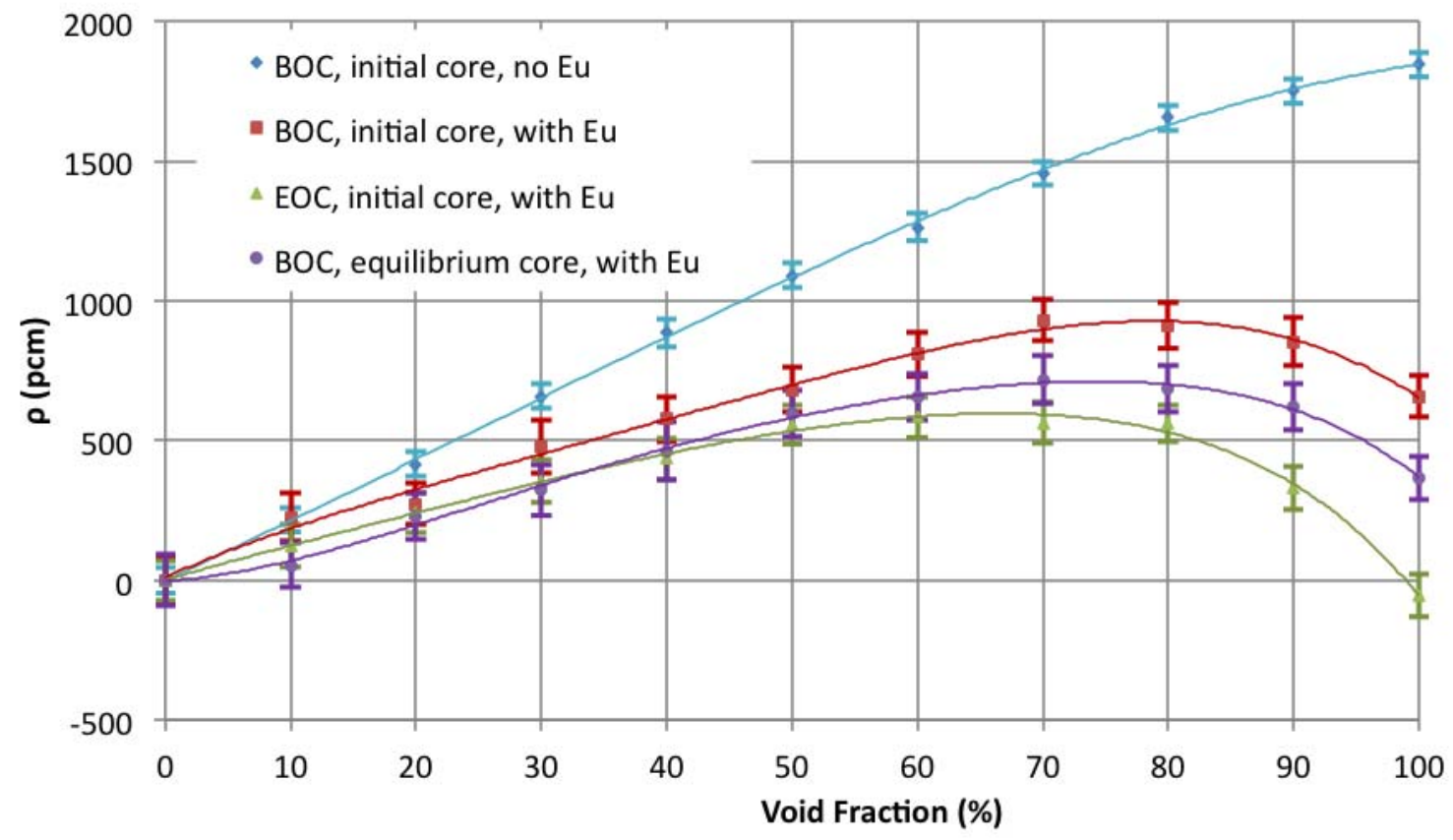

Fig. 21. AHTR core reactivity insertion by coolant voiding.

When BP is added to the fuel plates, the dependence of the void reactivity coefficient on the coolant void fraction becomes nonlinear. Moreover, the non-monotonic behavior of this dependence means that the void reactivity coefficient changes sign for different void fractions. The AHTR reactivity behavior is shown in Fig. 21 as a function of the coolant void fraction for four AHTR core configurations with and without BP. The error bars represent the $95 \%$ confidence interval statistical uncertainties. Based on these curves, the void reactivity coefficients are calculated and shown in Fig. 2222. 


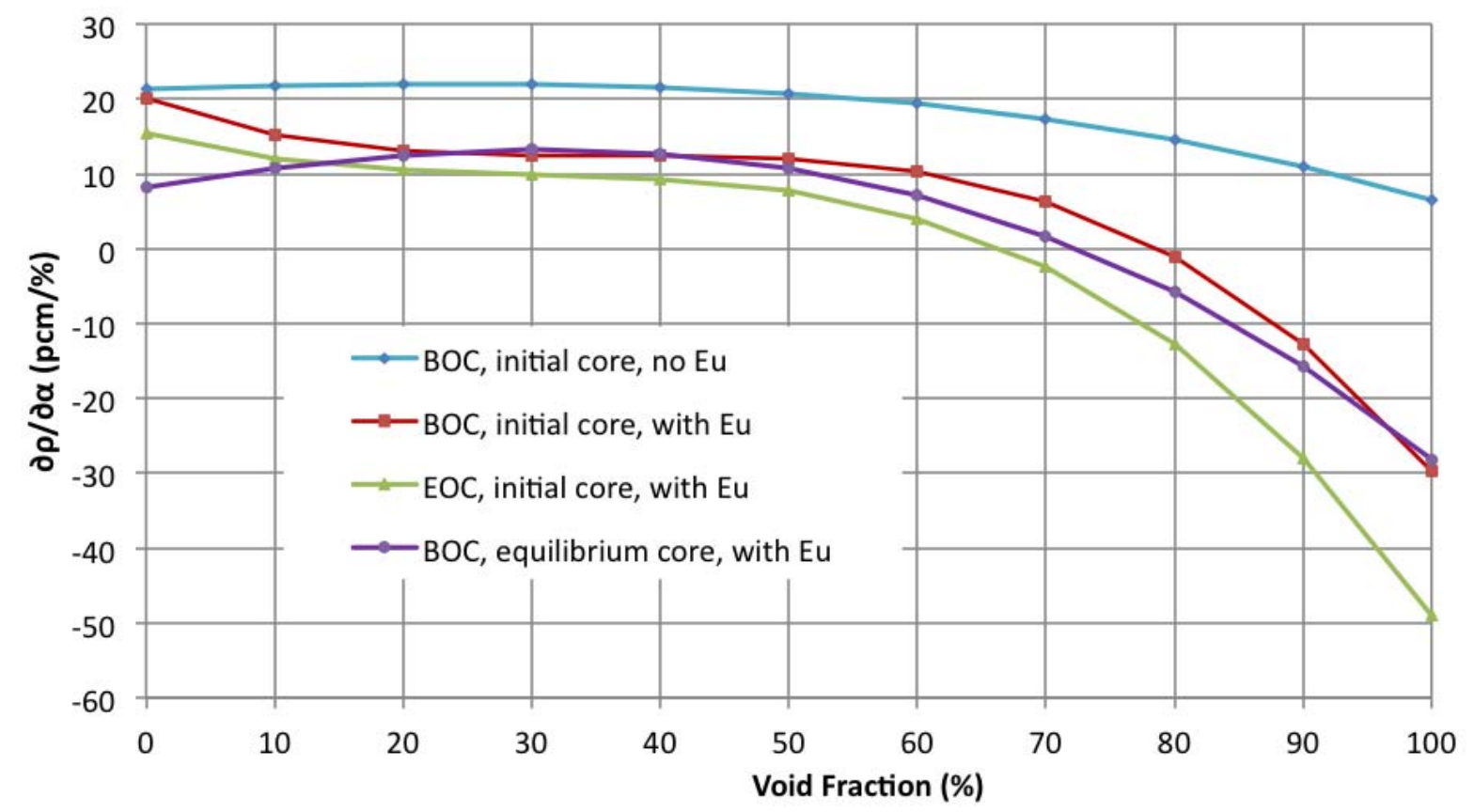

Fig. 22. Coolant void reactivity coefficient for AHTR core.

In order for the overall core temperature reactivity coefficient to remain negative, the fuel temperature reactivity coefficient must be more negative than the coolant thermal density decrease is positive. The coolant density will decrease with increasing temperature. The coolant density decrease is roughly $0.025 \%$ per one Kelvin increase in its temperature. ${ }^{8}$ For a $20 \mathrm{pcm} / \%$ density reactivity coefficient, this corresponds to a $0.5 \mathrm{pcm} /$ Kelvin reactivity coefficient due thermally induced density decrease. This means that the overall temperature reactivity coefficient stays negative as long as the isothermal reactivity coefficient is more negative than $-1 \mathrm{pcm} / \mathrm{K}$, which is always true for the core configurations analyzed (Fig. 20). Draining of the vessel is precluded by multiple design features. 



\section{REACTOR BUILDING}

\subsection{BUILDING DESCRIPTION}

The AHTR reactor building preconceptual design has been developed to meet several overall requirements, including safety, security, and reducing construction cost and schedule. The major approach for the reactor building is for it to be a below-grade, seismically isolated type of building. Fig. 7 gives an overall layout of the plant. The reactor building is a circular shaped building with a rectangular shaped containment building inside, for containment of the argon environment (Fig. 23).

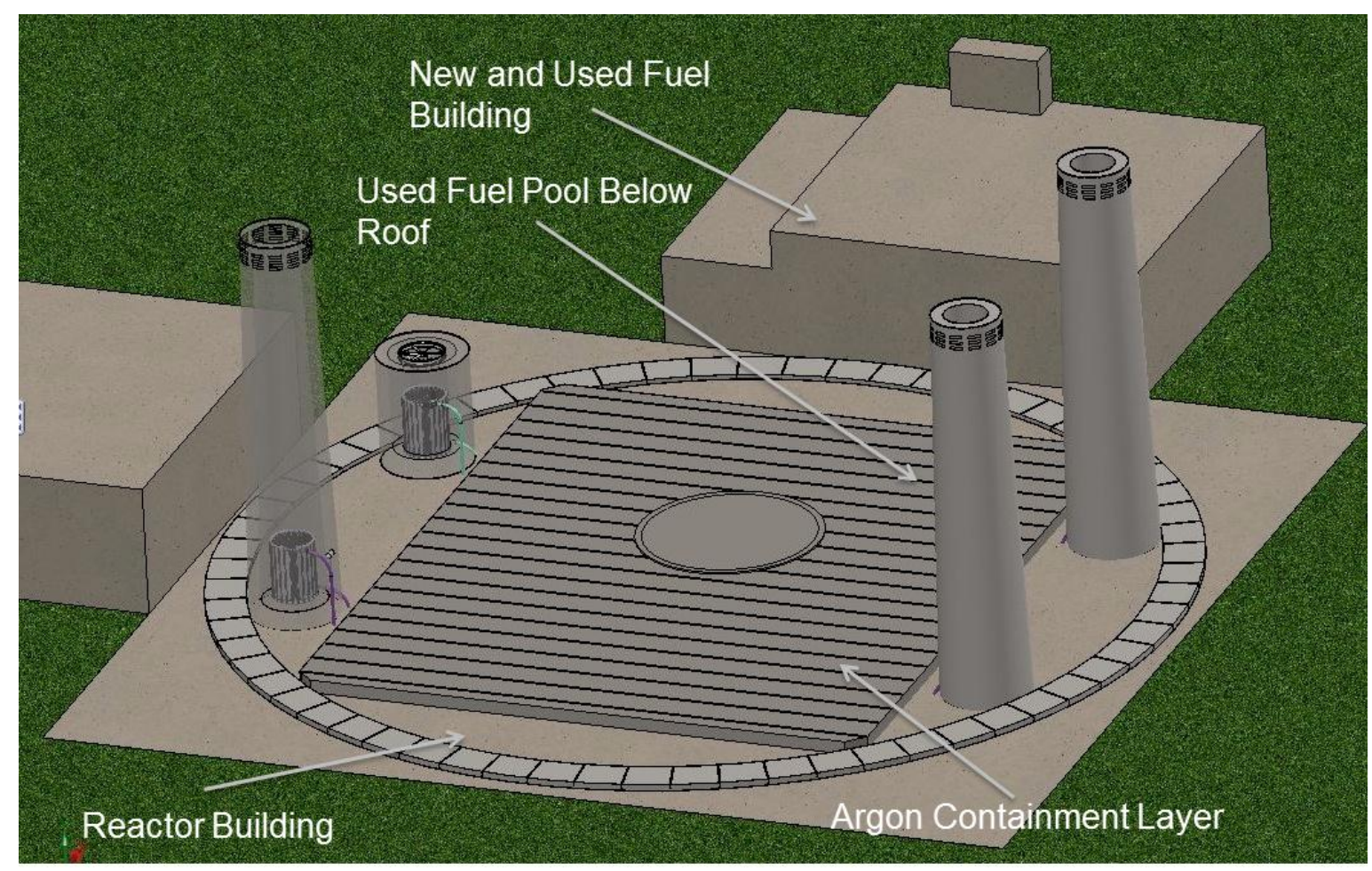

Fig. 23. AHTR reactor building.

The entire reactor is housed below ground level to offer protection against an aerial impact. Being underground, mitigates the requirement for large impact assessment. The shell of the reactor building extends slightly above ground level and is surrounded by four support buildings (Fuel Handling Building, Waste Handling Building, Control Building, and HVAC/ Electrical Utility Building). As the surrounding buildings are also mechanically robust, they provide additional screening protection for the reactor. An overall schematic of the reactor building showing the multiple levels of containment (1) TRISO (not shown), (2) reactor vessel, (3) reactor building, and (4) seismic well and surface building are illustrated in Fig. 24. 


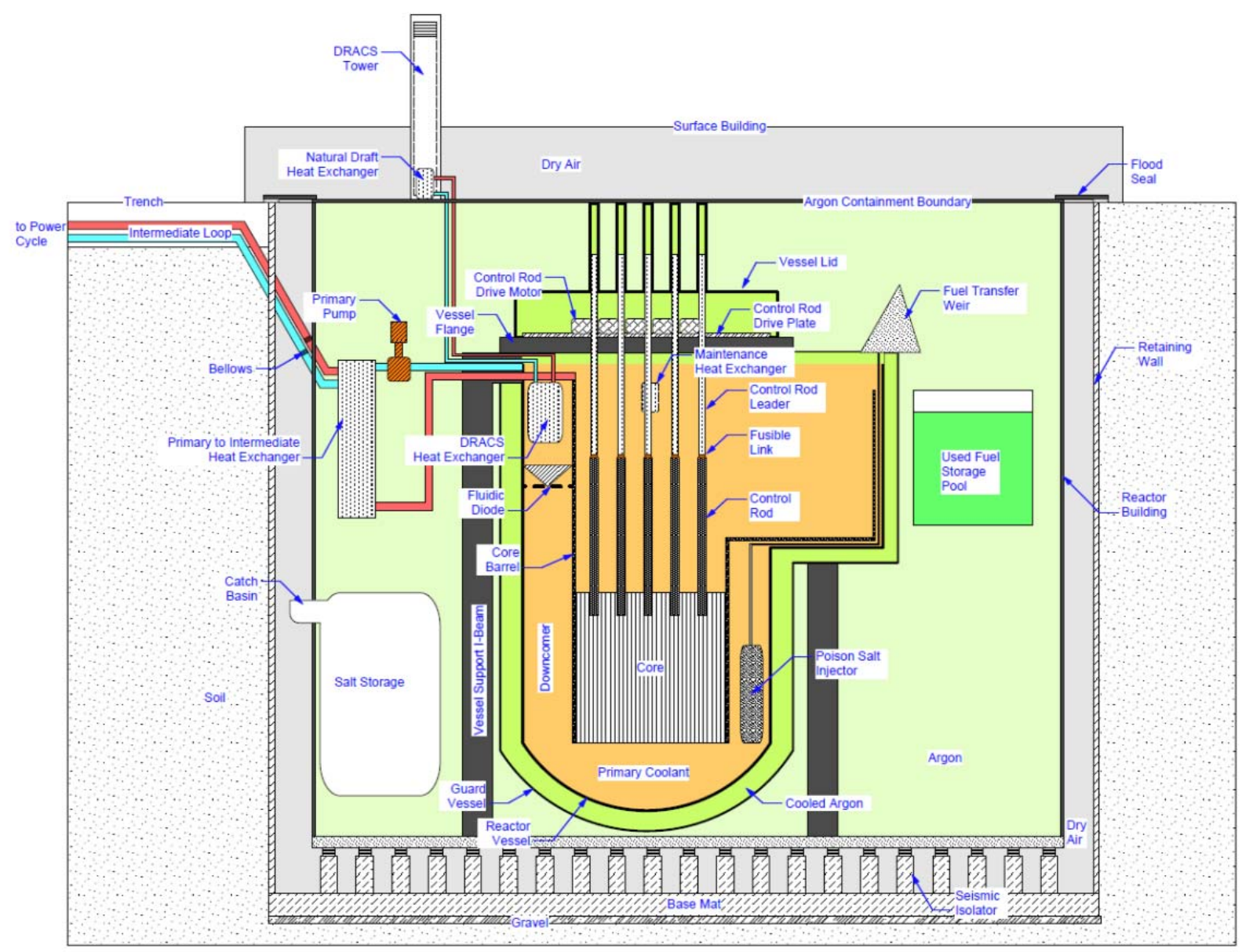

Fig. 24. Overall schematic of the AHTR reactor building.

Shown in Fig. 25, the AHTR reactor building includes four major elements: (1) the below-grade excavation, (2) the below-grade foundation, (3) the seismic isolation layer, and (4) the reactor building.

The below-grade excavation is cylindrical and approximately $81.5 \mathrm{~m}$ in diameter and $43 \mathrm{~m}$ deep. At the base of the excavation, the foundation consists of a 2-m-thick poured concrete foundation on top of a 1-m-thick gravel base layer. A concrete retaining wall will be required, and it is recognized that for some sites, other support features such as pilings may be required, depending on the geotechnical properties of the site.

A 1-m gap is provided between the reactor building and the retaining wall. To maintain weather protection and prevent water from entering the trench, a steel cover is provided (Fig. 26). The steel cover is attached only to the reactor side but rests freely on the soil outside the 1-m gap. The soil is graded to provide a slope away from the reactor building to prevent water accumulation near the reactor. An inflatable seal around the reactor building prevents water from entering the $1-\mathrm{m}$ trench. 


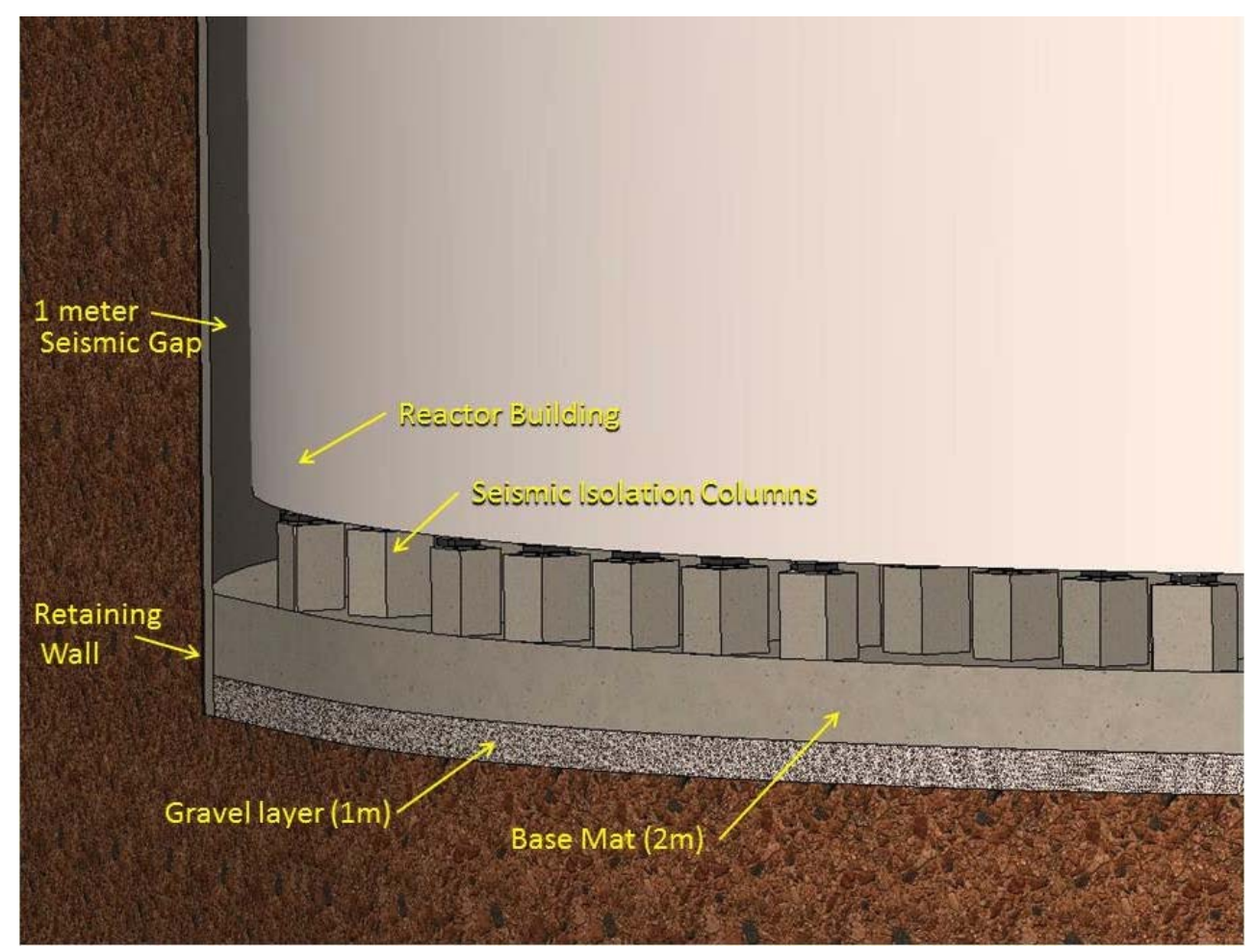

Fig. 25. Reactor building excavation, foundation, and seismic isolation.

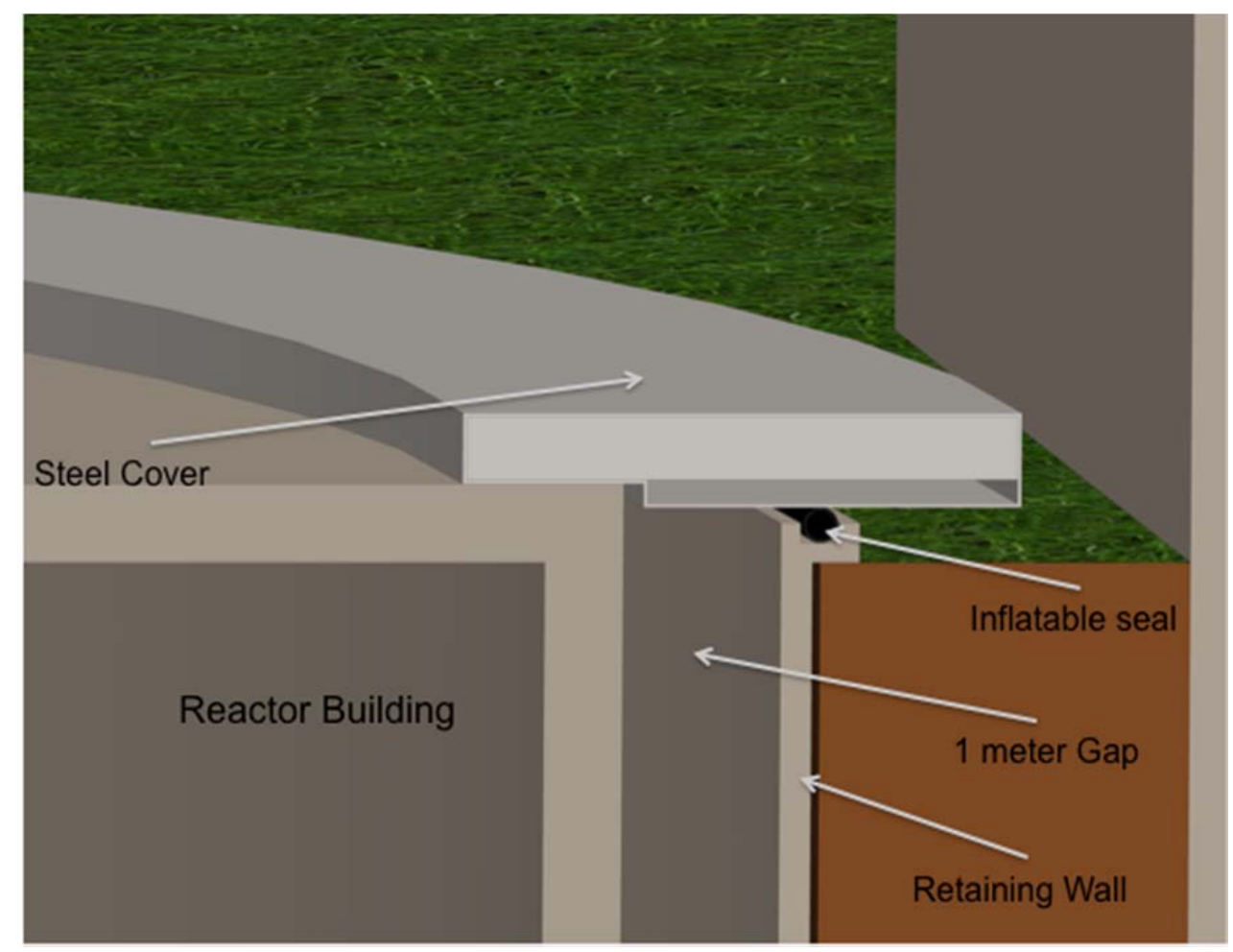

Fig. 26. Seal between the reactor building and the soil outside the retaining wall. 
The reactor building is a cylindrically shaped building, constructed below grade elevation, on top of the seismic isolation layer. The seismic isolation layer is constructed on top of the concrete foundation. The major components of the seismic isolation layer are the concretes bases and the antiseismic pads. The concrete bases are rectangular concrete blocks approximately $1.5 \mathrm{~m}$ square on each side and approximately $2.1 \mathrm{~m}$ tall. The antiseismic pads are an assembly consisting of top and bottom steel mounting plates, which are anchored into the concrete base below and the building above. Between the top and bottom plates are layers of elastomeric rubber and steel plates, which allow lateral deflection under seismic accelerations. Each of the antiseismic pads has an estimated vertical load capacity of approximately 1000 metric tons. ${ }^{15}$ These seismic isolators are distributed underneath the building in a two-dimensional array, approximately $3.5 \mathrm{~m}$ apart. A closeup of the seismic isolation layer is shown in Fig. 27.

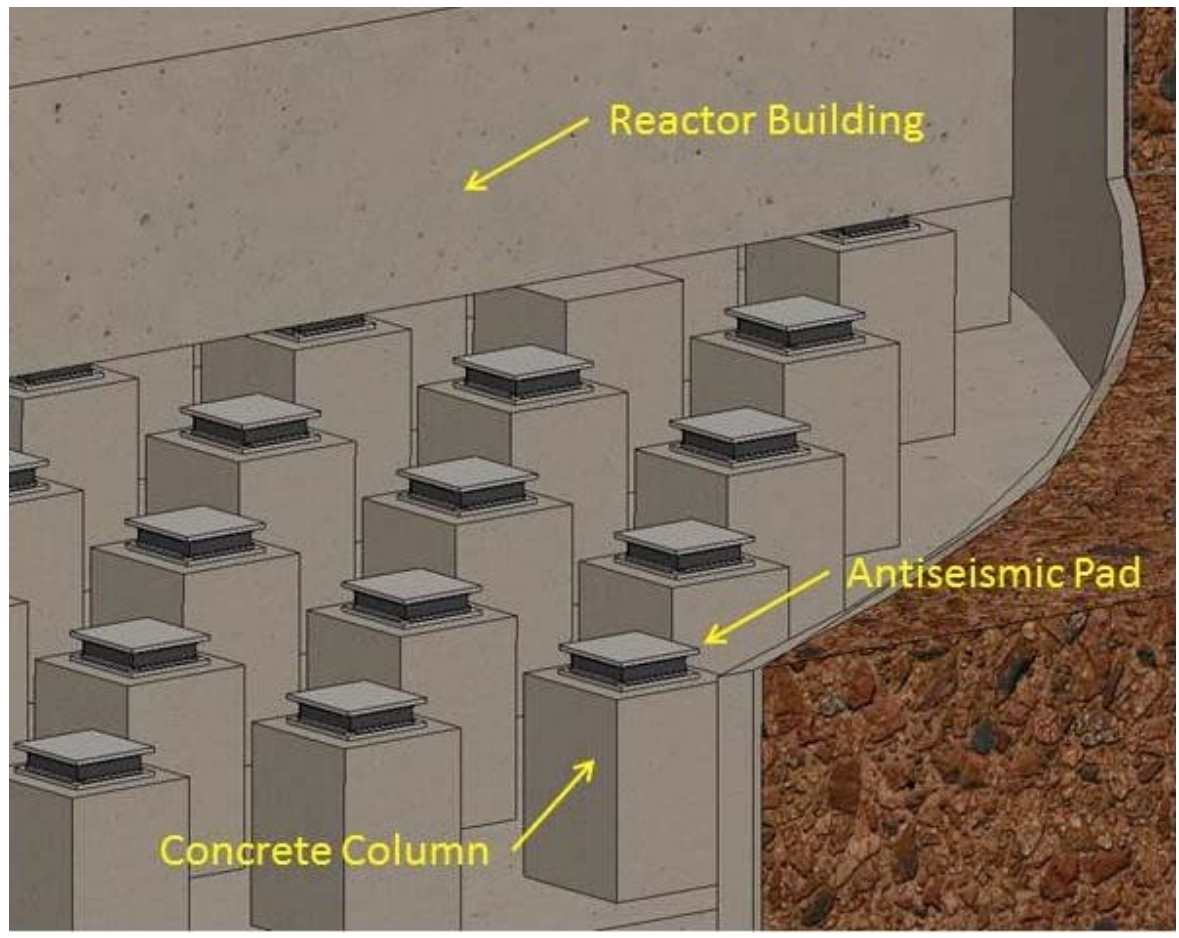

Fig. 27. Seismic isolation closeup.

Two layers of containment are provided in the reactor building: (1) the outermost layer of containment, the flood seal, which is the outer circular shaped wall of the structure and (2) the argon environment containment, which are internal walls and structures which separate the argon gas environment from the dry air environment (Fig. 28). 


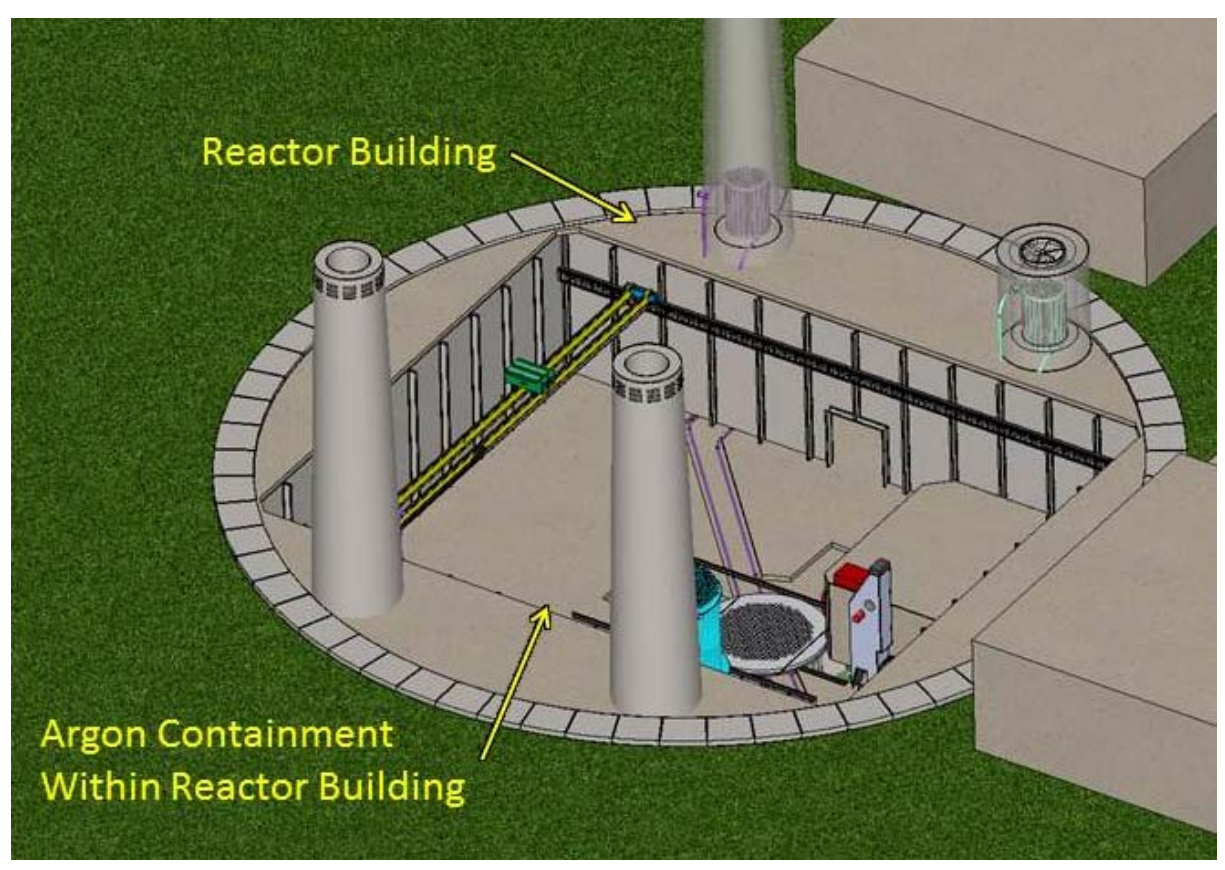

Fig. 28. Argon environment containment.

The reactor building will be constructed using steel-plate-reinforced concrete modules. The steel structure is used as the concrete pouring form, saving time during construction. The steel plates become the permanent exterior face of the structure. Figure 29 shows a steel plate form with reinforcing steel tie rods.

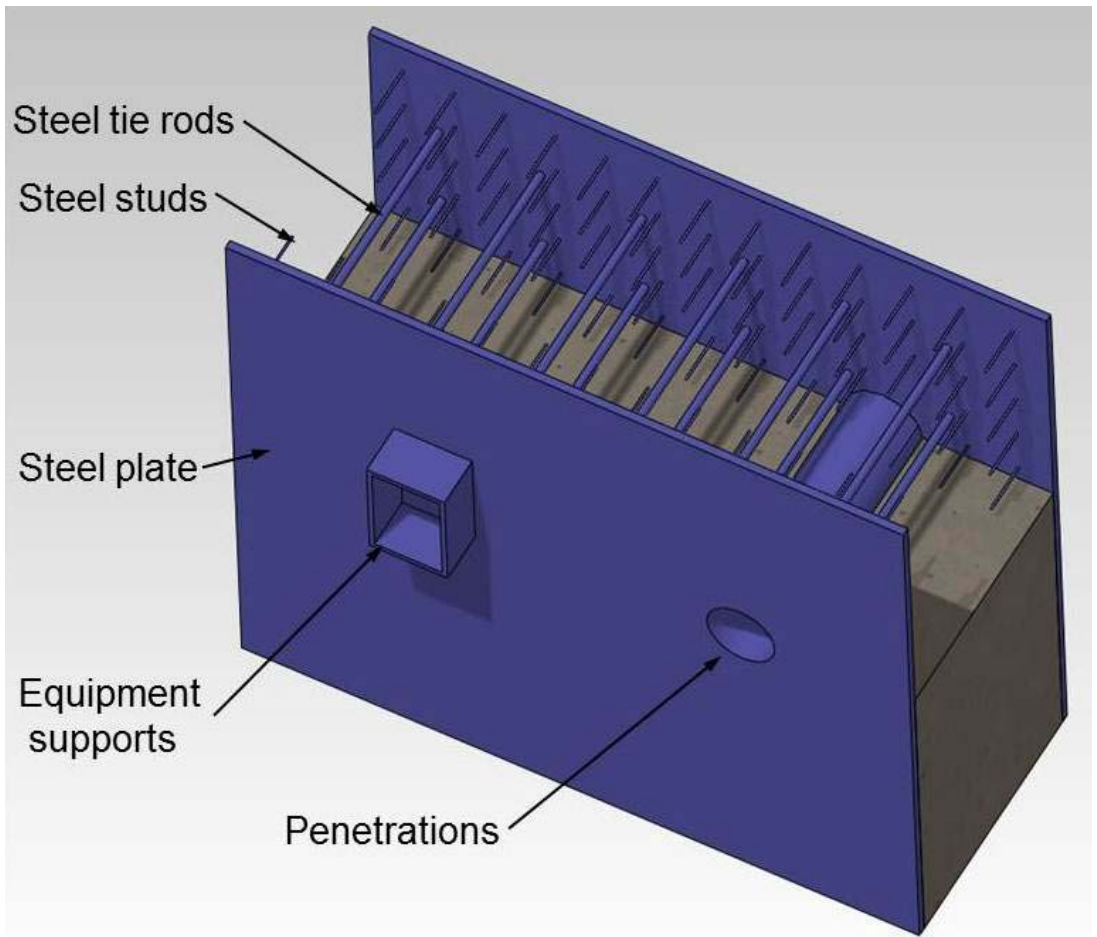

Fig. 29. Steel-plate construction method. 
Steel studs are welded on the inner surface of the steel plates. The studs become embedded in the concrete during pouring. Other features such as penetrations or equipment mounting supports are also welded into the plates. Steel tie rods are also welded between the plates to provide strength for the modules for handling. These steel forms are constructed in modules at a fabrication shop and transported by rail to the construction site for erection of the building. On-site, the modules are fitted together, welded, and filled with concrete after being welding together.

Steel-plate form construction saves a significant amount of time compared to conventional concrete pouring, where steel rebar is first assembled, then wooden forms are constructed around the rebar, then concrete is filled inside the wood forms, followed by removing the wood forms after several days of concrete curing. Published reports indicate that the steel-plate concrete wall construction is twice as fast as traditional wooden form concrete construction. ${ }^{16}$ Cost analysis studies in the same report also indicated that even when the fabrication cost for the steel forms are higher, the overall net production costs for the building construction is lower.

\subsection{REACTOR VESSEL}

This section describes the AHTR reactor vessel and the vessel interior structures.

Table 3 lists the reactor vessel design parameters. The reactor vessel is roughly a cylinder with a short refueling lobe extension on its upper half. The reactor vessel is hung from its upper flange. Hanging the vessel minimizes the vessel stresses incurred due to thermal expansion during heat-up. The flange rests on building I-beams that are supported by the reinforced concrete building floor, which is supported by vibration isolators (Fig. 30).

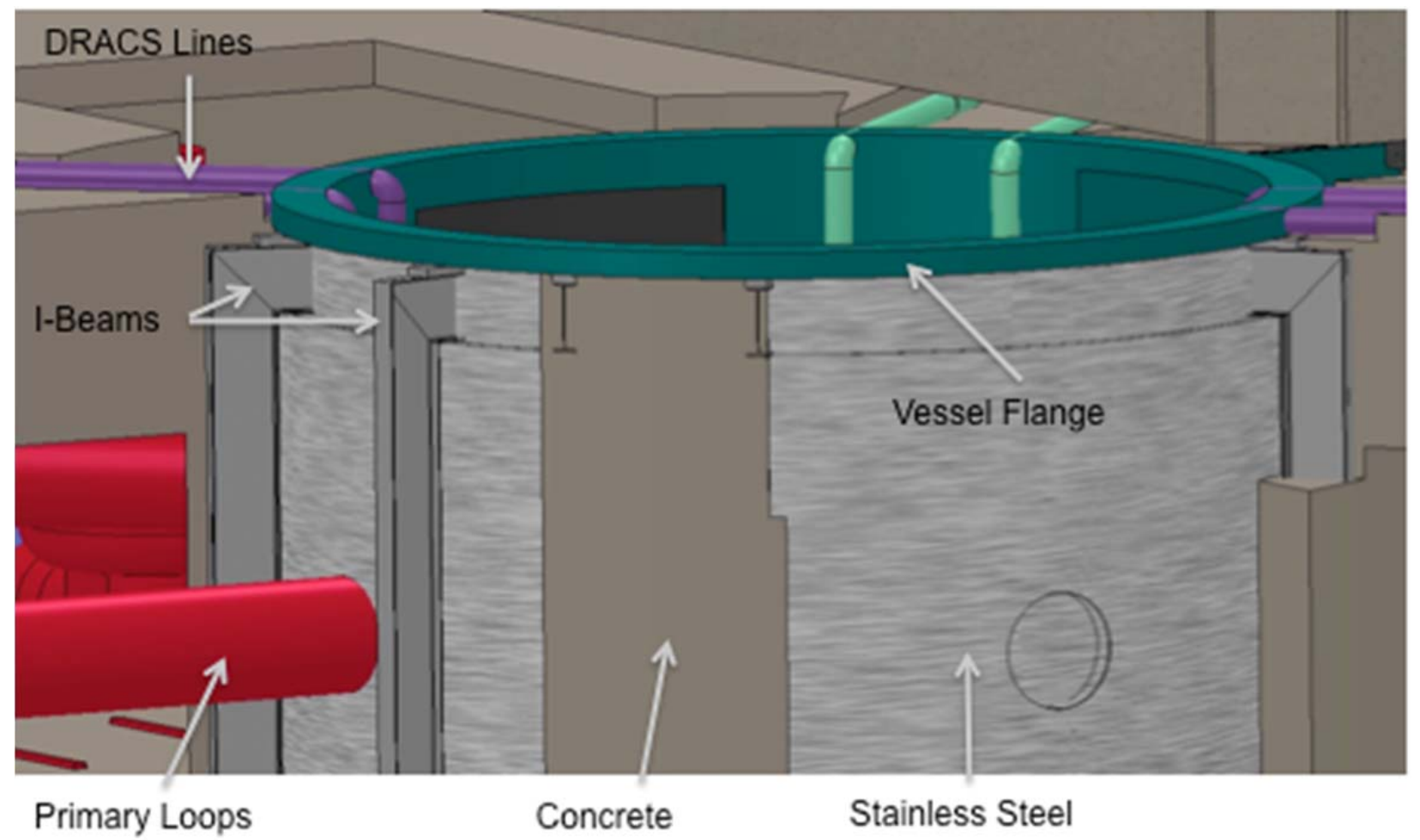

Fig. 30. Reactor vessel resting on the building I-beams. 
Table 3. Reactor vessel design parameters

\begin{tabular}{lcc}
\hline \multicolumn{1}{c}{ Parameter } & Unit & Value \\
\hline Exterior vessel diameter & $\mathrm{m}$ & 10.5 \\
Vessel height & $\mathrm{m}$ & 19.1 \\
Primary salt mass & $\mathrm{MT}$ & 3076 \\
Primary salt depth above upper core support plate & $\mathrm{m}$ & 7.15 \\
Primary piping interior diameter & $\mathrm{m}$ & 1.24 \\
Number of DRACS & & 3 \\
Core barrel material & & C-C Composite \\
Reactor vessel and primary piping material & & $800 \mathrm{H}$ with Alloy N \\
& & lining \\
Number of fuel assemblies & & 252 \\
Number of control blades & & 252 \\
Upper and lower core support plates & SiC-SiC composite \\
\hline
\end{tabular}

Figure 31 provides an overall view of the reactor vessel, while Fig. 32 shows a sectional view of the reactor inside.

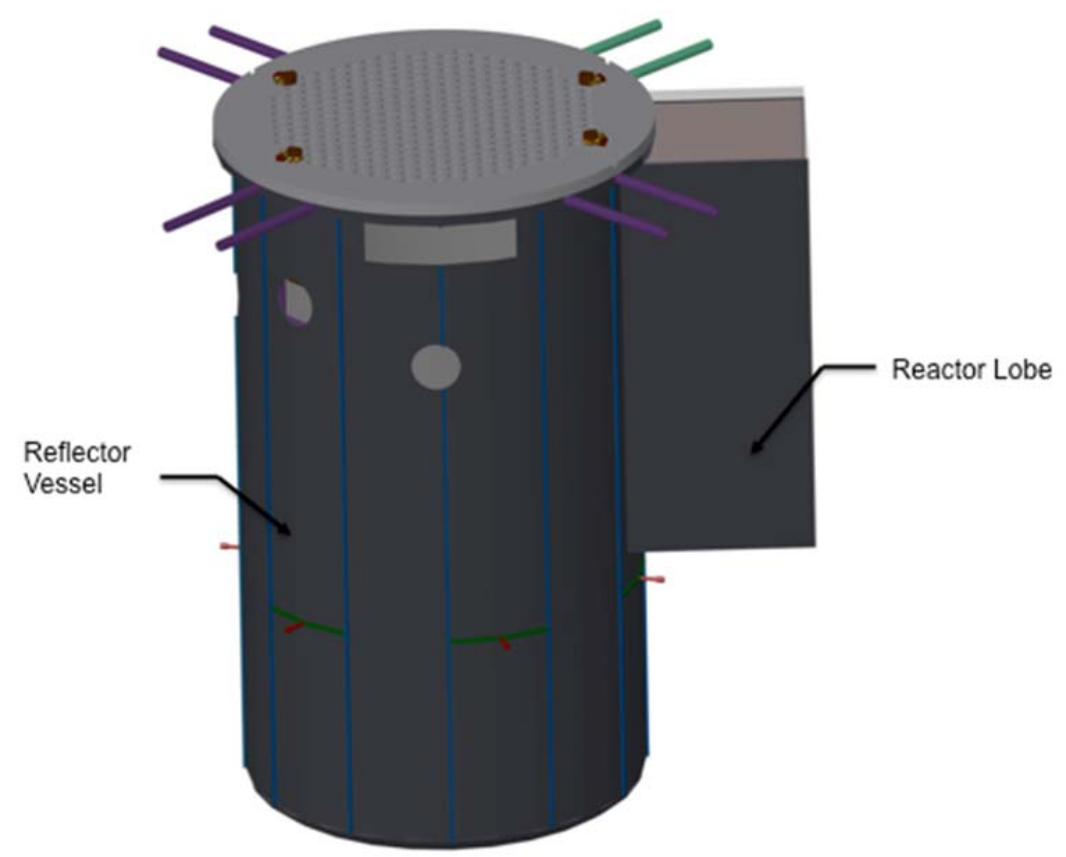

Fig. 31. Overall view of the reactor vessel. 


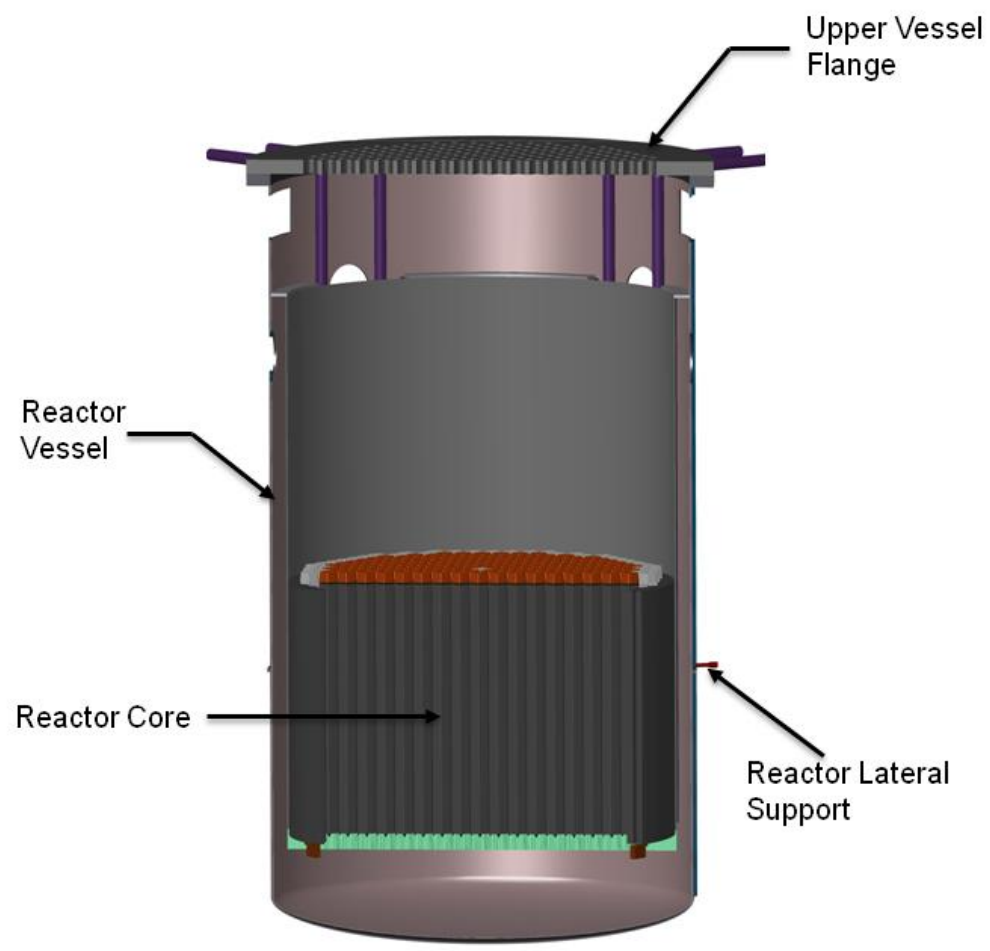

Fig. 32. Sectional view of the reactor vessel.

Since the vessel is almost $19 \mathrm{~m}$ long and $10.6 \mathrm{~m}$ in diameter, it cannot be transported by rail in one piece. For a piece of material to be transported by railroad, the length must be $\leq 24.97 \mathrm{~m}$, the width $\leq 2.77 \mathrm{~m}$, and the height $\leq 2.77 \mathrm{~m}$. Hence, the vessel has to be brought to the site in sections, welded together in a temporary building, assembled, and placed inside the reactor. Depending on the weight of the sections, multiple sections can be transported in a single cart. Figure 33 shows the reactor sections for fabrications. Another option for the bottom section of the reactor if held below 30 tons is for it to be air lifted to the site.

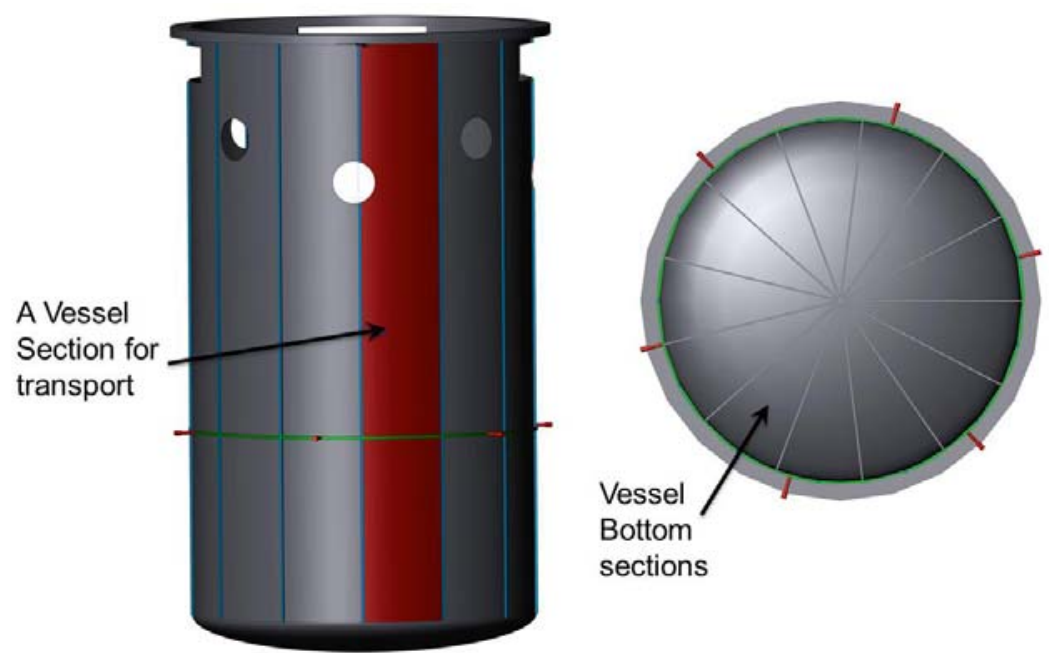

Fig. 33. Sectioning of the reactor vessel for transportability. 
The area where the sections are joined together is also where there is a rib. These longitudinal and circumferential ribs give further structural rigidity to the vessel. The lateral support for the vessel is connected at the circumferential rib on the vessel (see Fig. 32).

The lateral support consists of damper spring assemblies that offer a reaction force along the radii of the vessel. The spring reacts against the concrete that embeds the I-Beam that supports the reactor vessel. During a seismic event, these lateral supports reduce the swinging pendulum motion that the reactor may suffer if these supports are not provided (Fig. 34).

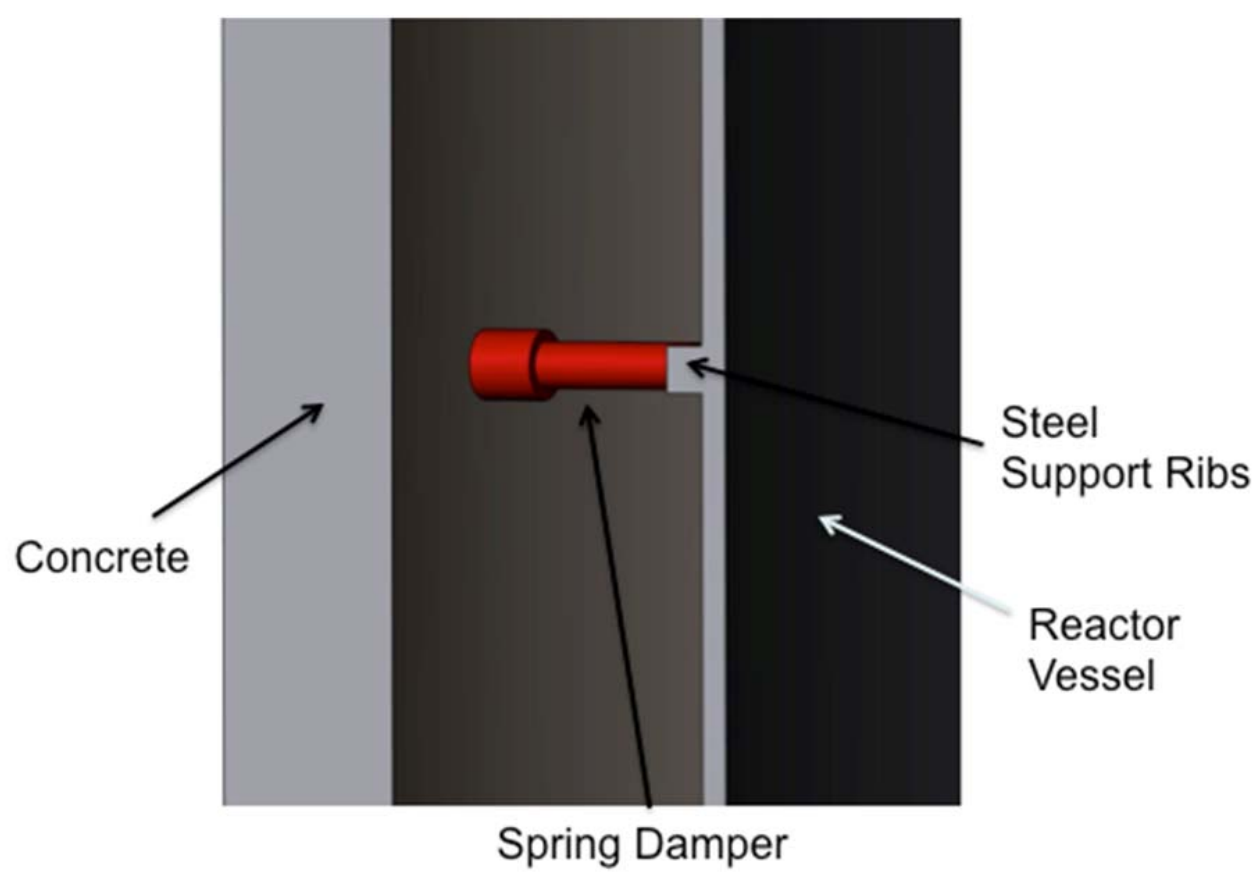

Fig. 34. Lateral support details.

The reactor vessel is made from $800-\mathrm{H}$ alloy, which has an allowable yield strength of $20 \mathrm{MPa}$ at $700^{\circ} \mathrm{C}$. Since there can be possible corrosion with FLiBe coolant, the $800 \mathrm{H}$ has a thin liner $(1 \mathrm{~cm}$ thick) made of Alloy N.

The top flange of the reactor is again a large stainless steel disk $11.6 \mathrm{~m}$ in diameter and $35 \mathrm{~cm}$ thick. Transportation of such a big piece will be difficult even by rail. Hence, a truss structure with thin $1.5-\mathrm{cm}$ top and bottom plates will be welded in the temporary fabrication building. The two top and bottom plates will also be transported to the temporary fabrication building in sections. A conceptual representation of the top flange is given in Fig. 35. 


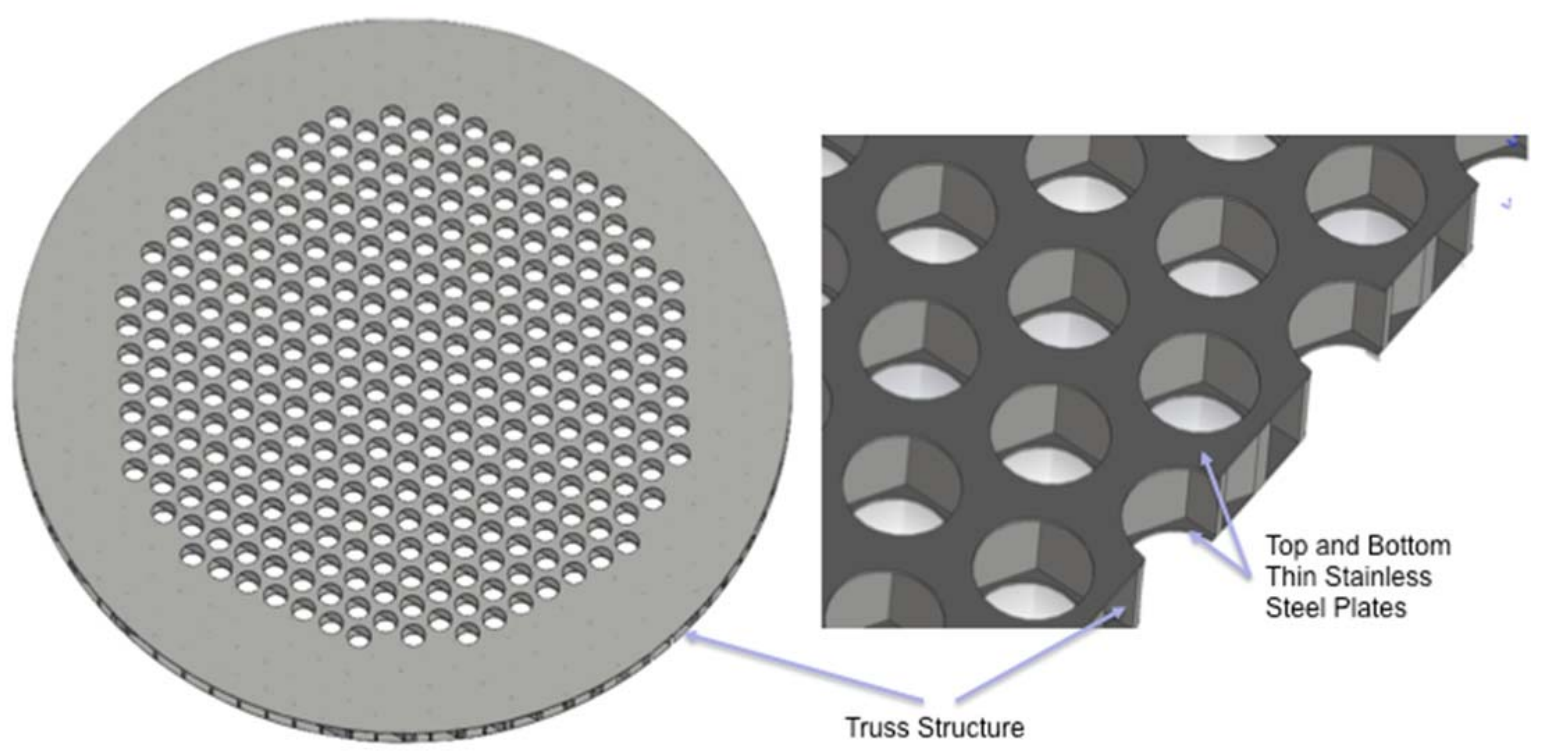

Fig. 35. Top support plate fabricated from two thin plates with a truss structure in between.

\subsubsection{Reactor Core}

The reactor core consists of 252 fuel assemblies supported by upper and lower support plates (Fig. 36). The fuel assemblies are described in Section 4.3 of this report. Table 4 lists the main core characteristics of the reactor. A row of hexagonal replaceable reflector graphite columns, a permanent graphite reflector, and a $\mathrm{C}-\mathrm{C}$ composite core barrel radially surround the reactor core. The downcomer region and the reactor vessel are located radially outside of the core barrel. Figure 37 shows the upper reactor vessel upper internal components. The downcomer is divided vertically into eight angular zones - three downcomer regions, three DRACS, one maintenance cooling system, and refueling lobe (Fig. 38).

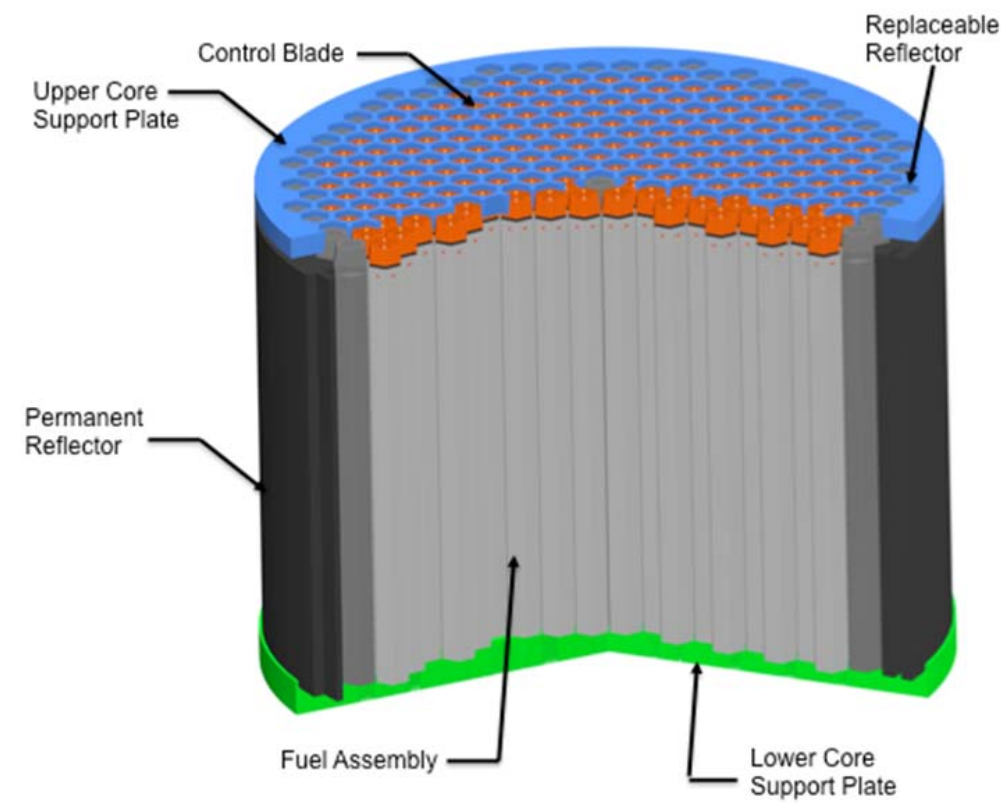

Fig. 36. Cross-sectional view of the reactor core. 
Table 4. Main core characteristics of the reactor

\begin{tabular}{lcc}
\hline \multicolumn{1}{c}{ Parameter } & Value & Units \\
\hline Power (thermal) & 3,400 & $\mathrm{MW}$ \\
Number of fuel assemblies & 252 & - \\
Assembly lattice type & Hexagonal & - \\
Fuel type & Coated particle & - \\
Moderator & Graphite & - \\
Reflector & Graphite & - \\
Coolant & FLiBe & - \\
Coolant pressure drop across core & 1 & $\mathrm{~atm}$ \\
Core height (fueled region) & 5.5 & $\mathrm{~m}$ \\
Core height (including axial reflector) & 6.0 & $\mathrm{~m}$ \\
Equivalent core diameter (fueled region) & 7.81 & $\mathrm{~m}$ \\
Core diameter (including radial reflector) & 9.56 & $\mathrm{~m}$ \\
Average power per grain & 41 & $\mathrm{~mW} / \mathrm{particle}$ \\
Average power density in fueled region & 52 & $\mathrm{~W} / \mathrm{cm}^{3}$ \\
Volumetric core power density & 12.9 & $\mathrm{MW} / \mathrm{m}^{3}$ \\
Mass of heavy metal & 32.91 & $\mathrm{MT}$ \\
Fuel enrichment & 19.75 & $\%$ \\
\hline
\end{tabular}

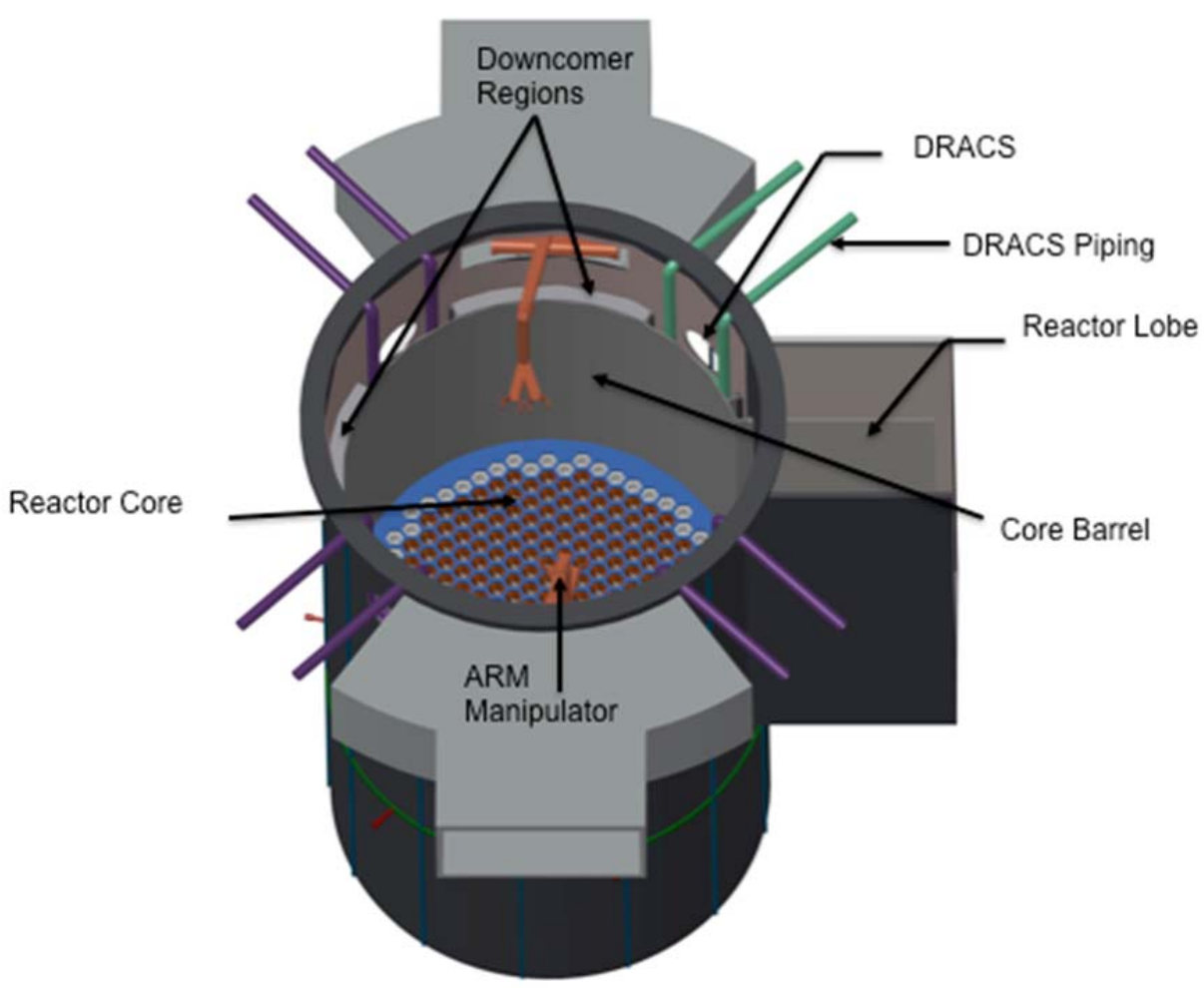

Fig. 37. Top view of the reactor. 


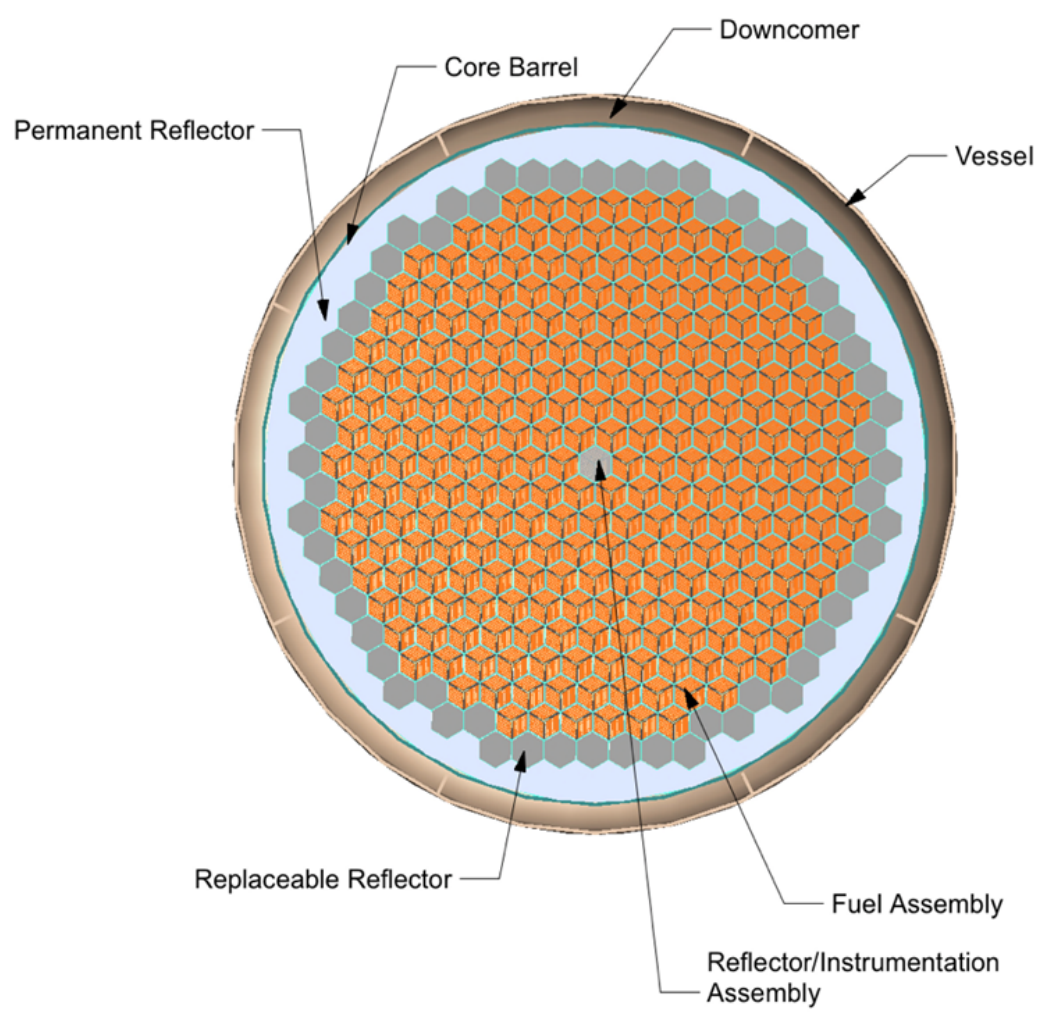

Fig. 38. Cross-sectional view of the reactor vessel.

\subsubsection{Lower core support plate}

The lower support plate is the base that supports the reactor core. It is a honeycomb structure formed from $\mathrm{SiC}-\mathrm{SiC}$ composite pieces and is $35 \mathrm{~cm}$ thick. Six mechanical pegs attach the lower support plate to the reactor vessel. Figure 39 shows how the pegs are inserted into the lower support plate and a stopper inserted to prevent the peg from being retracted. A permanent reflector block rest on top of each stopper.

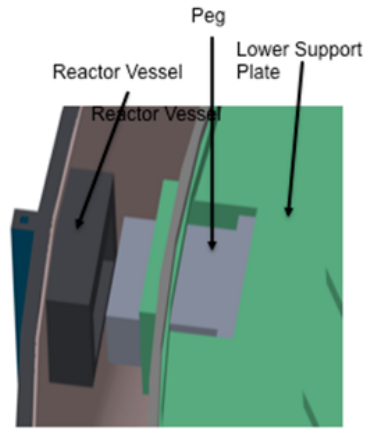

Not Attached

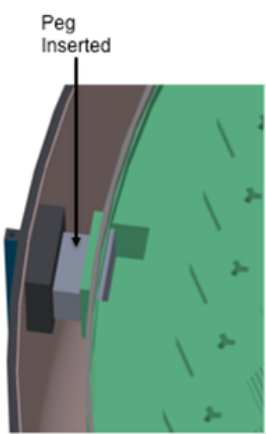

Attached, without stopper

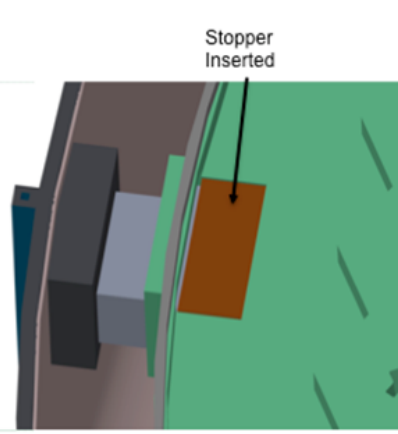

Attached with Stopper

Fig. 39. Lower support plate attachment to the vessel sequence. 
There are channels cut on the lower support plate to direct the flow into the fuel assemblies. Also, an indexing hole and guides on the lower support plates are used to align the fuel assemblies (Fig. 40). When the fuel assemblies are inserted, there is a 1.8- $\mathrm{cm}$ gap between them to accommodate for any mechanical distortion during operation.

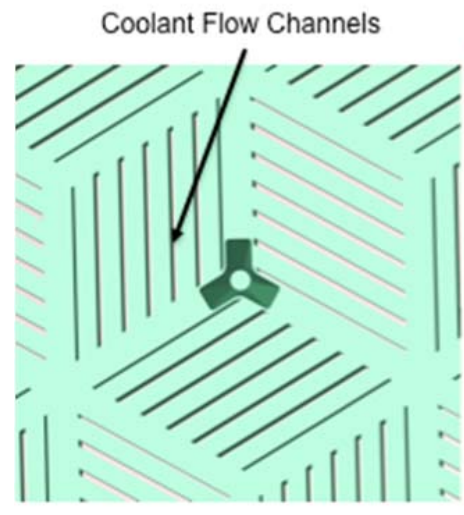

Locating Hole on Lower Support Plate

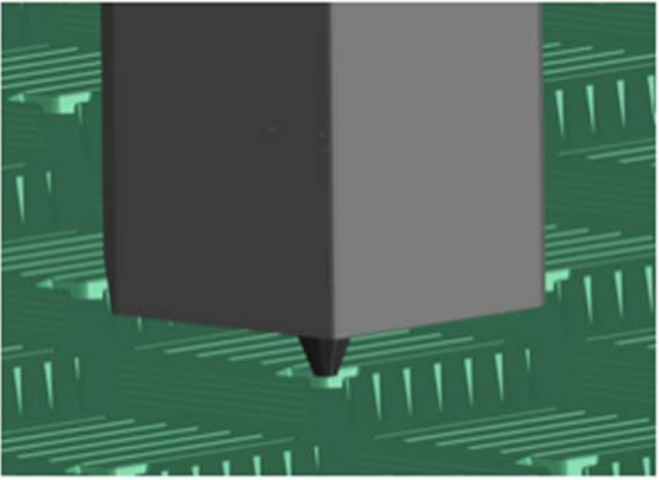

Fuel Assembly lining with the hole

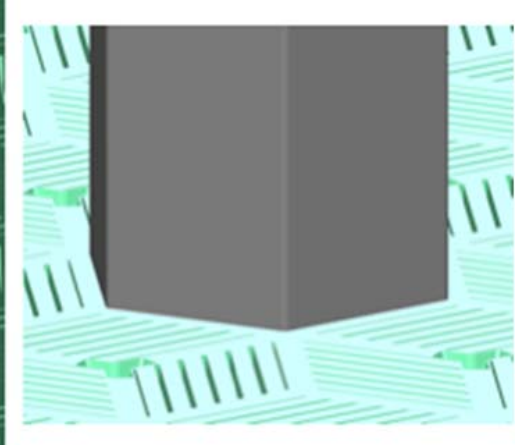

Fuel Assembly already mated

Fig. 40. Fuel assembly attachment to the lower support plate.

\subsubsection{Upper core support plate}

The upper core support plate at the top of the reactor core aligns and holds all the fuel assemblies in place during reactor operation. There is $1 \mathrm{~atm}$ of pressure drop across the core, which translates to $781 \mathrm{KN}$ of upward force. With a fuel core specific gravity of 1.59 , and a coolant specific gravity of 1.95 , without any external holding mechanism, the fuel assemblies will float. There are three independent mechanisms to hold the fuel assemblies down, one of which is the upper core support plate (other mechanisms are the guide tube and control blade). To prevent the fuel assemblies from floating when unconstrained during fuel loading, each fuel assembly includes a dense molybdenum hafnium carbide control blade that is locked into place until the upper core support plate is lowered onto the core.

The upper core support plate has four drive rods that are used to lower and raise the plate (Fig. 41). During normal reactor operation, the upper core support plate is in the down position interfacing with the fuel assemblies. The upper core support plate makes a tangential contact with the hemispherical contacts on the grappling collar of the fuel assemblies (Fig. 42). The webbing on the upper core support plate fills the interassembly gap to limit flow-induced fuel assembly vibrations. 


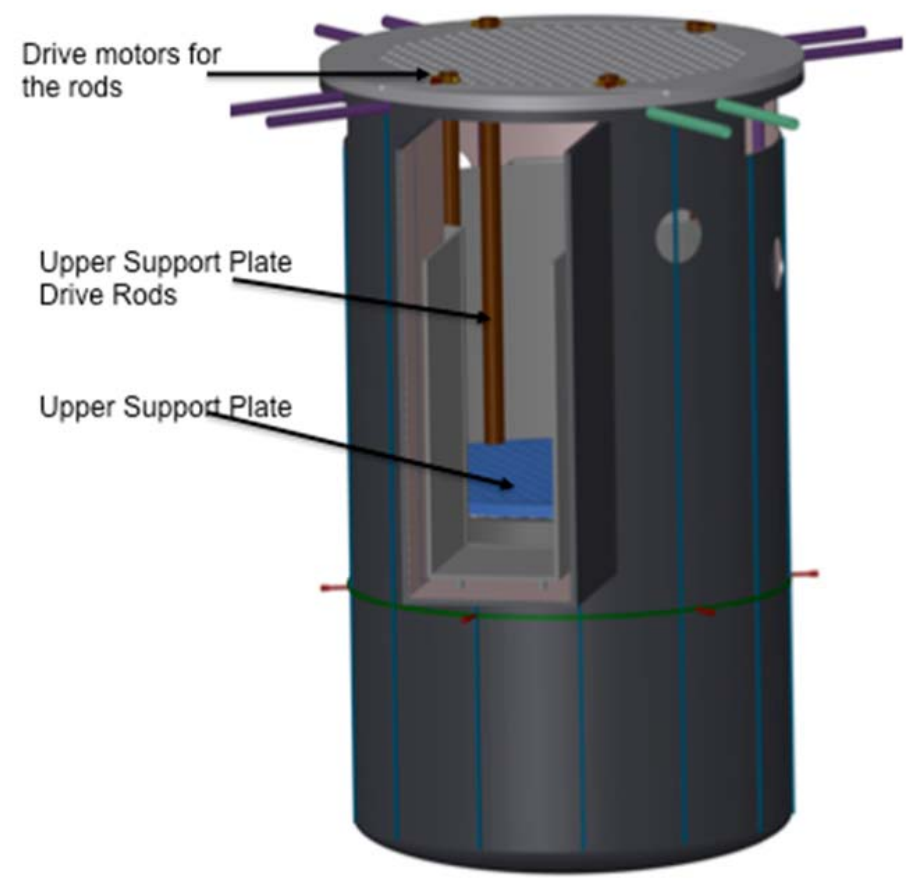

Fig. 41. Upper-support-plate drive mechanisms.

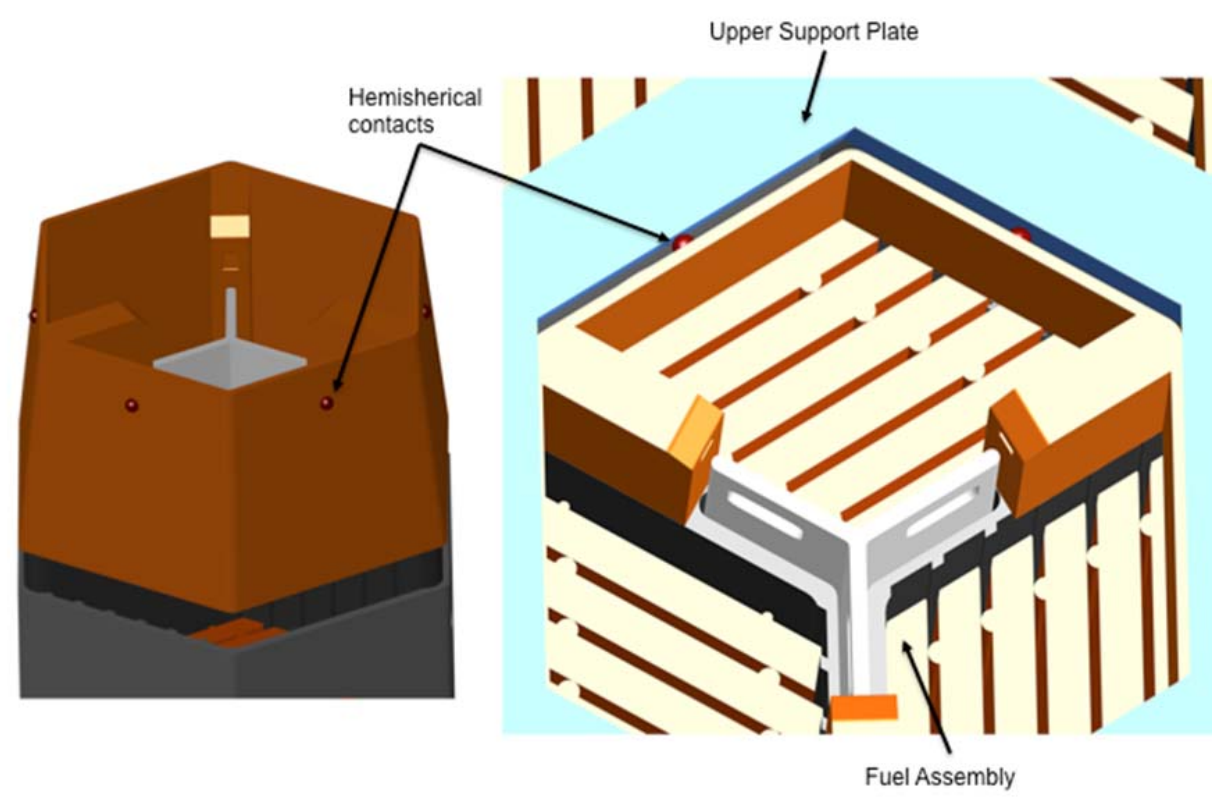

Fig. 42. Upper-core support plate in contact with fuel assembly.

\subsubsection{Replaceable and permanent reflector}

Around the fuel assemblies is a ring of removable reflector blocks made of graphite, followed by the permanent graphite reflector. The size and shape of the replaceable reflector are same as that of the fuel assemblies. They can be inserted or removed from the reactor core just like the fuel assemblies.

The permanent reflectors conform to the replaceable reflectors and give the reactor core a cylindrical shape. Since it is a large item, it is made in six sections. They are lowered individually and held in place 
with a locking mechanism with each other (Fig. 43). The recessed region on the lower core support plate allows for the permanent reflectors to be positioned correctly and securely.

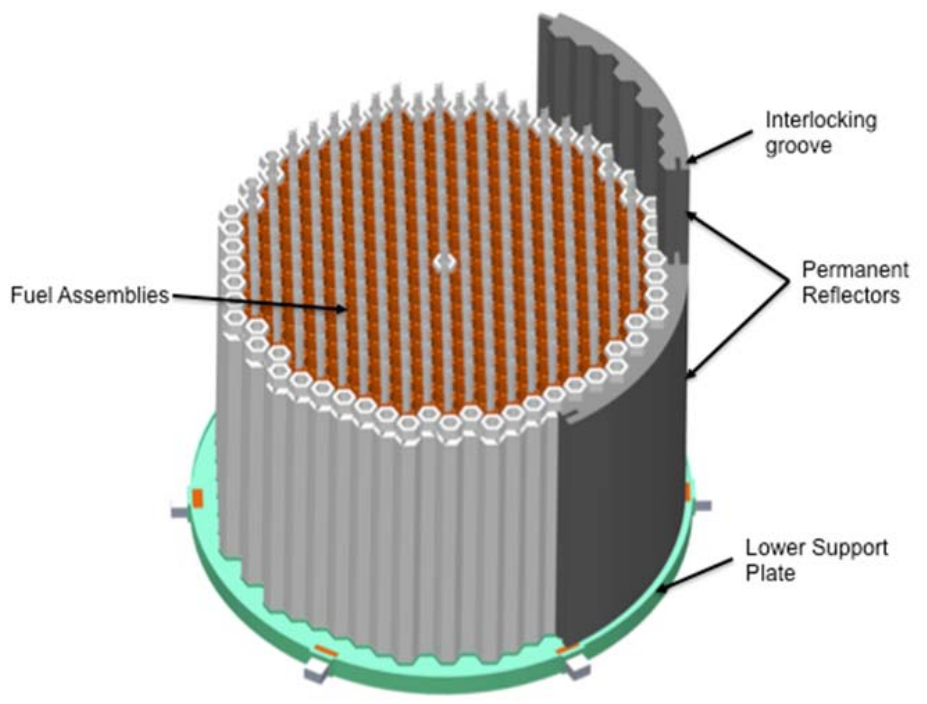

Fig. 43. Permenant reflector interlocking mechanism.

\subsubsection{Core Barrel and Downcomer Region}

The fueled core and the radial reflector are contained within a 2-cm-thick core barrel made of C-C composite that separates the up-flow from the downcomer. The inside of the core barrel facing the core has a thin plating $(1 \mathrm{~cm})$ of boron carbide to reduce the neutrons to the reactor vessel. The downcomer is sized so that its transverse flow area is at least twice the in-core flow area. The downcomer is bounded by the reactor vessel liner, made of Alloy N.

Since the cold primary salt from the heat exchangers enters the downcomer region, the reactor vessel is nominally maintained at $650^{\circ} \mathrm{C}$. The direction of the salt flow is downward in the downcomer region, while it is upward in all the other interstitial regions between the core barrel and the reactor vessel. This again ensures that the reactor vessel including the lobe is kept at $650^{\circ} \mathrm{C}$ (Fig. 44). 


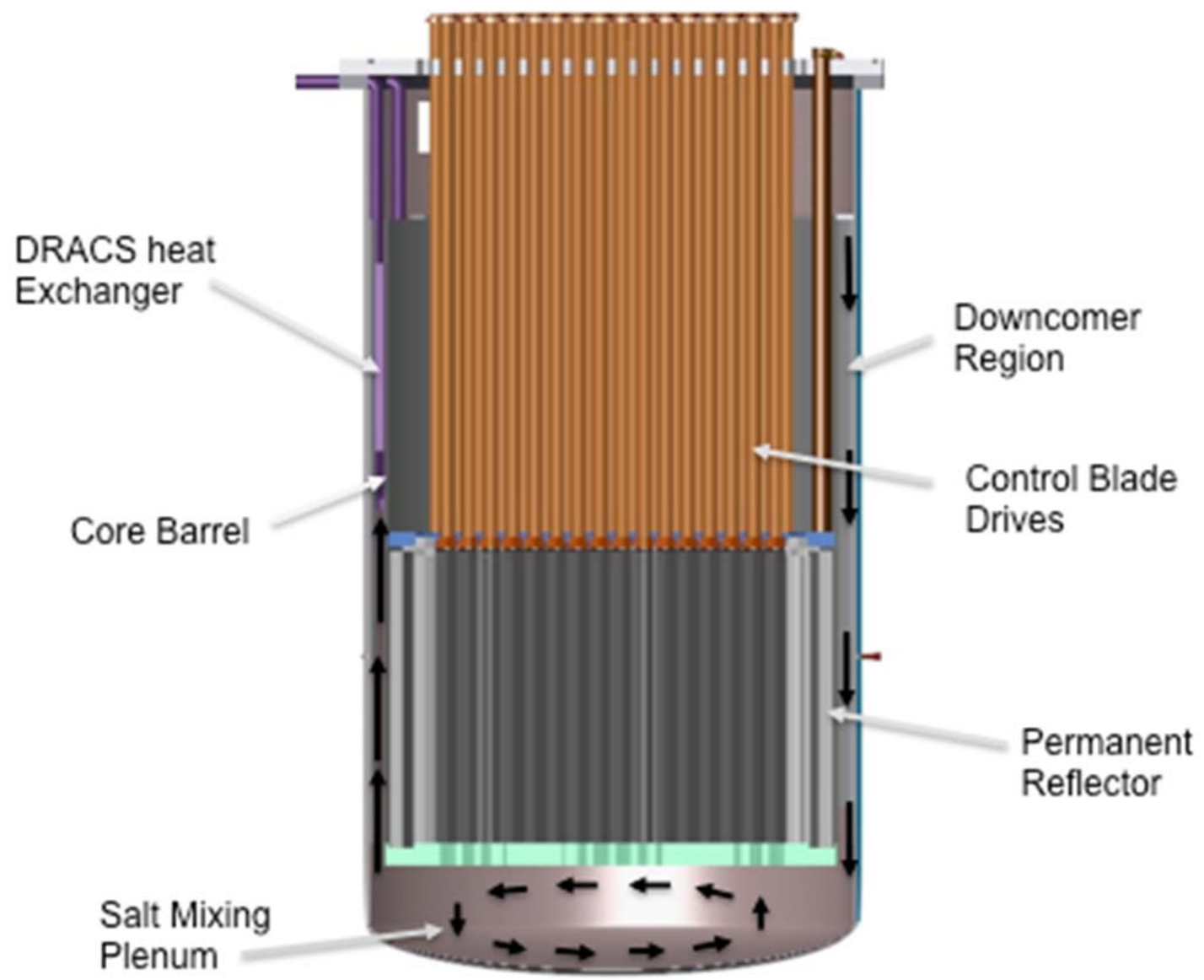

Fig. 44. Cross section showing the downcomer and coolant flows.

\subsection{FUEL ASSEMBLY}

The fuel assembly is a 6-m tall hexagonal prismatic box with 1-cm-thick walls made of C-C composite. The outer apothem (half the side-to-side distance) of the hexagon is $22.5 \mathrm{~cm}$. The interior ("channel") of the hexagonal box ("channel box") is divided into three symmetric regions by a 4-cm-thick Y-shaped structure ("Y-shape"), also made of C-C composite. In each of the three regions there are six equidistant fuel plates that are supported at one end by the $\mathrm{Y}$-shaped structure and at the other end by the channel box. The $0.7-\mathrm{cm}$ distance between two fuel plates is filled by the FLiBe coolant ("intra-assembly coolant"). For the plates adjacent to the walls (channel box or Y-shape), the coolant thickness is half the thickness between plates: $0.35 \mathrm{~cm}$. Table 5 summarizes the main geometric characteristics of the AHTR fuel assembly, while Fig. 45 shows a cross section through a fuel assembly inside the core.

The channel boxes of two adjacent assemblies are not in direct contact but are separated by $1.75 \mathrm{~cm}$ of coolant ("interassembly coolant") inside the core region. All the fuel assemblies have a fuel assembly grappling collar that interfaces with the upper core support plate and provides a grappling interface for fuel reloading. A design constraint for the grappling collar is to maintain at least double the flow channel area as the combined interstitial area between the fuel plates to avoid the upper core support becoming a significant portion of the pressure drop along the primary coolant flow path. Hemispherical contacts on 
the grappling collar interfaces with the upper core support plate to hold the fuel assemblies down since the fuel is slightly buoyant in salt.

At the center of the Y-shape is the control blade slot, also Y-shaped. The slot is $1.75 \mathrm{~cm}$ thick, and each wing is $10.38 \mathrm{~cm}$ long.

Table 5. Main characteristics of the fuel assembly

\begin{tabular}{lcc}
\hline \multicolumn{1}{c}{ Characteristic } & Value & Units \\
\hline Total height & 600 & $\mathrm{~cm}$ \\
Fueled region height & 550 & $\mathrm{~cm}$ \\
Fuel assembly pitch & 46.75 & $\mathrm{~cm}$ \\
Outer apothem & 22.5 & $\mathrm{~cm}$ \\
Channel box wall thickness & 1 & $\mathrm{~cm}$ \\
Y-shape thickness & 4 & $\mathrm{~cm}$ \\
Coolant thickness between plates & 7 & $\mathrm{~mm}$ \\
Coolant thickness between plate and wall & 3.5 & $\mathrm{~mm}$ \\
Control blade thickness & 1 & $\mathrm{~cm}$ \\
Control blade location wing length & 10 & $\mathrm{~cm}$ \\
Fuel plate thickness & 2.55 & $\mathrm{~cm}$ \\
Number of fuel plates & 18 & - \\
\hline
\end{tabular}

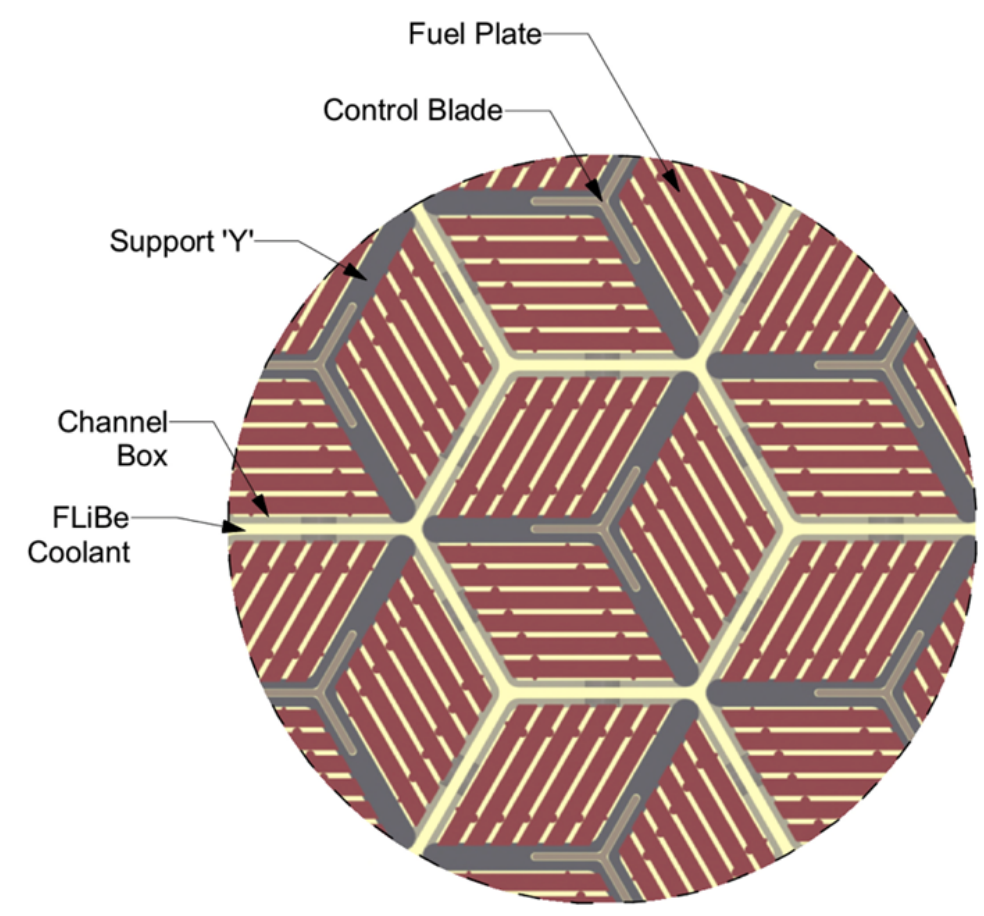

Fig. 45. Transverse cross section of a group of fuel assemblies showing the interassembly spacing.

Table 6 shows the material composition and their densities for the main components of the AHTR assembly. A dimensioned cross-sectional view of a single fuel assembly is shown in Fig. 46. 
Table 6. Material characteristics of the fuel assembly

\begin{tabular}{llc}
\hline \multicolumn{1}{c}{ Part } & \multicolumn{1}{c}{ Material } & $\boldsymbol{\rho}\left(\mathbf{g} / \mathbf{c m}^{3}\right)$ \\
\hline Channel box & C-C & 1.95 \\
Y-shape & C-C & 1.95 \\
Coolant & FLiBe & $1.95 @ 700^{\circ} \mathrm{C}$ \\
Fuel plate & Graphite/Carbon/UCO & - \\
\hline
\end{tabular}

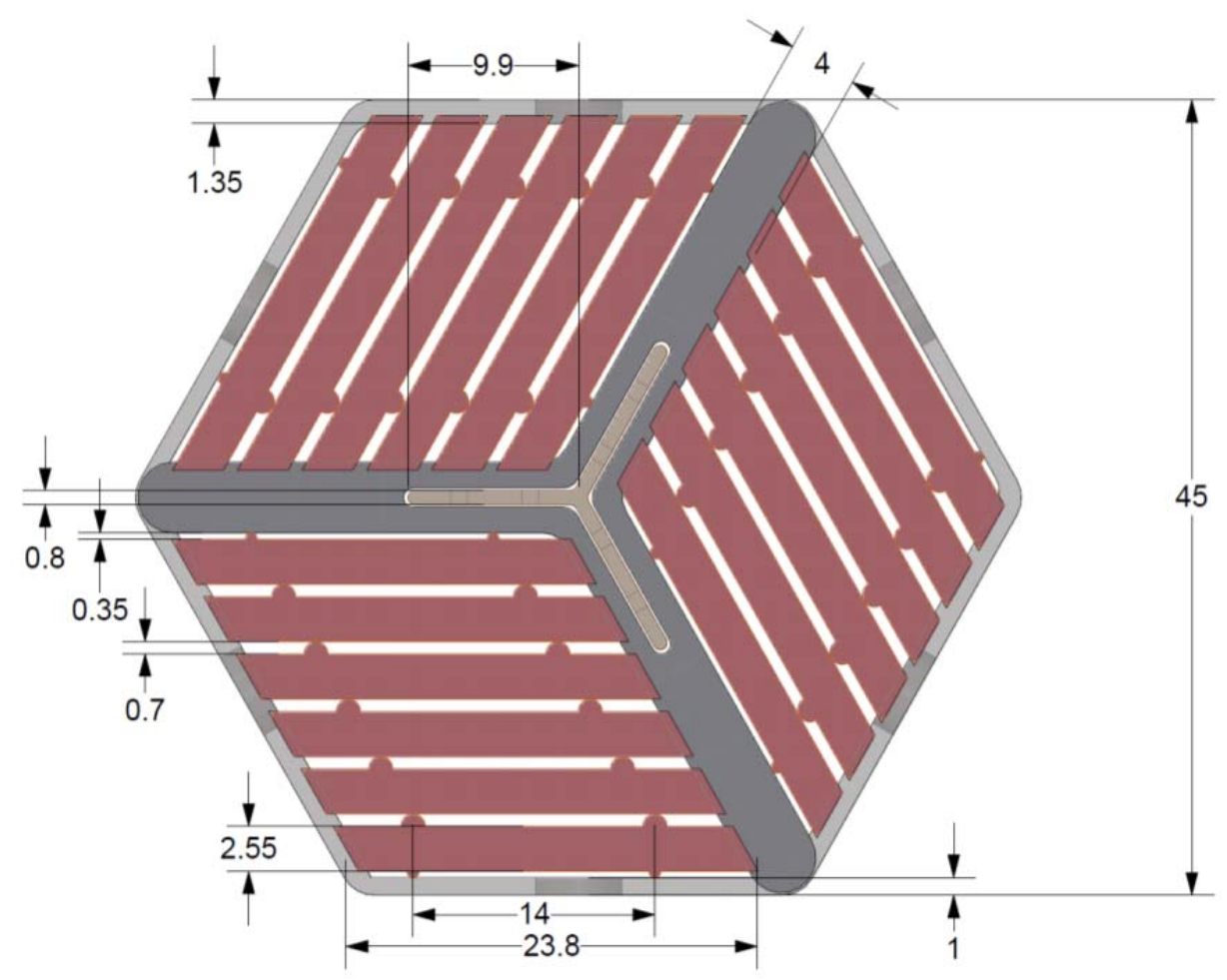

Fig. 46. Transverse cross section of the fuel assembly with dimensions in centimeters.

\subsection{FUEL PLATE}

The plate design for the fuel elements represents a design evolution from the SmAHTR design. ${ }^{17}$ Within the slab fuel element, the TRISO fuel particles are distributed in two stripes separated by central carbonaceous material. This represents the main departure from the SmAHTR fuel, where the fuel was distributed throughout the plate. This design was chosen taking into account both neutronic considerations, to allow better moderation, and also thermal-hydraulic considerations, to allow better cooling. A thin ( 1-mm-thick) sleeve of carbonaceous material separates each fuel stripe from the FLiBe coolant, preventing individual fuel particles from eroding away.

Figure 47 shows a cross-sectional view of the fuel plank as modeled for the depletion calculations. The thickness of the fuel stripes is designed to allow maximum thermal-hydraulic performance (i.e., minimize the maximum temperature in the fuel) and to maximize the lifetime of the reactor core. It should be pointed out that maximization of the once-through cycle length does not automatically also lead to maximization of the fuel burnup. 


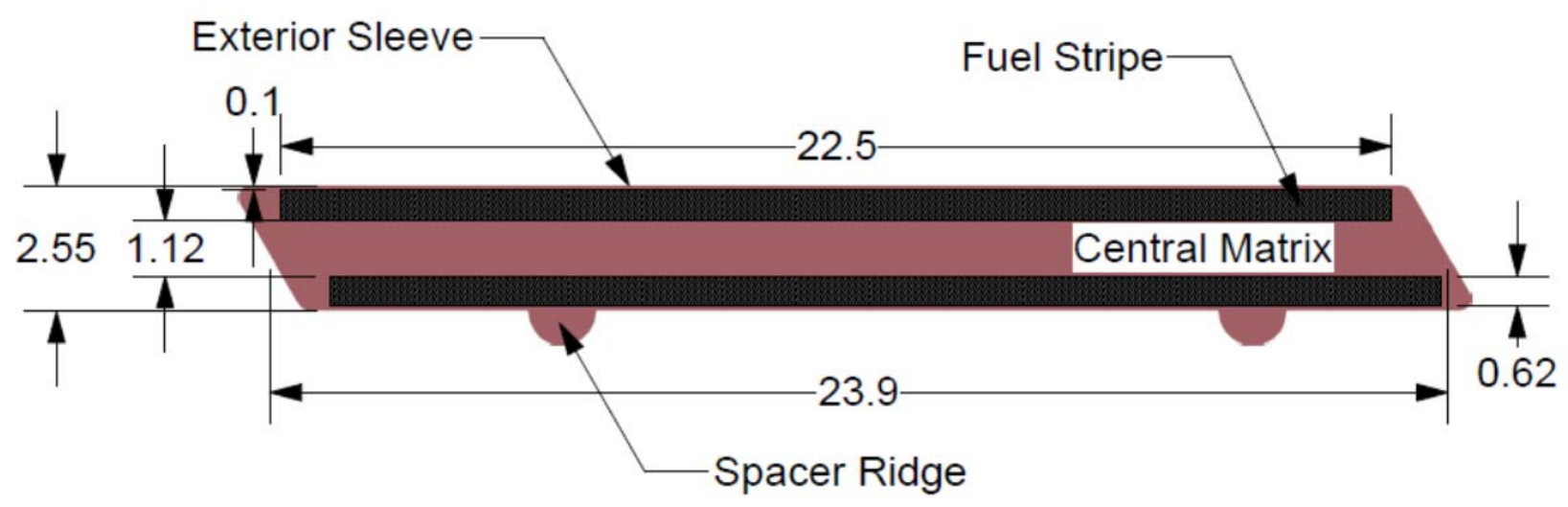

Fig. 47. Transverse cross section of a fuel plate.

\subsection{CONTROL BLADE DESIGN}

The AHTR employs one control blade per fuel assembly with each control blade having relatively low reactivity worth. The control blade remains with the fuel assembly throughout the fuel loading and unloading procedure to preclude criticality accidents during fuel handling. The current AHTR design employs a molybdenum-hafnium carbide alloy (MHC) as its neutron absorber and structural material. The control blade may be removed, and possibly reused, following fuel transfer into the poisoned spent fuel storage pool after a decay period of $\sim 18$ months. MHC is a commercial, particle-strengthened molybdenum-based alloy with 1.2 wt. \% hafnium and 0.1 wt. \% carbon. MHC has a density of $10.28 \mathrm{~g} / \mathrm{cm}^{3}$.

The control blade leader rod grips the control blade using the grappling holes (Fig. 48) located in its upper end. Figure 49 shows the control blade inserted into the top of a fuel assembly. The control blade is designed to sink into a full-length slot within the C-C composite support $\mathrm{Y}$, displacing primary coolant, upon release. The control blade has a $0.38-\mathrm{cm}$ clearance on all sides to its guide slot. To accommodate mechanical distortion of C-C composites under core level irradiation, the control blade is made in sections. Figure 48 shows a six segmented control blade design, although it can be made with more segments if the amount of warpage is deemed to be large. The ball joint design of the segmented control blade allows for correction in two longitudinal axes, but not for roll. 


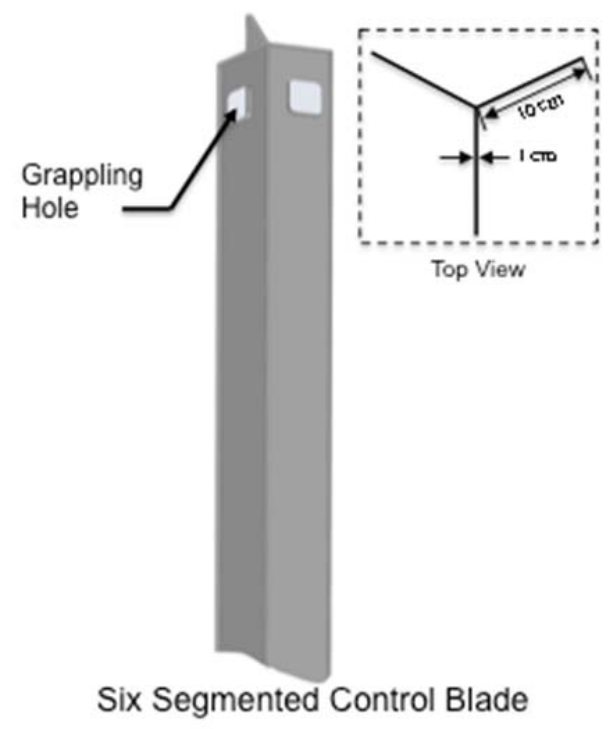

Fig. 48. Control blade with details of the top portion.

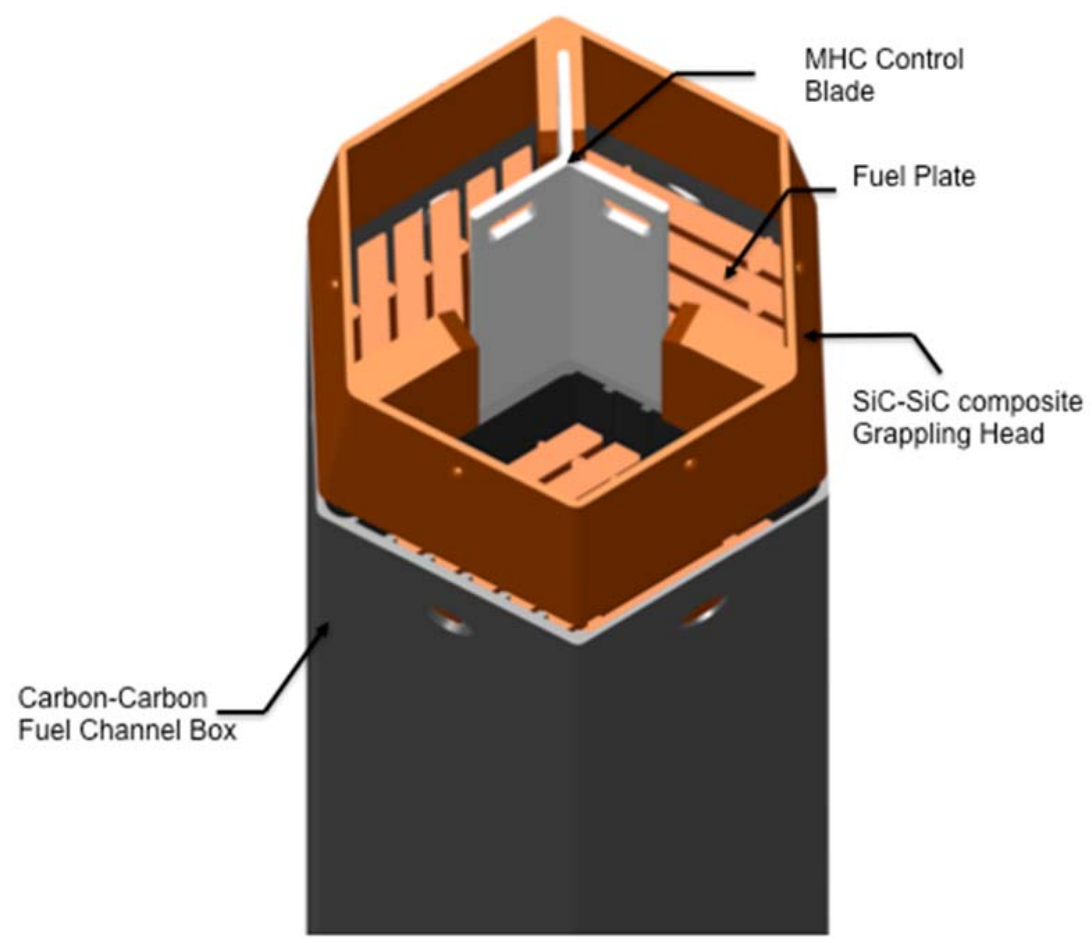

Fig. 49. Upper end of the fuel assembly with control blade inserted. 


\subsubsection{Control Blade Drive Mechanism}

The control blade drives are located on a plate above the reactor vessel upper flange. Each control blade is independently driven and has a leader rod that extends from the top of the control blade through the reactor vessel to the control blade drive motor. Each control blade leader rod is encased in a control blade guide tube. The guide tubes both provide mechanical alignment for the control blade-leader rod assembly and structural support to the upper core support plate against the upwards thrust produced by primary coolant flow during operation. Both the guide tubes and leader rods are made from SiC-SiC composite as they are exposed to the primary salt and the cooler argon atmosphere above the pool.

An argon atmosphere is maintained above the top of the pool within the reactor vessel. Sufficient argon flow is provided to maintain the upper vessel flange at $\sim 250^{\circ} \mathrm{C}$ during normal operation. The flowing argon is continuously cleaned to remove any contaminating moisture or tritium that is released from the primary coolant. Each leader rod and guide tube extends through the upper vessel flange to a control blade drive motor assembly. The control blade drive motor assemblies are mounted on a plate located above the upper vessel flange. The control blade motor assembly plate is mounted on rails to enable lateral translation to clear the upper vessel flange during refueling. The upper vessel flange does not provide a containment seal as both the guide tubes and leader rods pass freely through it. The upper vessel atmosphere containment is provided by an upper vessel closure that seals against the top surface of the upper vessel flange. The upper vessel closure consists of a set of tubes extending upwards to envelop the leader rods and guide tubes when in their withdrawn position. Fig. shows an exploded view of the upper vessel structure and control blade drive pieces.

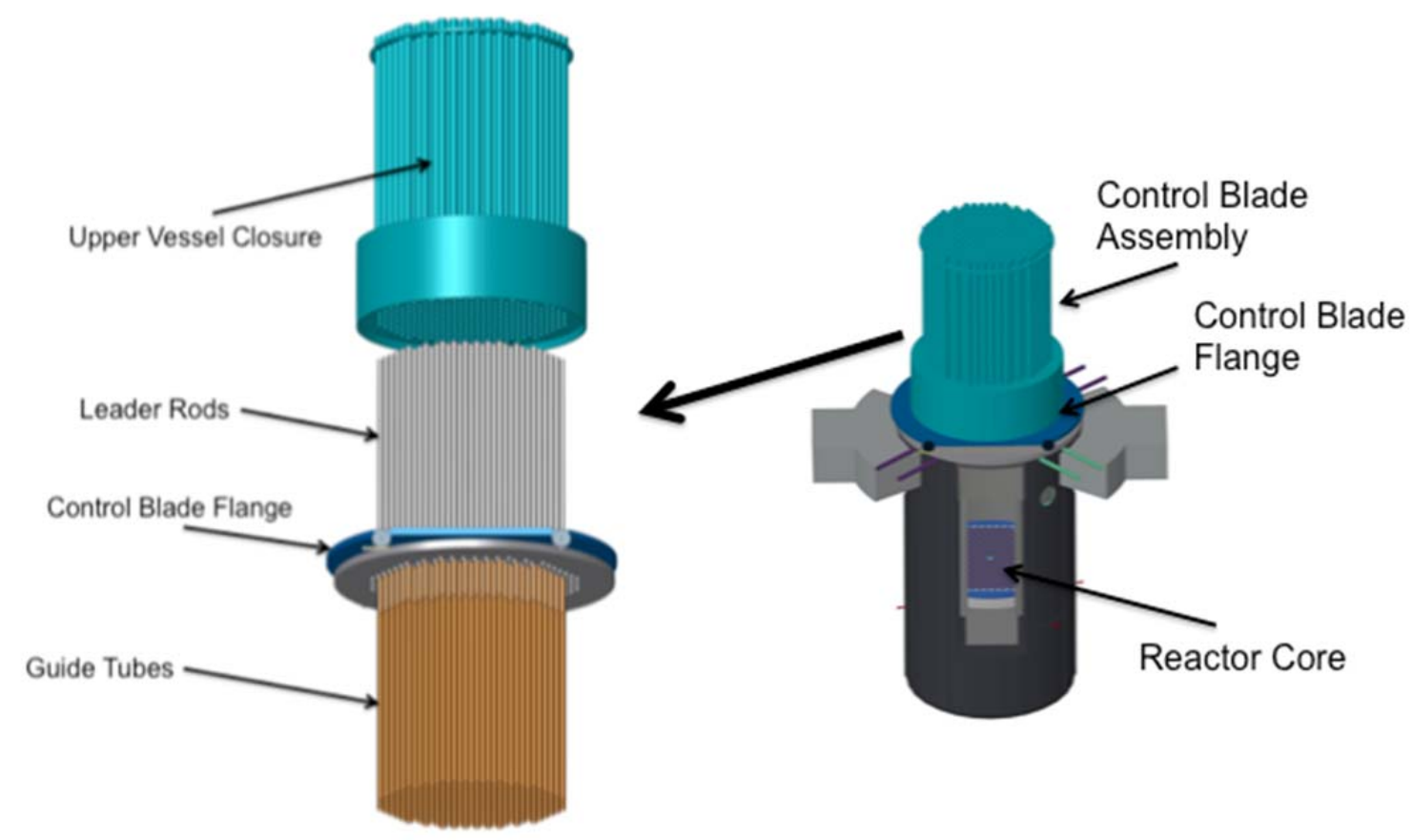

Fig. 50. AHTR upper vessel components in exploded view with retracted control blade.

Separate motors drive both the control blade leader rods and the guide tubes. The control blade leader rods slide inside the control blade guide tubes (Fig. 51). The drive motor for the leader rod is mounted on a solenoid actuator that releases the leader rods if power is lost. When the drive mechanism is disconnected, the control blades fall into the core by gravity. The leader rods remain connected to the 
control blade during this scenario. Each leader rod also has a fusible link just above its end-effector. If the temperature of the coolant rises above a (yet to be determined) threshold, the fusible link melts and the control blade is released and falls into the fuel assembly. The core can still be defueled using the normal mechanisms even if the blades have been released due to the fuse melting.

Each leader rod has an end-effector that allows it to connect to its respective control blade. By rotating the leader rod (using a motor mounted to the control blade flange), the end-effector attaches to the control blade (Fig. 52). The end-effector has a wider disk at its end to prevent detaching the leader rod unless the control blade is fully inserted into the fuel assembly. The leader rod can be raised or lowered by actuating the motor mounted to the control blade plate.

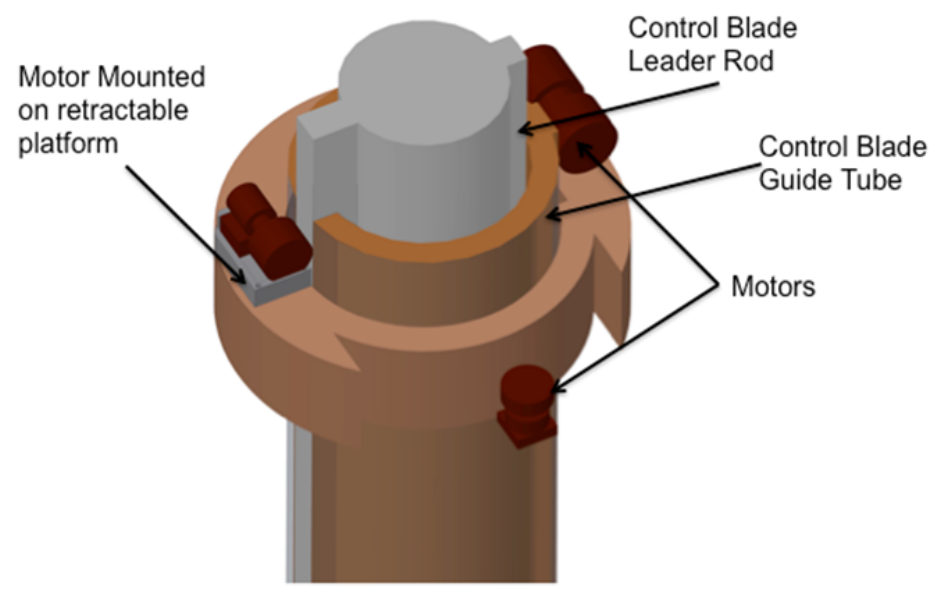

Fig. 51. Control blade motor assembly.

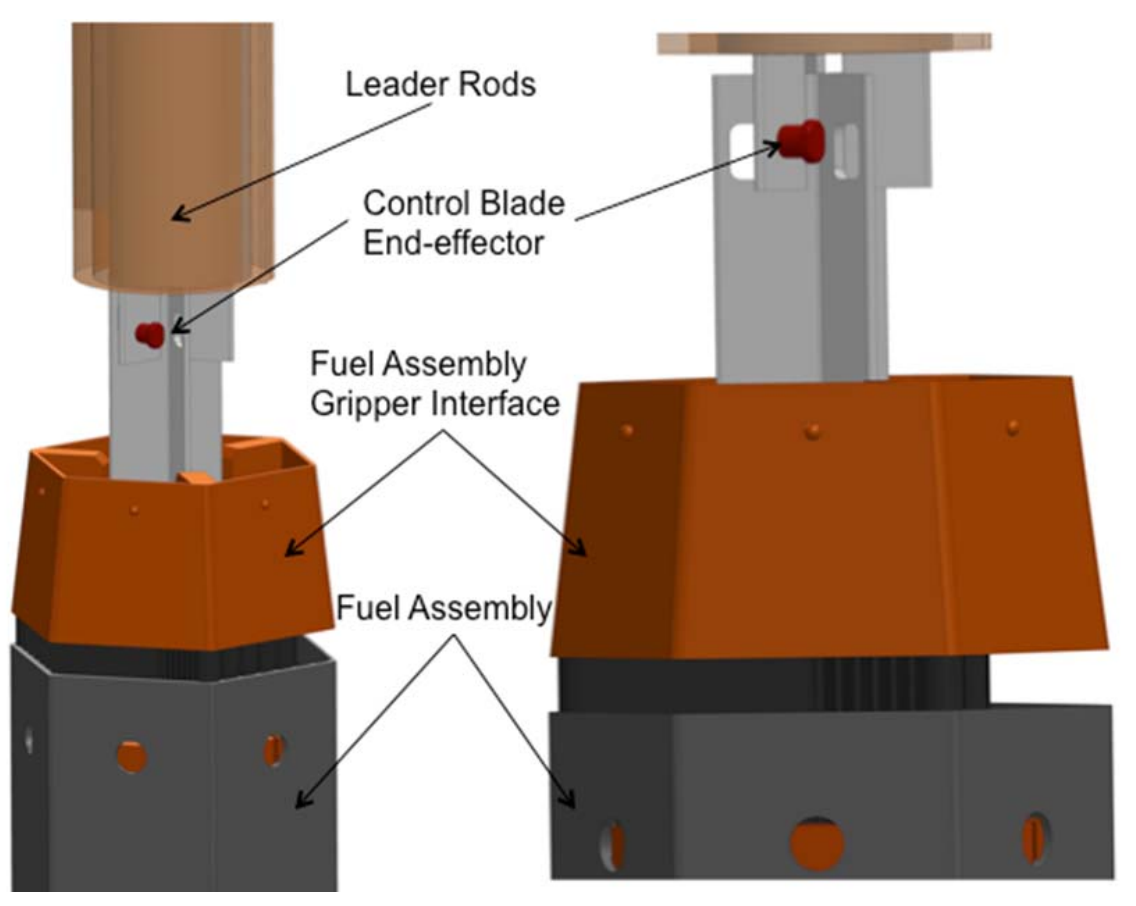

Fig. 52. Control blade attachment to the leader rods. 
Each control blade also has a $\mathrm{SiC}-\mathrm{SiC}$ composite control blade guide structure that serves as a support pillar against the upward thrust on the fuel assemblies produced by the primary coolant upflow through the core (Fig. 53). During refueling the control blade is detached from the control blade leader rod and left inserted in the core. The control blade leader rods and control blade guide structures are withdrawn through the top of the reactor vessel. The entire control blade mounting plate is then moved horizontally, out of position, to enable the vertical in-vessel fuel handling manipulator machine to be placed on the reactor vessel upper flange (see Fig. 54).

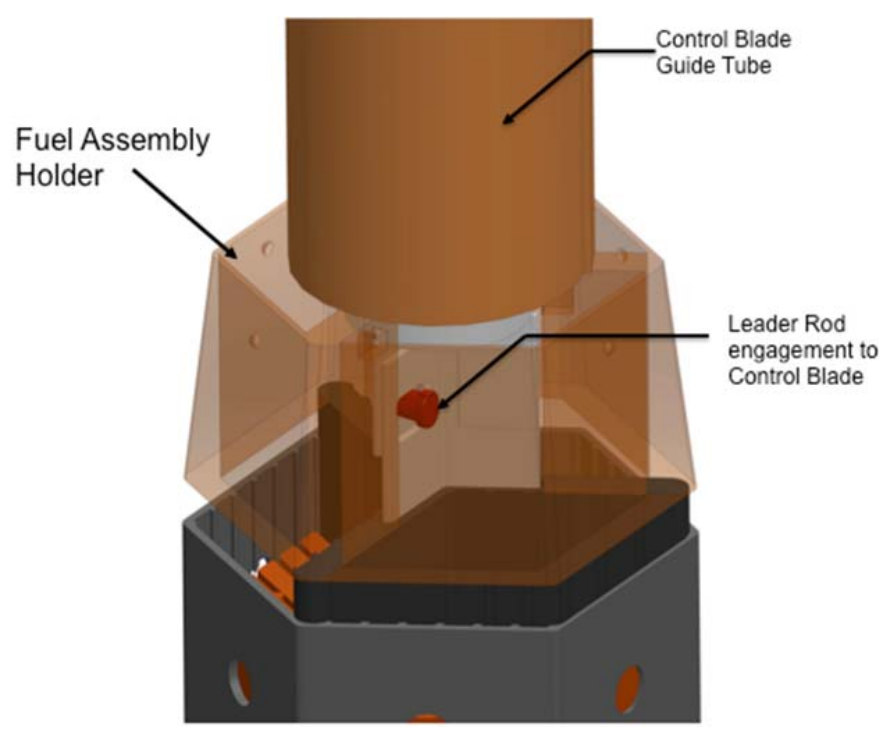

Fig. 53. Control blade guide tube resting on the fuel assembly while leader rod is connected to the control blade.

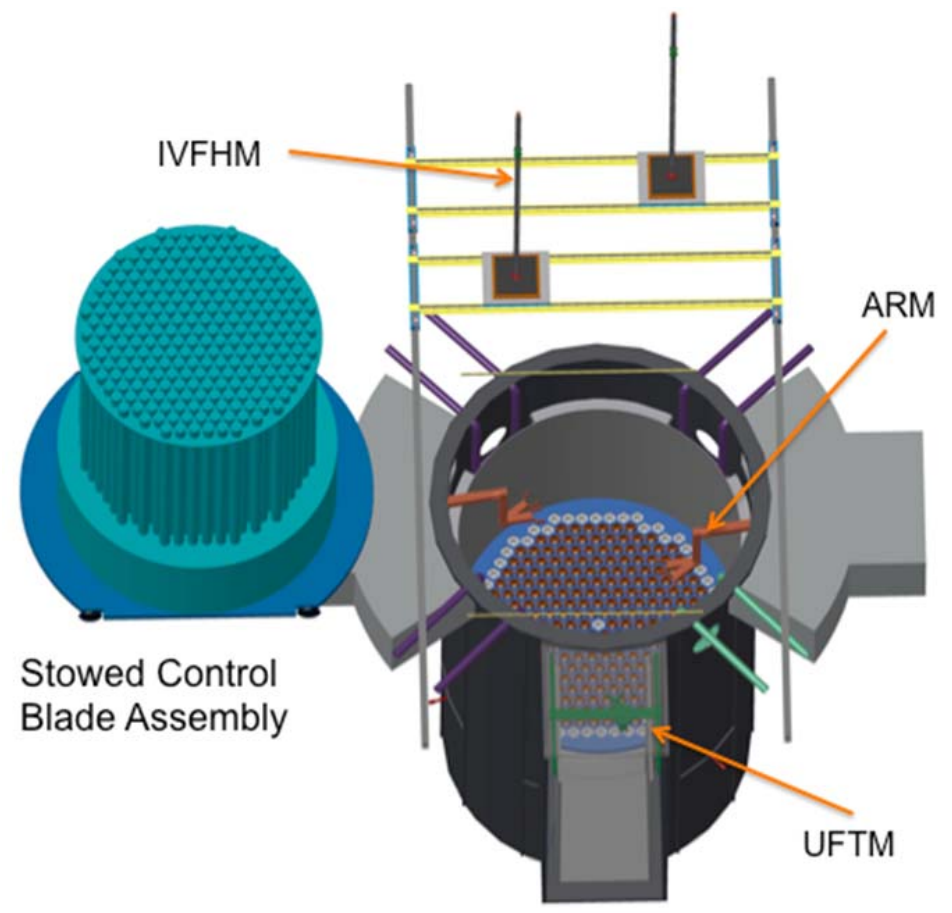

Fig. 54. Control blade assembly in stowed position. 


\subsection{REFUELING LOBE}

The refueling lobe is where the new fuel is staged before it is transferred to the reactor core and also the where used fuel is placed before it is transferred to the used fuel storage pool (Fig. 55). The refueling lobe houses the Used Fuel Transfer Manipulator (UFTM) that interfaces with the Annular Ring Manipulator (ARM) and the new and used fuel transfer mechanisms. A salt level of $2 \mathrm{~m}$ is maintained above the fuel assemblies (except when they are lifted from the salt) to minimize the radiation levels above the salt. The $\mathrm{C}-\mathrm{C}$ core barrel continues into the refueling lobe to maintain the walls of the reactor vessel in this region at lower temperature $\left(650^{\circ} \mathrm{C}\right)$ due to bypass flow outside of the core barrel.

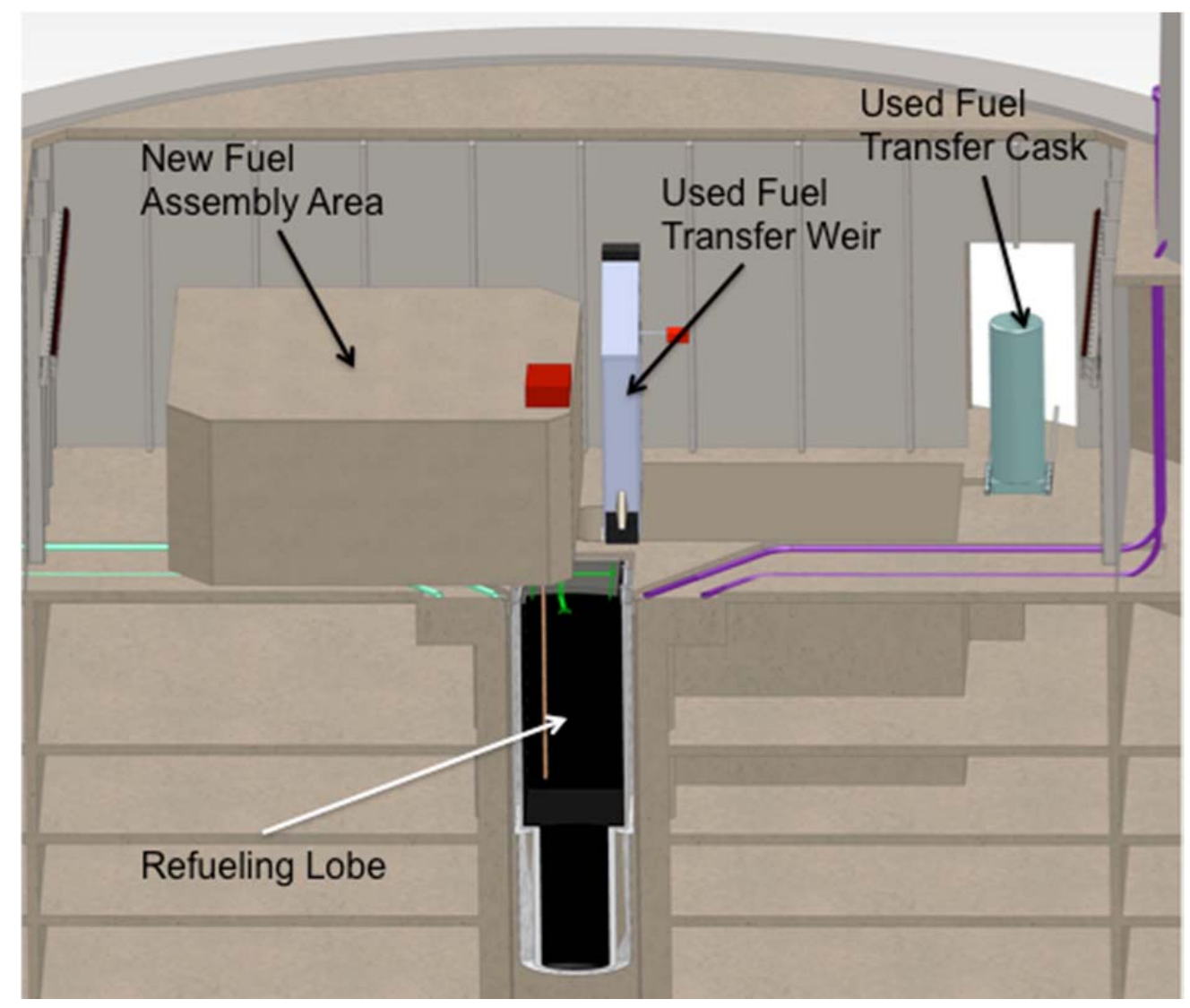

Fig. 55. Refueling lobe and its interfaces.

\subsection{NEW FUEL ASSEMBLIES AREA}

New fuel assemblies arrive at the reactor by rail and are manually inspected by personnel in the fuel receiving building before being transferred to the New Fuel Assembly Area (NFAA). The new fuel assemblies each enter the reactor building on its own carriage and are brought down to the reactor level by an elevator (Fig. 55). These carriages interface with the serpentine rail system at NFAA. The NFAA includes a double-door gas interlock entrance to enable transitioning to an inert atmosphere in the NFAA. The NFAA is outside of containment and maintains an argon or dry air environment, depending on the stage of the new fuel loading process. Once all 126 assemblies are loaded, the dry air environment inside this room is flushed with dry argon. The temperature inside the building is then raised to $1000^{\circ} \mathrm{C}$ to remove entrapped moisture within the graphite fuel elements that may contaminate the salt. After maintaining the temperature at $1000^{\circ} \mathrm{C}$ for a few days, the temperature is decreased to $650^{\circ} \mathrm{C}$. The fuel is 
now ready for insertion into the salt. Since nearly 6 months elapses between new fuel introductions, ample time is available for the preparatory actions.

The serpentine rail system has a built-in platform for lowering fuel assemblies into the refueling lobe (Fig. 56). The platform is lowered and raised by a cable and pulley system inside the NFAA. The platform also has a sealed surface that seals the opening for maintaining a vacuum inside the NFAA. The upward force for sealing is provided by the cable drive mechanism. The platform is lowered and raised using guide rails that are permanently attached to the inside of the refueling lobe. A sealing surface on the loading platform mates with the floor to enable creating a containment seal below the new fuel assembly area (Fig. 57).
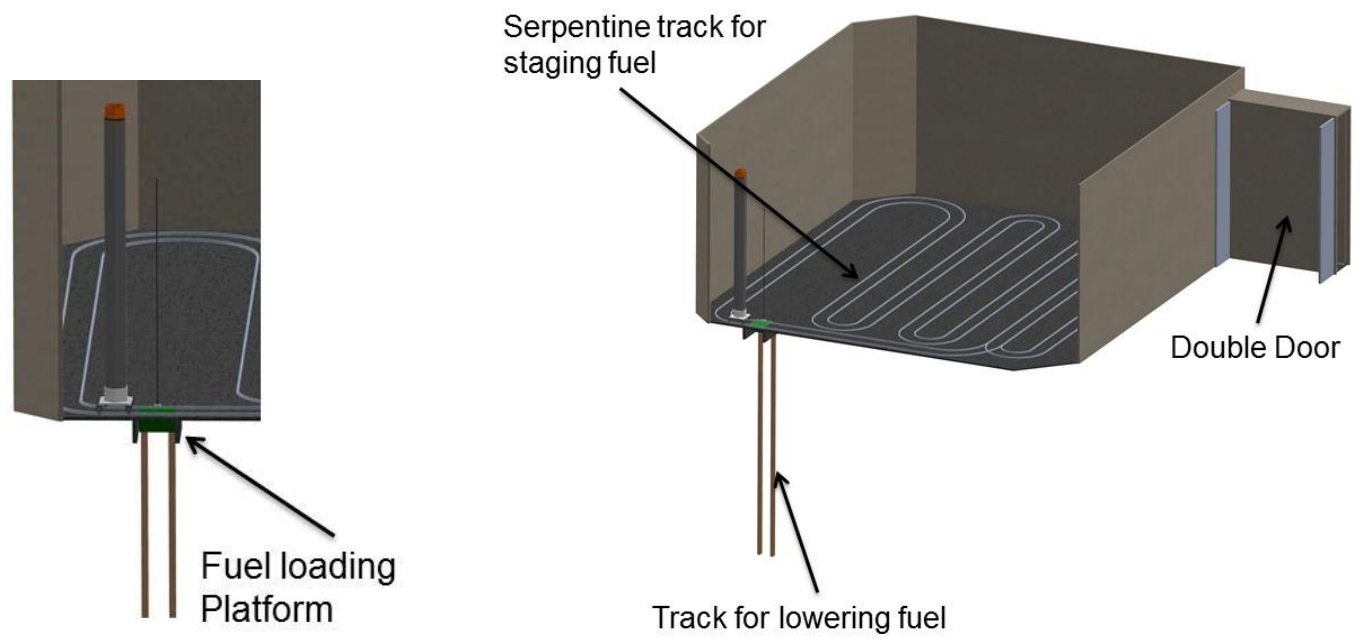

Fig. 56. New fuel assembly area with loading platform.

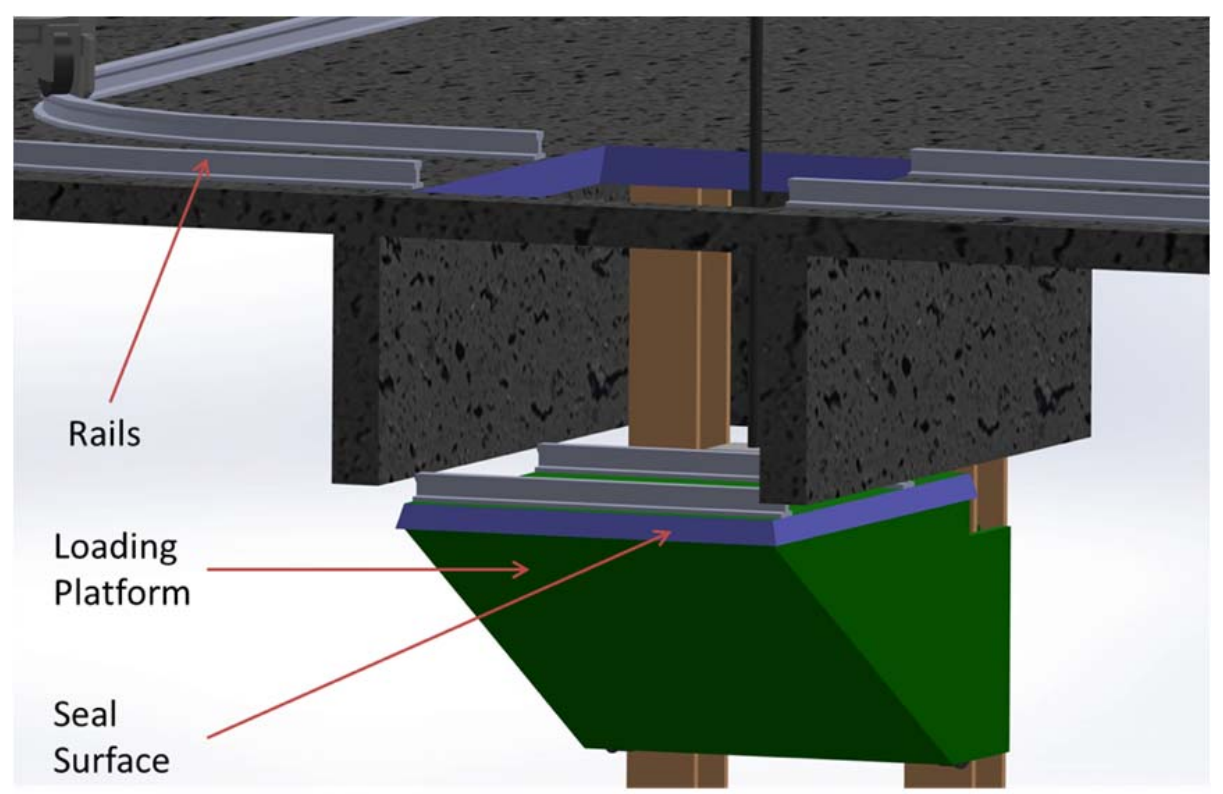

Fig. 57. Seal on the loading platform at the new fuel assembly area. 
A carriage on the serpentine rail system has four support wheels. Fixed guides on the wheel assembly provide lateral support to prevent the 6-m-long fuel assemblies from tipping while translating along the rail system (Fig. 58).

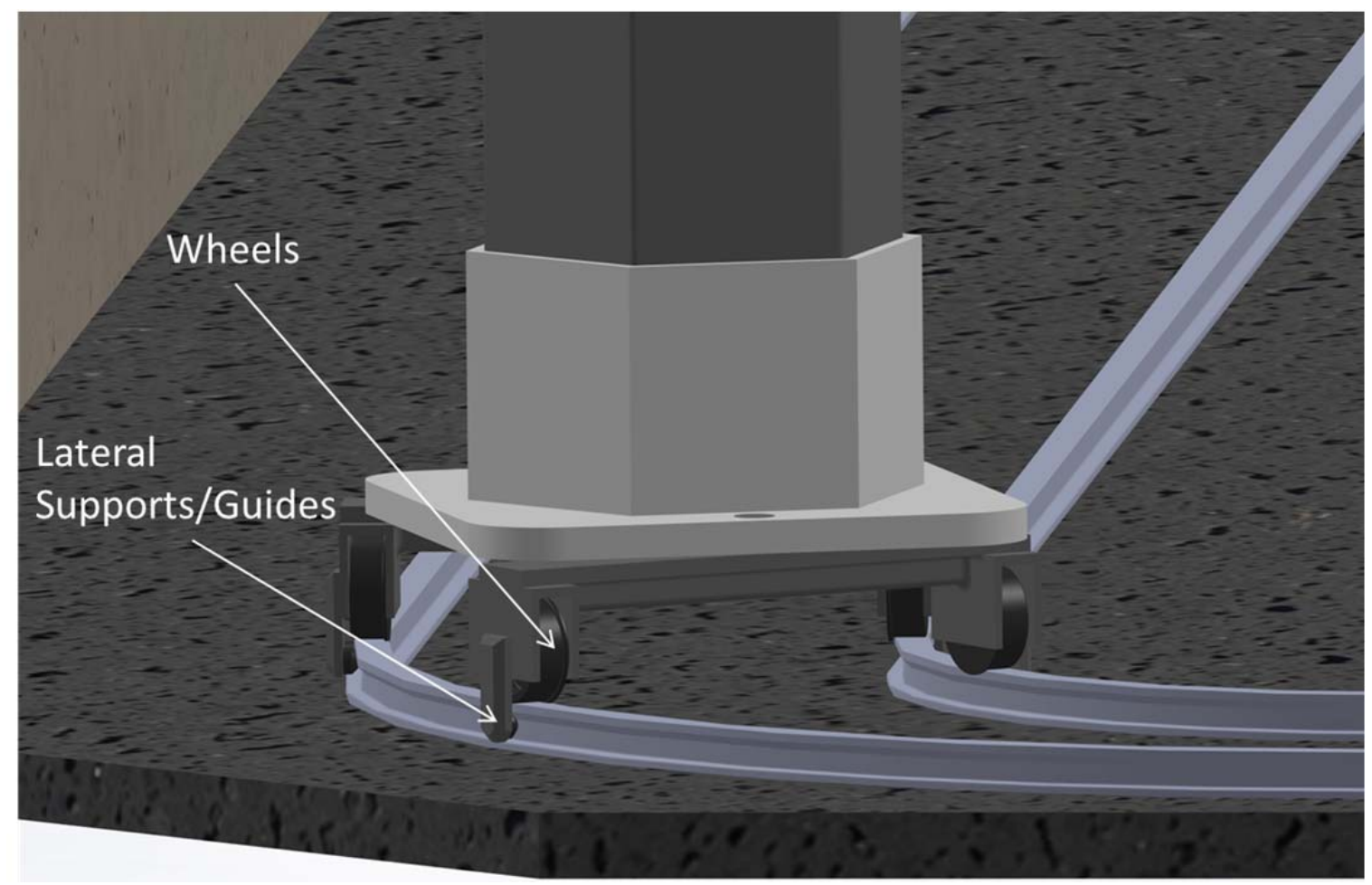

Fig. 58. Lateral guides on the fuel-handling carriage.

New fuel assemblies that are introduced into the reactor are placed into position within the reactor core by the three manipulators described in Sect. 4.9.

\subsection{USED FUEL TRANSFER WEIR}

The used fuel transfer weir is shown in Fig. 59. The grapple mechanism used by the gripper is similar to the one employed by the In-Vessel Fuel Handling Manipulator (IVFHM).

Figure 60 shows the grapple attachment to the fuel assembly. Unlike the rotary actuation for the IVFHM, this gripper employs a spring. Once the grapple secures a grasp on the fuel assembly, the hoist pulls the fuel assembly out of the refueling lobe.

The location of the pivot point on the hoist automatically aligns the fuel assembly to the used fuel pool. Argon blowers are located on the slanted transfer channel to provide fuel cooling during the transfer process and to remove any primary salt that remains on the surface of the fuel assemblies. A gate valve is provided to isolate the salt in the used fuel pool and the refueling lobe. A fusible link on the grapple ensures that in the event that the fuel assembly motion is delayed while outside the salt, the fuel will be released to slide gently into the salt where it will remain below fuel damage temperature. 


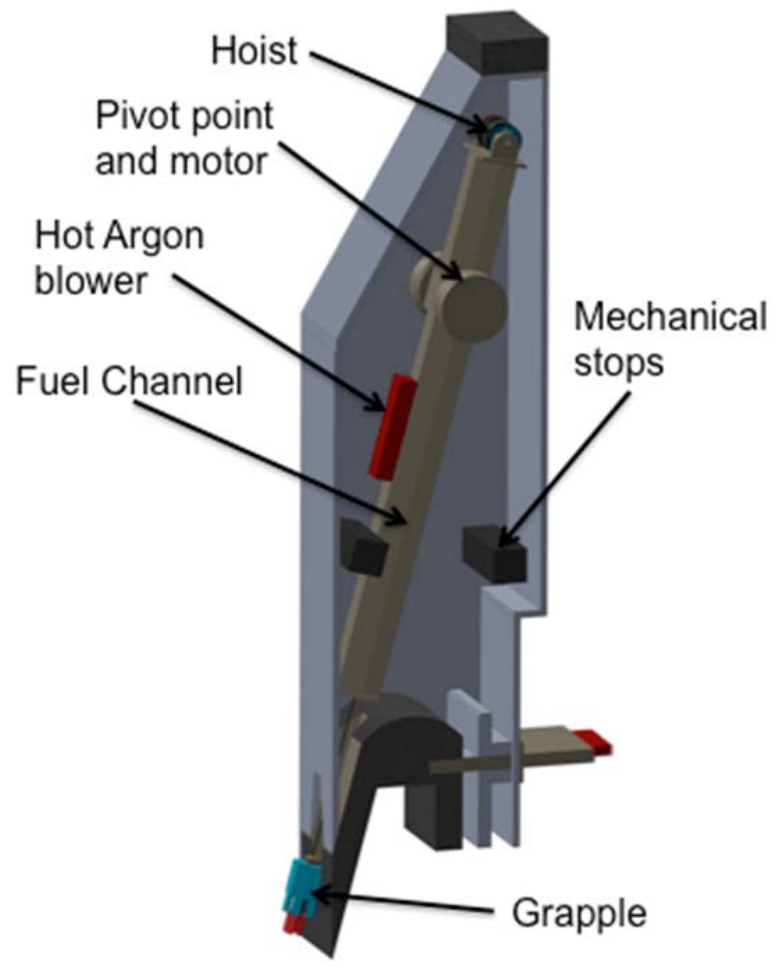

Fig. 59. Used fuel transfer weir.
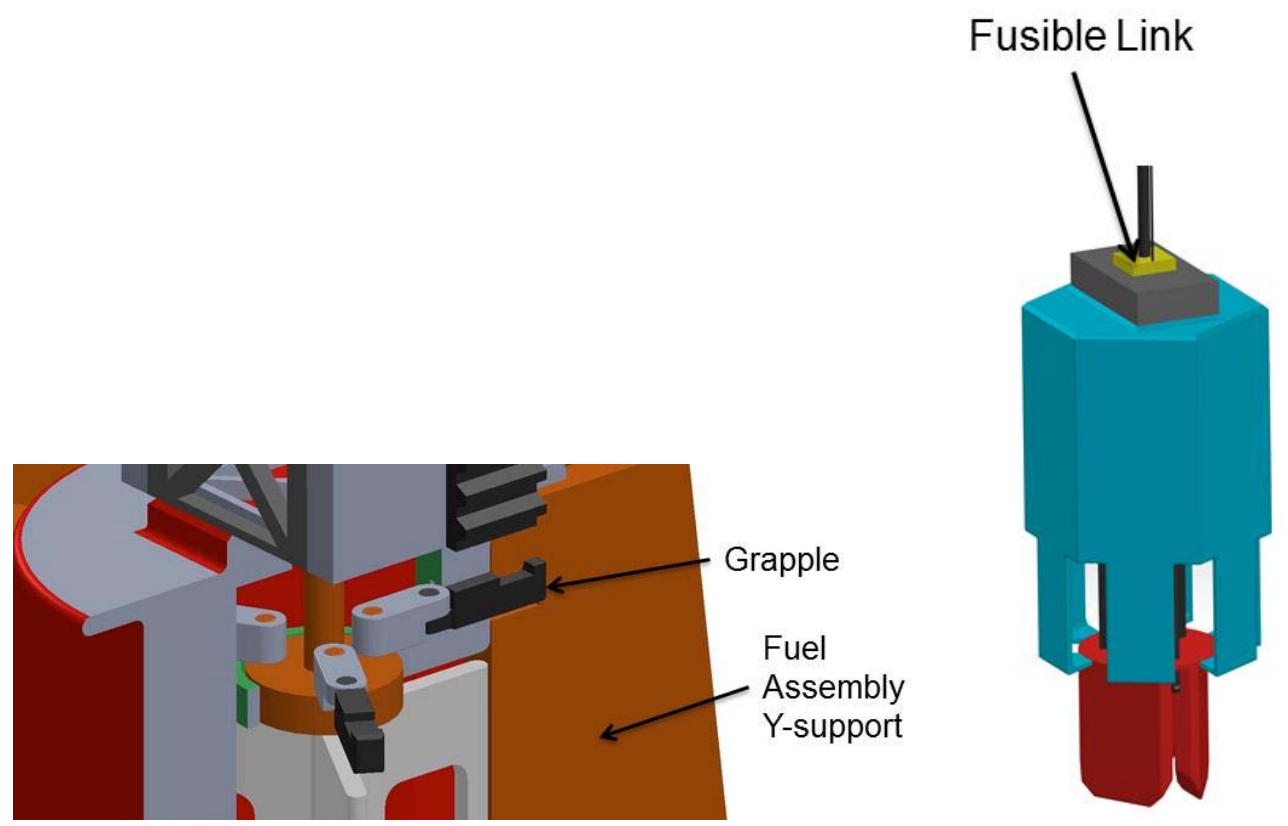

Fig. 60. Grapple attached to the fuel assembly.

The used fuel storage pool has the capacity to hold 252 fuel assemblies, with some excess capacity to hold any damaged fuel assemblies. The salt in the used fuel storage pool is $\mathrm{KF}^{-} \mathrm{ZrF}_{4}$. During each outage, 126 new used fuel assemblies are added to the storage pool. The salt in the pool is maintained at around $500^{\circ} \mathrm{C}$. The used fuel pool will be cooled under normal operation by a maintenance cooling system. The 
system will also have redundant natural draft passive cooling system to account for loss-of-active-cooling accident scenarios. The design intent is to maintain a sufficient temperature margin in the used fuel storage pool such that in the event of a loss-of-forced-cooling accident, the natural draft cooling systems will prevent the pool from boiling $\left(>1400^{\circ} \mathrm{C}\right)$ or fuel damage $\left(>1600^{\circ} \mathrm{C}\right)$.

Between outages, the used fuel assemblies that have been in storage for more than 6 months are removed from the used fuel storage pool. A bottom-loading cask is used to remove these radioactive fuel assemblies from the reactor.

\subsection{MECHANISMS OVERVIEW}

Three fuel-handling mechanisms interface with the reactor vessel. They work cooperatively during a refueling cycle to reduce the duration of the outage. The three manipulators are as follows and are shown in Fig. 61:

- In-Vessel Fuel Handling Manipulator (IVFHM)

- Annular Rolling Manipulator (ARM)

- Used Fuel Transfer Manipulator (UFTM)

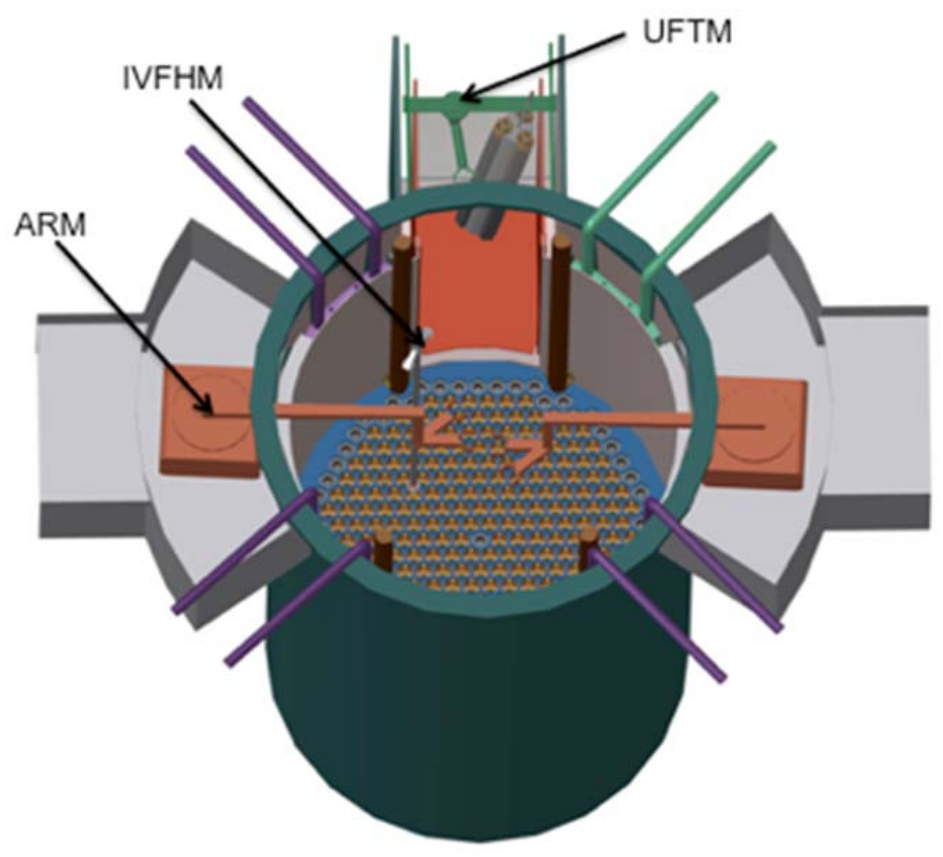

Fig. 61. Reactor top view showing all three manipulators.

\subsubsection{IVFHM}

The IVFHM manipulator is primarily used for vertically lifting a fuel assembly and inserting fresh fuel into the resulting empty slot in core. Two IVFHMs operate simultaneously during refueling (Fig. 62). The IVFHM has a gripper that inserts a rectangular pin into slots in the Y support plate of the fuel assembly to secure a grasp onto the fuel assembly (Fig. 63). Provisions on the gripper passively guide it both laterally and axially onto the fuel assembly. Once the gripper is correctly located, a rotary actuation on the IVFHM rod engages the pins. The lips on the pins prevent the pins from disengaging accidently during fuel transfer. Once the pins are engaged, the fuel assembly can be lifted out of the reactor core. 


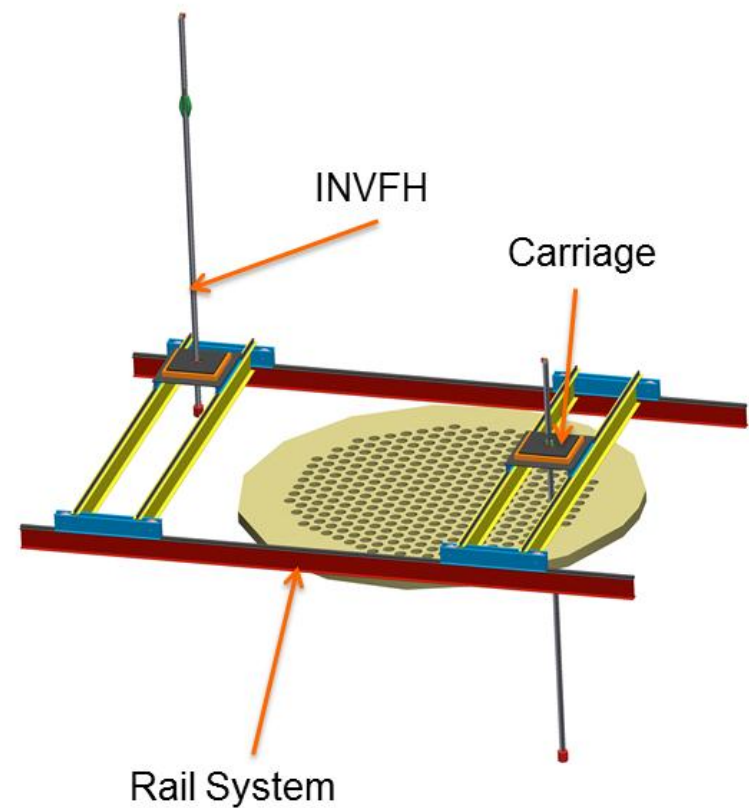

Fig. 62. IVFHM with the rail and carriage system.

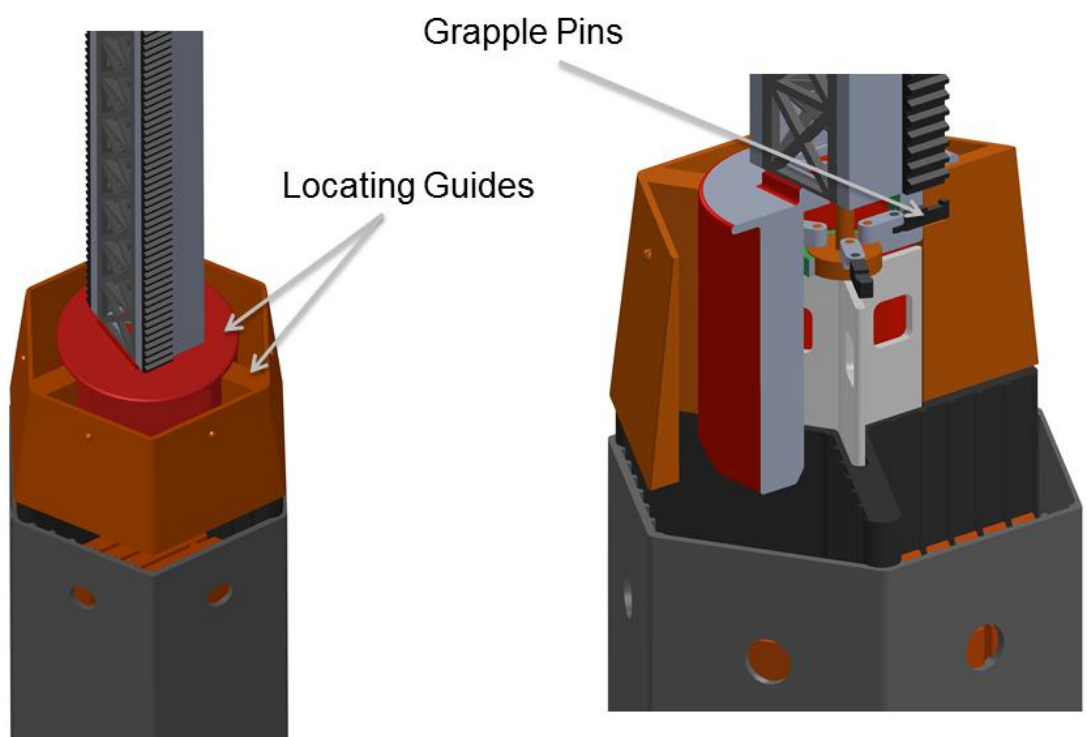

Fig. 63. IVFHM holding the fueling assembly and showing details of the gripper.

A rail on the reactor floor that runs perpendicular to the rail system for the control blade is used for mounting the IVFHMs. Each IVFHM is mounted on a carriage that runs perpendicular to the rail. This two-axis system is used to position the IVFHM over any hole location on the reactor flange corresponding to a fuel assembly. On the carriage, a compliance mechanism helps accommodate slight misalignment of the IVFHM and the fuel assembly. 
Each of the two IVFHM positioning systems covers just over one-half of all the fuel assemblies. Once the fuel assemblies are lifted out, the used fuel assembly is transferred to the ARM manipulator. The new fuel assembly that is already within the other gripper of the ARM robot is then placed in the empty slot in the reactor core. This ensures that the salt flow through the empty slot does not unacceptable reduce flow through the rest of the fuel assemblies.

\subsubsection{ARM}

The ARM manipulator transfers the fuel from the top of the core to the refueling lobe. It has two pairs of grippers to enable replacing the used fuel assembly with a new one immediately after it has been taken out of the core (Fig. 64). The offset link enables the fuel assembly to remain immersed in the salt during transfer to the refueling lobe. The base rotary joint on this mobile manipulator allows it to reach the fuel assemblies and the refueling lobe. The wheels on the base allow the robot to translate along the arc of the ARM housing.

During normal reactor operation, the ARM robot is stowed away. To stow the ARM robot, the prismatic joints are fully retracted and the offset link pulled up from the opening in the reactor top flange and rotated to make the link horizontal. A mounting pin is then inserted into the shoulder rotary joint to hold the offset link in place. The base of the ARM is then translated radially outward from the reactor vessel to the manipulator storage area. The annular opening is then slid closed to provide containment sealing.

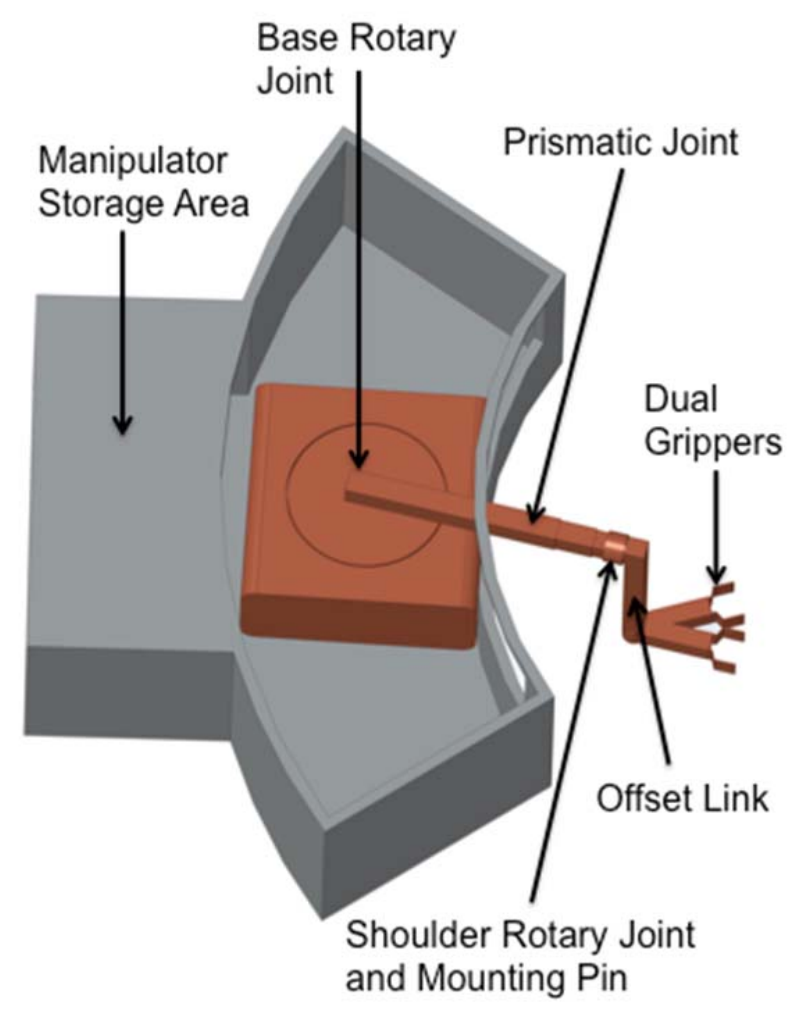

Fig. 64. ARM manipulator with two grippers.

\subsubsection{UFTM}

The UFTM interfaces with the ARM, the new fuel assemblies, and the used fuel assemblies (Fig. 65). The ARM brings used fuel assemblies to the refueling lobe where it transfers them to the UFTM. The UFTM 
places a used fuel assembly in the rotating carousel. It then picks a new fuel that is already staged on the elevator platform. The new fuel is then transferred to the ARM that brought the used fuel assembly.

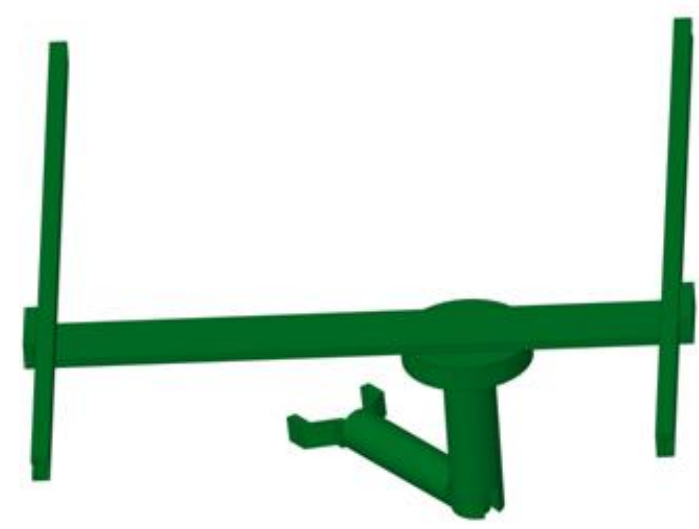

Fig. 65. UFTM.

\subsection{COOLANT STORAGE TANKS}

When the reactor is operating, the primary coolant, which is the FLiBe salt, circulates from the reactor vessel, through the primary piping to the heat exchanger, then through the primary pump and returns to the downcomer in the reactor vessel. Prior to operation, and for infrequent, major maintenance shutdowns, such as primary pump maintenance or reactor internals replacement, the FliBe salt will be drained and stored in the primary salt drain tank. This is shown in Fig. 66.

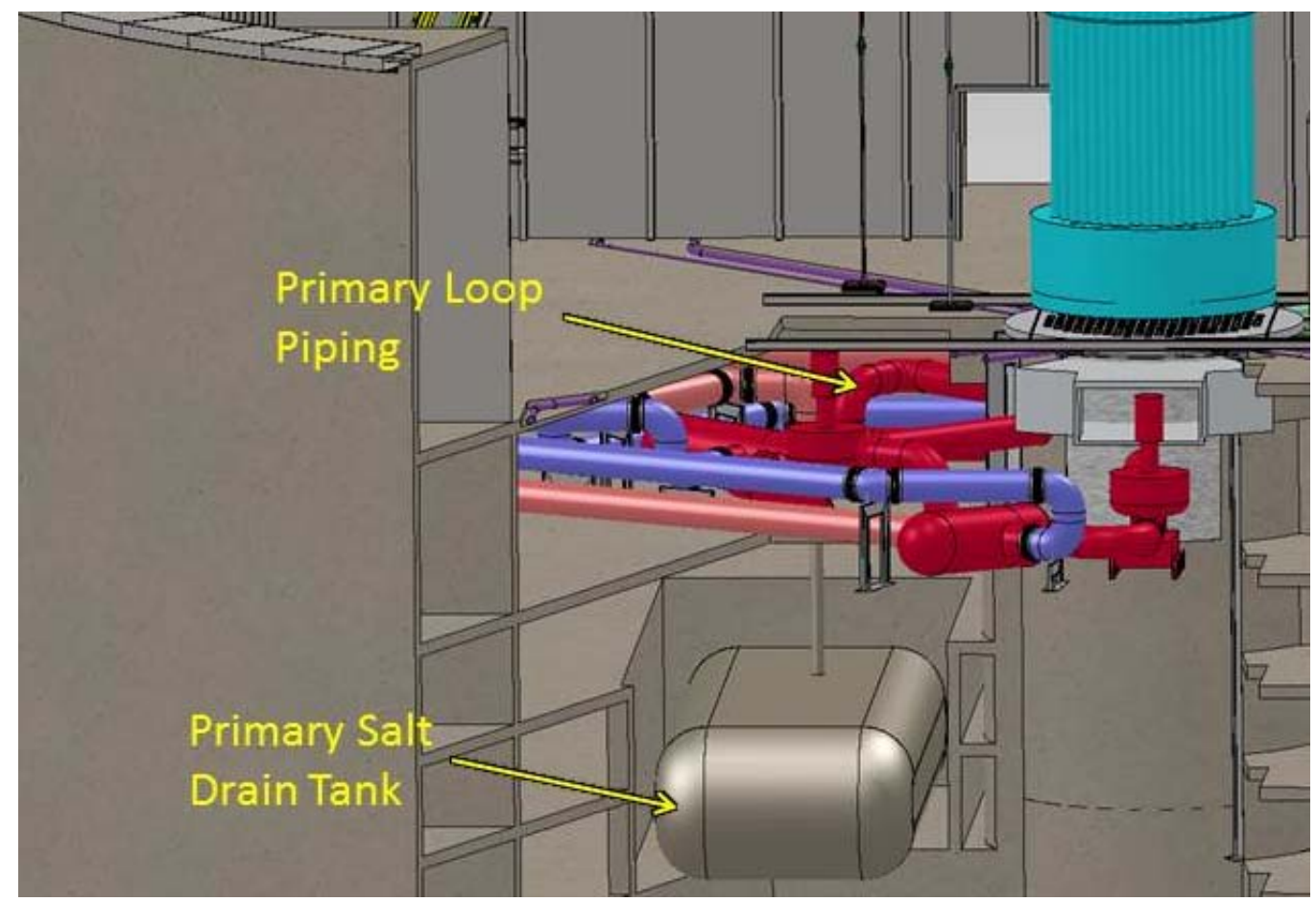

Fig. 66. Primary salt drain tank. 
The tank is fabricated from Alloy N. The tank will be heated and insulated to facilitate pumping the salt out of the tank to refill the reactor vessel.

The intermediate salt will not be FLiBe salt. It will be a less expensive salt. There are three intermediate salt flow loops. These are shown in Fig. 67.

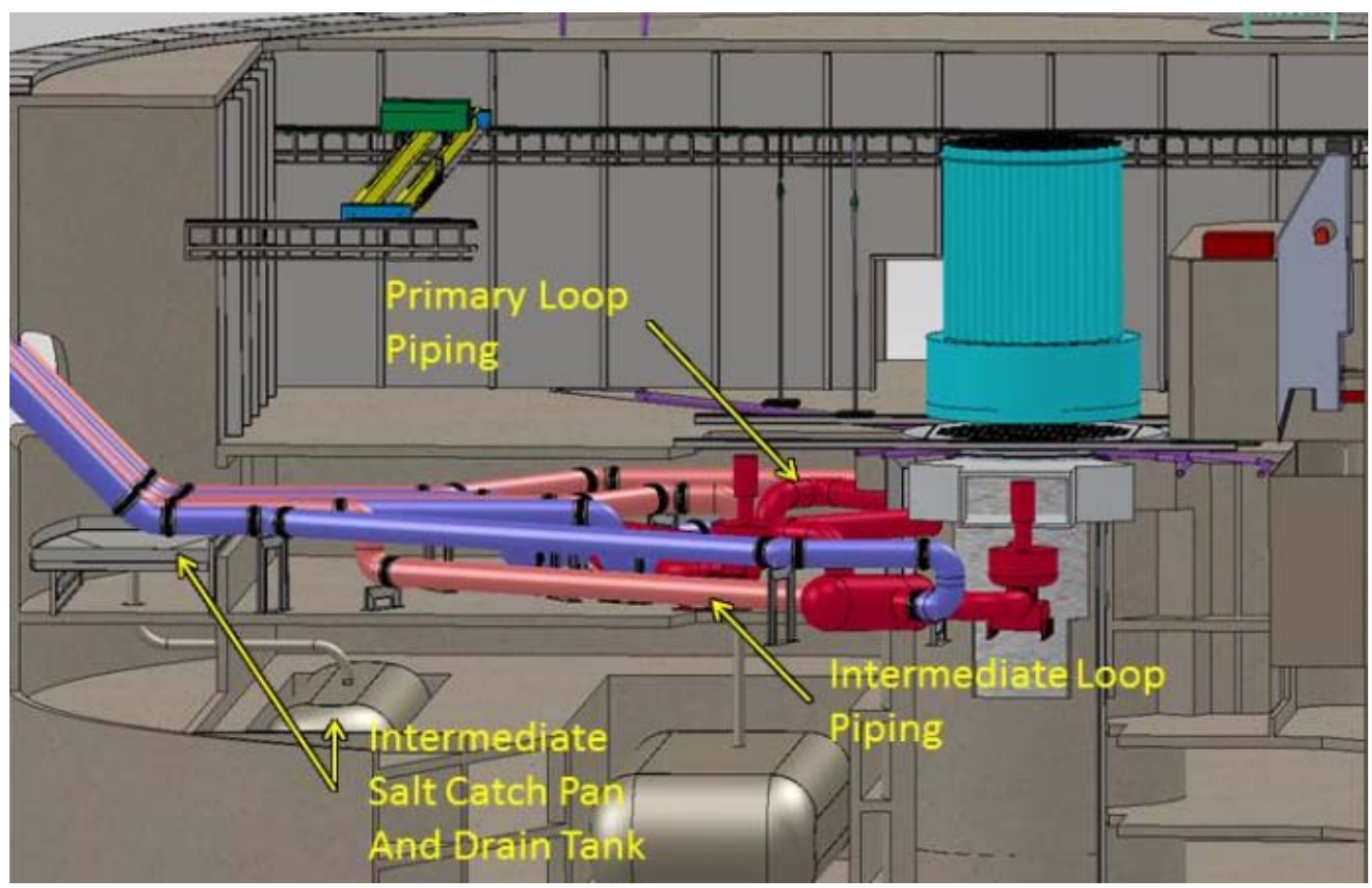

Fig. 67. Intermediate salt piping, catch pan, and drain tank.

The intermediate piping runs from the primary heat exchangers in the reactor building, to the steam generators in the steam turbine building. Seismic events may cause large relative motions of the intermediate piping. In particular, since the reactor building is on seismic isolation pads that can allow up to $1 \mathrm{~m}$ of lateral movement, the piping within reactor building, may move significantly relative to the intermediate piping outside of the reactor building. In order to prevent large forces on the intermediate piping from being reacted back to the primary loop heat exchangers, the intermediate piping is fixed to the reactor building at the perimeter of the building. That way, if lateral movement is severe, it will cause the intermediate piping to potentially rupture instead of the primary piping. If this happens, a catch pan and drain tank are provided in the preconceptual layouts which would catch the intermediate salt and contain it in case of rupture during this type of event.

The design incorporates bellows where there is relative movement between the pipes. The bellows are able to accommodate some relative movements between the pipes either due to differential thermal expansion or seismic events. The bellows prevent the forces being reflected back to the reactor outer vessel (Fig. 68). 


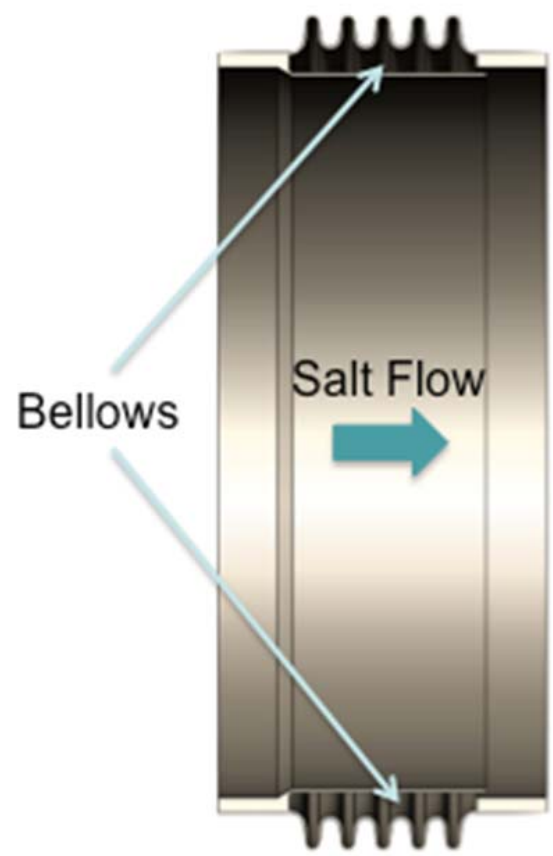

Fig. 68. Bellows design for the salt pipes. 



\section{REACTOR COOLING SYSTEMS}

\subsection{PRIMARY LOOP}

During normal operation, primary heat removal is provided by three primary coolant loops. The primary salt loops consist of the primary piping, the primary heat exchanger, and the primary salt pump. When the reactor is operating, the primary coolant FLiBe circulates from the reactor vessel, through the primary piping to the heat exchanger, then through the primary pump, and returns to the downcomer in the reactor vessel. This is shown in Fig. 69.

The hot coolant emerges from the core into the reactor vessel upper plenum. The mixed mean temperature of the upper plenum is limited to $700^{\circ} \mathrm{C}$ to limit the Alloy $\mathrm{N}$ hot leg temperature. Cooler core bypass flow (primarily from reverse [upward] flow through the fluidic diodes at the bottom of the DRACS heat exchangers) also mixes into the upper plenum. All of the components within or in contact with the coolant in the upper plenum before mixing are ceramic composites or refractory alloys (control blades). The core barrel includes a bypass flow into a cold leg temperature region surrounding the reactor vessel refueling lobe. The AHTR hydraulic design has received only very limited effort as of yet, and the key design details remain to be completed.

The inlet and outlet primary coolant piping penetrations are at the top of the AHTR vessel to avoid the possibility of draining the reactor vessel due to an external piping break. As seen in Fig. 69, the reactor hot leg pipes lead to the primary-to-intermediate heat exchangers (P-IHX). From the P-IHX, the cooler salt $\left(650^{\circ} \mathrm{C}\right)$ is pumped back into reactor vessel. To prevent this salt from mixing with the higher temperature salt at the top, the returning salt is directed through an annular downcomer region to the lower reactor vessel plenum (Fig. 44).

The primary heat exchanger is a tube-and-shell-type heat exchanger. The primary side of the heat exchanger is FLiBe salt, and the intermediate side of the heat exchanger is a cheaper salt. The primary loop components would be mounted on rollers, or slides to allow them to move with thermal expansion of the piping.

The primary pump is a cantilever-type pump, with the motor, bearings, and seals located above the pump rotor. The motor would be located such that the FLiBe salt level is below the motor, and could never be high enough to contact the motor components. 


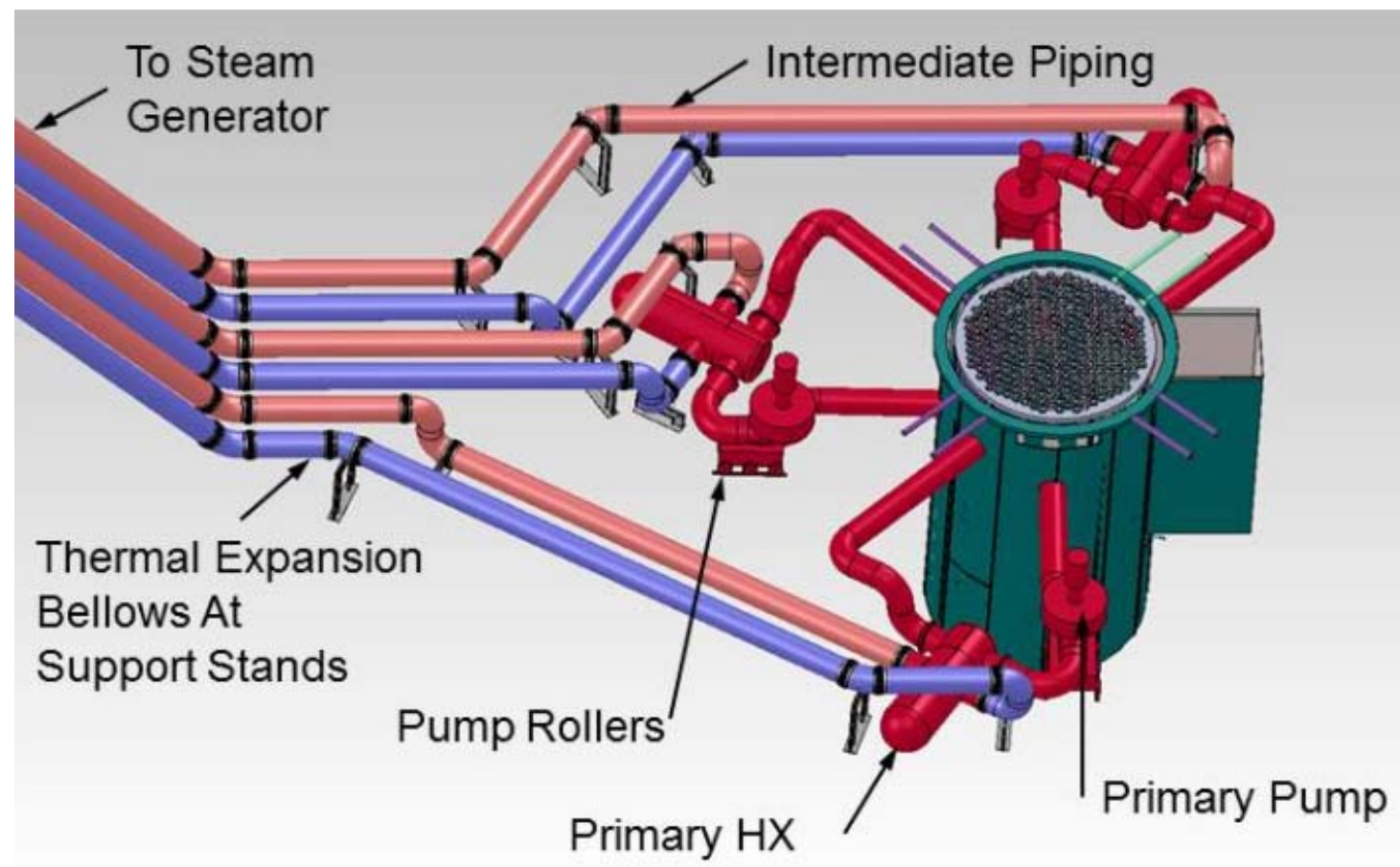

Fig. 69. Primary and intermediate salt cooling loops.

As the cooled salt flows back to the downcomer, it flows down to the area below the core. The salt flows up through the core, cooling the core and heating the salt. The salt then flows out of the reactor vessel from above the core and continues circulating through the primary loop again.

\subsection{INTERMEDIATE LOOP}

The intermediate piping, also shown in Fig. 69, runs from the primary heat exchangers to the steam generators in the steam turbine building. The intermediate piping is $1.24 \mathrm{~m}$ inside diameter, and the material is Alloy N. For the expected temperature differential, the pipes are estimated to expand approximately $2.5 \mathrm{~cm}$ per $3 \mathrm{~m}$ of length. To allow for thermal expansion, flexible metal bellows-type expansion joints are located as close as possible to the elbows, which are anchored on support stands. (Intermediate pipe guides may also be used for the straight sections to constrain expansion to the axial direction, although these are not shown in the figures.) This is a typical bellows arrangement that limits expansion in the axial direction for each of the sections of straight pipes.

\subsection{DRACS COOLING SYSTEM}

Decay heat removal is provided by modular decay heat removal loops known as direct reactor auxiliary cooling systems (DRACS). Three DRACS heat removal loops, each sized for $0.25 \%$ of full power, are provided. The DRACS cooling loops are shown in Fig. 70. 


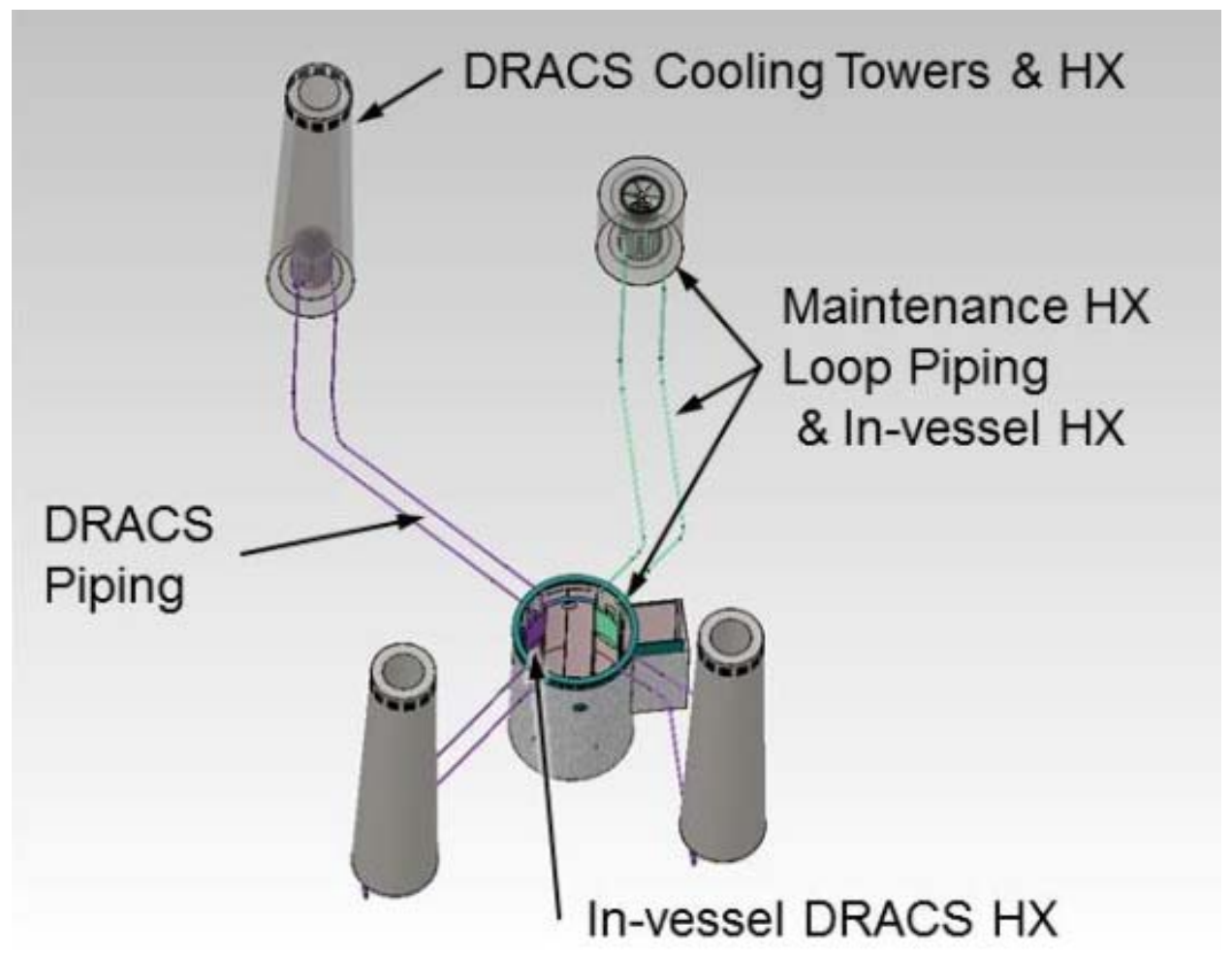

Fig. 70. DRACS and maintenance cooling loops.

The downcomer is segmented into seven regions by radial fins extending from the surface of the reactor vessel to the core barrel - three DRACS, three cold leg return flows, and one refueling lobe cooling flow. The lower vessel plenum where the cold salt is directed serves as a common manifold for the three primary inlet regions, the reactor core and three angular sections that house the fluidic diodes and DRACS heat exchangers. The DRACS heat exchangers are located slightly below the primary piping and thus do not become uncovered if the vessel is drained to the lowest surface of the primary coolant inlet piping. The downcomer annular section incorporates a siphon break at the top to prevent siphoning salt from the vessel in case of a piping break anywhere in the external loop.

The primary coolant pipes are $1.24 \mathrm{~m}$ in diameter. The hot leg reactor vessel penetration is above the DRACS secondary salt piping, and the cooled primary salt returns to the downcomer annular section. The DRACS sections are open at the top and are not completely sealed. DRACS heat exchangers are designed for removal from the top of the reactor during a major maintenance outage. The P-IHX heat exchangers are housed in a mezzanine level next to the reactor, reducing the complexity of access to the primary heat transport components.

The cooled salt in the lower reactor vessel plenum is directed through the core via a nozzle arrangement in the lower support plate. The nozzles direct cold salt between the fuel plates and ensure an even flow distribution among the fuel plates to prevent hot spots from forming in the reactor core due to uneven cooling. The hydraulic design for the lower core support plate has yet to be performed.

Each DRACS is designed to remove $0.25 \%$ of the reactor full power [ $8.5 \mathrm{MW}(\mathrm{t})]$ when fully functional. During normal operation the fluidic diodes limit the primary coolant flow through the DRACS heat exchanger. Both sides of the DRACS are designed to operate in natural circulation flow for decay heat removal. During normal operation, the fluidic diode below the DRACS heat exchanger limits the primary coolant flow. The restricted primary coolant flow is used to keep the DRACS secondary coolant salt from 
freezing. The DRACS secondary coolant salt is a $\mathrm{KF}-\mathrm{ZrF}_{4}$ eutectic mixture (53-47 mol \%) that does not contain lithium (to avoid contaminating the primary salt in case of a leak) and beryllium (to reduce toxicity).

The piping connects the in-vessel heat exchangers to the DRACS cooling tower heat exchangers, which are located a minimum of $16 \mathrm{~m}$ vertically, above the in-vessel heat exchangers in order to provide natural flow of the DRACS coolant salt due to density of the hotter salt in the reactor vessel relative to the cooler salt in the DRACS towers. The hotter salt naturally rises from the level of the reactor vessel, to the tower, and the cooler salt naturally descends from the DRACS tower back to the reactor vessel. Similarly the DRACS cooling towers provide natural air circulation to remove heat from the DRACS tower heat exchanger. The air that is heated by the heat exchanger rises, and pulls in cooler air at an inlet at the top of the tower, and flows down into the bottom of the heat exchanger to cool the salt.

The DRACS heat exchangers are interconnected to natural draft heat exchangers located outside the reactor containment in an air-cooled chimney. Since the DRACS cooling loops are closed loops, passive decay heat removal through the DRACS would still occur if primary coolant piping is completely sheared from the reactor vessel, avoiding the external piping having a safety role in providing decay heat removal. The chimneys for the natural draft heat exchangers are situated outside the reactor building in three separate impact resistant chimneys.

\subsection{MAINTENANCE COOLING SYSTEM}

The maintenance heat exchanger provides additional heat removal from the reactor when the reactor and the primary cooling system are shut down for planned maintenance. The maintenance heat exchanger loop is also shown in Fig. 70. The maintenance heat exchanger inside the reactor vessel is essentially the same as the in-vessel DRACS heat exchangers. The maintenance heat exchanger is located slightly below the level of the primary coolant outlet. The main difference is that the salt flow in the maintenance heat exchanger loop is forced convection, circulated by a pump during reactor maintenance. In addition, forced air circulation through a salt-to-air heat exchanger outside the reactor building removes heat from the salt, rather than natural draft air circulation. Because of forced convection, the maintenance heat exchanger removes significantly more heat removal than the DRACS heat exchangers, approximately $5 \%$, or $170 \mathrm{MW}(\mathrm{t})$.

\subsection{REACTOR CAVITY AND COMPONENT COOLING SYSTEM}

The design of the DRACS and the thermal shields interact and influence the required capacity of the Reactor Silo Cooling System. If the thermal shields were not in place, the vessel would lose perhaps as much as $15 \mathrm{MW}(\mathrm{t})$ to the Reactor Silo Liner during normal steady-state operation. The two thermal shields can reduce the heat loss below $5 \mathrm{MW}(\mathrm{t})$ and to even a smaller number if the surfaces can be coated or treated to maintain a low emissivity. Improvement, however, in the insulation between the vessel and the reactor silo means that less heat is lost parasitically during accident scenarios. Thus for identical reactor and DRACS systems, the system with less heat flow to the Reactor Silo will experience higher temperature excursions going through similar transient events. 
Figure 71 shows typical responses of the AHTR to an accident involving decay heat lost through the DRACS and through two thermal shields. In this example, the Reactor Silo Liner is assumed to be actively cooled to $27^{\circ} \mathrm{C}$. The heat lost to the Reactor Silo Liner in this case becomes an indicator of the cooling capacity that would be required to maintain that temperature if the temperature were not allowed to increase. In the scenario, the inner shield is heated to warm the reactor vessel to temperatures above the freezing point of the primary salt. Once above this temperature, the heaters would be used to maintain the temperature until the reactor can be started, which could be as long as several months for the initial startup. The amount of heat that must be supplied from the inner shield increases with higher heat loss to the Reactor Silo through the outer shield.
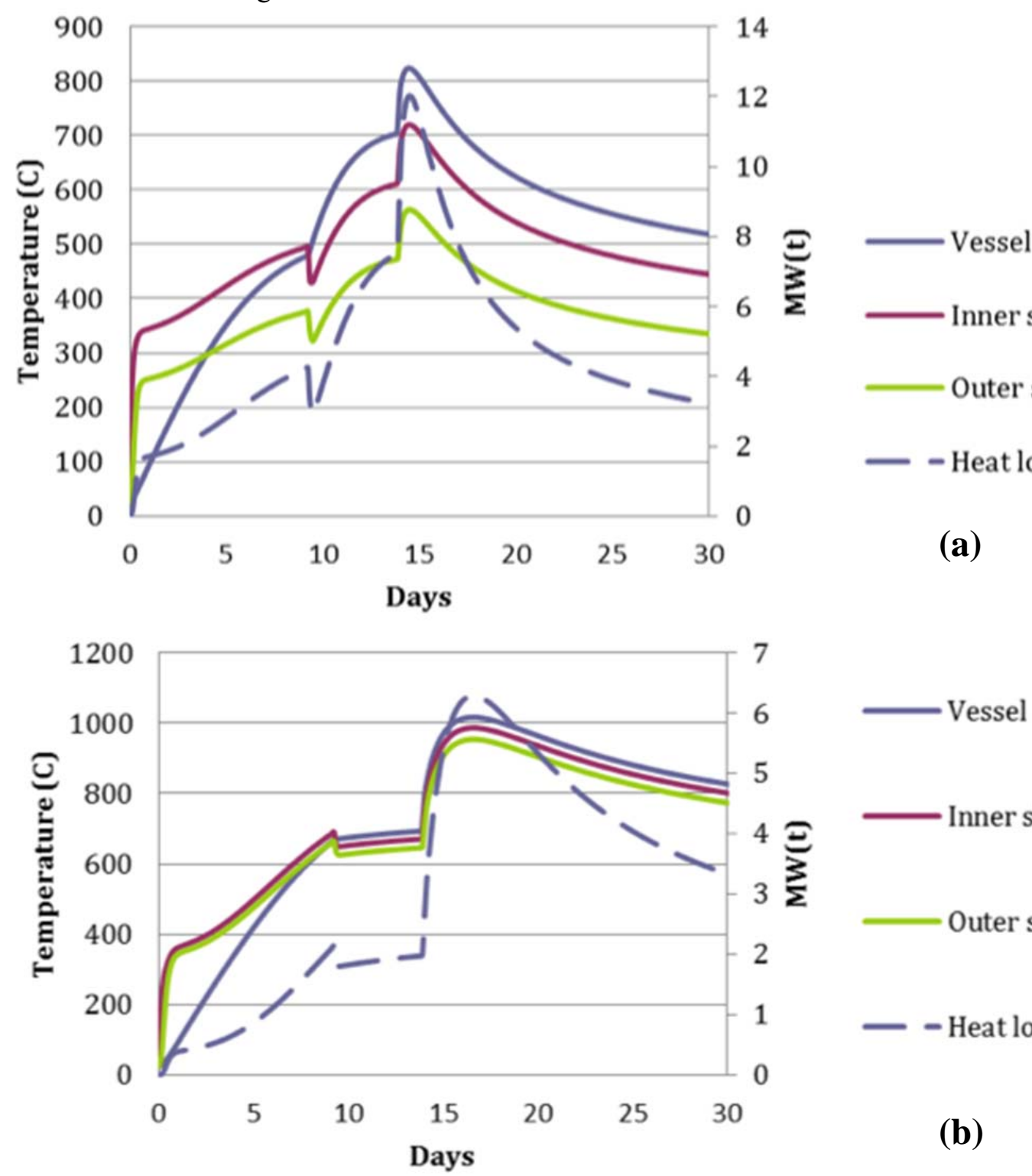

5

$4=\quad$ Inner shield (heated)

3

- Heat lost to silo

(a)

nner shield (heated)

uter shield (passive)

eat lost to silo

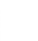

Outer shield (passive)

2

- Heat lost to silo

(b)

Fig. 71. Typical response of the AHTR vessel and shields to a loss-of-primary-coolant-flow accident: (a) high emissivity and (b) low emissivity.

Once the reactor is started and the heaters are turned off, the temperature of the reactor vessel increases above that of the heated inner shield. The vessel is shielded from the Reactor Silo Liner by two shields. The emissivities of the surfaces of those shields determine the amount of heat loss, and thus determine the 
amount of reactor power that must be maintained to keep the primary salt above melting temperature. In the top graph in Fig. 71, the outer shield is assumed to have a high emissivity, and the heat lost to the Reactor Silo Liner is higher. The temperature differences between the vessel and the shields are greater; the outer shield operates approximately $200^{\circ} \mathrm{C}$ below that of the reactor vessel. Under the assumption of lower emissivity surfaces, the heat loss from the vessel is lower and the temperatures of the shields are closer to that of the vessel.

Once the reactor vessel is at operating temperature, excess heat is taken from the primary system through the intermediate loops and the reactor vessel temperature is independent of reactor power. In an accident in which the primary coolant flow goes to zero, the reactor will be shut down and the fission power will quickly go to zero. The decay heat in the core is higher than that heat required to maintain reactor vessel temperature when the DRACS are not operational. Therefore, the temperature of the vessel will initially increase during a transient from full reactor power to decay heat levels with a loss of primary coolant flow.

For the case with higher heat loss to the Reactor Silo, the peak vessel temperature is lower during the transient. Thus, by increasing the effectiveness of the thermal shielding, the capacity of the Reactor Silo Cooling System can be decreased, but the DRACS system's capacity must be increased in order to keep the peak vessel temperature from increasing.

If power is lost to the AHTR plant, the passive safety features will cool the reactor. If the Reactor Silo Cooling system loses power, the temperature of the concrete in direct contact with the Reactor Silo Liner will increase. It is desirable to maintain the concrete temperature well below $100^{\circ} \mathrm{C}$ during all transients. If this is not possible, then an active RVAC system could be used to pull heat from the vessel and inner and outer shields before it could flow into the Reactor Silo Liner.

An issue with long power outages at the AHTR site is related to the fact that the primary, intermediate and DRACS salts will eventually approach their freezing points. With more effective thermal shields, the time until this becomes a concern is longer than it is with more effective shields. DRACS and RVACS systems can be shut down but the inherent heat loss through the thermal shields will remain.

The results shown in Fig. 71 are preliminary and approximate. However, they indicate that the required power levels for the inner, heated shield can range from 2 to $8 \mathrm{MW}(\mathrm{t})$ and that the peak thermal loads to the Reactor Silo Liner could range from 6 to $12 \mathrm{MW}(\mathrm{t})$. During warm-up and during transients the reactor silo temperature can be allowed to increase to reduce the power required in the heaters and the capacity of the Reactor Silo Cooling System.

Argon is a key component of AHTR operation. It is used as the overpressure gas in the reactor vessel and it is used as the fill gas between the primary system and the reactor silo structure. The reactor silo structure will be actively cooled. The currently baseline for this cooling system is to allow liquefied argon to flow and expand through piping structure embedded in the silo concrete structure. If an RVACS system is necessary, the argon in the thermal shield region could be included in the Reactor Silo Cooling System by opening a series of isolation valves. Thus the RVACS could be an extension of the Reactor Silo Cooling System. Because the heat loss from the reactor vessel is dominated by radiation heat transfer, the ability to produce and maintain low emissivity surfaces on the outer shield and the Reactor Silo Liner should be investigated.

\subsection{SECONDARY SHUTDOWN METHODOLOGY}

There are several possible techniques of providing diverse means of inserting an adequate amount of negative reactivity into the core to shutdown the critical fission reaction. However, as deploying the secondary shutdown mechanism implies that the primary control rod insertion shutdown mechanism has failed, a technique that does not involve insertion of a mechanical component into the core provides greater diversity. 
The secondary shutdown mechanism selected for the AHTR is the injection of a rare earth fluoride neutron poison $\left(\mathrm{EuF}_{3}\right.$ and/or $\left.\mathrm{GdF}_{3}\right)$ into the primary coolant. The most detailed information about the poison salt is given in ORNL/TM-2011/365 (Ref. 1).

One possible mechanism for injecting rare earth poison fluoride into the primary coolant would be to position cartridges of poison salt within the primary coolant in the downcomer region. An argon accumulator would be configured to drive a piston forcing the poison salt powder into the primary coolant once the cartridge is triggered. An Au-Sn braze with specific melting point (slightly above operating temperature) could be used to seal the cartridge. Heater wiring near the braze joint would enable operator triggering of the cartridge. Figure 72 shows a poison salt cartridge configuration.

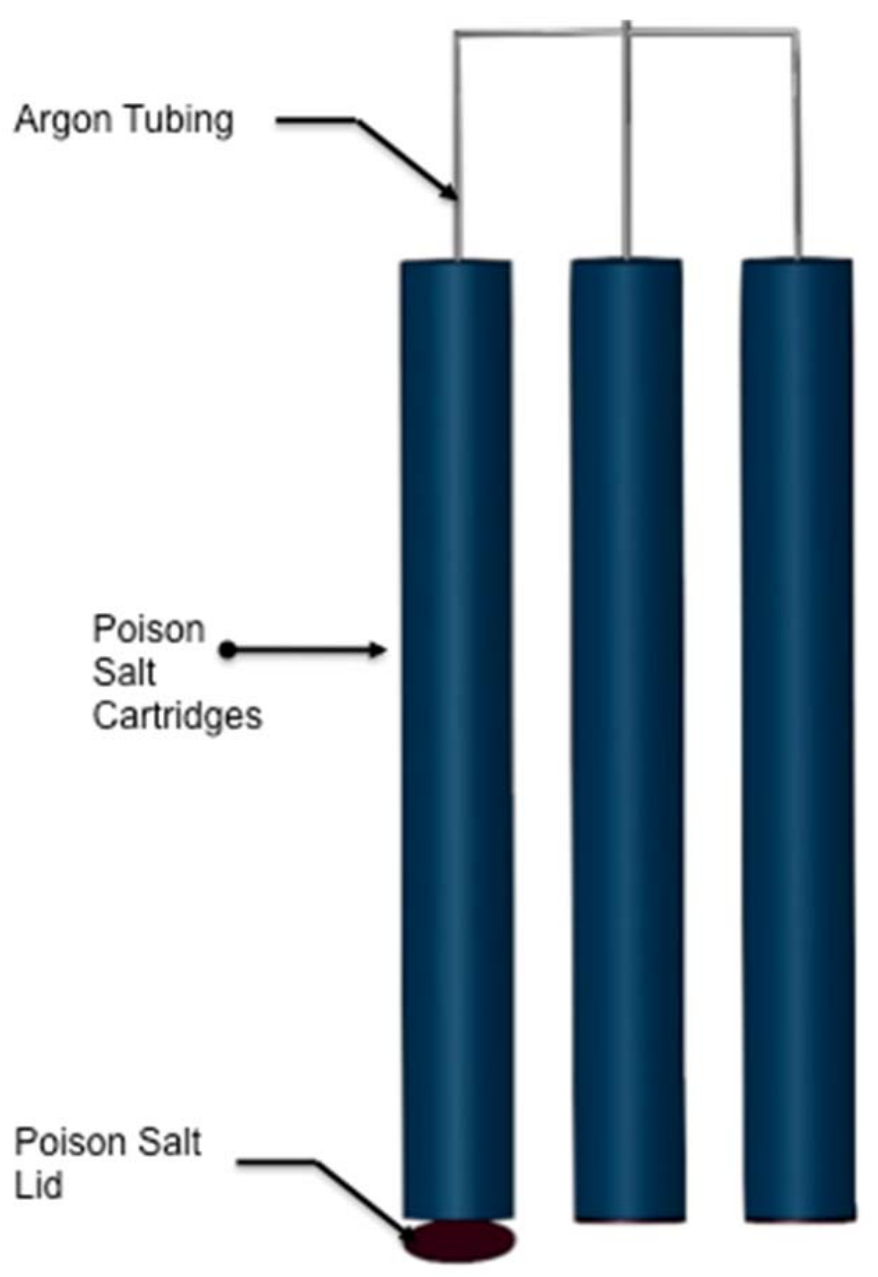

Fig. 72. Secondary shutdown poison salt cartridge configuration.

For the volume of salt used in AHTR, this translates to $1150 \mathrm{Kg}_{\text {of }} \mathrm{EuF}_{3}$. Due to the width of the downcomer region, three cartridges were required to accommodate $0.18 \mathrm{~m}^{3}$ of $\mathrm{EuF}_{3}$ necessary for shutdown of the reactor. 


\subsection{THERMAL BALANCE IN THE PRIMARY SYSTEM}

The AHTR primary coolant averages $675^{\circ} \mathrm{C}$ and the pressure vessel is a thin-walled structure. Heat will be lost from the vessel to the reactor silo structure surrounding it. The amount of heat lost during normal operation determines the nominal capacity of the Reactor Silo Cooling System.

The temperature of the concrete in the surrounding reactor silo structure must remain at some margin below $100^{\circ} \mathrm{C}$ to avoid damage due to vaporization of retained water. It is currently limited by design to $80^{\circ} \mathrm{C}$ during credible system transients. The temperature maintained during normal operation is the effective heat sink temperature of the vessel thermal system.

When the reactor is not operating, the reactor vessel is heated by a surrounding stainless steel wall that houses electrical cartridge heaters on the inner surface. The heaters are used to maintain the vessel above a temperature that will prevent salt freezing. The amount of heat required depends on the minimum vessel temperature, the temperature of the reactor silo, and the heat loss conditions between the two.

The reactor silo represents the ultimate heat sink temperature for the reactor vessel and it can be controlled through the use of a cooling system. The vessel surface is Alloy $800 \mathrm{H}$ and it operates at nominal temperatures of $675^{\circ} \mathrm{C}$. The heated shield, including the surfaces of the cartridge heaters facing the reactor vessel, operates at temperatures approaching $1000^{\circ} \mathrm{C}$ when the vessel is being heated externally. To avoid excessive heat loss from the heated shield and to therefore reduce both the required capacity of the electrically powered heater system and the cooling capacity for the reactor silo, insulation is required between the heated wall and the reactor silo liner.

A comparison of the heat lost by conduction through the argon and from radiation heat loss from the heated shield shows that radiation heat transfer is by far the dominant heat loss mechanism. The heat lost through conduction is negligible. Thus a radiation shield between the heated liner and the reactor silo liner is the most effective way to reduce heat loss and limit the required capacity of the system. Thus the baseline design for the reactor thermal shield is a heated inner shield, surrounded by an outer passive shield, both of which are contained between the vessel and the reactor silo liner.

To first order, the presence of the surrounding heated wall reduces heat flow due to radiation from the vessel to the reactor silo liner in half. The addition of the outer shield reduces the overall heat transfer to approximately one third of that for an unshielded amount. The gap between the reactor vessel and the reactor silo liner is approximately $45 \mathrm{~cm}$. Equally spacing the two interstitial structures would result in three $\sim 14-\mathrm{cm}$ argon-filled gaps and two radiation shields as the baseline reactor vessel thermal shielding system.

It is envisioned that the inner and outer shields would be a common concentric structure that provides additional strength to the thermal shield assembly. The gap between the inner and outer shield could potentially be filled with high-temperature insulation, but any insulating material will add mass, hinder inspection and be less effective than stagnant argon. Therefore, all three spaces between the vessel and the heated shield and between the heated shield and the reactor silo liner are baselined as being filled with argon and the space is assumed to contain structures that limit natural circulation within the spaces. Having argon trapped in these regions is also advantageous in the application of a Reactor Vessel Auxiliary Cooling System should such a system prove to be necessary.

Because the conduction heat loss path from the reactor to the silo is negligible, the number of thermal shields and the emissivity of those shields is the dominant factor in overall parasitic heat loss from the vessel. Also, because the thermal shields are essentially 4-pi shielding arrangements, the distances between shields do not affect thermal performance. The two thermal shields can be positioned within the gaps in whatever manner is best suited to installation, operation and maintenance.

Six surfaces exist from the outer diameter surface of the reactor vessel to the inner diameter surface of the reactor silo liner. The reactor vessel surface is essentially the same temperature as the primary coolant in 
flowing contact with the inner diameter surface of the vessel. For the AHTR this temperature is $650^{\circ} \mathrm{C}$ in the (lower) downcomer region of the vessel and it is $700^{\circ} \mathrm{C}$ in the upper plenum section. These temperatures and regions are essentially fixed source temperatures during normal operation. The reactor silo liner temperature is the sink temperature and it can be controlled. During warm-up it is allowed to increase to near the maximum allowable temperature (currently set by design to $80^{\circ} \mathrm{C}$ ) and during normal operation it is assumed to be controlled $27^{\circ} \mathrm{C}$, or near ambient temperature.

The emissivities of the six surfaces that comprise the reactor vessel thermal system determine heat loss between the source temperature (the reactor vessel) and the sink temperature (the reactor silo liner). Because the reactor vessel operates at high temperatures and is a 60-year component, it is assumed that the emissivity of the reactor vessel is (or will eventually become) a high value for stainless materials and that surface treatments will not be used. The same is assumed for the heated, inner shield which will operate well above the reactor vessel temperature during system warm-up. The outer shield's two surfaces and the reactor silo liner inner diameter surface are assumed to be treatable and maintainable in order to ensure a low emissivity over the life of the plant. The value of the emissivity that can be maintained on these three surfaces ultimately determines the overall heat loss from the reactor vessel to the reactor silo. 



\section{NEW AND USED FUEL BUILDING}

A separate building is provided adjacent to the reactor building to perform the functions of new fuel transfer to the reactor building, and used fuel transfer from the reactor building. The new and used fuel building is shown in Fig. 73. The reactor building floor level will be approximately $15 \mathrm{~m}$ below ground level, relative to the new and used fuel building. Elevators will be used to transfer the new and used fuel between the two buildings.

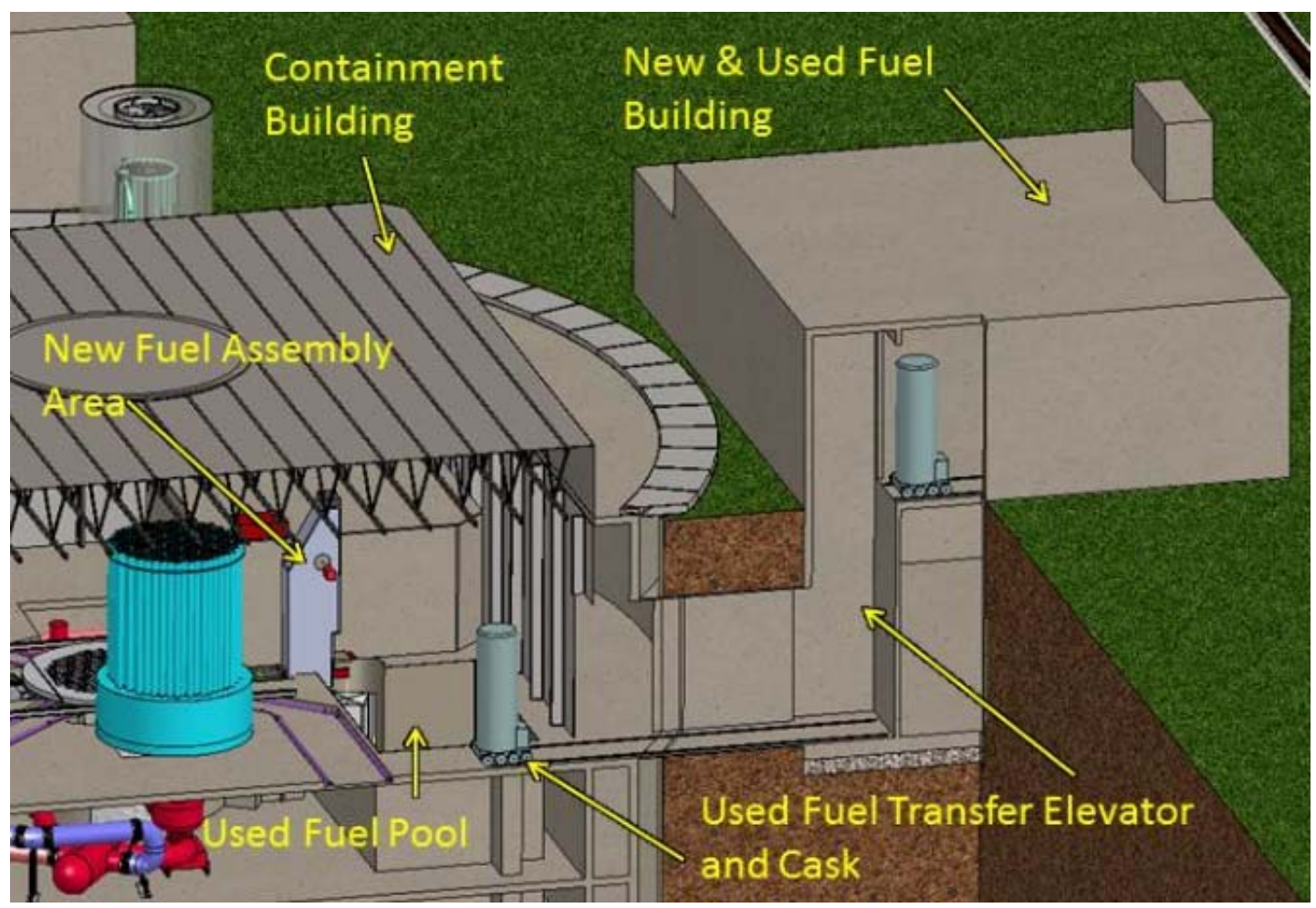

Fig. 73. New and used fuel building.

The used fuel assemblies will be maintained in an in-containment used fuel cooling pool for the next fuel cycle following removal from core (six months) and then transferred to local dry storage using a bottomloading used fuel cask. The used fuel storage pool is sized for storing one complete core plus a number of damaged fuel assemblies. The cask travels by rail from inside the argon containment building, through an air lock, and across the seismic isolation gap to the elevator in the new and used fuel building. It is moved from that building to storage in on-site dry wells. Each half-core is intended to be stored in a single local dry well. Each well will be $\sim 800$-m deep and $50 \mathrm{~cm}$ in diameter. The dry well will have continuous casing and cementing to prevent groundwater from infiltrating into the well. The silicon carbide containment layer within TRISO fuel is not water soluble, providing a backup radionuclide containment barrier if the well casing and cementing fail.

New fuel assemblies arrive at the reactor by rail and are manually inspected by personnel in the new fuel receiving building before being transferred to the New Fuel Assembly Area (NFAA). The new fuel assemblies each enter the reactor building on its own carriage and are brought down to the reactor level by an elevator. 
These carriages interface with the serpentine rail system at NFAA. The NFAA includes a double-door gas interlock entrance to enable transitioning to an inert atmosphere in the NFAA. The NFAA can provide either a dry air environment or an argon gas environment depending on the stage of the new fuel loading process. Once all 126 assemblies are loaded, the dry air environment inside this room is flushed with dry argon. The temperature inside the building is then raised to $1000^{\circ} \mathrm{C}$ to remove entrapped moisture within the graphite fuel elements that may contaminate the salt. After maintaining the temperature at $1000^{\circ} \mathrm{C}$ for a few days, the temperature is decreased to $650^{\circ} \mathrm{C}$. The fuel is inserted into the salt using an elevator which lowers the fuel into the fuel handling lobe of the reactor vessel. 


\section{REACTOR REFUELING}

\subsection{CONCEPTUAL OVERVIEW}

Designing a refueling scheme has several competing requirements. Plant availability is maximized by decreasing both refueling outage durations and frequency. Fuel cost is minimized by decreasing the number of fuel assemblies used, decreasing the fuel uranium enrichment, and increasing the uranium discharge burnup. The number of fuel assemblies required depends on both the fuel loading within the assembly and its enrichment. Also, the value of electricity can vary significantly both during individual days and seasonally, so outage scheduling is financially important. Significant additional fuel costs may also accrue if uranium requires enrichment beyond what can be supplied using current enrichment facilities. Coated particle fuel fabrication has not yet been scaled up to a continuous, industrial scale process. Consequently, accurate cost models for coated particle fuel manufacturing and used coated particle fuel storage/recycling do not currently exist. Therefore a good deal of uncertainty remains with current fuel-related cost estimates.

The dominant refueling consideration for the current design effort was to maximize the AHTR availability. A core design was developed that required less than $10 \mathrm{wt.} \%$ uranium enrichment and at least a six month refueling interval to match the seasonal demand minimums. A two-batch 9 wt. \% enriched refueling scheme was identified that meets the enrichment and refueling interval requirements. Multibatch fuel cycles enable the excess reactivity of the lower-irradiated fuel to offset a reactivity deficit of the more highly irradiated fuel. The resultant increased neutron economy can be utilized to either increase discharge burnup, reduce the uranium enrichment requirements, or a combination of both.

Additionally, the reactivity swing over an equilibrium fuel cycle will be decreased, reducing the negative reactivity worth requirements of the AHTR's control systems. The linear reactivity model predicts that the limit of discharge burnup in a multibatch fuel cycle can reach twice that of a single-batch fuel cycle. Increases in discharge burnup directly reduce the fuel cycle costs for natural uranium, enrichment, and fuel fabrication per unit energy produced. Limiting the enrichment requirements to less than $10 \mathrm{wt}$ \% ${ }^{235} \mathrm{U}$ is believed to enable the use of existing uranium enrichment facilities rather than having to build dedicated facilities.

\subsection{REFUELING MECHANICS}

The refueling steps are obtained by breaking the overall refueling task into a series of subtasks and analyzing the manipulator movement to accomplish the task.

\subsubsection{Preliminary Steps Before Refueling}

To begin the refueling process, the core is first taken subcritical by inserting the control blades. This stops the generation of fission power, and the decay heat begins to decline as the result of radioactive decay. Next, the coolant flow is reduced by slowing the primary coolant pumps. Since the force exerted by the upflow of the coolant salt on the fuel assemblies is relatively large (1.0 MT force in the current design), reducing the flow to a few percent of full flow greatly increases the handling ease. At $5 \%$ flow, the each fuel assembly the relative weight of each fuel assembly is about $1600 \mathrm{~N}$.

Fuel assemblies rest on the lower core support plate and are held at the top by the upper core support plate. Fuel assemblies are held down by three independent means: (1) weight of the assembly (including the control blade during refueling), (2) upper support plate, and (3) control rod guide tube. The density of the fuel assembly $\left(\sim 1.89 \mathrm{~g} / \mathrm{cm}^{3}\right)$ is slightly less than the density of salt, which is $1.95 \mathrm{~g} / \mathrm{cm}^{3}$. 
The heavy control blades will be left in the fuel assemblies during refueling to prevent the fuel assembly from floating upward in salt or from being carried away by the upward flow. The upper core support plate pushes against the hemispherical contacts on the fuel assemblies. The upper support plate provides lateral positioning of the fuel assemblies while also providing support against force exerted by the flow. The control blade guide tube is an annular cylindrical rod that holds down the fuel bracket (as well as guides the control blade into the fuel assembly) as shown in Fig. 74. The control blade guide tube is an integral part of the control blade drive mechanism and is removed when the control blades are removed from the reactor vessel.

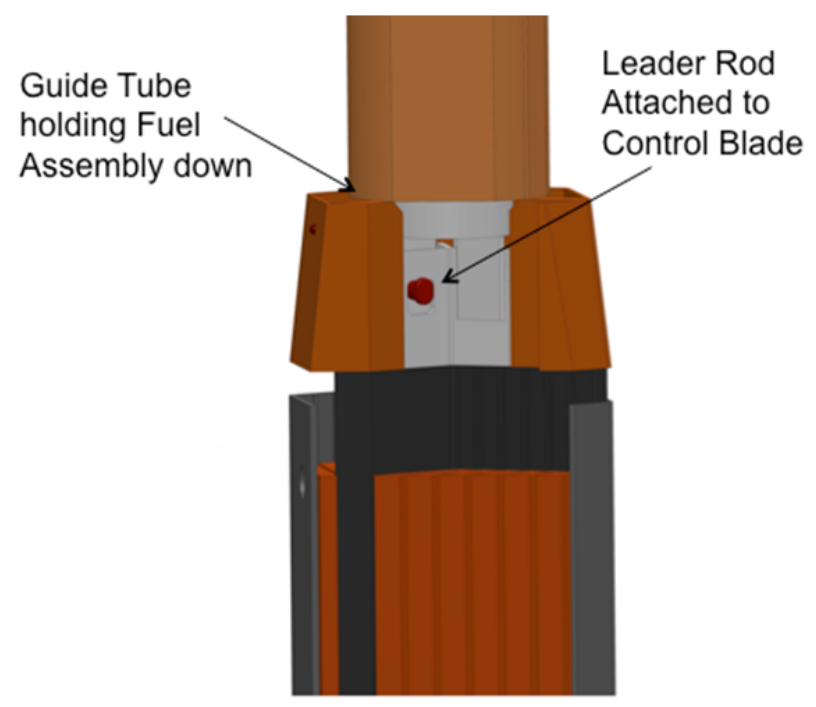

Fig. 74. Guide tube pressing down on the fuel assembly.

\subsection{REFUELING SEQUENCE OF OPERATIONS}

Every 6 months, 126 fuel assemblies are replaced with new fuel assemblies. The reactor is expected to be refueld in 2-3 days time. The outage of the reactor during refueling is minimized by the use of visually guided automated refueling manipulators. The new fuel assemblies are loaded into the refueling lobe. 
Refueling the AHTR involves the following steps.

1. All control blades are inserted into the fuel assemblies. Control blades are detached from the leader rods. (see Fig. 75).

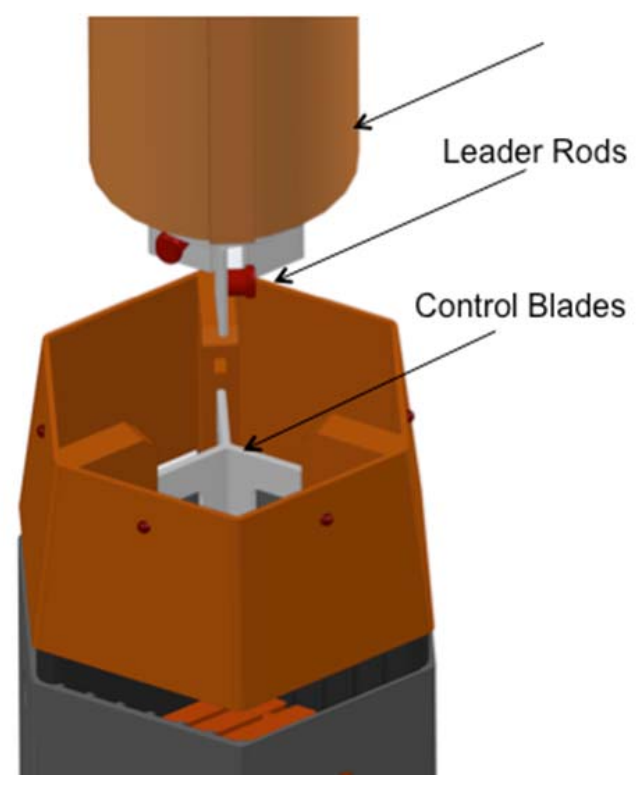

Fig. 75. Control blade detached from leader rod.

2. The control blade leader rods and guide tubes are retracted from the reactor vessel (Fig. 76).
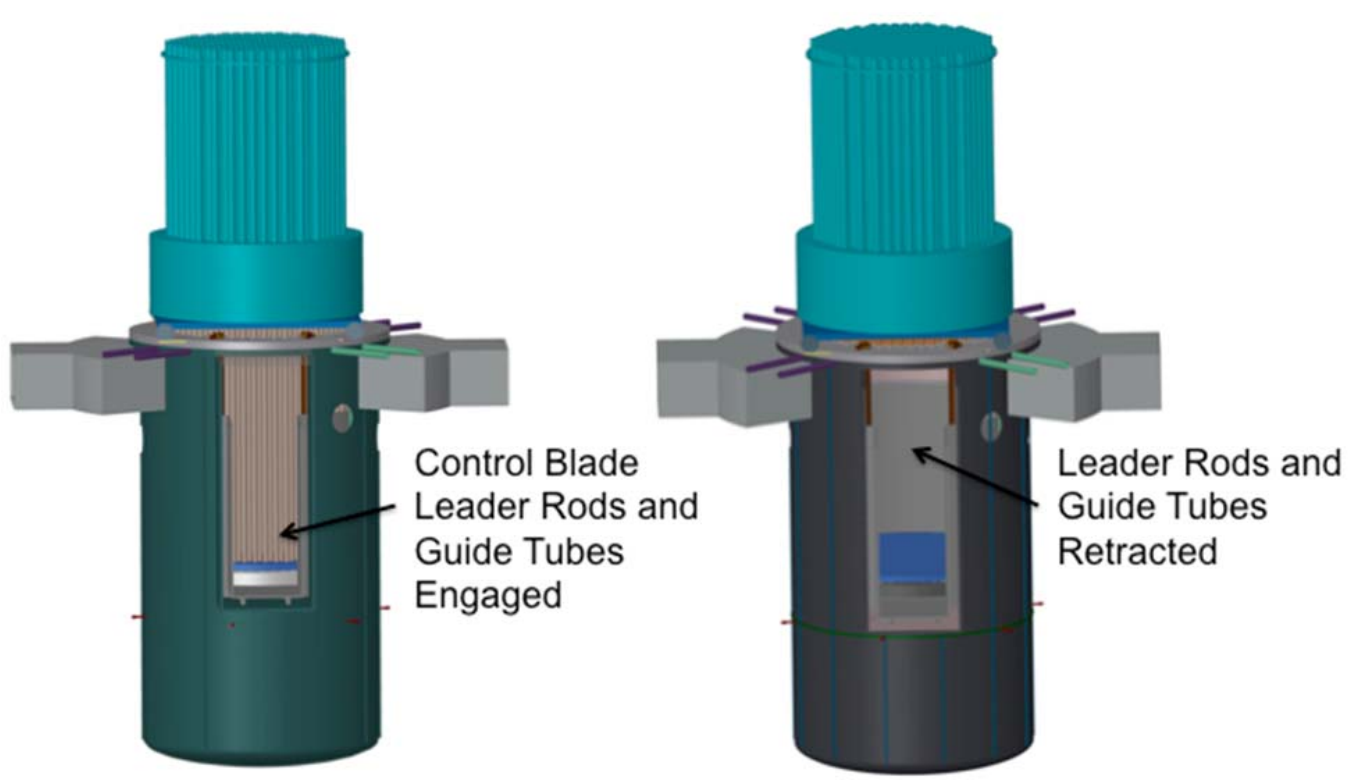

Fig. 76. Leader rods and guide tubes fully retracted.

3. The control blade flange with all the control blade drive mechanisms is translated laterally to provide a clear access to the top flange (Fig. 77). 


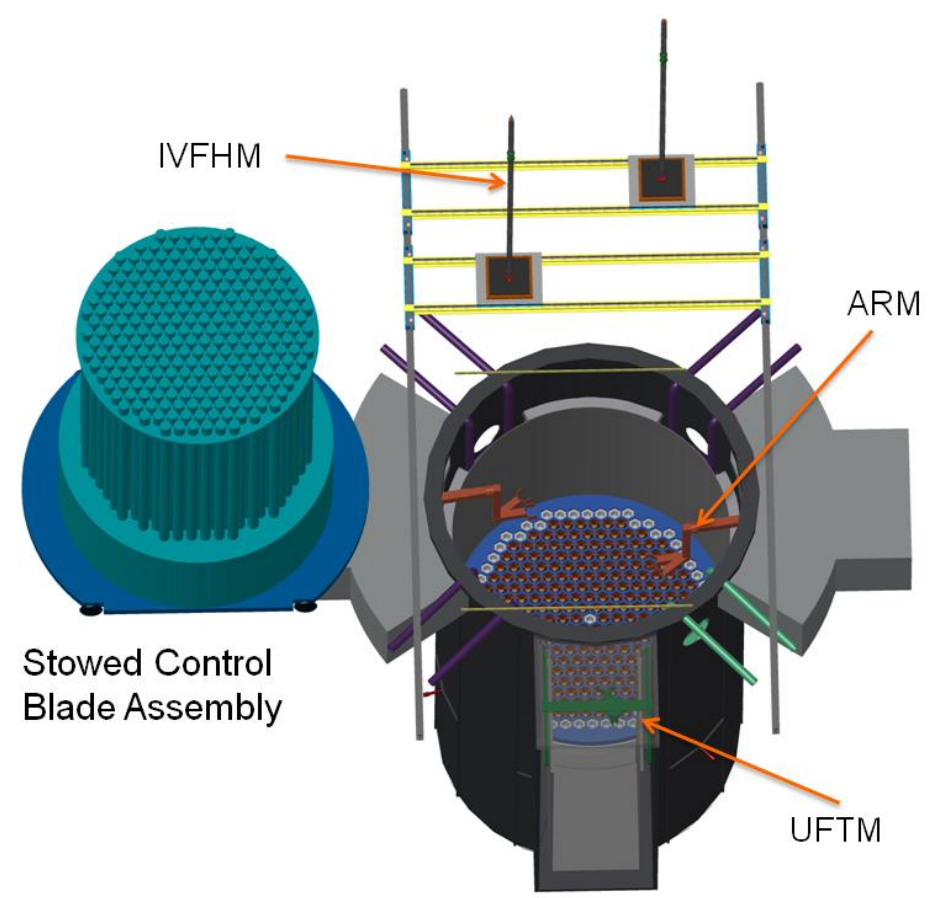

Fig. 77. Control blade assembly stowed to the side.

4. The ARM robot is positioned so that it is over the downcomer area and does not hinder the raising of the upper core support plate.

5. The primary coolant loop pump flow is reduced to about $5 \%$, or the maintenance cooling system is brought on-line (forced convection).

6. The upper core support plate is raised until it rests below the reactor top flange (Fig. 78 and 79).

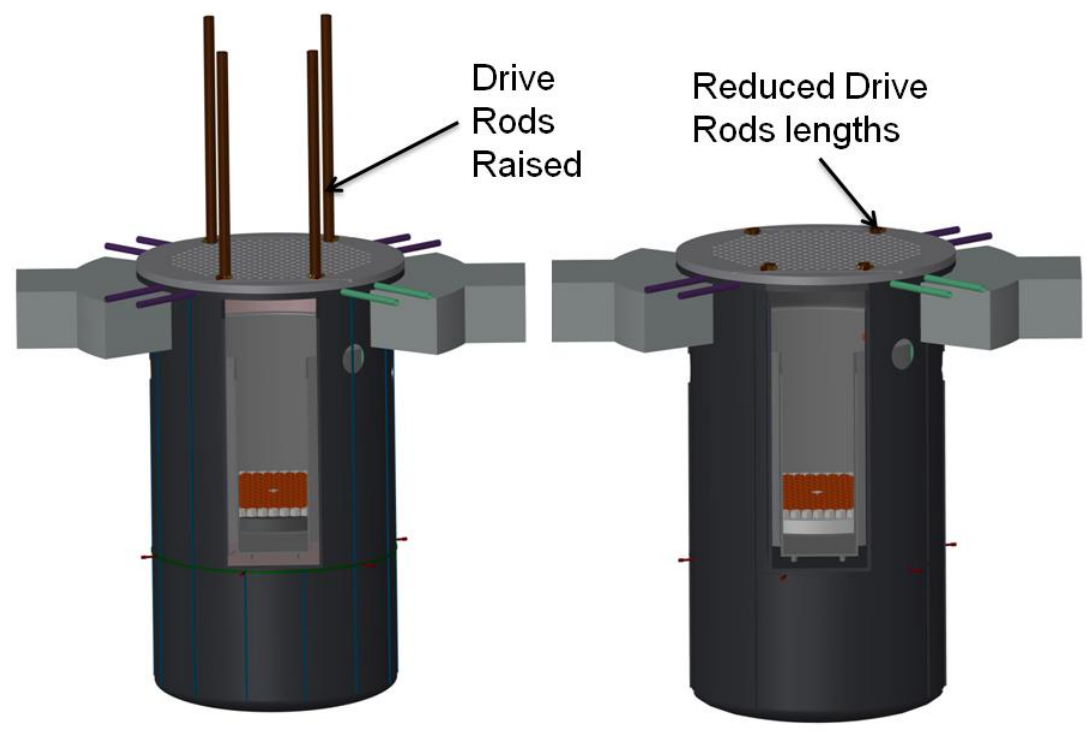

Fig. 78. The upper core support plate drive rods are raised bringing it next to the upper flange. 


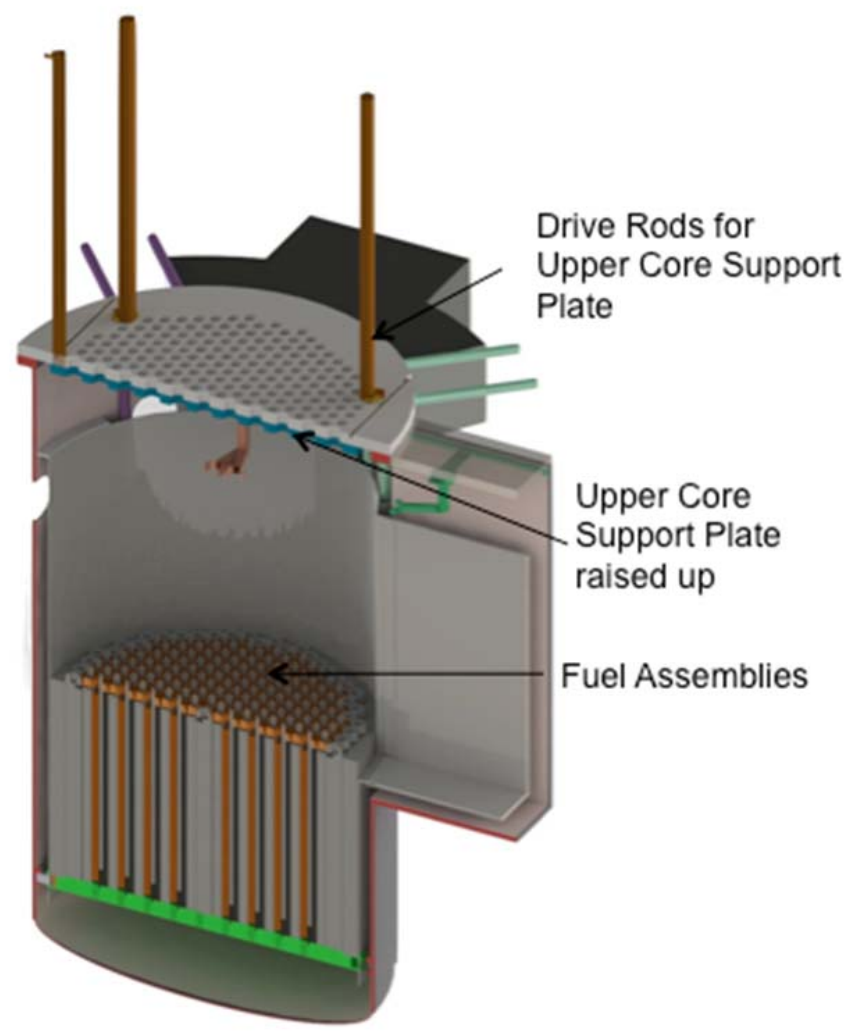

Fig. 79. Upper core support plate is raised allowing access to the fuel assemblies for refueling.

7. Since the drive rods stick out in the way of the IVFHM travel, the length of these rods have to be reduced. Using a twist lock mechanism, the lengths of the rods are reduced to allow for the IVFHM to position itself above the reactor (see Fig. 80).
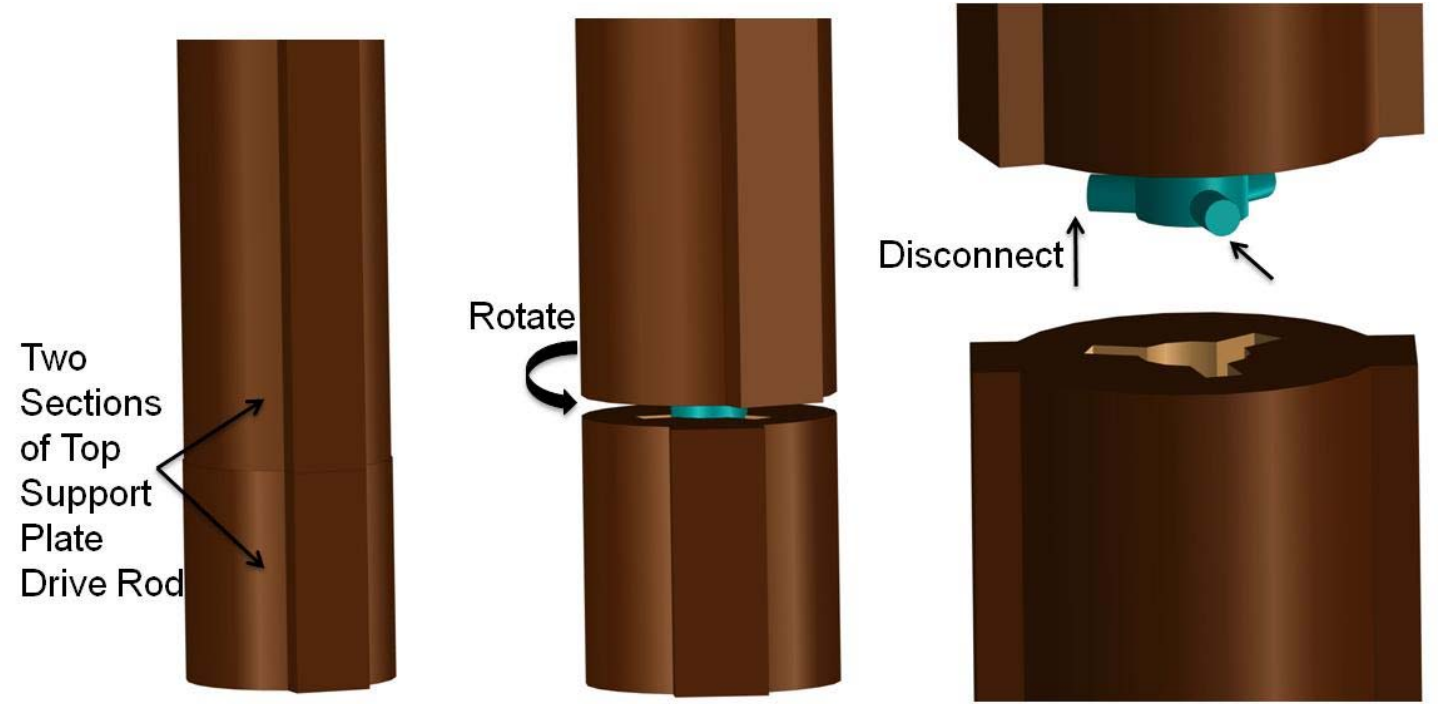

Fig. 80. The mechanism for shortening the upper core support plate drive motor. 
8. UFTM grasps a new fuel assembly from the new fuel assembly area and transfers the fuel assembly to ARM (see Fig. 81).

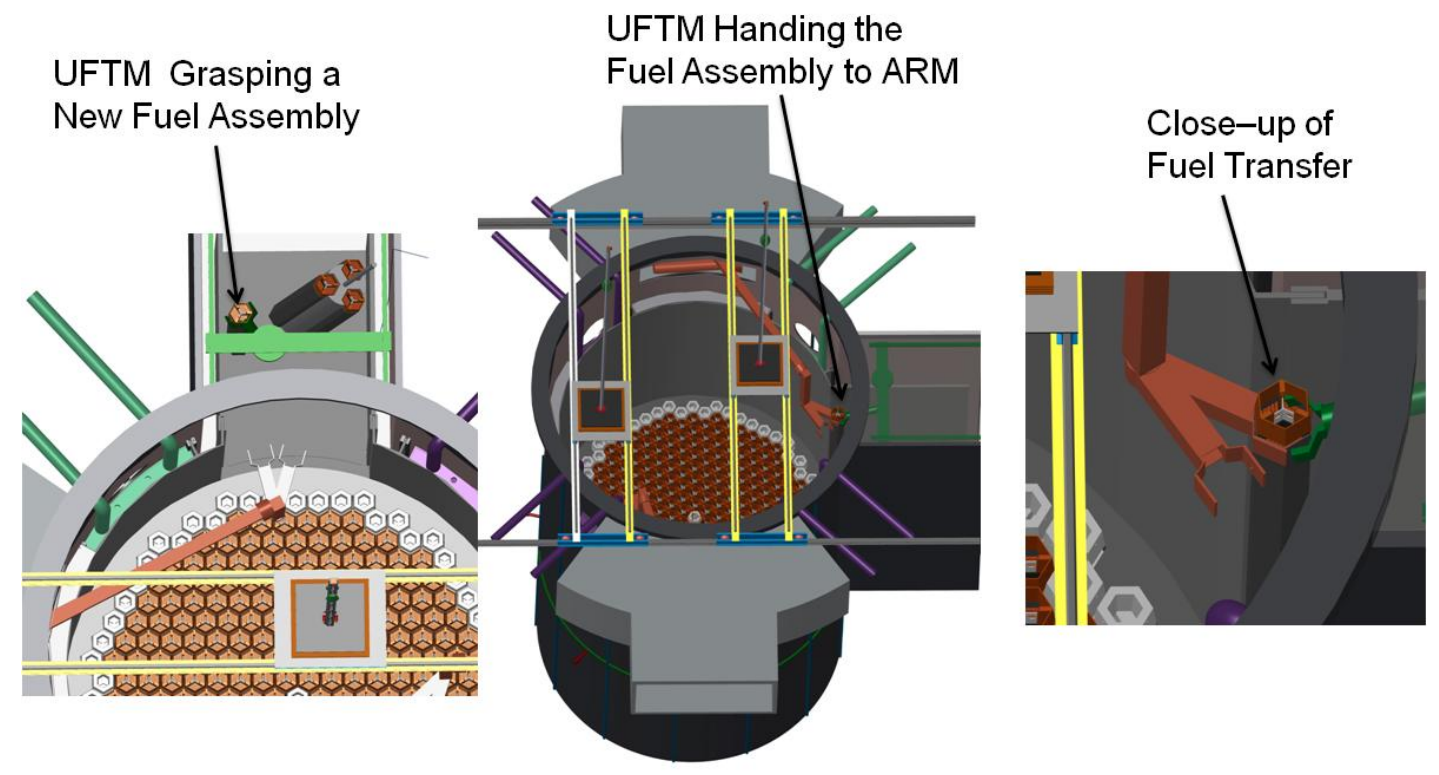

Fig. 81. New fuel sssembly transfer from UFTM to ARM.

9. The IVFHM is inserted in the region where the fuel assemblies are to be removed.

10. The IVFHM is lowered over the fuel assembly and grapples the fuel assembly. The design of the grapple allows for visual verification of the grasp (Fig. 82).

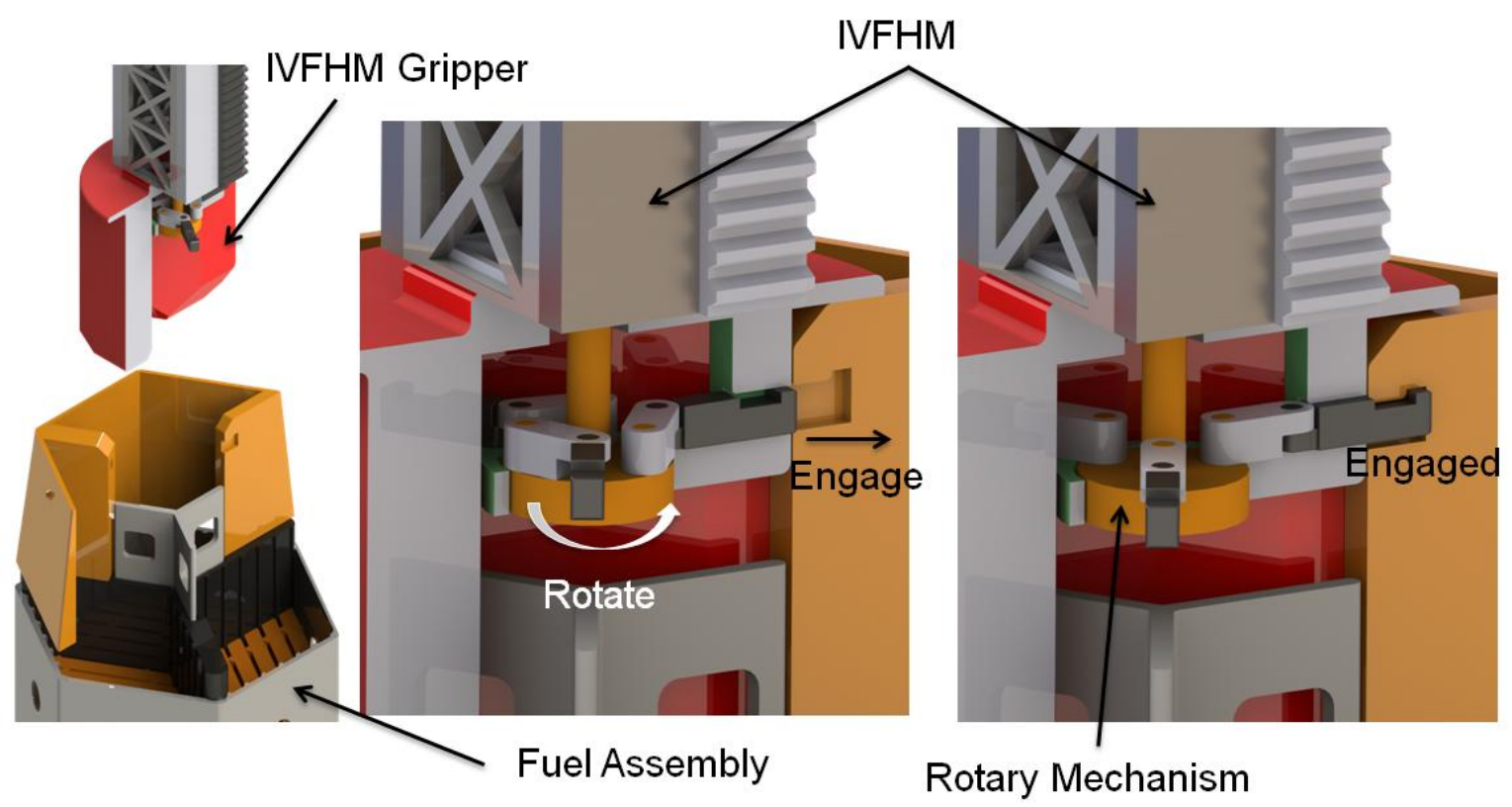

Fig. 82. IVFHM grasping the fuel assembly.

11. The fuel assembly is lifted out of the core, where it is within the reach of the ARM robot. 
12. The ARM robot already has a new fuel assembly at one of its grapple. The ARM secures the used fuel assembly on its other grapple while it is still held by the IVFHM (see Fig. 83).

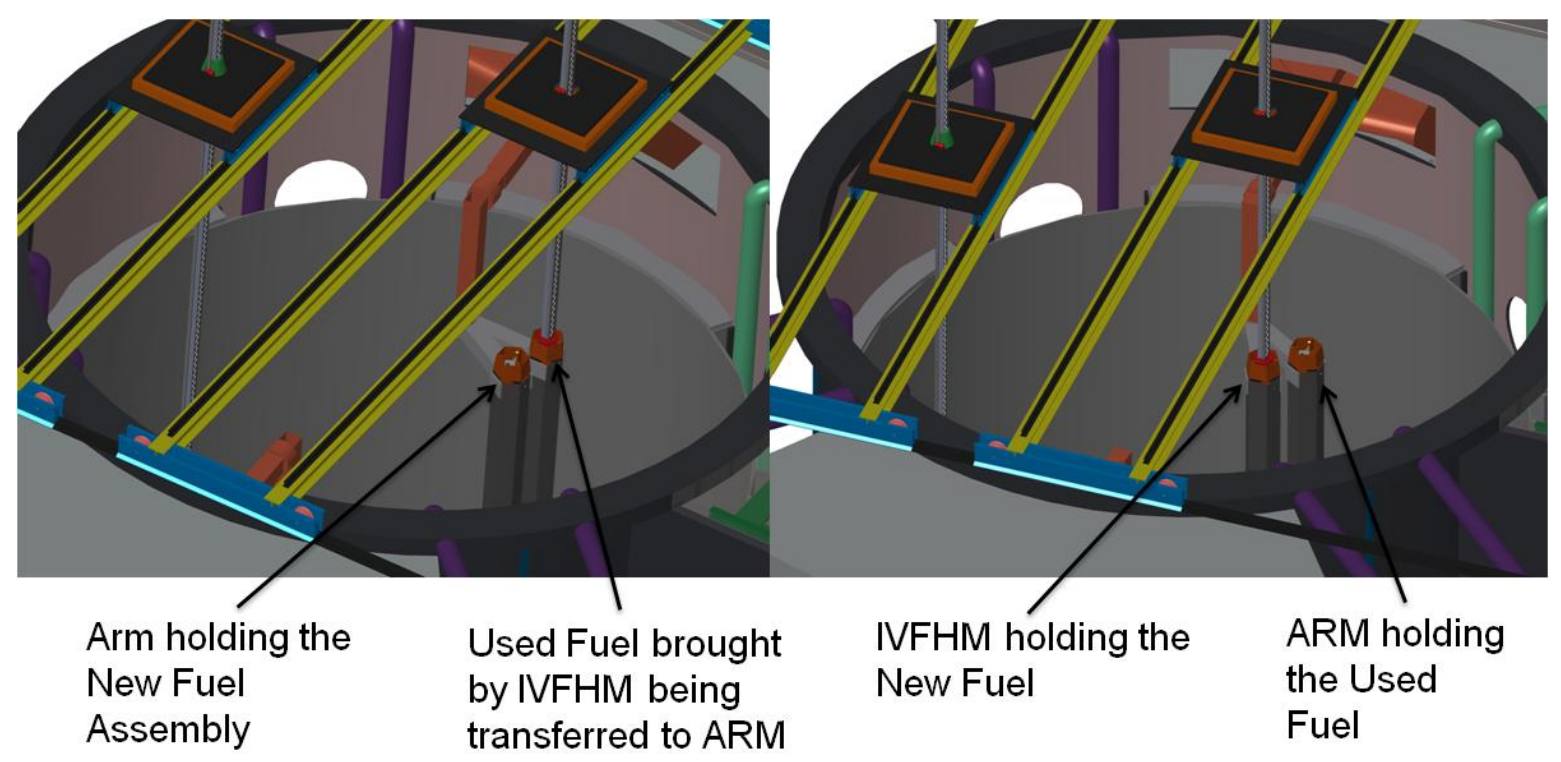

Fig. 83. Exchange of used and new fuel assemblies between IVFHM and ARM.

13. A mechanical actuation on the ARM provides visual confirmation about the integrity of the grasp.

14. The IVFHM releases the grasp on the used fuel assembly and translates upward about $0.5 \mathrm{~m}$. The ARM rotates the end-effector and indexes the grapple with the new fuel under the IVFHM. The IVFHM secures the grasp on the new assembly while the ARM is still holding it (Fig. 83).

15. The IVFHM lowers the new fuel assembly and positions it on the bottom support plate.

16. The ARM moves the assembly to the used fuel transfer area.

17. The UFTM grasps the fuel assembly while the ARM is still holding it (see Fig. 84). 


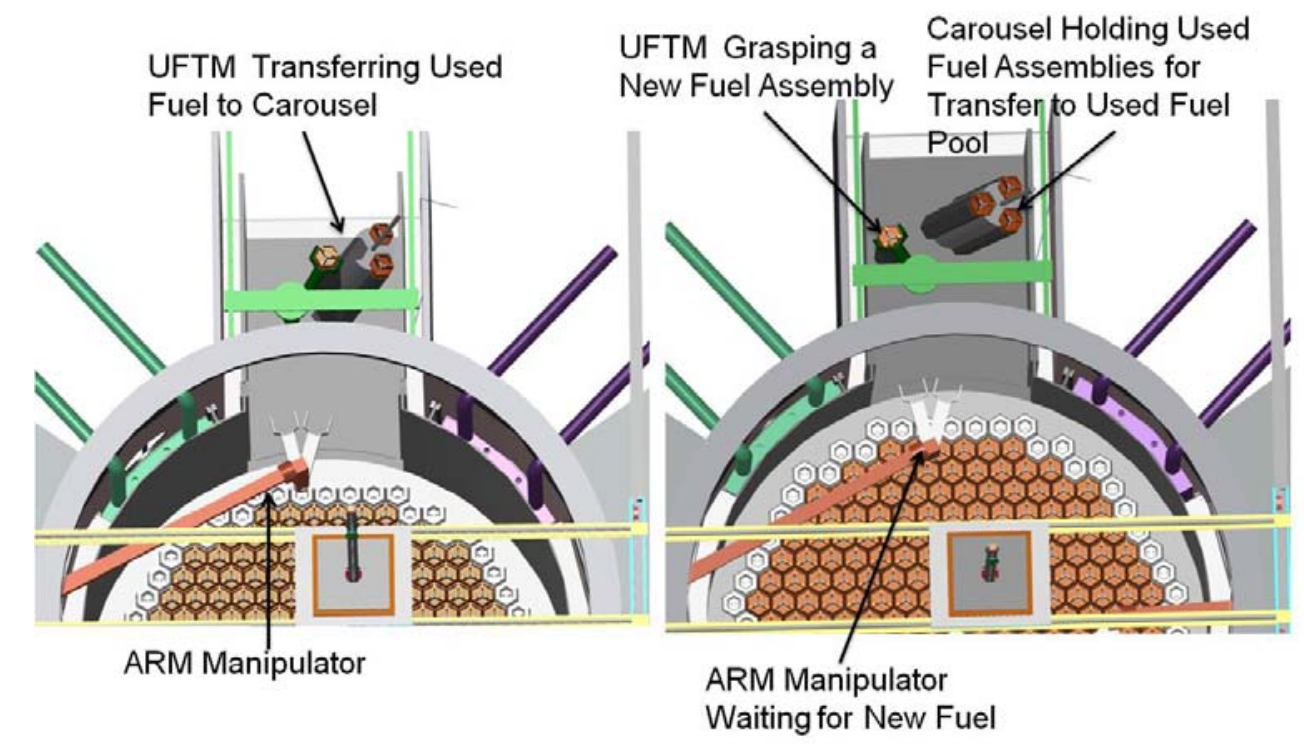

Fig. 84. ARM manipulator transfers the fuel assembly to UFTM. UFTM loads the fuel in the carousel. UFTM then obtains a new fuel assembly.

18. Again, a mechanical visual cue is used to ensure that the grasp by the UFTM is secure before the ARM releases the fuel assembly.

19. The used fuel assembly is then placed onto a carousel at the used fuel transfer area. A separate winch mechanism grasps the used fuel and transfers it to the used fuel transfer canal on its way to longer-term storage pool.

20. The UFTM grasps a new fuel assembly from the new fuel loading platform. A new fuel assembly is loaded onto the salt pool every time the UFTM grasps the new fuel already in the used fuel transfer area (see Fig. 84).

Overall, fuel reloading is an optically guided, mechanical transfer process. Fuel movement is a critical path item for restarting the reactor, and as such, a fully automated system is being developed to maximize transfer speed. The largest challenge to the transfer system design is the requirement to keep all of the sensors and electronics in cooled regions above the salt surface. The mechanical elements grasping the fuel are roughly 10-m long, increasing the required directional precision of the mechanical elements. However, the fuel assemblies are intended to reduce the required machine precision by use of mating elements that have self-aligning features.

The area above the reactor vessel upper flange is both inert and contaminated with both $\mathrm{BeF}_{2}$ and tritium. As such, it is intended that fuel handling be entirely automated. The plant operators will, thus, be in an oversight supervisory role with a primary responsibility to respond to machine or instrument failures or incorrect operation (i.e., ensuring that the system actually replaces the fuel assemblies intended during the current outage). The fuel is transferred between different manipulators inside the reactor vessel. During each such transfer, once a secure grasp is obtained, the system will wait for the operator input to proceed to the next step. This ensures a verification of the integrity of the grasp during every critical fuel assembly transfer.

While plant staff can enter containment with proper protective equipment to perform major or unanticipated maintenance actions, they do not enter the containment during a normal refueling outage. The refueling mechanisms are planned to be retracted out of the containment boundary for anticipated maintenance procedures. 
While the reactor is operating, the vessel interior temperature will be $\sim 650^{\circ} \mathrm{C}$ and the core temperature above $700^{\circ} \mathrm{C}$. The combination of the Cerenkov light emission and the thermal emission is anticipated to provide adequate lighting for power imaging. However, during refueling additional lighting will likely be required. The current design concept is to illuminate the vessel interior using relay optics that also provides optical access for the cameras. This lighting will be at the outer rim of the top cover flange.

Removing the in-vessel, fuel hold-down mechanical structures also provides improved optical access to the fuel that is not being replaced during an outage. While sufficient information about the anticipated mechanical changes to fuel assemblies during operation is not currently available, if necessary, imaging systems can be placed within the control blade holes in the control blade flange (Fig. 85) and used to observe the mechanical condition of the fuel assemblies that remain in the core.

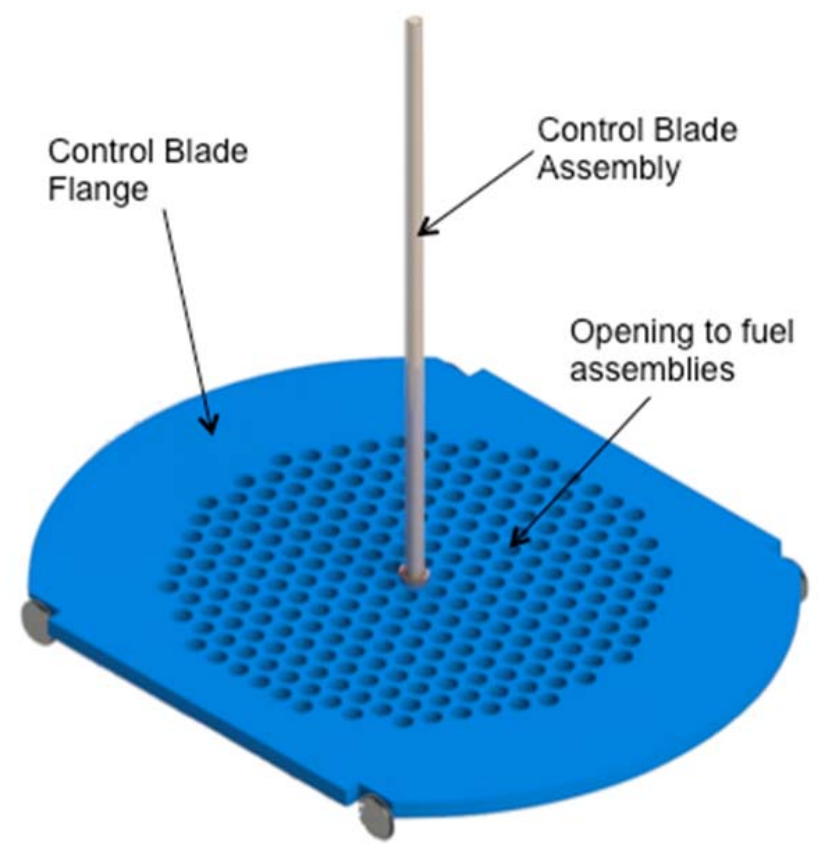

Fig. 85. Control blade flange with a single control blade drive mechanism retracted.

The grappling mechanism for used fuel transfer uses a winch for lifting fuel out of the refueling station. Once the fuel is lifted, gravity causes the fuel to swing in a pendulum-like motion to the used fuel transfer chute, and the winch then lowers the fuel to the head end of the used fuel transfer canal. During this transfer, the fuel is outside the salt and can heat up. The heat capacity of an AHTR fuel assembly is roughly $1.38 \mathrm{MJ} / \mathrm{K}$, and the freshly shutdown heating rate of a fuel assembly is roughly $1 \mathrm{MW}$. Thus, without any cooling, a fuel assembly will heat up at about $44 \mathrm{~K}$ per minute. By limiting the coated particle fuel peak temperature to $1250^{\circ} \mathrm{C}$, to maintain a large margin to fuel damage under normal conditions, and assuming that the fuel peak temperature shortly after shutdown is $\sim 800^{\circ} \mathrm{C}$ yields a maximum time without cooling of $8.5 \mathrm{~min}$. As $1-2 \mathrm{~min}$ is a reasonable period in which to transfer a used fuel assembly from primary to storage salt, fuel handling has a transfer time margin of several minutes.

By using a wedge-shaped used fuel transfer weir (as has been used in liquid metal reactors ${ }^{18}$ ), the fuel is always maintained over coolant salt. If at any time the fuel transfer mechanism does not function properly, the fuel can be released to slide back into coolant salt and thereby to resume passive cooling. 


\subsection{INSTRUMENTATION DESCRIPTION}

The primary salt is transparent. All of the grasping and positioning actions can be confirmed visually provided optical access is available above the pool, and cameras are provided at the proper locations. Views of the vessel interior will be provided to both the operators and the control system via relay lenses located around the periphery of the top cover flange. The optical system design concept is at a very early phase. As such, only a conceptual outline is currently available.

It is also desirable to observe the narrow coolant flow channels within the core during operation. The Cerenkov light emerging from between the fuel plates will be indicative of the local power generation. Observing the core from above also allows the degree of mechanical warping of the fuel to be observed. Consequently, additional relay lens systems will also be aligned directly above the core in the control blade flange to allow observation into the fuel channels. Additionally, since the upper core elements have high emissivity; their thermal glow will be indicative of the local coolant temperature, avoiding the need for wired temperature measurement. Overall, the camera systems will be the key to refueling and beneficial to power operations.

Observing the refueling process requires overcoming several design challenges. The interior surface of the top cover flange and control blade flange are at elevated temperature. While the flange temperature will be lower than that of the salt due to argon flow in the region above the pool, the optical elements within the flange will need to accommodate elevated temperatures. The current phase of the design envisions only relay lenses in the top flange with cameras located above the vessel in a controlled environment.

Optical alignment will change as the core expands and contracts with temperature. Cameras will have to automatically reposition to accommodate changes in the location of the relay lens.

The salt surface will include ripples as the salt flows. The rippling will need to be removed computationally to enable accurate imaging of the components.

$\mathrm{BeF}_{2}$ will evaporate from the salt surface and deposit as a polycrystalline film on cool surfaces, rapidly clouding lenses. The first surface lenses will need to be heated, mechanically cleaned, or otherwise protected from condensation.

Apart from the optical system, the other sensor system required in the motion system will be limit switches employed as backup sensors for the handling mechanisms while positioning over the fuel assembly. Flux measurement sensors will be incorporated into a limited number of core positions. The electrical signals from these sensors will be routed along a cable tray accompanying the control blade flange. All drive motors will incorporate torque measurements to prevent inadvertent accidental breakage or failure. When the motors are experiencing greater-than-anticipated torque, the work will be stopped to investigate the issue under human supervision. 


\section{LONG TERM FUEL HANDLING AND STORAGE}

Fuel assemblies are intended to be stored in local dry wells for the life of the reactor site. Local dry wells consist of a borehole roughly half a meter in diameter to accommodate stacking the fuel assemblies from a single reload into a single hole. The hole will be cased with steel pipe and cemented to prevent water ingress. The top of the hole will be capped with a concrete plug. A first fuel assembly deployed into a borehole is illustrated as Fig. 86.

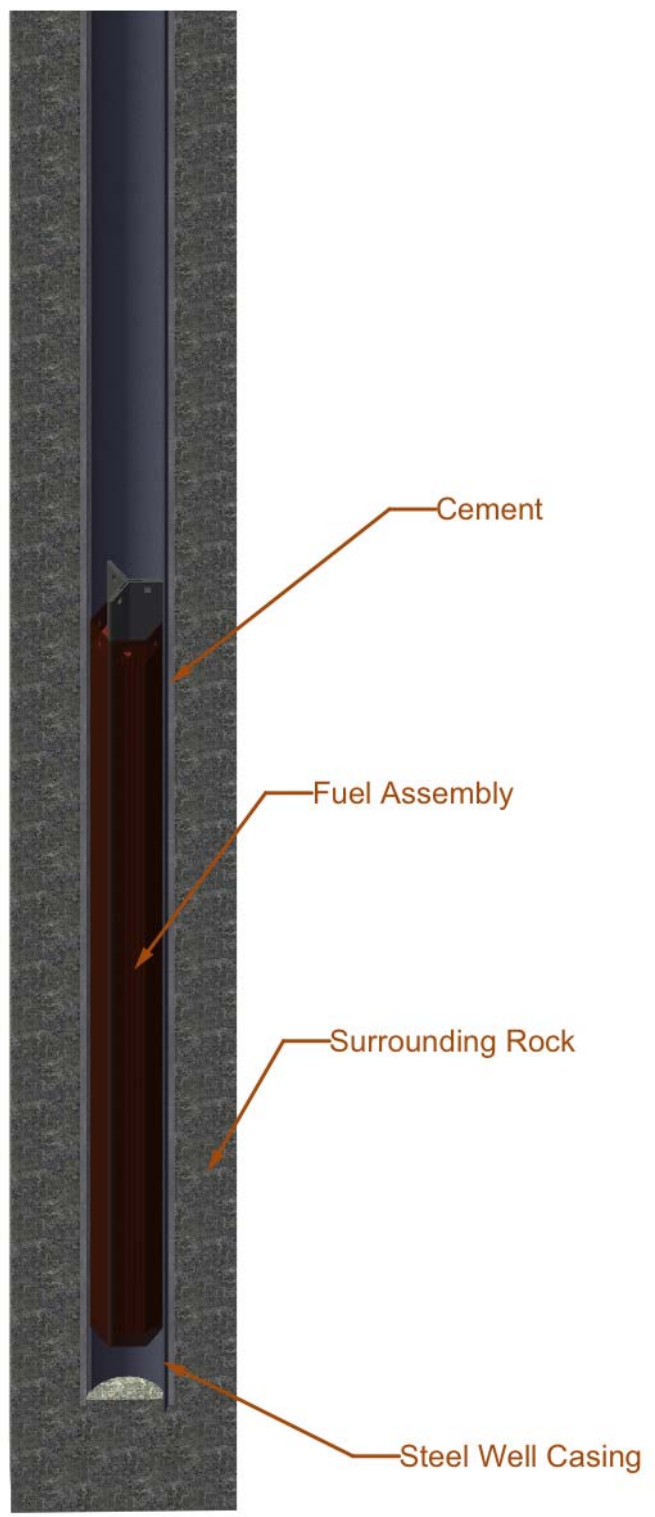

Fig. 86. Fuel assembly at the bottom of a dry well. 
Once the fuel assembly has been placed into a dry well the decay heat will need to be conducted away from the assembly into the surrounding rock. A reasonable approximation to the fuel assembly power can be obtained using the approximation suggested by Glasstone ${ }^{19}$ for thermal spectrum uranium fuel (see Fig. 87).

$$
P=5 \times 10^{-3} P_{0} a\left[\tau_{\text {elapse }}^{-b}-\left(\tau_{s}-\tau_{\text {elapse }}\right)^{-b}\right]
$$

where $\mathrm{P}_{0}=3400 \mathrm{MW} / 252=1.35 \mathrm{MW}$

$\mathrm{a}=27.43$ and $\mathrm{b}=0.2962$ for more than 150 seconds after shutdown and less than 25 years $\tau_{\text {elapse }}=$ time since reactor shutdown in seconds $\tau_{\mathrm{s}}=$ time fuel assembly is in core $(1$ year $)$ in seconds $=31.5 \times 10^{6}$.

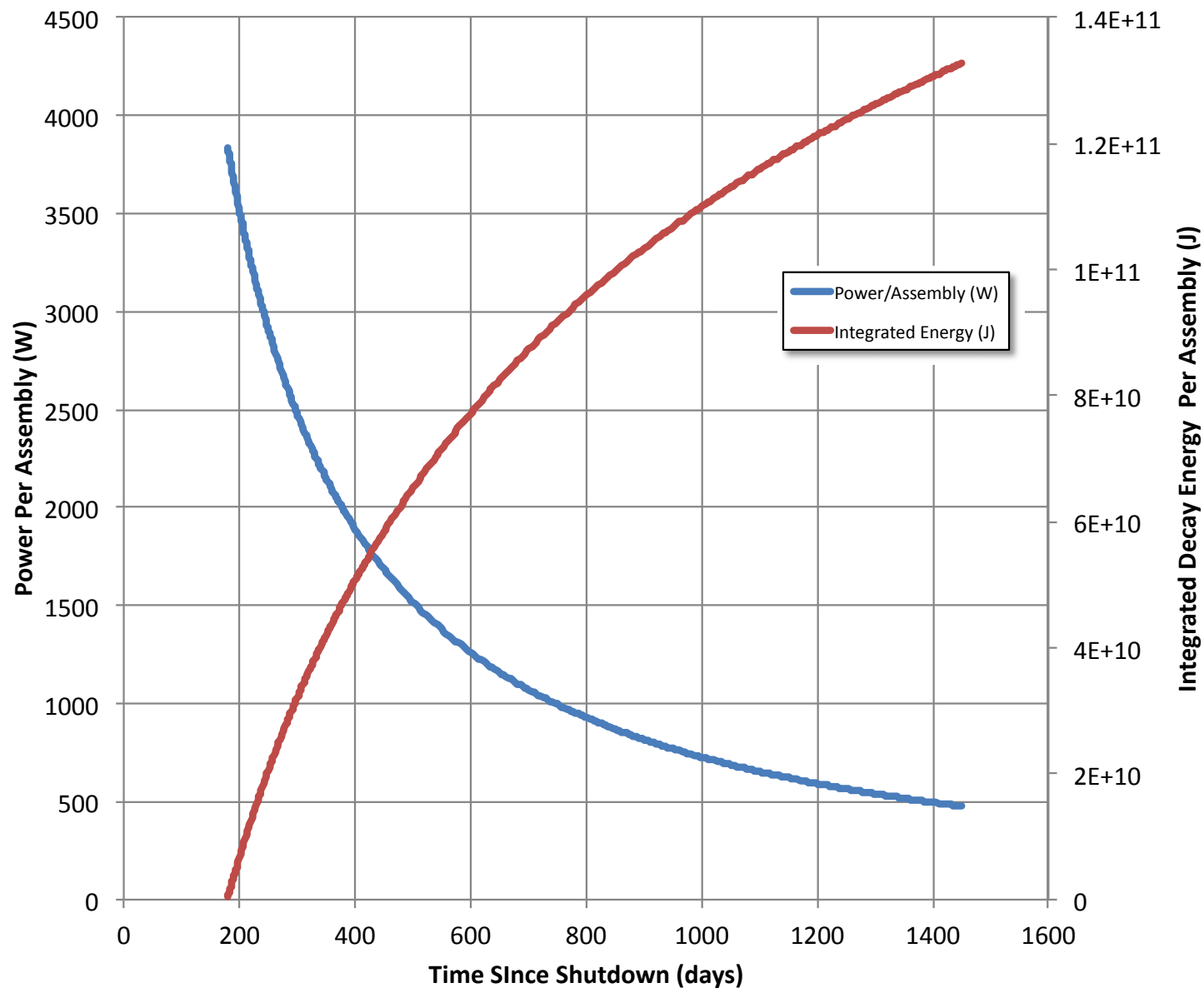

Fig. 87. Fuel assembly power as a functional time after shutdown.

An illustration of the heat transport can be obtained by assuming that the surrounding rock is granite with density $2.7 \mathrm{~g} / \mathrm{cm}^{3}$ heat capacity $2.13 \mathrm{~g} / \mathrm{cm}^{3}$ and thermal conductivity of $0.017 \mathrm{~W} / \mathrm{cm}-\mathrm{K}$. In this case within the first 1000 days after emplacement the freshest fuel assembly (emplaced 180 days after reactor shutdown) has released sufficient energy to heat a cylinder of granite $6.2 \mathrm{~m}$ in diameter (6-m tall) by $75^{\circ} \mathrm{C}$. At this point the fuel assembly is producing less than $100 \mathrm{~W} / \mathrm{m}$ and further rock heating is small. In order to avoid heating the rock to over $100^{\circ} \mathrm{C}$, dry wells that are filled in sequence should be at least $12 \mathrm{~m}$ 
apart. However, wells that have several years of intervening time between being used can likely be spaced somewhat closer together. 



\section{SAFETY DESIGN SUMMARY}

\subsection{APPROACH AND OVERVIEW}

FHRs feature full passive safety and, thus, do not require any system or operator active response to avoid core damage or large off-site release of radioactive material for any design basis accident or nonlowfrequency beyond design basis accident, including severe earthquakes, tsunamis, large civilian plane impact, or permanent station blackout. The safety characteristics of FHRs arise from fundamental physics as well as well-designed, constructed, and maintained systems, structures, and components (SSCs).

This report section describes, at a preconceptual level of detail, the major AHTR SSCs whose primary purpose is to ensure safe reactor operation. It then describes AHTR design features intended for accident avoidance or mitigation in terms of their intended response to potential accident scenarios. The normal operational aspects of the systems and structural details are described in Sect. 2.2 and 4.1 of this report. The information presented here is intended to be illustrative of the potential performance of a future design. However, none of the SSCs, accident scenarios, or design features has been subjected detailed evaluation, and no implications should be drawn about the performance or adequacy of any SSC.

\subsection{MAJOR SAFETY SSCS}

\subsubsection{Primary Shutdown System}

The AHTR's primary shutdown mechanism is to insert neutron absorbing control blades into the core. Each fuel assembly includes its own control blade. In-core the control blades are guided by a passageway within the carbon-carbon composite the fuel assembly support ' $Y$ '. In order to minimize the possibility for the control blade becoming stuck in the support if the passageway becomes distorted, a clearance of $7.5 \mathrm{~mm}$ is provided and the long control blade is subdivided into linked segments to provide blade flexibility as shown in Fig. 48. The number of links in control blade can be adjusted to accommodate the maximum credible passageway distortion as determined by a future AHTR materials irradiation program.Multiple means have been included in the AHTR conceptual design to insert the control blades into the core. The first of these is the control blade drive motor, which moves the control blade via a rackand-pinion system with the drive motor mounted to a plate above the reactor vessel flange (see Fig. 51). The second insertion mechanism is a scram on loss of power in series with a permissive scram. The pinion gear of the control blade drive system is electromagnetically engaged with the rack (that is formed into the control blade leader rod). In the event of either a loss of power or receipt of a scram signal, the drive motor would pivot out of position (due to mechanical springs that are normally compressed by electromagnets) and the control blade would fall into the core.

Each control blade is attached to a leader rod. Each leader rod includes a fusible link (likely formed from an Au-Sn alloy) in its attachment to the control blade. The fusible link is located in the upper salt plenum and is designed such that if its temperature rises significantly the link will melt releasing the control blade to fall into the core. Due to the depth of the upper plenum, even if the control blades are fully removed from the core, the fusible links remain immersed in the salt.

\subsubsection{Secondary Shutdown System}

The AHTR's secondary shutdown mechanism is based upon the injection of rare earth fluoride salt into the core inlet plenum. The general operation of the secondary shutdown system was described a September 2011 AHTR preconceptual design report. ${ }^{1}$ Figure 88 shows the planned deployment configuration of the secondary shutdown salt canisters. Three canisters are planned to be located in the 
segment of the downcomer region located under the vessel refueling lobe. The canisters would be set to release their poison salt under a slightly more severe accident than the primary shutdown fusible link release due to the additional difficulty of cleaning the poison salt from the primary coolant. The canister lids would be retained by a hinge and pin system, after use, so that the lids would not be transported by the salt and possibly blocks flow into the core. An electric heater system would be included near the fusible seal to allow the plant operators to manually engage the secondary shutdown system.

A pressurization line is included with the shutdown salt canisters to provide assurance that the pressure to drive the canister piston has not been lost and to provide a protected path to route cabling to the canister seal heaters. A check valve would be included at the distal end of the pressurization line to prevent injection pressure loss in the event of a leak in the pressurization line.

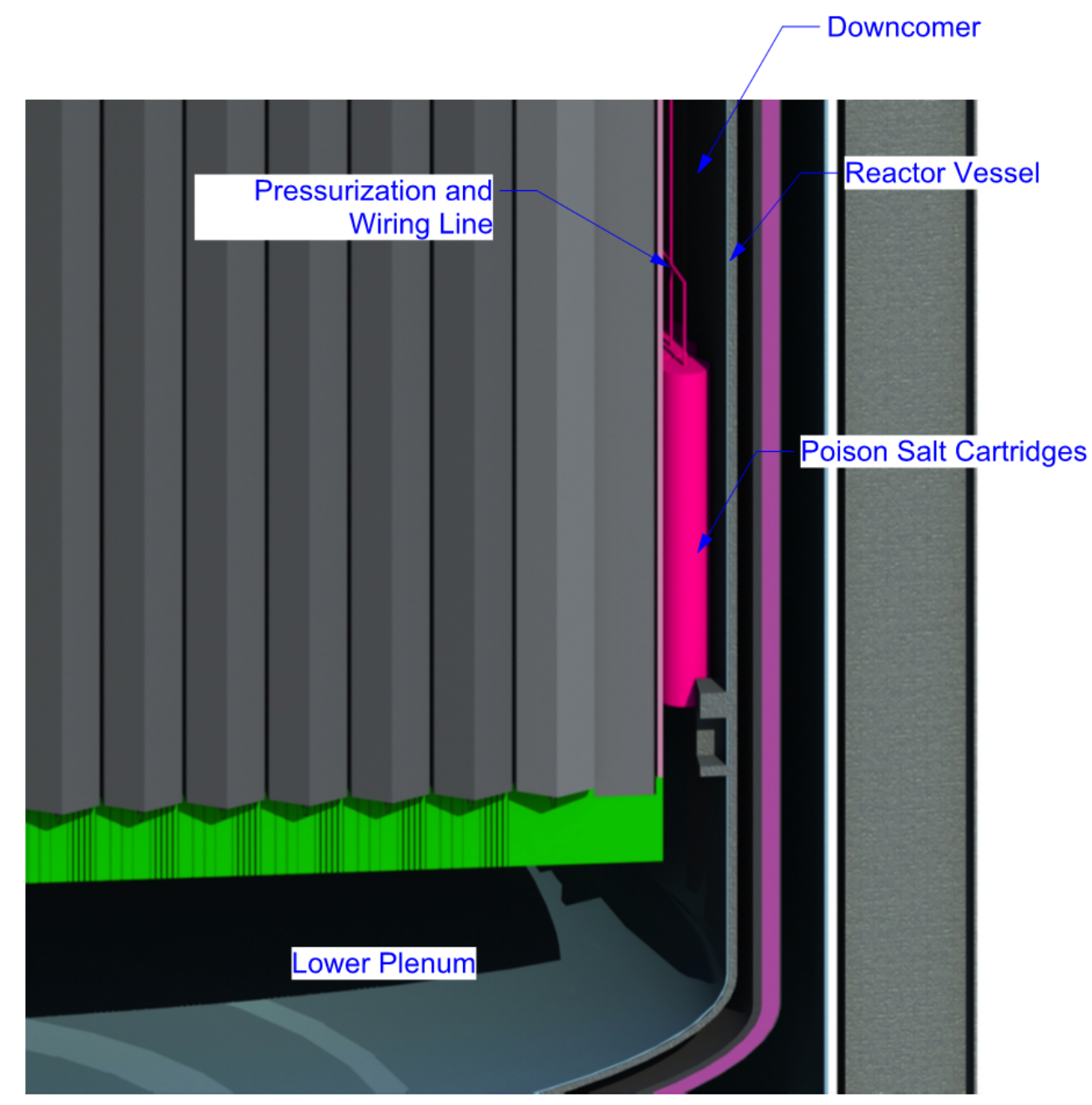

Fig. 88. Secondary shutdown canisters in AHTR downcomer region.

\subsubsection{Decay Heat Rejection}

Decay heat can be removed via any of four different systems at the AHTR. The intended functioning and mechanical configuration of the normal heat removal systems are described in Chapter 5 of this report. The normal means of removing decay heat is via the primary heat transfer loops. The heat that escapes from the reactor vessel and primary piping during normal operation will be removed via an active reactor 
cavity cooling system. In the event that the primary heat transport loops are unavailable (for example when they are under maintenance) the core decay heat would be removed via the maintenance heat removal system. If the maintenance heat exchange system were to also fail, the core decay heat would be removed by the DRACS system.

The used fuel storage pool at the AHTR will also be at liquid salt temperature $\left(>500^{\circ} \mathrm{C}\right)$. The large temperature difference between the used salt pool and the ambient environment, which is inherently provided by the decay heat of used fuel, enables generation of electrical power. The ability to autogenerate sufficient electrical power to operate the used fuel pool and reactor vessel maintenance cooling systems is a distinctive advantage of FHRs. Stirling cycle power generators are available with cycle efficiencies of $\sim 25 \%$ at liquid salt temperatures for power loads in the ten kilowatt range. ${ }^{20}$ Passive heat pipes are available to connect the hot end of the Stirling cycle generator to the used fuel pool and the cold end to the outside air.

In the event of loss of connection to the grid, the AHTR would be run back to a low power level such that it would continue to provide power to its plant systems. In this island mode, the plant would still continue to employ the primary cooling loops to reject waste heat. If a grid disconnection accident occurred while the plant was shut down a combination of the passive DRACS and the auto-powered maintenance cooling systems would be the design intent decay heat removal system for any fuel in the reactor vessel. The maintenance cooling system's Stirling cycle based power generation system would continue to draw its energy from the temperature difference between the used fuel pool and the ambient environment.

The highest heat load in the AHTR used fuel pool would be just after fuel unloading is completed. For the AHTR, one half of the reactor core is removed during a normal outage. In this case the AHTR used fuel cooling pool would contain half of a two cooling day core and half of $180+$ cooling days core. A forced cooling loop that rejects heat to the ambient air via the exterior maintenance heat exchanger would be employed for normal heat rejection. The pump for the cooling loop will draw its power (about $10 \mathrm{~kW}$ ) from a Stirling cycle generator that employs the used salt pool as its heat source and rejects waste heat to the ambient air either via a high temperature heat pipe or a self-powered pumped loop. Additional Stirling cycle generator sets will be employed as a power source for the maintenance cooling system pump.

Heat removal from the used fuel pool also occurs via a combination of radiant transfer from the fuel and natural convection transfer from the surface of the salt to the stainless steel roof of the low-pressure containment over the used fuel pool. The roof of the used fuel pool containment will be shaped (peaked) to promote the development of convective loops above the pool and thereby enhance the heat transfer and the containment interior surface will be conditioned to promote radiant heat absorption. The exterior of the roof of the used fuel containment structure will directly reject heat to the ambient air via natural convection.

The decay heat from fuel 2 cooling day fuel is $\sim 0.5 \%$ and that for 180 days is $\sim 0.1 \%$. Consequently, the maximum heat load for the used fuel pool is $\sim 10 \mathrm{MW}$. Over the first few weeks the heat load will decrease to about $5 \mathrm{MW}$. The used fuel storage pool will contain roughly $1500 \mathrm{~m}^{3}$ of $\mathrm{KF}_{-} \mathrm{ZrF}_{4}$ salt and will be at $\sim 500^{\circ} \mathrm{C}$ under normal operating conditions. The first damage that would occur to the used fuel pool if it were allowed to overheat would be creep of the metal pool walls. Several hundred Kelvin of margin is available before the creep damage would become significant.

Given the large volume of salt and its high heat capacity a few days would be required to overheat the pool even if all cooling were removed. The normal cooling of the used fuel pool is passive but requires moving parts. The Stirling cycle electrical generator is intended to operate continuously and thus would not need to start up during a loss of power accident. The Stirling cycle electricity generation efficiency and thus the cooling pump flow rate would inherently increase with an increase in used fuel pool temperature. 
As the temperature of the pool and fuel rises the passive portion of the heat rejection will also inherently increase. The radiation heat transport will increase with temperature to the $4^{\text {th }}$ power. The interior surface of the used fuel pool will be conditioned to promote emissivity. Partially confounding the increased radiation transport, $\mathrm{ZrF}_{4}$ will preferentially evaporate from the pool at higher temperatures and condense into an unconsolidated white powder on the first cool surface that it impinges upon. Zirconium tetrafluoride sublimates at $\sim 600^{\circ} \mathrm{C}$ providing an upper temperature limit to the reflective surface development. The convective transport of the argon above the pool surface will also increase with temperature. If the Stirling cycle system were to fail and the station were to suffer permanent blackout, the radiative and natural convection cooling system would be sufficient to remove the decay heat without fuel damage. Significant, additional design and simulation of the used fuel pool decay heat rejection system remains to be performed.

\subsubsection{Seismic Isolators}

In order to be widely deployable worldwide the AHTR will need to be able to withstand large earthquakes. The AHTR preconceptual design is not yet sufficiently mature to evaluate earthquake response with technical depth. However, design features that have been found to be useful in other large civil structures have been incorporated into the AHTR base preconceptual design. None of the seismic endurance features are necessary parts of the AHTR and they may not be included for deployments in nonseismically active regions.

The AHTR rests on a base isolation system. The mechanical structures of the base isolation system are described in Sect. 4.1. The number and size of seismic isolator columns is based upon that of the JulesHorowitz Research Reactor (scaled to the mass of the AHTR building) that is being constructed at CEACadarache in France. ${ }^{21}$ The AHTR reactor building is below grade and is separated from the surrounding earth by a $\sim 1 \mathrm{~m}$ trench. The AHTR reactor vessel is supported only from its top flange to accommodate thermal expansion. Pendulum like vessel motion is damped by lateral dissipative spring type mounts against lower portions of the vessel (see Fig. 34).

The intermediate loop piping and turbine building of the AHTR are not on base isolated. The intermediate loop piping extends from the seismically isolated reactor building to the non-seismically isolated turbine building. A weak link style attachment has been selected to minimize the stress that motion of the intermediate loop piping can apply to the reactor building. Several design options remain under consideration for the weak link. A shielded bellows (see Fig. 68) is the baseline design. If the piping were to fail at the weak link the intermediate coolant would drain into a catch basin and storage tank system below the weak link (Fig. 67).

\subsubsection{Containment Layers}

The AHTR has four separate containment layers, as illustrated in Fig. 89. The innermost layer is the silicon carbide layer within the coated-particle fuel. The second layer is the primary circuit and upper gas region containment shell. The third containment layer is the argon-gas-filled, low-pressure containment structure within the reactor building. The outermost containment layer is the steel-lined trench surrounding the reactor building combined with a flexible upper seal structure (intended to prevent flooding of the seismic isolation trench). 


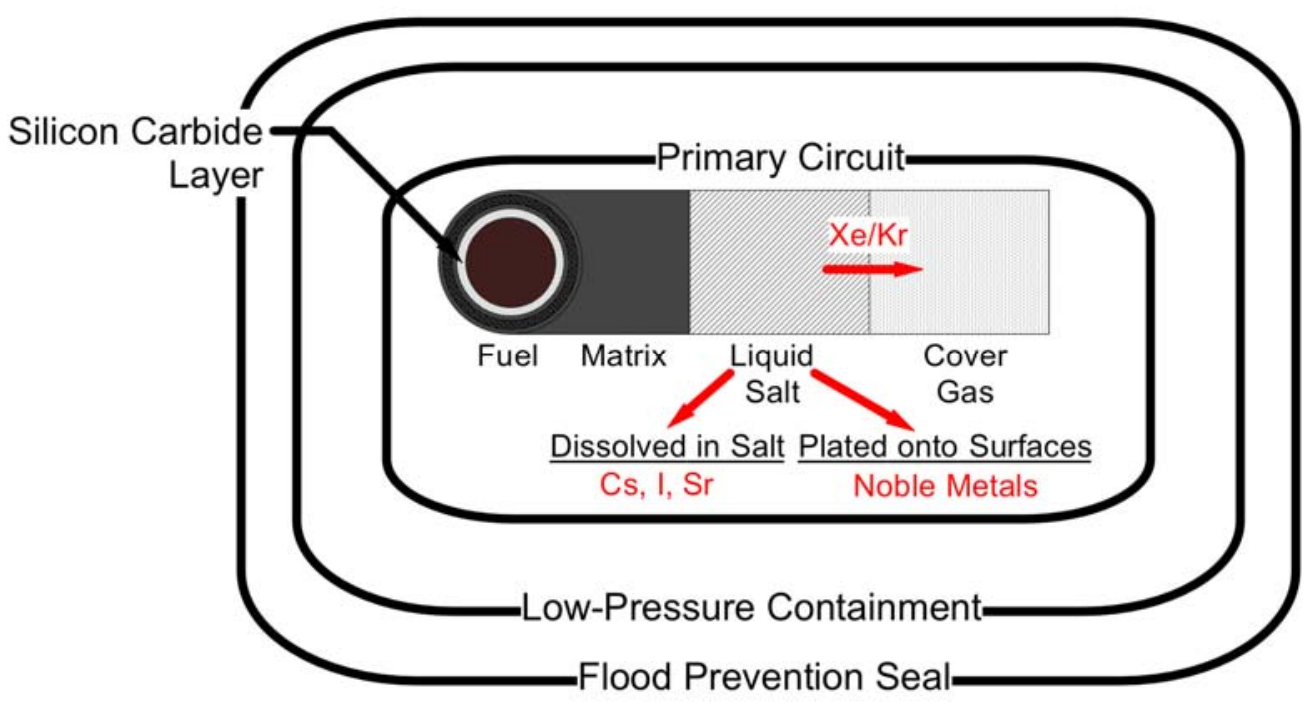

Fig. 89. FHR radionuclide release barriers.

In the case of a failed silicon carbide containment layer, the emerging radionuclides will be trapped on the carbon surfaces within the core, dissolve into the liquid salt, and/or be confined by the next reactor containment layer. The noble gases will largely escape from the top surface of the salt and be trapped by the upper level gas containment shell. The upper gas containment shell is sealed to the top flange of the reactor vessel to provide a second level of containment during operation. The upper containment shell envelops the control element drive mechanisms (located on the upper vessel flange) and provides closed end guide thimbles for the control blade leader rods and guide tubes when retracted outside of the vessel. Note that the reactor vessel itself does not form a gas-tight containment in that the upper head penetrations are only loose fitting. In addition to serving as a radionuclide containment, the upper layer seal provides an initial tritium and beryllium contamination barrier.

All of the nonnoble gas fission products have been shown by experience with molten salt reactors to be well retained within the salt (the noble metals tend to plate out on surfaces or form suspended colloids), reducing the available radionuclide source term. The reactor vessel and primary piping are located within a low-pressure, low-leakage, inert atmosphere containment building below grade, providing a third fission product barrier. The steel-lined trench that surrounds the reactor building as part of the seismic protection system also has a flexible liquid and vapor impermeable seal at its top to avoid flooding accidents and, thus, provides a fourth fission product barrier.

The primary-to-intermediate loop heat exchanger is located at the low point of the intermediate loop, resulting in a higher pressure on the intermediate coolant side of the heat exchanger. Thus, tube ruptures in the primary-to-intermediate heat exchanger would results in inward leakage of intermediate coolant rather than outward leakage of potentially contaminated primary coolant. The intermediate loop is not a significant radionuclide escape route due to the pressure differential between the loops. The inward leakage rationale also applies to the primary to direct reactor auxiliary cooling system (DRACS) heat exchangers due to the elevation of the DRACS loops.

\subsubsection{Primary System Instrumentation}

While fully passively safe operation of the AHTR is intended without requiring operator intervention or equipment response, operators and automatic equipment will continue to serve in a backup role for safety response. The goal for primary system instrumentation is thus to enable the operators to maintain 
situational awareness. Much of the instrumentation employed for reactor operation and control can also be employed for plant and process condition monitoring.

Primary system instrumentation system design has not yet been performed for the AHTR. However, the AHTR's instrumentation system architecture will more closely resemble that of other high value process control industries as opposed to that for LWRs because of the instrumentation's relegation to a secondary role in ensuring safe operation.

For example, monitoring the core outlet temperature distribution helps to establish the plant thermal balance for power level control. If the primary coolant emerging from fuel assembly were to rise unacceptably, the design intent is for a fusible link in the control blade string to melt and the channel's control blade to fall into core. The robust fuel and large margin to boiling make the rapid observation of the core outlet temperatures unnecessary for the inherent safety response, however, the temperature distribution would continue to be monitored (likely by optical observation) as a confirmatory measurement of proper reactor operation.

Similarly, due to the large negative temperature driven reactivity feedback, flux monitoring does not have a primary safety purpose but remains useful as part of the reactor control system. Lacking a primary safety function, flux monitors with a lesser regulatory pedigree may be the preferred measurement technology. Visual observation of the Cerenkov illumination via optical components located above the coolant pool would be indicative of neutron flux levels and yet would not have to be at high temperatures or exposed to liquid salt.

\subsection{DESIGN FOR ACCIDENT AVOIDANCE AND/OR MITIGATION}

This section provides an overview of the intended response of the AHTR to a variety of different accident scenarios. The accidents presented here are an initial set of potential accidents, which do not to represent a complete set of accidents. Also, the accident progression descriptions presented are intended only for illustrative purposes and lack both detailed analysis and validation.

\subsubsection{Over Cooling}

Fluoride salts have high melt temperatures. It is possible to over cool and freeze the primary reactor coolant, the intermediate coolant, or the DRACS coolant. While used fuel remains in the reactor vessel, its decay heat makes freezing the primary coolant in the reactor vessel incredible. The primary FLiBe coolant salt has a higher melt point than the intermediate coolant salt $\mathrm{KF}_{\mathrm{ZrF}}$. If both the power cycle and intermediate loop pumps remain on and the primary loop pumps are turned off after reactor shutdown, the higher melt point FLiBe will freeze in the primary to intermediate heat exchangers. Similarly, if the intermediate pumps are turned off and the power cycle pumps remain on following reactor shutdown the intermediate coolant salt will freeze. While neither of these events directly damages the fuel, they both remove the normal condition heat rejection path from operation. Both automatic controls and procedures are planned to prevent inadvertent overcooling of the primary heat transport path.

The DRACS are the last line of defense in keeping the fuel cool during an extended station blackout. As such they are a reactor safety feature and high assurance must be continuously available they are capable of performing their safety function. Under normal conditions, the DRACS will continuously reject heat and represent a small parasitic load. Instrumentation (temperature measurement) will be provided to ensure that the DRACS component temperatures remain well above freezing and that they are properly functioning.

The AHTR DRACS are sized to remove $0.75 \%$ of full power under fully developed flow conditions. With a station blackout accident, the reactor temperature will initially rise and then fall again as the fuel decay heat decreases. The DRACS heat rejection rate will increase with the larger temperature difference to ambient and then decrease as the reactor cools. The current design intent is to manually shut the louvers 
in the DRACS tower a few days following a station blackout accident to minimize the cooling provided through the DRACS. Also, the viscosity of fluoride salts increases significantly as they near their freeze points decreasing the heat rejection naturally. Moreover, solid salt is a thermal insulator. Salt would begin to freeze at the cooler pipe walls in the NDHX and thereby decrease the heat transferred from the interior hotter salt. Significant additional modeling and experimentation will be required to demonstrate how long would be necessary for the DRACS to freeze solid given the complex interactions between the solidification, insulation, viscosity, and fluid flow rate and whether this would occur at a sufficiently long time (months) following shutdown such that the small amount of conduction and convection cooling through the vessel would keep the fuel temperature sufficiently low.

\subsubsection{Air or Water Ingress}

The principal hazard for water ingress into the AHTR fluoride salt coolants is to increase the corrosion rate. A basic design principal for the AHTR is to avoid large volumes of water in the reactor building. The lack of water in containment avoids the potential for a steam explosion or pressurizing the containment. Also, significant emphasis is placed on baking newly arrived fuel, to remove entrapped moisture and oxygen, just prior to its insertion into the salt. Both the atmosphere above the salt and the salt itself will be monitored for moisture or oxygen contamination. Leaks of small amounts of oxygen into the AHTR containment would result in formation of a protective oxide film on the first heated surface that the oxygen impinges upon. Thus, to some extent dry air is beneficial to the AHTR primary circuit exterior surface.

\subsubsection{Large Civilian Plane Impact}

The AHTR reactor building is located below grade under an obscuring structure to avoid being an easy impact target. While the used fuel pool roof is directly exposed to the air to promote heat transfer, the pool itself is below grade and a plane impact is not expected to prevent the normal cooling circuits from functioning. The AHTR has three separate DRACS circuits and is designed to be able to come to safe shutdown following station blackout, with simultaneous failure of the thermally driven Stirling cycle driven maintenance cooling system pump, using only two of the DRACS. The DRACS cooling towers are widely spaced requiring more than a single impact to destroy two towers.

\subsubsection{ATWS}

The AHTR has two independent, thermally driven, passive shutdown systems. Moreover the poison saltbased shutdown system does not require that the core remain intact to provide large negative reactivity. ATWS heat-up of the reactor vessel is thus not believed to be a credible accident.

\subsubsection{Inadvertent Control Element Movement}

If the control system were to inadvertently direct the control blades to be withdrawn improperly, the fuel's strong negative thermal reactivity feedback would mitigate the reactivity increase. The mechanical design of the control blade drive system does not permit the control blades to be moved rapidly. In the event of a large positive temperature excursion, the passive negative reactivity insertion mechanisms (negative temperature coefficient fuel and melt point fuse controlled shutdown systems) would activate preventing fuel damage. No mechanisms exist in the reactor building to rapidly move control blades, so a control blade ejection event is not credible.

\subsubsection{Reactor Vessel Breach}

The AHTR's design includes a guard vessel that would be capable of containing the contents of the reactor vessel without allowing the reactor pool level to drop below the level of the DRACS heat 
exchangers. The AHTR's guard vessel is in thermal contact with the concrete silo, so that the first salt that impinges upon the guard vessel would solidify and form a thermal and chemical protective barrier.

\subsubsection{Primary Loop Break}

The primary loop piping connections are near the top of the reactor vessel. Both the maintenance and DRACS heat exchangers are located below the level of the primary heat exchangers, thus two independent means for removing decay heat would remain functional in the event of a primary loop detachment (double guillotine break).

\subsubsection{Loss of Forced Flow}

If the primary coolant pumps were to fail, the reactor would first shut down either under operator control or passively. The fuel's decay heat would be removed by a combination of the maintenance cooling loop system and the DRACS. The maintenance cooling system's flow is provided by a combination of natural circulation in the reactor vessel and a Stirling cycle motor driven loop with an external forced flow salt to gas heat exchanger. The power for the external cooling fan also draws its power from a Stirling cycle engine with its hot end thermally connected to the used fuel pool and its cold end rejecting heat via a heat pipe to the ambient atmosphere. Both the maintenance cooling system and the DRACS are independently sufficient to remove the decay heat, so redundant cooling capabilities remain following the loss of primary cooling. Additionally, the maintenance cooling system's power can be manually switched to an alternate power source, so either grid or backup diesel generators could be used to provide an additional power source for cooling.

\subsubsection{Loss of Ultimate Heat Sink}

Loss of ultimate heat sink is similar to the loss of forced flow and the response to it would, therefore, be similar.

\subsubsection{Station Blackout}

In the event of a full station blackout, the reactor would first shut down either under operator control or passively. The fuel's decay heat would be removed by a combination of the maintenance cooling loop system and the DRACS. The maintenance cooling system's flow is provided by a combination of natural circulation in the reactor vessel and a Stirling cycle motor driven loop with an external forced flow salt to gas heat exchanger. The power for the external cooling fan also draws its power from a Stirling cycle engine with its hot end thermally connected to the used fuel pool and its cold end rejecting heat via a heat pipe to the ambient atmosphere. Both the maintenance cooling system and the DRACS are independently sufficient to remove the decay heat, so redundant cooling capabilities remain following the loss of power. The maintenance cooling system electrical power is normally a separate circuit from the remainder of the plant. Consequently, loss of power within the plant would not impact the maintenance cooling system's functionality. Electrical power, however, can be manually switched to an alternate power source; so backup diesel generators could be used to provide an additional backup power source for cooling.

\subsubsection{Loss of Grid Connection}

The AHTR is designed to help with restart of a black grid. The AHTR has redundant, passive decay heat removal systems removing the requirement for external power to cool the reactor core. In the event of loss of connection to the grid, the AHTR would be run back to a low power level such that it would continue to provide power to its plant systems. In this island mode, the plant would still continue to employ the primary cooling loops to reject waste heat. If a grid disconnection accident occurred while the plant was shut down a combination of the passive DRACS and the auto-powered maintenance cooling systems 
would be the design intent decay heat removal system for any fuel in the reactor vessel. The maintenance cooling system's Stirling cycle based power generation system would continue to draw its energy from the temperature difference between the used fuel pool and the ambient environment.

\subsubsection{Failure of Reactor Vessel Internals}

The AHTR's fuel is slightly buoyant in the coolant. If any reactor vessel internal were to fail, the AHTR is designed to keep the fuel submerged in the salt and to shut down the reactor. Coolant flow is upwards through the AHTR's core. The pressure drop across the core for the upward coolant flow produces significant upward force on the fuel assemblies. If the upper core support plate were to break, each fuel assembly would still be independently held down by its control blade guide tube, which serves as a pillar located above the fuel assembly. Additionally, once the primary pumps are runback, the control blade in each fuel assembly is sufficiently heavy to cause the fuel assemblies to sink.

\subsubsection{Partial Flow Blockage}

If a component in the downcomer or lower plenum were to fail and be forced against the inlets to the lower core support plate, flow would be starved to the fuel assemblies with the blocked inlets. This accident scenario closely parallels the Fermi 1 flow blockage accident. ${ }^{22}$ Partial flow blockage would also occur if an AHTR's fuel plates were to warp excessively or pieces were to break off from a fuel plate.

The AHTR's fuel is, however, thermally robust. With a substantial flow blockage in a fuel assembly, the temperature of the fuel would rise substantially. The higher temperature would cause the control blade above the fuel assembly to release and the negative Doppler reactivity feedback in the fuel assembly to increase. These two effects would locally depress the power generation. However, partial core flow blockage could lead to local boiling and local fuel damage.

If the silicon carbide layer within the coated particle fuel does become damaged due to high temperatures, following coolant boiling and dry out, the released radionuclides would dissolve into the primary coolant salt in the upper plenum forming a dissolved fuel molten salt reactor salt. The noble gas fission products, however, would release into the argon gas layer above the primary coolant pool. The radionuclide releases would be readily detectable and result in manual plant shutdown.

The transparency of the primary coolant salt provides additional opportunities to observe a partial flow blockage accident at its onset, prior to fuel damage. The core exit visualization system would indicate the increase in the top surface temperature of the fuel assembly. Also a periscope type system can be deployed in the downcomer region to allow direct visualization of the core inlet region. Finally, the flow channels within the core can be directly visualized from above. The AHTR's instrumentation system remains to be designed, so which of these instruments will actually be deployed remains to be determined.

\subsection{TRITIUM IN THE AHTR}

\subsubsection{Overview}

Tritium is generated by the interaction of neutrons with the lithium and beryllium in the AHTR primary coolant in and near the core. Tritium production is an important safety issue at FHRs because it is the only radionuclide that under normal operating conditions, without failed fuel that has the potential for significant release. At high temperatures tritium can permeate through structural alloys. The large contact surface area and thin walls of heat exchanger tubes means that heat exchangers are a primary release pathway into the power cycle steam, maintenance heat exchanger coolant, and/or DRACS natural draft heat exchanger and eventually out into the environment. Several approaches can be employed either separately or in combination to greatly reduce the spread of tritium. This report section describes the production and transport of tritium in the AHTR and technologies to minimize its spread. 


\subsubsection{Production}

The significant tritium production reactions in FLiBe and their cross sections are shown in Fig. 90.

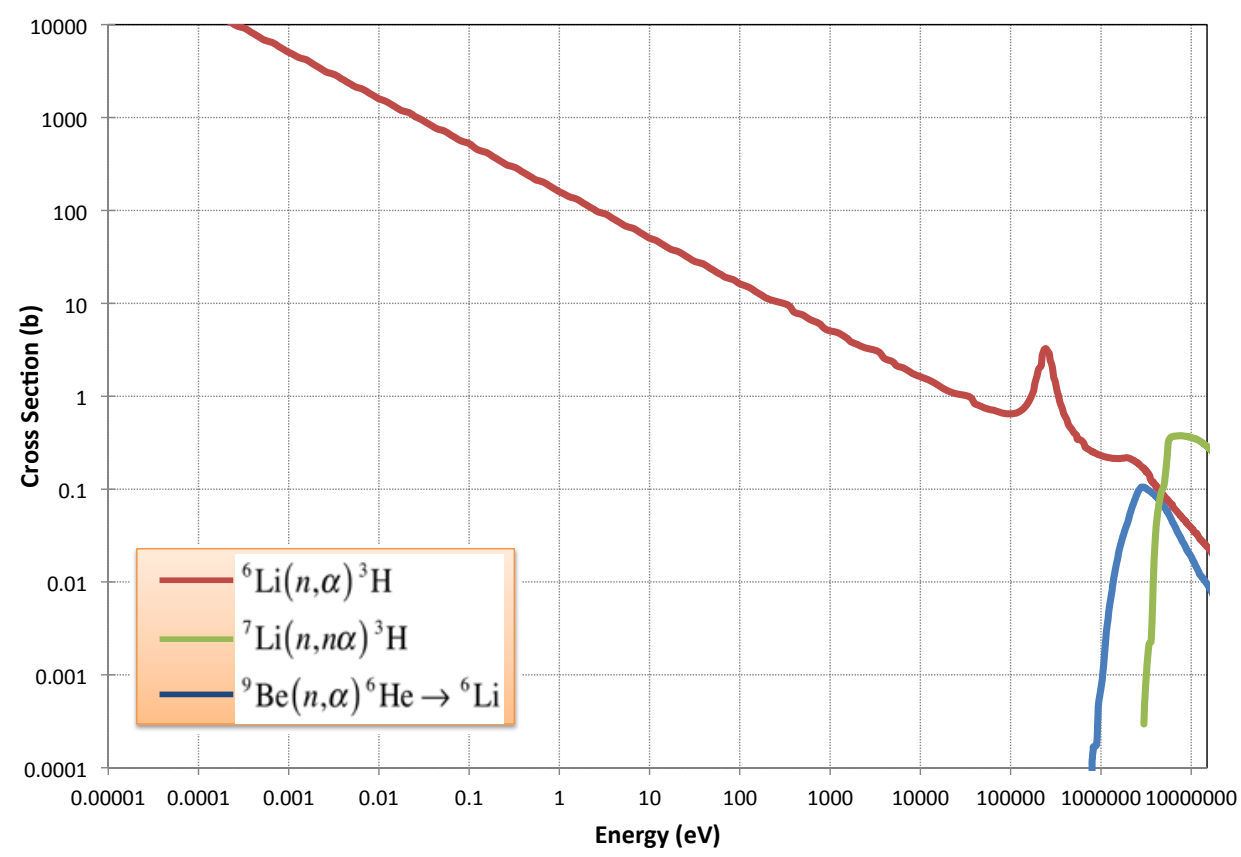

Fig. 90. Tritium producing reactions in FLiBe.

In a molten salt reactor the total tritium production has been estimated to be roughly one Curie per megawatt thermal per day. ${ }^{23}$ While somewhat less will likely be generated in the AHTR due to the larger ratio of graphite to salt in the AHTR core and the somewhat softer neutron spectrum reaching the salt due to neutron production within a carbonaceous fuel plate, a tritium production rate of one Curie per megawatt thermal per day remains a reasonable design estimate. In comparison the average rate of production at a light water moderated reactor is roughly $0.015 \mathrm{Ci} / \mathrm{MW}(\mathrm{t})$ per day and $1.75 \mathrm{Ci} / \mathrm{MW}(\mathrm{t})$ per day for a heavy water moderated reactor. Using a non lithium or beryllium fluoride salt as the primary coolant in the AHTR would reduce, but not eliminate the tritium issue as lithium and boron impurities in graphite as well as the small, high energy ${ }^{19} \mathrm{~F}\left(\mathrm{n},{ }^{17} \mathrm{O}\right){ }^{3} \mathrm{H}$ cross section would still result in sufficient tritium to require mitigation much as with the NGNP. ${ }^{24}$

The tritium will transport with along with the salt. The generated tritium can be trapped by the carbonaceous materials in the primary loop, escape through the open primary coolant surface into the argon cover gas, permeate through the reactor vessel or piping, or permeate through the heat exchanger tubing into the intermediate loop, DRACS loop, or maintenance cooling loop. From the intermediate loop the tritium can either permeate through the piping or permeate through the intermediate to power cycle heat exchanger tubing to the steam cycle.

The specific activity of tritium is $9,800 \mathrm{Ci} / \mathrm{g}$. Thus the mass of tritium produced per day by the AHTR would be roughly $350 \mathrm{mg} /$ day. The relatively small mass of tritium produced is important in that the core carbon materials can sorb the produced tritium and given their much larger mass would not be anticipated to saturate during their lifetime. 


\subsubsection{Tritium Trapping}

The tritium will be produced as either as an isolated gas atom or as a tritium fluoride molecule within the primary coolant salt with a probability ratio that depends on the redox conditions in the salt. As the boiling point of hydrogen fluoride is near $20^{\circ} \mathrm{C}$ both species would have high vapor pressure whenever the salt is liquid. Upon reaching a carbon surface the tritium and tritium fluoride can diffuse into the pores and be sorbed onto the surfaces. The presumption employed by the MSBR program was that any tritium and/or tritium fluoride that reached a graphite surface was retained by the graphite. ${ }^{23}$ Hollow carbon nanoparticles have been shown to accumulate tritium under fusion plasma type operating conditions. ${ }^{25} \mathrm{As}$ similar particles are under consideration to improve the thermal conductivity of $\mathrm{FLiBe}^{26}$ and exhibit a very large aggregate surface area further study to understand the potential for the carbon nanoparticles to trap and retain tritium is recommended.

A sodium fluoroborate eutectic was proposed at the MSBR intermediate coolant salt to trap the tritium as a borohydrate formed by the reaction of the tritium with hydrogenous impurities in the salt. ${ }^{27} \mathrm{BF}_{3}$ based tritium trapping is not being pursued at the AHTR due to several deleterious properties of $\mathrm{BF}_{3}$. Boron trifluoride is highly toxic and will hydrolyze to form hydrogen fluoride and hydroxyfluoroborate upon contact with moist air (or in the lung). Any leakage of moisture into the coolant system would rapidly generate highly corrosive $\mathrm{HF}$ and hydroxyfluoroborate. Further $\mathrm{BF}_{3}$ has a relatively high vapor pressure and even operations such as bubbling an inert gas through the salt can cause plugging problems due to the local depletion of $\mathrm{BF}_{3}$ from the salt and the resultant local increase in the melting point. ${ }^{28}$

\subsubsection{Tritium Transport}

Tritium permeation through metallic alloys involves a sequence of steps: (1) adsorption onto the alloy surface and decomposition if in fluoride form, (2) permeation through the alloy, and (3) re-emergence at the opposite surface. Transport of tritium can be blocked at any of these steps. The permeation process step has an Arrhenius type temperature relationship. The equation describing the steady-state permeation flux, J, of tritium through unoxidized metals follows: ${ }^{29}$

$$
J=\frac{D_{0} K_{0}}{t} e^{\frac{-E}{k T}}\left(P_{2}^{1 / 2}-P_{1}^{1 / 2}\right)
$$

where

o $\mathrm{D}_{0}$ is a constant related to diffusivity of tritium through the metal,

$0 \quad \mathrm{~K}_{0}$ is a constant related to the solubility of tritium in the metal,

$\mathrm{O} \quad \mathrm{E}$ is the activation energy for permeation (the product of the enthalpy of solution for tritium in the metal and the energy of activation for diffusion),

$\mathrm{o} \mathrm{k}$ is the gas constant,

$0 \mathrm{~T}$ is the temperature,

$0 \mathrm{t}$ is the wall thickness, and

o $\quad \mathrm{P}_{2}$ and $\mathrm{P}_{1}$ are the tritium partial pressures on opposite sides of the wall.

Simple surface oxides typically provide about one order of magnitude reduction in tritium permeation in many structural alloys. ${ }^{30}$ The hot, flowing fluoride salt will prevent development of an oxide layer on any structural to which it is exposed. Consequently, the oxide permeation barriers are only possible on the steam side of the power cycle heat exchanger and the air side of the natural draft and maintenance heat exchangers. However, the surface oxide layer may include imperfections such that some of the tritium can emerge from the metal without diffusing through the oxide. 
The composition of the oxide formed at an alloy surface is function of the alloy composition. Generally, alloys are design to provide a slow growing, adherent, oxide layer for chemical and mechanical protection. Specifically engineered alumina or titania surface oxides can achieve much high permeation reduction factors (up to 10,000 ) with reasonable durability. ${ }^{30}$ Hence an alumina forming alloy or coating method will be desirable for the AHTR heat exchanger tube alloy.

An alternative technique to prevent tritium from migrating into the intermediate loop is to employ a double walled heat exchanger with flowing helium as a helium purge gas between the tube walls. Double walled heat exchangers are commonly used to transfer heat between fluids that cannot be allowed to mix. For an FHR the hot helium would be stripped of tritium as it exits the heat exchanger and then reused. Double walled heat exchangers are always larger, more complex, and more expensive than single walled systems due to the requirement to pass heat through two additional surfaces. One technique that can be employed to minimize their thermal performance disadvantage is to connect the two tube layers with a thermally conductive webbing to provide an alternative heat transfer path with minimal tritium diffusion potential through its thickness. The designing of a double walled tritium barrier type heat exchanger for the AHTR remains to be performed.

\subsubsection{Tritium Removal}

Tritium will evaporate from salt free surfaces. The solubility of $\mathrm{H}_{2}$ and $\mathrm{D}_{2}$ in FLiBe is low and has been measured to be

$$
\log \left(10^{3} K_{c}\right)=\log T-\frac{1535}{T}-0.7684
$$

where $\mathrm{T}$ is the temperature in Kelvin $(773 \mathrm{~K}<\mathrm{T}<973 \mathrm{~K})$ and $\mathrm{K}_{\mathrm{c}}$ is the ratio of the dissolved gas concentration to the gas phase concentration (Ostwald coefficient). ${ }^{31}$ Figure 91 shows the dissolved hydrogen fractionation in FLiBe as a function of temperature. For AHTR temperatures, in excess of $99.5 \%$ of the hydrogen will be in gas phase.

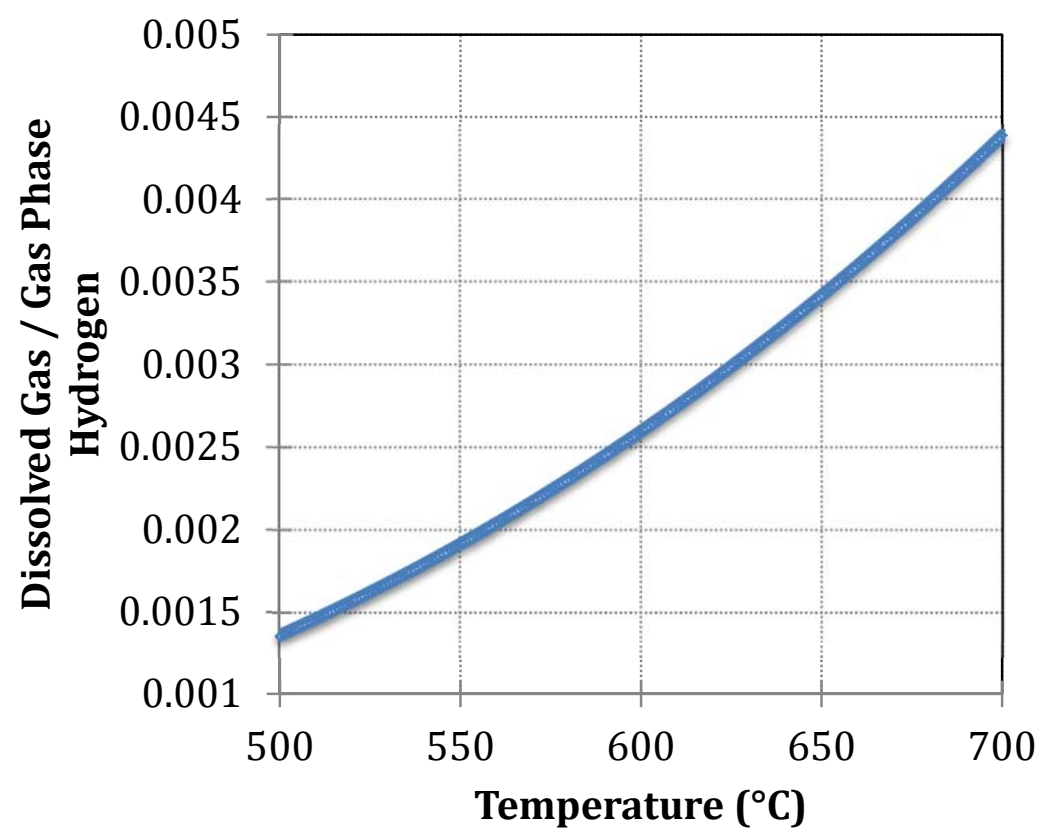

Fig. 91. Dissolved hydrogen to gas phase ratio vs temperature in FLiBe. 
The University of Rochester Laboratory for Laser Energetics has recently published a review article on technologies for removing tritium from both air and inert gas streams. ${ }^{32}$ The AHTR containment environment is argon. Tritium can be effectively removed from argon by passing the gas through a heated metal (zirconium-iron or uranium typically) filter to form a metal hydride. The environment in the tunnel between the AHTR reactor building and the turbine building is dry air. Tritium can be removed from air by passing it through a hot copper oxide bed to oxidize the tritium into tritiated water and capturing the resultant water in a molecular sieve type dryer.

Tritium that escapes into the steam cycle will need to be removed prior to the water being discharged. Tritium would be removed from the steam cycle water by transfer to an elemental hydrogen stream, followed by membrane diffusion tritium stripping and enrichment, and final tritium enrichment by thermal diffusion. ${ }^{33}$

Shifting the redox potential of the fluoride salt will to a more reducing condition will shift the tritium to tritium-fluoride ratio towards isolated tritium. Metallic beryllium contact has been shown to effectively reduce tritium fluoride in FLiBe. ${ }^{34}$ Providing excess beryllium in the salt has been estimated to enable keeping the FLiBe tritium fluoride concentration below 20 ppt. $^{35}$ Tritium fluoride can also be decomposed by electrolyzing the melt at lower voltage than would be necessary to decompose the salt (either FLiBe or $\mathrm{KF}-\mathrm{ZrF}_{4}$ ). ${ }^{36}$ The tritium would appear at the cathode (negatively charged electrode where electrons enter the salt) and be swept out of the salt by an argon stream before it can back react into the salt.

Tritium evolution from the salt can be enhanced both physically and chemically. The MSBR program was planning on employing helium sparging to remove fission product gasses from the fuel salt along with some fraction of the tritium. ${ }^{37}$ Sparging involves inserting large numbers of small, inert-gas bubbles into a liquid that contains dissolved constituents. The dissolved constituents diffuse into the bubbles in response to the concentration gradient. Small bubbles are used to maximize the diffusion surface area and minimize the required diffusion length.

Ultrasound is a technology commonly employed to degas liquids. Ultrasonic degassing could be applied at an AHTR by employing an external ring type ultrasonic resonator to the coolant piping. Free tritium within the melt would become nucleation points for ultrasonic cavitation within the melt. Cavitation, however, requires adding significant ultrasonic energy to the melt. The requirement to cause cavitation to nucleate bubbles can be avoided by combing ultrasonic excitation with inert gas sparging. Carbon nanoparticles, if used, would also provide bubble nucleation sites. The bubbles (either cavitation or nozzle released) would then grow due to the dynamics of diffusion-induced penetration of dissolved tritium into pulsing bubbles. Upon reaching adequate size the bubbles will float to the surface of the melt.

The ultrasonic waves cause the bubbles within the melt to shrink and swell. When the bubble is compressed its tritium concentration is higher and will thus tend to diffuse out of the bubble. However, at this point the bubble surface area is a minimum reducing the outflow. When the bubble diameter is at a maximum the tritium concentration within it is at a minimum and thus the tritium diffusion will be inward. ${ }^{38}$ The amount of tritium entering the bubbles when they are expanded is larger than that leaving when they are compressed. Individual pulsating bubbles coalesce to form progressively larger bubbles due to the Bjerknes force and the development of acoustic microflows in the vicinity of pulsating bubbles.

\subsubsection{Tritium Summary}

Tritium is the most significant radiological health and safety issue for an FHR employing FLiBe as its primary coolant due to the propensity of tritium to permeate through structural alloys at high temperatures. Significant quantities of tritium are generated in the coolant under normal operating conditions. A series of technologies show the potential to separate and sequester the AHTR's tritium, however, the technologies remain too immature to be able to confidently rely on them to build a working reactor. Developing and demonstrating the technologies necessary to understand and mitigate the AHTR's tritium is thus a high priority technology development item. 
Separated tritium is a valuable commodity both as a fuel for fusion reactors as well as due to its decay $\left(\mathrm{T}_{1 / 2}=12.33\right.$ years) into ${ }^{3} \mathrm{He}$ for which there currently is a worldwide shortage. Tritium may, therefore, be regarded as both a challenge and an opportunity for a supplemental revenue source. 


\section{CONSTRUCTION}

\subsection{DESIGNING FOR CONSTRUCTION}

Even at this early design concept stage, the AHTR design process addresses construction and assembly as well as the characteristics of the finished product. Modern three-dimensional computer-aided design tools used to develop the design and visualize the finished product are also being used to evaluate construction, assembly, and inspection sequences. This assures, from the very beginning, that cost-effective constructability is incorporated into the design. At the present preliminary design concept phase, the design of the construction process has focused primarily on the nuclear island facilities.

Key to a cost-effective and fast-paced construction process is proper preparation for design. The AHTR project design incorporates a well-equipped construction on-site construction facility, modularization, a heavy-lift crane, and open-top construction techniques. As with most advanced nuclear power systems, the AHTR will be implemented as a standard design, licensed using a 10CFR Part 52 design certification and combined operating license (COL). Unlike early nuclear power plants, where the reactor was designed and handed off to a construction contractor, the AHTR construction process is being developed as an integral part of the initial design. As with the standardized plant design, this allows standardization in the construction process, including design and standardization of the tooling used to construct the plant. Under a standardized process, a larger investment in tooling intended for use at multiple sites results in a better equipped on-site construction facility and a more efficient and higher quality construction process.

Under the Part 52 licensing process, the operating license is issued prior to initiation of the construction process. As construction and equipment installation progresses toward completion, a series of inspections, tests, analyses and acceptance criteria (ITAAC) are performed, as required by the design certification and COL. The design of the AHTR construction process will incorporate the necessary elements for implementation of ITAAC.

Experience in the construction industry, including construction of complex, high-quality systems such as nuclear-powered submarines, shows dramatic differences in fabrication cost, quality, and time between a fully-equipped factory setting, a controlled on-site shop setting, and true field construction in a partiallycompleted building setting. The construction process for the AHTR will utilize modular techniques to the extent possible. Transportation and a tightly-controlled design and construction process are keys to effective use of modularization. The size of factory-built modules will be consistent with transportation by rail or heavy-lift helicopters. Barge transportation may be considered as an option, but a standardized construction process utilizing barge transport would eliminate potential reactor sites that lack barge access.

A detailed evaluation of the application of modern and advanced construction techniques and on their impacts on construction times was performed for DOE-NE by Dominion Energy and several partner firms, including MPR Associates. ${ }^{16,39,40}$ Similar studies have been issued by the International Atomic Energy Agency. ${ }^{41,42}$ Among the recommendations of these studies are the full implementation of computer-aided design and records management systems, incorporating three-dimensional interface definition, interference checking, and general visualization tools. Accurate interface definition is absolutely necessary for the integration of modules constructed at remote sites. Historically, a significant portion of the schedule delay incurred in nuclear plant construction and acceptance relates to proper documentation of the construction process, such as materials and weld reports or vendor calibrations and certifications. A comprehensive electronic library tied to the CAD design model and backed up by hardcopy files enhances the collection, review and audit of fabrication and construction records. 
The AHTR is to be built on a seismic isolation system. This simplifies the design, construction and support systems for equipment tied to the isolated reactor building base. The seismic supports and isolation pads have been incorporated into numerous buildings constructed in seismically-active areas, and are being utilized in the construction of the Jules-Horowitz research reactor and the ITER international fusion reactor facility.

The Dominion and MPR references also provide a review of specific modern and advanced construction techniques. The use of prefabrication, preassembly and modularization of equipment and building segments will be implemented to the limits of rail or air-lift transportation systems. Open-top construction techniques are used, with heavy equipment lifted into the reactor block prior to closure of the roof. For the AHTR, open-top techniques will extend to major maintenance during operation. This is more readily implemented in the AHTR than many other reactor systems, as the salt-cooled reactor system does not lead to accident scenarios requiring a thick-walled, high-pressure containment structure. The layout of the reactor block during the construction phase is shown in Fig. 92. A heavy-lift crane is positioned to move large equipment and modules from the construction facility into the developing reactor building. Rail and truck access is provided for the construction facility. Components or modules can be unloaded using the heavy-lift crane or smaller equipment. An additional pad area is available for constructing building segments on grade level prior to being lifted into place in the building.

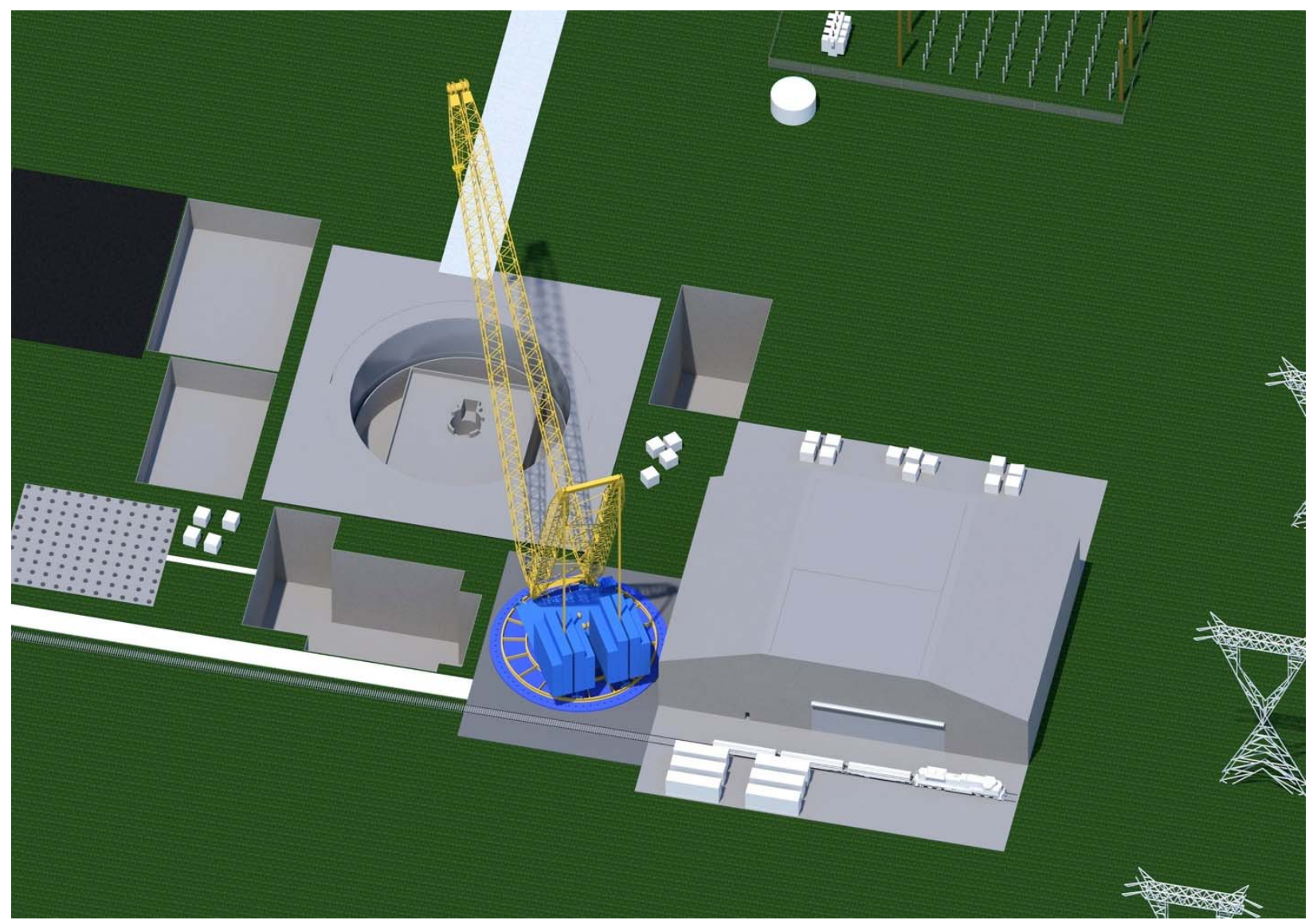

Fig. 92. Site layout during AHTR construction.

Precision blasting can be used to simplify rock removal during the initial excavation phase. The MPR Associates report ${ }^{16}$ describes applications of this technology during construction of some of the later existing nuclear plants, including applications that were adjacent top operating facilities. This technique not only decreases excavation time, but improves the shape of the excavation and reduces the amount of material to be removed. Additionally, early arrival of the heavy-lift crane could allow vertical lifts of 
materials from the excavation, minimizing the need for side ramps and thus minimizing the size of the excavation.

Steel plate reinforced concrete structures are being incorporated into the design of the AHTR buildings. This technique utilizes steel plate on the exterior surfaces of concrete walls, with steel tie-bars between the two. Strength of these walls can be higher than that of traditional concrete with imbedded reinforcing rods. Construction of walls using this technique can be completed in half the time needed for traditional reinforced concrete walls. Erection of the steel plates replaces the tedious assembly of reinforcement, erection of forms, and removal of forms after the concrete has set. A number of advanced admixtures and additives to improve flow characteristics, ultimate strength and setting times of concrete also offer improvements in the construction process. Advanced vibratory and other compaction techniques will also be considered.

A number of advanced welding and metal fabrication techniques will be considered as the design of the construction process continues. These generally require more sophisticated and automated tooling. Designing to maximize factory fabrication and providing the site with a standardized, well-equipped construction shop allows the cost-effective implementation of better welding equipment in both off-site and on-site work. High deposition rate welding equipment may allow faster welding of large equipment; techniques developed for thick-walled structures are not as applicable as the low pressure of the AHTR does not lead to thick-walled steel components. Standardization of construction equipment facilitates more efficient welding and fabrication processes, with the cost of large jigs and specialized welding tooling spread over multiple construction sites. Modularization, and possible large equipment on-site, allows the use of bent pipe as opposed to welded elbows. This would not only minimize the time needed for welding, but also limit the number of welds and associated inspection and documentation requirements.

Traditionally, pulling cable through the reactor building and other portions of the plant has been a timeconsuming aspect of construction, with large areas of the plant allocated to cable trays and routing. Separation of safety-significant trains of cable adds to this complexity. As documented in MPR-2610 (Ref. 16), NRC standards have called for integral cable interconnections, disallowing splices in all but extremely limited scenarios. The use of non-segmented cables pulled through the plant is inconsistent with integration of fully equipped plant modules. The primary aspect of the AHTR design for limiting this impact has been developing a reactor system that does not depend on active systems for safety, reducing the amount of highly-reliable, redundant instrument and power cables needed. The use of digital instrumentation and data systems, and distributed and integrated data collection and control technology, further minimizes the amount of large cables. Advanced technologies for cable lubrication and pulling aid where intact cables are required. Advanced technologies for cable splices may be shown to meet NRC reliability requirements, allowing preinstallation of cabling in modules prior to final assembly.

\subsection{CONSTRUCTION SEQUENCE}

Computer-aided design tools used for early design concept definition are being used to ensure that the developing design concepts for the reactor block are consistent with efficient construction and equipment installation techniques. Thus far, the focus of the effort has been on the reactor building and associated nuclear island facilities. Later efforts will address the turbine building, cooling towers, and other site facilities.

Figure 92 depicts a generalized construction site around the reactor building. The construction shop, the heavy-lift crane, and the reactor building base are shown. The arrangement for open top movement of material from the shop or adjacent pads into the reactor building is seen. Although site specific features may lead to some adaptation of the standard site layout, the basic relationships shown will be maintained so that a standardized construction process is maintained. 
Figures 93 and 94 depict the assembly sequence of the reactor building, along with summary depictions of the adjacent fuel handling and salt processing and radioactive waste handling buildings.

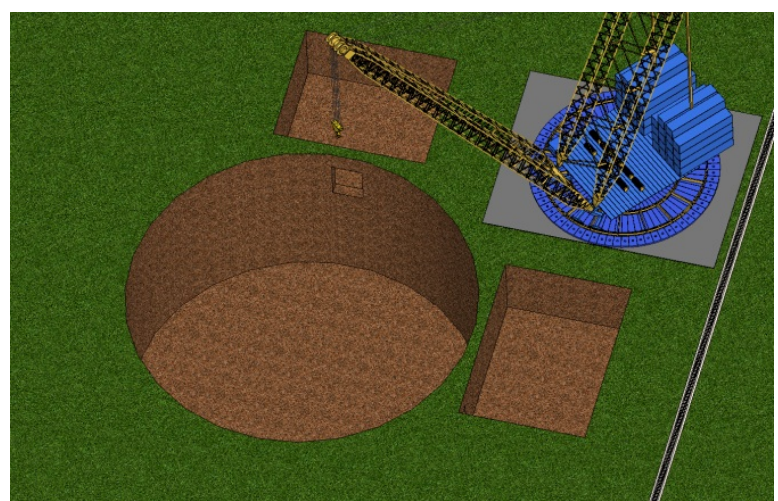

1. Building excavation.

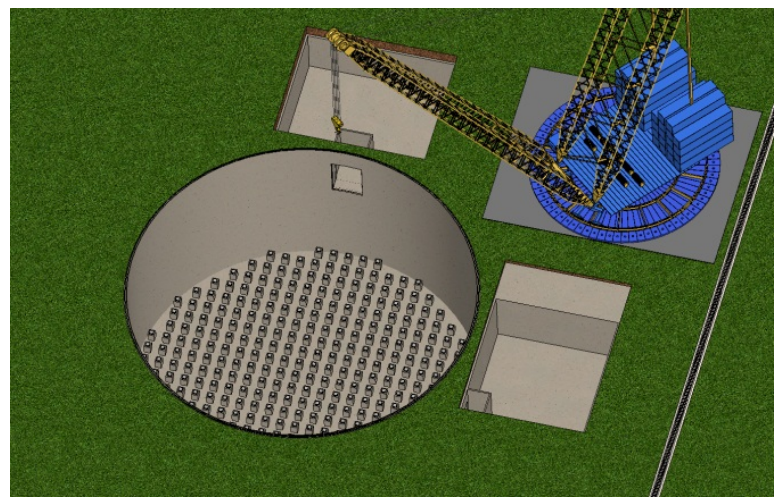

3. Seismic isolation.

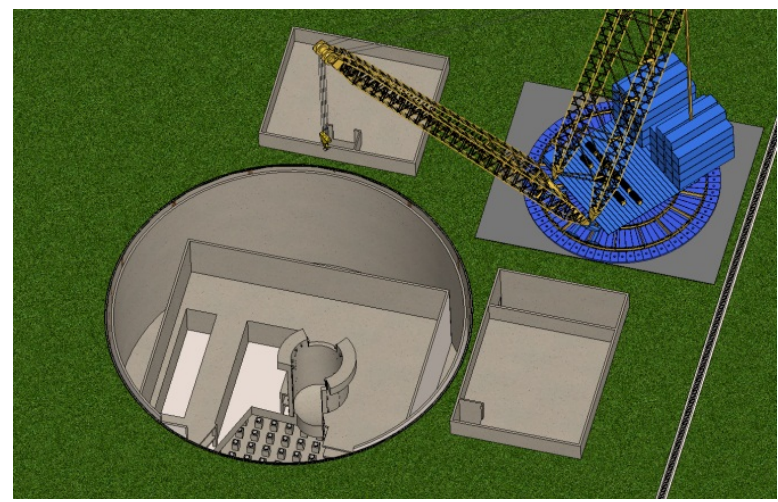

5. Reactor silo and next two floors.

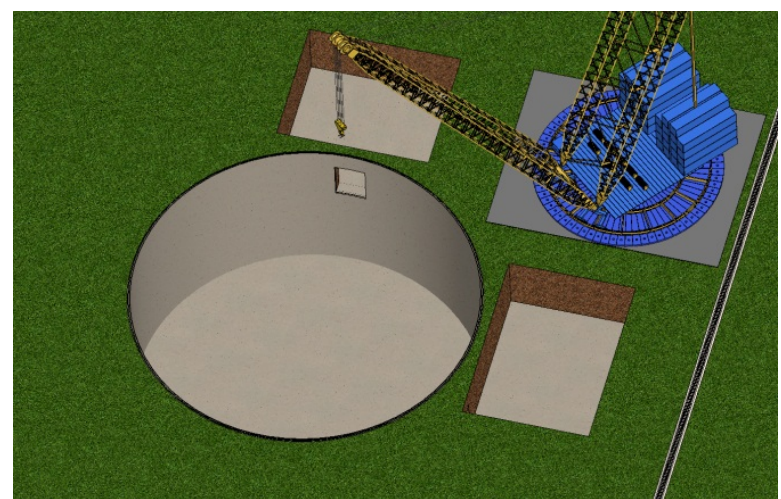

2. Basemat and retaining wall.

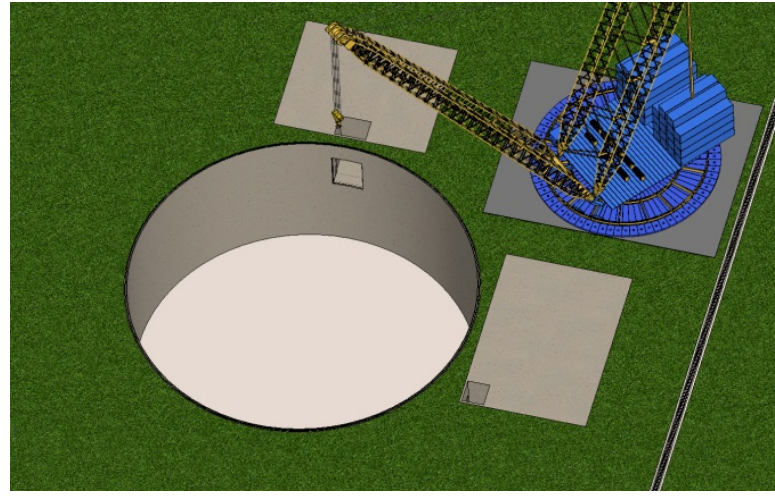

4. Reactor building base floor.

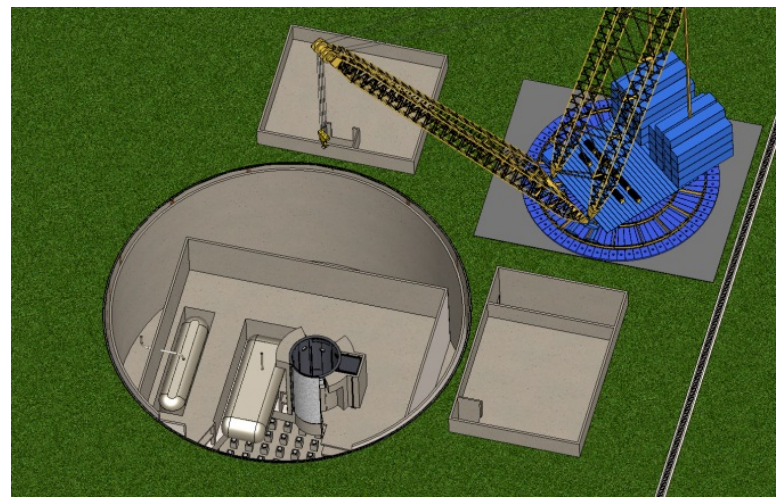

6. Reactor vessel and salt drain tanks.

Fig. 93. Reactor block construction sequence, page 1. 


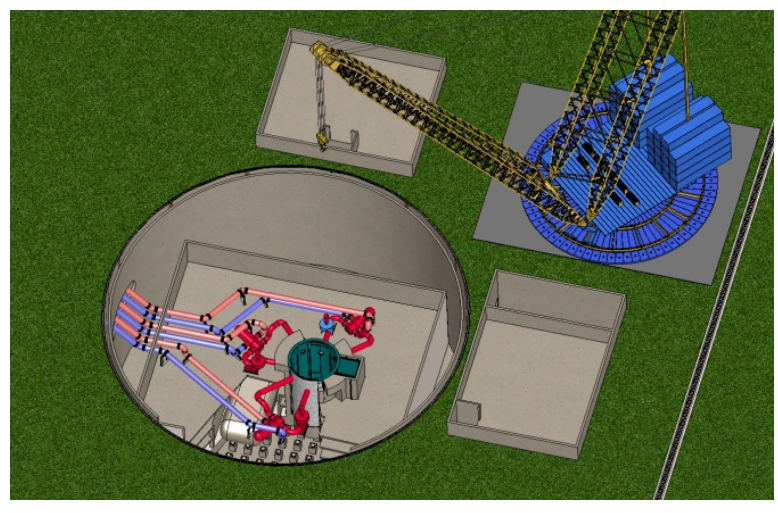

7. Fourth level and salt piping.

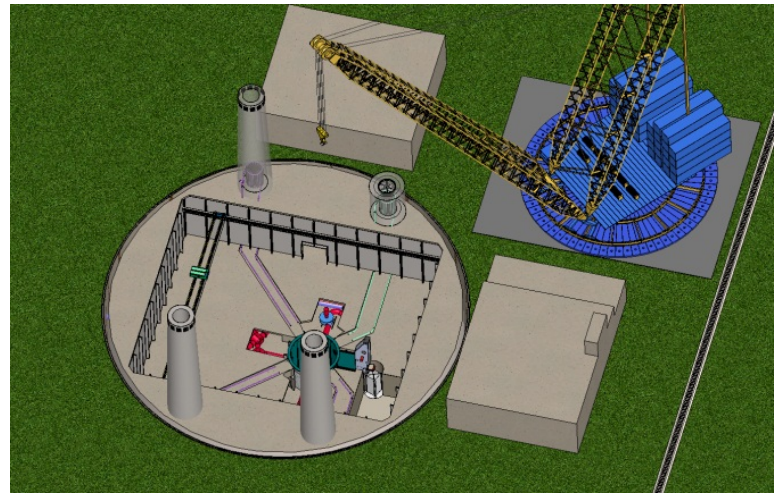

9. DRACS and side walls.

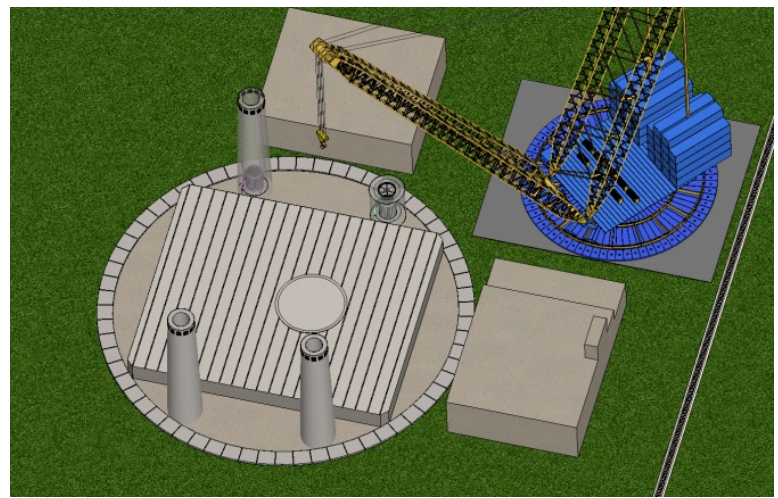

11. Complete building enclosure.

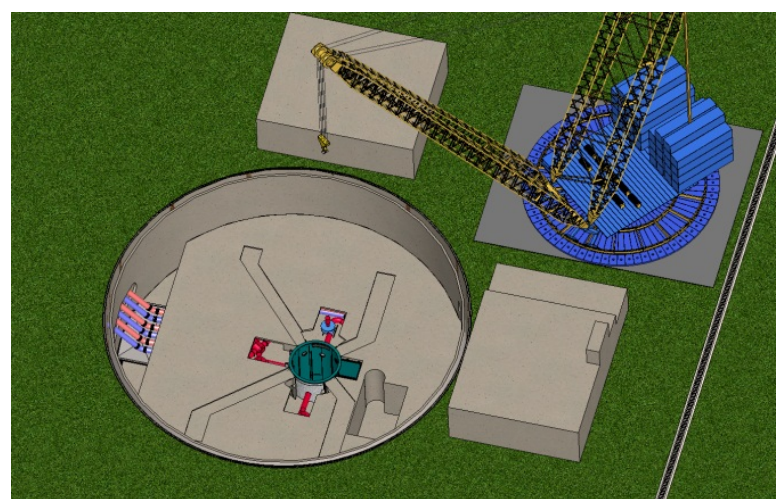

8. Fifth level and salt pool.

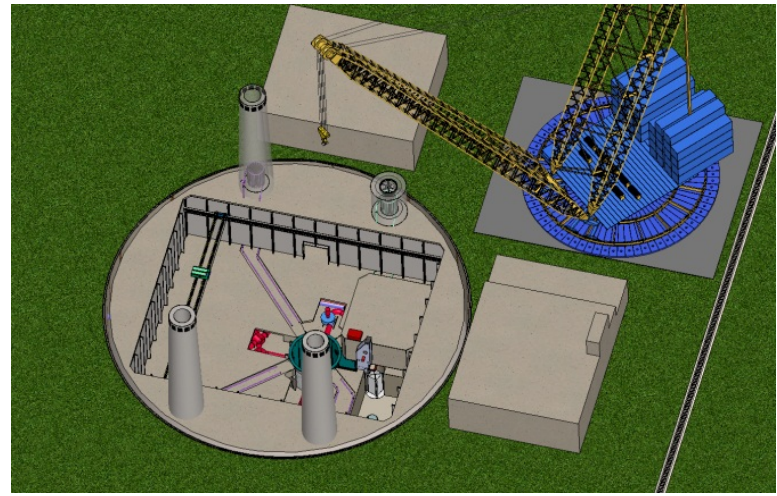

10. Fuel handling and drying facilities.

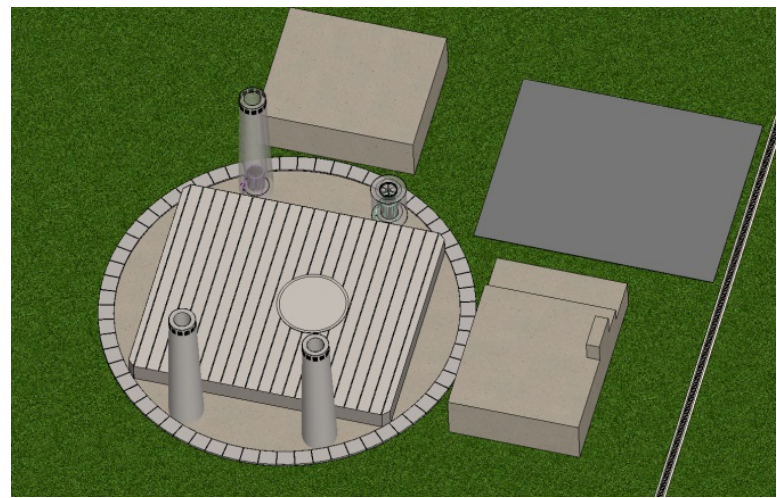

12. Remove construction equipment.

Fig. 94. Reactor block construction sequence, page 2. 
Panel 1 shows an idealized initial building excavation. Precision excavation techniques and the use of vertical lifts may be used to minimize excess excavation. Panel 2 shows the addition of the gravel base and concrete basemat, along with the reactor building retaining walls and the foundations for the adjacent structures. Panel 3 shows the addition of the seismic isolation structures, and panel 4 adds the base floor of the reactor building.

Panel 5 adds the next two floors of the reactor building, the concrete silo that surrounds the reactor vessel, and the rectangular steel structure around the reactor equipment. Panel 6 depicts the installed reactor vessel, with its associated thermal shields and insulation, and the salt drain tanks that extend down to the lowest level of the reactor building.

In panel 7, the fourth floor of the reactor building is added, along with both primary and intermediate salt piping and equipment. Panel 8 adds the fifth floor of the building, including the used fuel pool structure.

Panel 9 continues to extend the rectangular structure around the reactor assembly up to grade level, installs a grade floor around the outer perimeter, and shows the DRACS piping and stacks along with the maintenance decay heat transfer system. Panel 10 adds fuel handling and drying facilities.

The reactor building is enclosed in panel 11. The removable roof access for open-top maintenance is seen, along with the window for ultimate heat rejection from the used fuel pool to atmosphere. The heavy-lift crane is removed in panel 12; the pad for the crane remains, and a crane can be brought back to the site as needed for maintenance during the life of the facility.

The crane system can also be used for the ultimate decommissioning of the reactor complex. A reverse implementation of the preceding sequence would be used for dismantlement, with appropriate shielding for removal of activated materials.

\subsection{CONSTRUCTION SCHEDULE}

Recovery of capital used to construct a nuclear plant is the most significant element of the cost of electricity, and the amount of capital that must be raised poses a potential impediment to the implementation of nuclear power. Minimizing the construction schedule can both directly reduce capital requirements by reducing the overall hours needed for project support functions, and reduce the interest on capital incurred prior to commercialization.

Considerable effort has been devoted to reducing construction times for nuclear power plants. In Japan, the repetitive construction process for similar advanced BWRs, with a focus on optimization of the construction process, reduced the time between first nuclear concrete and initial fuel loading at Kashiwazaki-Kariwa units 6 and 7 and Shika unit 2 to under 40 months. MPR-2627 (Ref. 40) provides an evaluation of construction times posed by vendors for various advanced light-water-cooled reactors, with projected construction times from first concrete to fuel load ranging from 36 to 42 months, and the Dominion report (Ref. 39) develops a generalized schedule for construction of a nuclear power plant under Part 52 licensing with 39 months from first nuclear concrete to fuel load.

The construction time goal for the AHTR is 36 months, first nuclear concrete to fuel loading. This goal would apply to an " $n^{\text {th }}$-of-a-kind" (NOAK) facility, as opposed to a "first-of-a-kind" (FOAK) facility. Thus, at commencement of the NOAK project, a design certification has been approved by NRC, and a supplier chain has been established. Considerable early work goes into general site preparation, including building the construction facilities and pads and bringing in the heavy-lift crane. Under a limited work authorization issued by NRC before completing approval of the combined operating license (COL), site preparation for the nuclear island begins prior to obtaining the approved COL. Similarly, early procurement of equipment and fabrication of modules begins at pre-approved vendor sites. Once the COL is obtained, the reactor building sequence described in the previous section begins, with setting gravel and the basemat under the seismic supports for the reactor building. 
The overall schedule presented in the Dominion report has been adapted to remove the design certification and early site permit activities and to show 36 months from first concrete to fuel load in Fig. 95. In addition to the broad schedule drawn from the Dominion and MPR Associates work, the figure breaks out the reactor sequence activities discussed in the prior section. At this time, these are allocations of time, as the design has not progressed far enough to provide actual schedule data.

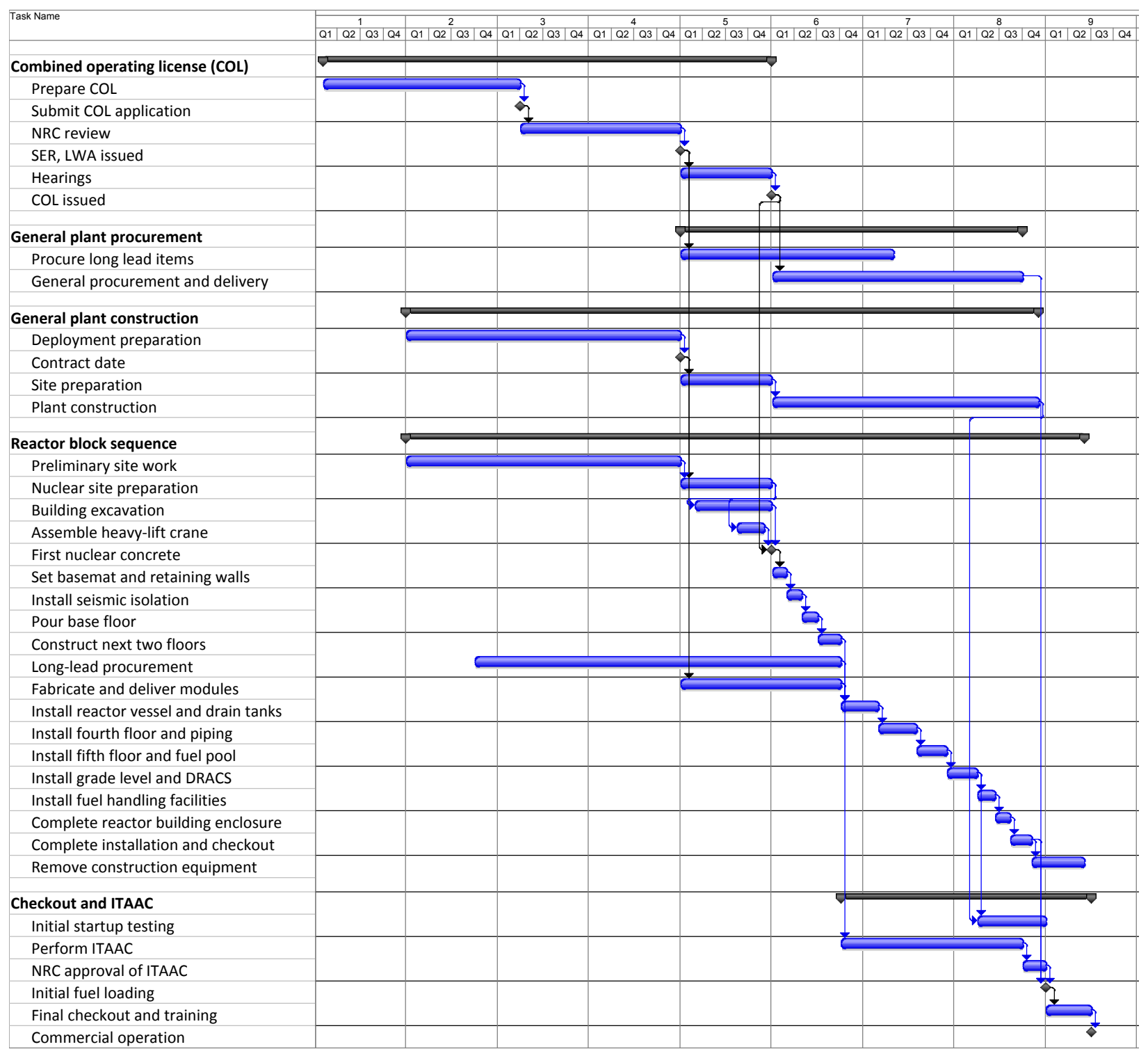

Fig. 95. Overall construction schedule.

The schedule shown in Fig. 95, in arbitrary years, begins with preparation of a COL application Initial preparations for general site preparations being in year two, and contracts for long-lead equipment and modules, built to the standard design, are let near the end of the year. The COL is submitted to NRC early in year three, and the NRC issues a Safety Evaluation Report (SER) and Limited Work Authorization (LWA) at the end of year four. At this point, significant excavation and construction preparations begin. The site is ready for delivery of modules when the COL is issued at the end of year five. Rapid assembly of pre-fabricated modules continues over the next three years, with initial startup testing completed in time to support fuel loading at the end of year eight. 
An important element of this schedule is the performance and NRC acceptance of ITAAC. Although the license is granted prior to construction, based on the design certification, final safety analysis report, and environmental impact reviews, approval to operate the plant is based on confirming successful completion of ITAAC. This is conducted as a formal process; hearings may be requested but are not presumed in the above schedule. Under Part 52 licensing, acceptance of ITAAC is required before operation can commence, including loading of fuel. Performance of ITAAC begins with building construction and module fabrication; some ITAAC may be conducted at module fabrication sites. The ITAAC are completed soon after relevant construction activities are completed, with review by NRC throughout the construction process.

Similar attention to schedule is needed to address the turbine-generator and associated structures and systems, the cooling water system, and other aspects of construction such as the simulator and other support facilities. In particular, a simulator is needed to support training of operators prior to initial plant testing. Unless standardization is adequate to allow training on a central or sister plant simulator, this brings up the simulator in overall construction schedule. 


\section{DEVELOPMENT PATH}

The overall objective of the development effort is to bring all required AHTR technologies to a maturity level where owners of private capital can make a reasonable judgment to invest in FHRs. The development tasks are a combination of conceptual design refinement along with technology development. Concept and technology development are intertwined since the scope and depth of development challenges only becomes apparent with application of discipline expertise to specific issues of the nuclear power system, and new technologies as they are developed reflect back into the concept design.

FHRs remain at an earlier phase of development than other reactor advanced reactor classes. However, their higher thermal efficiency, large output, shorter refueling outages, simplified systems, and less massive structures provides the opportunity for AHTR to be highly economically desirable while maintaining full passive safety. In order to be able to attract commercial investors, the FHR development program needs to advance the AHTR design concept and constituent technologies sufficiently to provide the technical basis for a confident expectation of a favorable return on investment.

Creation of a full development path is beyond the scope of the present recommendations. Additional development path analysis is planned over the next year with a goal of producing an initial cost-and-risk weighted timeline for AHTR deployment. The development issues presented here are limited to the mechanical and structural issues that have become apparent in developing the AHTR preconceptual design. Important development topics are not addressed in the present report. The omissions represent a lack of maturity in the development plan and a scope restriction of the present effort rather than a decision that other tasks are of lower importance.

The AHTR is approaching a sufficiently mature concept to allow more detailed evaluation of the development needs and a commercialization path. The maturity of concept development directly influences the completeness of the technology development recommendations. Both technology challenges and potential solutions only become apparent when analyzing the reactor SSCs in some depth. For example, the potential to employ the temperature difference between the used fuel pool and the ambient environment to power decay heat removal cooling pumps only becomes apparent with a plant design with sufficient depth to include the used fuel pool. Similarly, the degree of utility of visually based $\mathrm{I} \& \mathrm{C}$ does not become apparent until refueling activities are considered.

The most significant hurdle to introducing a new reactor class is the very long time (decades) to market. The time to market includes system evaluation, technology development, performance demonstration, technology qualification, and licensing framework development, prior to design, licensing, and construction. While to some degree the development activities can take place in parallel, developing and qualifying a new material for long-duration, high temperature nuclear power plant service requires at least a decade. Fortunately, the nuclear industry does not need to independently develop fully custom technology and can take advantage the broad spectrum of technologies developed for other industries.

Construction of a test reactor is a key intermediate term development recommendation. The maturity of systems necessary for a test reactor is significantly lower than for a commercial power reactor due to their different scale (and therefore accident consequence potential), lifetime, and mission. The lower power density of an FHR core coupled with the full passive safety changes the scale-up paradigm from that of LWRs where the slow development of confidence in fuel performance, emergency cooling systems, and heavy walled vessel fabrication restricted unit size growth. In contrast, an FHR test reactor is likely to have a power density and thus fuel performance issues equal to that of a commercial power plant. Most of the remainder of the AHTR is modular with each pump and piping for a three-loop plant nearly identical to those of a single loop plant one third of its size. 
In order to minimize the time to market the FHR development path will emphasize maturing the minimum set of necessary FHR technologies. The reactor vessel will be the temperature limiting structure in the AHTR. FHRs will have several hundred degrees of margin to fuel damage or coolant boiling remaining following first generation FHR deployment providing ample room for thermal efficiency increases as improved vessel materials is developed. The AHTR's upper plenum mixed mean temperature of $700^{\circ} \mathrm{C}$ was selected as a reasonably achievable goal that both avoids the fluoride salt viscosity increase at lower temperatures while minimizing materials and power cycle technology development requirements. A $700^{\circ} \mathrm{C}$ mixed mean upper plenum temperature allows employing a supercritical steam power cycle identical to that already employed by advanced fossil plants. Similarly, the AHTR development team elected not to pursue on-line refueling (pebble bed) to avoid the more challenging technology development necessary to manipulate fuel while the reactor is critical.

Another aspect of the FHR development is generating intellectual property that will allow an FHR reactor vendor technology licensee to differentiate themself from imitators. Much of the technology for any FHR will be common and, moreover, will be required to be disclosed, albeit only in a general fashion, during the public portion of the licensing process. Thus without intellectual property protection it would be prudent for any reactor vendor to wait until someone else has incurred the first-of-a-kind licensing and development expenses. Intellectual property generation will become a larger issue once the AHTR concept development transitions from preconceptual towards a conceptual design with specific technology implementations. Generating an intellectual property strategy will be part of the AHTR development path evaluation over the next year.

FHR technologies have significant potential competitive value with early phase development at government expense. Therefore, as required by law, the implementing details of FHR technologies will thus not be publically disclosed, but will be available for licensing. Intellectual property will also be embedded in the component technologies developed under the FHR program. While the component technologies are more likely to be commercialized by a component as opposed to a reactor system vendor, intellectual property is also required for a healthy supplier base.

FHRs have an almost entirely different set of materials and systems issues as compared to LWRs. Nearly 30 years were required in the United States for LWRs to achieve their present level of availability. A key development issue for FHRs is to apply modern technology ranging from modeling and simulation to diagnostics and prognostics to shortcut the learning process.

The AHTR concept development has not yet fully reached a preconceptual level (where the general processes underlying the plant have all been evaluated as reasonable). In particular, the AHTR hydraulic design has yet to be performed even to a preconceptual level. Key issues such as flow distribution in the core, upper and lower plenum flow and mixing, DRACS performance, and secondary shutdown system salt injection have yet to be considered.

The largest unresolved materials issue for FHRs is the development, manufacturing, and qualification of structural ceramic composite materials. As a high temperature reactor, the in-vessel components need to exhibit adequate strength, be compatible with fluoride salts at high temperature as well tolerating their design life neutron fluence. ASTM qualification of both C-C and SiC-SiC composites is also a requirement for the reactor to be licensable. The lower power density of FHRs as compared to LWRs also inherently makes their core structures larger. The larger scale complicates most of the materials manufacturing challenges. The AHTR lower core support plate will be a $\mathrm{SiC}$-SiC structure nearly $10 \mathrm{~m}$ in diameter. Also the core barrel is designed to be a large C-C structure. Further, the components may be manufactured in segments, so they can be transported by rail and mechanically joined on site. Thus FHR technology development will need to extend the fabrication technology base.

Another materials manufacturing challenge for FHRs is building large structured, coated particle fuel plates. While coated particle fuel compact manufacturing is relatively well known, the AHTR plates are layered structures are 6-m long. The base manufacturing technology for structured plate fuel is anticipated 
to be a combination of dispensing technology, vibratory compaction, a large linear press, plate transport stages, and a large vacuum furnace. While the current design intent is to employ full height fuel plates, the plates are mechanically positioned on their edges by grooves in the fuel support ' $Y$ ' and the fuel assembly channel box. The fuel plates could, therefore, be segmented and slid together into the fuel assembly slots with a tongue and groove type joint. None of the fabrication or assembly technologies are new and planar structures are anticipated to be less challenging to manufacture than annular pebbles. However, the fuel viability is critically dependent upon its structural quality. If the plates crack, delaminate, or warp excessively the core concept will not function.

Both the manufacturing and materials for the intermediate loop to power cycle heat exchanger will also be a major challenge. As this heat exchanger is where low pressure salt transfers heat at high temperatures to a power cycle fluid, the internal tubing of the heat exchanger has very high pressure differences at high temperatures necessitating as strong as possible materials. Also, as the AHTR is a large plant, the heat exchangers will be large and present significant manufacturing and quality control challenges. Since the intermediate to power cycle heat exchangers are isolated from the reactor by the intermediate loop (which includes large rupture disks) and are not required for decay heat removal, materials that are not qualified to the nuclear portion of the ASME boiler and pressure vessel code may be considered for the intermediate to power cycle heat exchanger.

Component design, manufacture, and testing is a significant remaining mechanical development task. A component test facility and development program will thus be a significant task as FHR technology is designed, developed and validated. Issues remaining to be addressed range from pump design and validation to process control instrument development to tritium barrier heat exchanger development. An illustrative example design, development, manufacturing, and demonstration project is creation of a double walled primary to intermediate salt heat exchanger. Tritium retention is a fundamental requirement for FHRs. While other technologies show potential to remove tritium from salts, tritium leakage through thin walled heat exchanger tubing is a significant remaining concept viability issue. Employing a double walled heat exchanger as the primary to intermediate loop barrier with a conductive interior structure has the potential to nearly eliminate the tritium release issue. However, a salt compatible, high temperature tolerant, double walled heat exchanger is not currently available and as a unique issue to FHRs is unlikely to be developed outside of an FHR program.

Thermal release of both the primary and secondary shutdown mechanism is based upon melting fusible links. While fusible links have extensive heritage as safety components, the specific mechanical design and chemical compatibility of the configurations have not been proven. Design, demonstration, and qualification of fusible links in the planned conditions environment are a required development task.

The performance of salt wetted mechanical elements such as the fuel element grippers and robotic arm also need to be confirmed. Moreover, the mechanical systems are planned to be guided through an automated vision based control system. One development focus will, therefore, be to design and demonstrate an upper vessel flange visual access system as well as integrating optical information from multiple cameras above a flowing salt surface into a mechanical arm control response.

The mechanical and neutronic design of the AHTR fuel and core will continue to evolve as more information is obtained from the other design tasks. For example, since the primary salt is a mid-Prandtl number fluid, improved heat transfer during natural circulation may result from texturing the plate surface to force detachment of the fluid boundary layer. Also, a somewhat higher power density may be possible reducing the size of all of the core components. Finally, the results of structured plate fuel irradiation will need to be fed back into the core design.

While the current baseline fuel design employs smooth surface, full core height fuel plates, advanced fuel plate features are possible. Within a fuel assembly, the fuel plates are mounted into slots in the channel box at one edge and in the fuel support ' $\mathrm{Y}$ ' at the other. The edge-mounting configuration may allow the fuel plates to be segmented for easier fabrication and then stacked within the guide slots to form the full 
height plate. Additionally, as fluoride salts are mid-Prandtl number fluids a textured fuel plate surface would improve the heat transport under loss of forced flow accident conditions, when the flow between the plates would be laminar, by promoting detachment of the fluid boundary layer. As the plates are intended to be isostatically molded, features can be readily included on the plate surface. Figure 96 shows two segments of a fuel plate that incorporate lozenge shaped surface dimples and have been segmented. Only very simplistic hydraulic design of the core has yet been performed. Thus the mechanical requirements of the edge mounting and spacer ridges have yet to be determined and no design optimization has been performed on potential natural circulation heat transfer enhancement surface features.

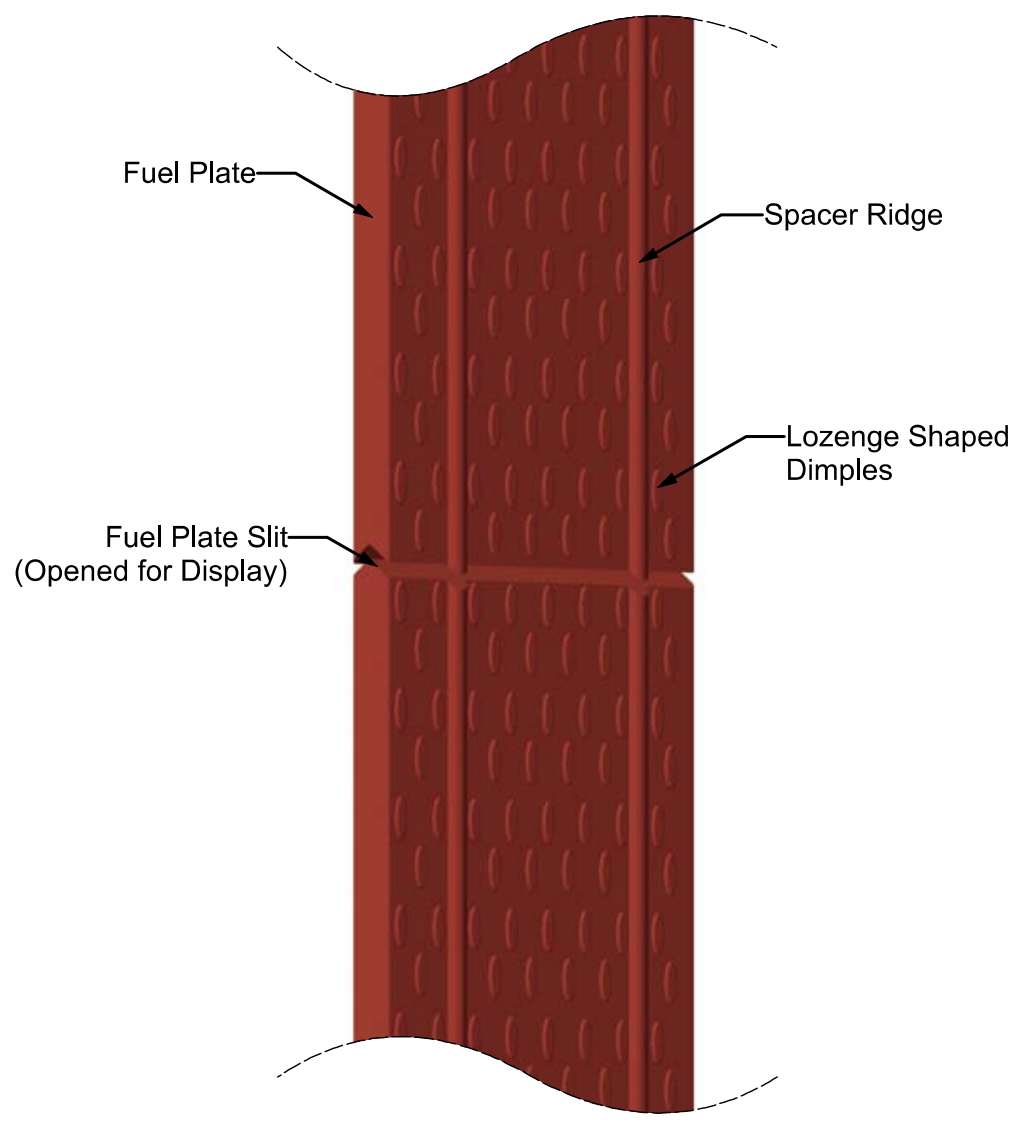

Fig. 96. Dimpled fuel plate segments.

The AHTR preconceptual design is approaching a level of maturity that permits evaluation of the major remaining conceptual design, technology development, and licensing hurdles. The AHTR continues to have a number of mechanical and structural development issues that need to be resolved before the reactor can confidently be claimed to be a passively safe, economically preferable power generation system. Generating an AHTR development roadmap that includes cost and schedule information is a planned program focus over the next year. 


\section{CONCLUSIONS}

The AHTR design concept has nearly reached a preconceptual level of maturity where the components combine together into a reasonable, self-consistent system. However, a few key technology aspects have yet to be evaluated and large amounts of both technology development and licensing development remain. In particular, AHTR hydraulic design for both normal and accident scenarios have yet to be performed and tritium retention remains a concept imperative that has yet to be fully resolved. Performing fluid flow evaluation within the reactor vessel will of necessity result in changing the configuration of the reactor vessel internals from the particular sizes presented in this report. Also, the AHTR design makes extensive use of large, ceramic composite structures that have yet to be qualified for nuclear power use.

The AHTR has elected to use off-line refueling as the technological and licensing hurdles required to manipulate fuel on-line (especially removing and reintroducing it to the salt) appear daunting, and the high-speed refueling enabled by the transparent coolant and robust fuel minimizes the refueling impact on plant availability. The AHTR employs plate fuel as the simplest fuel form to fabricate and one that can be formed into large, mechanically robust fuel assemblies. While long plates are the current design basis, the fuel assembly mechanical structures are designed to enable the plates to be segmented as necessary to minimize either the fuel fabrication cost or to improve the correlation of limited size fuel qualification test elements with deployed fuel.

This report provides an integrated layout of the major elements of the reactor systems, structures, and components. The high-temperature, low-pressure liquid fluoride salt cooling, robust fuel nature of the AHTR dictates employing several distinctive design elements.

1. The core power density is significantly lower than that of LWRs necessitating a large (albeit low pressure) vessel and in-vessel structures.

2. A principal safety requirement is holding the fuel under the coolant surface necessitating diverse, redundant fuel hold down components.

3. The most vulnerable element in safety analysis is not the fuel, but the reactor vessel. In order to maintain full passive safety, a secondary (guard) vessel is employed such that even in the event of catastrophic reactor vessel rupture the core's decay heat can still be passively rejected without fuel damage.

4. No reactor vessel penetrations exist below $\sim 30 \mathrm{~cm}$ above the DRACS heat exchangers to minimize the potential for loss of coolant accidents.

5. The reactor vessel is hung from its upper flange to minimize thermal expansion stresses and its horizontal motion damped during seismic events using horizontal viscoelastic elements.

6. The piping thermal expansion is accommodated using mechanical bellows on the intermediate heat transfer loops and radially moving elements on the primary loop elements.

7. The instrumentation system is primarily visually based with its elements above the salt surface to take advantage of the good transparency of the liquid salt and minimize the requirement for elements to withstand the near core environment.

8. The high temperatures of normal operation enable the use of the temperature difference to provide alternate power via Stirling cycle generators.

9. The intermediate coolant loop is located above the primary to intermediate heat exchangers to provide inflow in case of a heat exchanger leak avoiding a requirement for containment isolation valves.

The AHTR reactor building is located below grade to minimize vulnerability to aircraft impact. The reactor building is seismically isolated sitting on flexible columns and surrounded by a seismic isolation trench. The fluoride salt minimizes the radioactive material source term in the event of a fuel 
failure accident, transforming the AHTR into a molten salt reactor, with only the gaseous fission products escaping to the next level of containment.

The AHTR is a large, modular reactor and makes extensive use of modern construction technologies. The concept maturation effort includes initial evaluation of component transportability and on-site workshop assembly. A construction timeline has been generated that provides an overview of the major steps required to construct an AHTR with a 36 month timeline from first nuclear concrete to initial fuel load.

The AHTR concept development has now reached a stage of maturity where creation of a development roadmap would be especially useful. Development of new reactor fuels and materials, licensing demonstrations, and component qualification are all multi-year efforts. A test reactor appears necessary to provide adequate confidence to proceed to commercial scale power plants. Assessing the major costs and time required for FHRs to become economically preferable, fully passively safe nuclear power plants will both support federal program planning as well as allowing industry to evaluate commercial participation in the FHR development. 


\section{REFERENCES}

1. D. E. Holcomb, D. Ilas, V. K. Varma, A. T. Cisneros, R. P. Kelly, and J. C. Gehin, Core and Refueling Design Studies for the Advanced High Temperature Reactor, ORNL/TM-2011/365, Oak Ridge National Laboratory, Oak Ridge, TN, September 2011.

2. D. E. Holcomb, F. J. Peretz, and, A. L. Qualls, Advanced High Temperature Reactor Systems and Economic Analysis, ORNL/TM-2011/364, Oak Ridge National Laboratory, Oak Ridge, TN, September 2011.

3. J. L. Collins, et al, US 7,666,387 B2, Feb. 23, 2010, Carbonate Thermochemical Cycle for the Production of Hydrogen

4. $\quad$ http://www.world-nuclear.org/info/inf75.html.

5. http://web.mit.edu/nse/news/2011/advanced-reactors.html.

6. G. F. Flanagan, D. E. Holcomb, and S. M. Cetiner, FHR Generic Design Criteria, ORNL/TM2012/226, Oak Ridge National Laboratory, Oak Ridge, TN, June 2012.

7. Y. Katoh, D. F. Wilson, and C. W. Forsberg, Assessment of Silicon Carbide Composites for Advanced Salt- Cooled Reactors, ORNL/TM-2007/168 Revision 1, Oak Ridge National Laboratory, Oak Ridge, TN, September 2007.

8. D. F. Williams, L. M. Toth, and K. T. Clarno, Assessment of Candidate Molten Salt Coolants for the Advanced Hight-Temperature Reactor (AHTR), ORNL/TM-2006/12, March 2006.

9. G. Muralidharan, D. F. Wilson, L. R. Walker, M. L. Santella, and D. E. Holcomb, Cladding Alloys for Fluoride Salt Compatibility, ORNL/TM-2011/95, Oak Ridge National Laboratory, Oak Ridge, TN, 1995.

10. D. E. Holcomb, S. M. Cetiner, G. F. Flanagan, F. J. Peretz, and G. L. Yoder, Jr., An Analysis of Testing Requirements for Fluoride Salt-Cooled High Temperature Reactor Components, ORNL/TM-2009/297, Oak Ridge National Laboratory, Oak Ridge, TN, 2009.

11. D. Ilas, D. E. Holcomb, V. K. Varma, "Advanced High-Temperature Reactor Neutronic Core Design," Proceedings of PHYSOR 2012-Advances in Reactor Physics-Linking Research, Industry, and Education, Knoxville, TN, April 15-20, 2012.

12. Idaho National Laboratory, Technical Program Plan for the Next Generation Nuclear Plant/Advanced Gas Reactor Fuel Development and Qualification Program, PLN-3636, September 30, 2010.

13. M. J. Driscoll, T. J. Downar, and E. E. Pilat, The Linear Reactivity Model for Nuclear Fuel Management, American Nuclear Society, La Grange Park, Illinois, 1990.

14. SCALE: A Comprehensive Modeling and Simulation Suite for Nuclear Safety Analysis and Design, ORNL/TM-2005/39, Version 6.1, Oak Ridge National Laboratory, Oak Ridge, TN, 2011. (Available from Radiation Safety Information Computational Center at Oak Ridge National Laboratory as CCC-785.)

15. M. Nakahira, N. Takeda, H. Takahashi, A. Yagenji, Y. Akutsu, and E. Tada, "Design and Validation Test of Seismic Isolation for ITER," in Proceedings of the $7^{\text {th }}$ International Conference on Nuclear Engineering, Tokyo, Japan, April 19-23, 1999, ICONE-7046, 1999. 
16. C. Schlaseman et al., Application of Advanced Construction Technologies to New Nuclear Power Plants, MPR-2610, Revision 2, MPR Associates, September 24, 2004.

17. S. R. Greene, J. C. Gehin, D. E. Holcomb, et al., Pre-Conceptual Design of a Fluoride-SaltCooled Small Modular Advanced High-Temperature Reactor (SmAHTR), ORNL/TM-2010/199, Oak Ridge National Laboratory, Oak Ridge, TN, December 2010.

18. Y. Chikazawa, M. Farmer, and C. Grandy, "Technology Gap Analysis on Sodium-Cooled Reactor Fuel Handling System Supporting Advanced Burner Reactor Development," Nuclear Technology, 165, pp. 270-292 (March 2009).

19. S. Glasstone and A. Sesonske, Nuclear Reactor Engineering, Krieger Publishing Company, Malabar, FL, ISBN 0-89464-567-6 ( ${ }^{\text {rd }}$ Edition), 1981.

20. J. G. Wood, E. S. Holliday, and J. C. Stanley, "First Operation of a 12 kWe Stirling Power Conversion Unit of Fission Power Technology Demonstration," Proceeding of Nuclear and Emerging Technologies for Space 2012, March 21-23, 2012, The Woodlands, TX (2012).

21. http://www.iter.org/newsline/221/1159.

22. http://www.nrc.gov/info-finder/decommissioning/power-reactor/enrico-fermi-atomic-powerplant-unit-1.html.

23. R. B. Briggs, "Tritium in Molten-Salt Reactors," Reactor Technology, 14(4), pp. 335-343, Winter 1971-72.

24. S. R. Sherman and T. M. Adams, Tritium Barrier Materials and Separation Systems for the NGNP, SRNL, WSRC-STI-2008-00358, Rev. 1, November 2008.

25. A. Ya. Kislov, A. A. Skovoroda, A. V. Spitsyn, and A. N. Lyubimov, "Carbon Nanocapsules Formed in T-10 Tokamak," Technical Physics Letters, 36(7), pp. 585-587 (2010).

26. F. D. S. Marquis and L. P. F. Chibante, "Improving The Heat Transfer Of Nanofluids And Nanolubricants With Carbon Nanotubes," JOM, 57(12), pp. 32-43 (2005).

27. G. T. Mays, A. N. Smith, and J. R. Engel, Distribution and Behavior of Tritium in the CoolantSalt Technology Facility, ORNL-TM-5759, April 1977.

28. D. F. Williams, Assessment of Candidate Molten Salt Coolants for the NGNP/NHI HeatTransfer Loop, ORNL/TM-2006/69, Oak Ridge National Laboragtory, Oak Ridge, TN, 2006.

29. J. T. Bell, R. A. Strehlow, J. D. Redman, and F. J. Smith, "Tritium Permeation Through Steam Generator Materials," pp. 1577-1582 in Proceedings of the $14^{\text {th }}$ Intersociety Energy Conversion Engineering Conference, Boston, MA, August 5-10, 1979, Volume 2 (1979).

30. G. W. Hollenberg, E. P. Simonen, A. Terlain, and G. Kalinin, Tritium/Hydrogen Barrier Development, PNL-SA-24235, June 1994.

31. A. P. Malinauskas and D. M. Richardson, "The Solubilities of Hydrogen, Deuterium, and Helium in Molten $\mathrm{Li}_{2} \mathrm{BeF}_{4}$," Industrial and Engineering Chemistry Fundamentals, 13(3), pp. 242-246 (1974).

32. "University of Rochester Laboratory for Laser Energetics," LLE Review, 103, pp. 142-154 (2005).

33. A. Busigin, US Patent 7,815,890 B2, October 19, 2010, Process for Tritium Removal From Water by Transfer of Tritium From Water to an Elemental Hydrogen Stream, Followed by Membrane Diffusion Tritium Stripping and Enrichment, and Final Tritium Enrichment by Thermal Diffusion, October 2010. 
34. D. A. Petti, G. R. Smolik, M. F. Simpson, J. P. Sharpe, R. A. Anderl, S. Fukada, Y. Hatano, M. Hara, Y. Oya, T. Terai, D.-K. Sze, and S. Tanaka, "JUPITER-II Molten Salt Flibe Research: An Update on Tritium, Mobilization and Redox Chemistry Experiments," Fusion Engineering and Design, 81, pp. 1439-1449 (2006).

35. M. F. Simpson, G. R. Smolik, J. P. Sharpe, R. A. Anderl, D. A. Petti, Y. Hatano, M. Hara, Y. Oya, S. Fukada, S. Tanaka, T. Terai, and D.-K. Sze, "Quantitative Measurement Of Beryllium-Controlled Redox Of Hydrogen Fluoride in Molten FLiBe, Fusion Engineering and Design, 81, pp. 451-547 (2006).

36. W. F. Calaway, "Electrochemical Extraction of Hydrogen from Molten LiF-LiCl-LiBr and its Application to Liquid-Lithium Fusion Reactor Blanket Processing," Nuclear Technology, 39, pp. 63-74 (June 1978).

37. T. S. Kress, Mass Transfer Between Small Bubbles and Liquids in Cocurrent Turbulent Pipeline Flow, ORNL-TM-3718, Oak Ridge National Laboratory, Oak Ridge, TN, April 1972.

38. G. I. Eskin, "Cavitation Mechanism of Ultrasonic Melt Degassing," Ultrasonics Sonochemistry, 2(2), pp. S137-S141 (1995).

39. Study of Construction Technologies and Schedules, O\&M Staffing and Cost, Decommissioning Costs and Funding Requirements for Advanced Reactor Designs, Dominion Energy and Partners, May 27, 2004.

40. L. Crosbie and K. Kidwell, DOE 2010 Construction Schedule Evaluation, MPR-2627, Rev. 2, MPR Associates, September 24, 2004.

41. Construction Technologies for Nuclear Power Plants, IAEA Nuclear Energy Series No. NP-T-2.5, International Atomic Energy Agency, Vienna, Austria, 2011.

42. Construction and Commissioning Experience of Evolutionary Water Cooled Nuclear Power Plants, IAEA-TECDOC-1390, International Atomic Energy Agency, Vienna, Austria, April 2004. 